\title{
UNCLASSIFIED
}

\section{Prototype Integration of the Joint Munitions Assessment and Planning Model with the OSD Threat Methodology}

\author{
June 1994
}

\begin{abstract}
DISCLAIMER
This report was pecpared as an acosount of work spansoud by an agency of the Uaited Stutes Government. Neither the Uitited States Gowernment nar any agency thereof, nor any of their employess, makes any Hrarranty, express of implited, of assommes any kegal linbility or responsi-

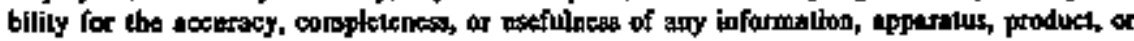
process disclosed, or represents that its uts woold not infringe privately owned rights. Reference berein to any apeifile cammereill product, prosess, or scrvile by trade name, trademark,

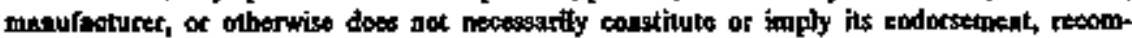
mendalioa, of favoring by the Uniled States Government of any agency thereof. The vietrst and oplakons of authars expressed beretn to not nexessarily state or renlect those of the Utilted Stales Government or any aquecy thereol.
\end{abstract}

Prepared for:

QM 29:94

Prepared by:

'

Los Alamos National Laboratory

Military Systems Analysis

and Simulation Group (A-S)

Los Alamos, New Mexico 87545

Roger Y. S. Lynn

J. J. Bolmarcich

Under Contract No.

9-X53-1599F-1

UNCLASSIFIED

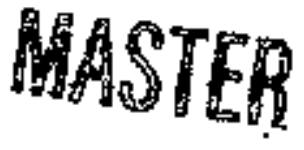




\section{DISCLAIMER}

Portions of this document may be illegible in electronic image products. Images are produced from the best available original document. 


\section{UNCLASSIFIED}

30 June 1994

MEMORANDUM (QM 29:94)

Contract No. 9.X53-1599F-1

To: Los Alamos National Laboratory

Mititary Systems Analysis and Simniation Group (A-5)

Los Alamos, New Mexico 87545

Attn: Mr. Douglas P. Anson

From: Roger Y. S. Lynn and J. J. Bolmarcich

Subject: Prototype Integration of the Joint Munitions Assessment and

Planning Model with the OSD Threat Methodology

The purpose of this Memorandum is to propose a prototype procedure which the Office of Munitions might employ to exercise, in a supportive joint fashion, two of its High Leval Conventional Monitions Models, namely, the OSD Threat Methodology and the Joint Munitions Assessment and Planning (JMAP) model.

Reference [a] describes the OSD Threat Methodology as comprising two parts: First, the OSD Threat Split Model, running within the R:BASE database manager, has the job of estimating how all types of enemy targets in the scenario will likely end up being killed by all types of "firendly" forces put there to combat them. And second, the OSD Threat Model (described in detail in reference [b]), running as a stand-alone application, estimates the munitions stockpiles needed to let the war torn out to match the OSD Threat Split Model estimates. Actually, the Threat Model prudently overestimates war reserve stockpiles by determining munitions bolh for expenditures and for \$ffely stocks. These safety stocks take the form of the non-expended portions of mumitions loadouts which are needed to assure that rounds are at the right place at the right time. Both Models consider time only in the aggregote; they tom be considered independent of time in comparison to dynamic combat models.

JMAP, as described in reforences [c], [d], and $[e]$, provides a means to optimize the allocation of munitions and platforms (shooters) to targets consistent with some user designated goal priorities. JMAP is a means of trading-off some munitions for others while appiying hard constraints to mumitions available and imposing specific goals on munition usage, target kill, shooter attrition, and costs. MAP is basically designed to show how to kill the most scenario targets while consuming the fewest dollars from tho existing irvestments in stocks of mumitions and shooters.

The joint application of JMAP and the OSD Threat Methodology provides a tool to optimize munitions stockpilos. From MAP's point of view, the Threat Methodology can help it work more realisticully with stockpile limits becanze in warfare not all of a stockpile can be expended at the

\section{UNCLASSIFIED}


eneny and the optimal shooter/muntion combination may not acquine each target. The Threat Model brings to MAP the ability to consider the cost of all munitions needed to support the scenario, the expenditures plus safety stocks; JMAP can thus be made to operate on whole stockpiles insteat of just on expenditures. From the Threat Methodology point of view JMAP gives it a way to trade-off one munition for another. JMAP supplies the ability to improve the allocation of shooters and mimitions to targets in such a way as to reduce cost while meeting goals priorities concerning kills and attrition. JMAP can also force minimum expenditures of a munition type as well as limit expenditures of munitions which can no longer be obtained.

To make the subject prototype integration manageable, we modify JMAP's Version 1.0 Production formulation of reference [e]; we use the data from the Maritime Prototype of reference [d], filling in data gaps using the LANL MRC-West database; and we employ the multi-abjective linear goal programming solver of Schniederjans utilized by the Mobile Hard Prototype of reference [c] as well as by the Maritime Prototype.

The joint application idea discussed in this memorandum involves the cyclic application of IMAP and the OSD Threat Methodology until a solntion emerges. The procedure is: (1) allow the OSD Threat Methodology: (a) to initialize the allocation of shooter munition combinations to targets, (b) to then generate a set of munitions oxpenditures, and (c) to then calculate the necessary safoty stocks needed to support those expenditures; (2) invoke JMAP to apply consiraints after factoring JMAP's munition costs to include the cost of the safety stocks - JMAP will then produce a more cost-efficiont allocation; (3) feed this new allocation back to the Threat Model and let it recaliculate the concomitant safety stocks, and (4) repeat steps (2) and (3) until a stable solution obtains.

To make this process work smoothly, we need to modify the formulation of JMAP Version 1.0 We remove the remaining time considerations from Yorsion 1.0 by converting minimum and maximum rates of expenditure to aggregate expenditure constraints. We also add to JMAP a set of upper and lower constraints on the number of targets of each type a particular shooter type can kill; this is a critical output of the Threat Methodology. We privilege the Threat Methodology this way because it has passed both LANL's technical (references [f] and [k]) and the OM's utility (reference [h]) evaluations. We also suspend the quickest-kill munition selection within the Threat Methodlogy so that it can initialize JMAP properly.

The JMAP/Threat Pair works fine when JMAP is operated as originally designed, that is, when JMAP is free to make any allocation of shooter/ munition combination to targets; in this case all targets turn out to be taken by aireraft with JMAP optimizing the allocation of aircraft/munition combinations to target type. The Pair also works fine when the minimal Threat Methodology shooterftarget allocation constraint is applied; Exhibit 0 displays the stockpile preforred by the JMAP/ Threat Pair in this constrained case as compared to the now robust stockpile produced by the Threat Methodology atone. Wheress the Threat Methodology spreads out the combat activity over all shootors and munitions brought into the scenario, the

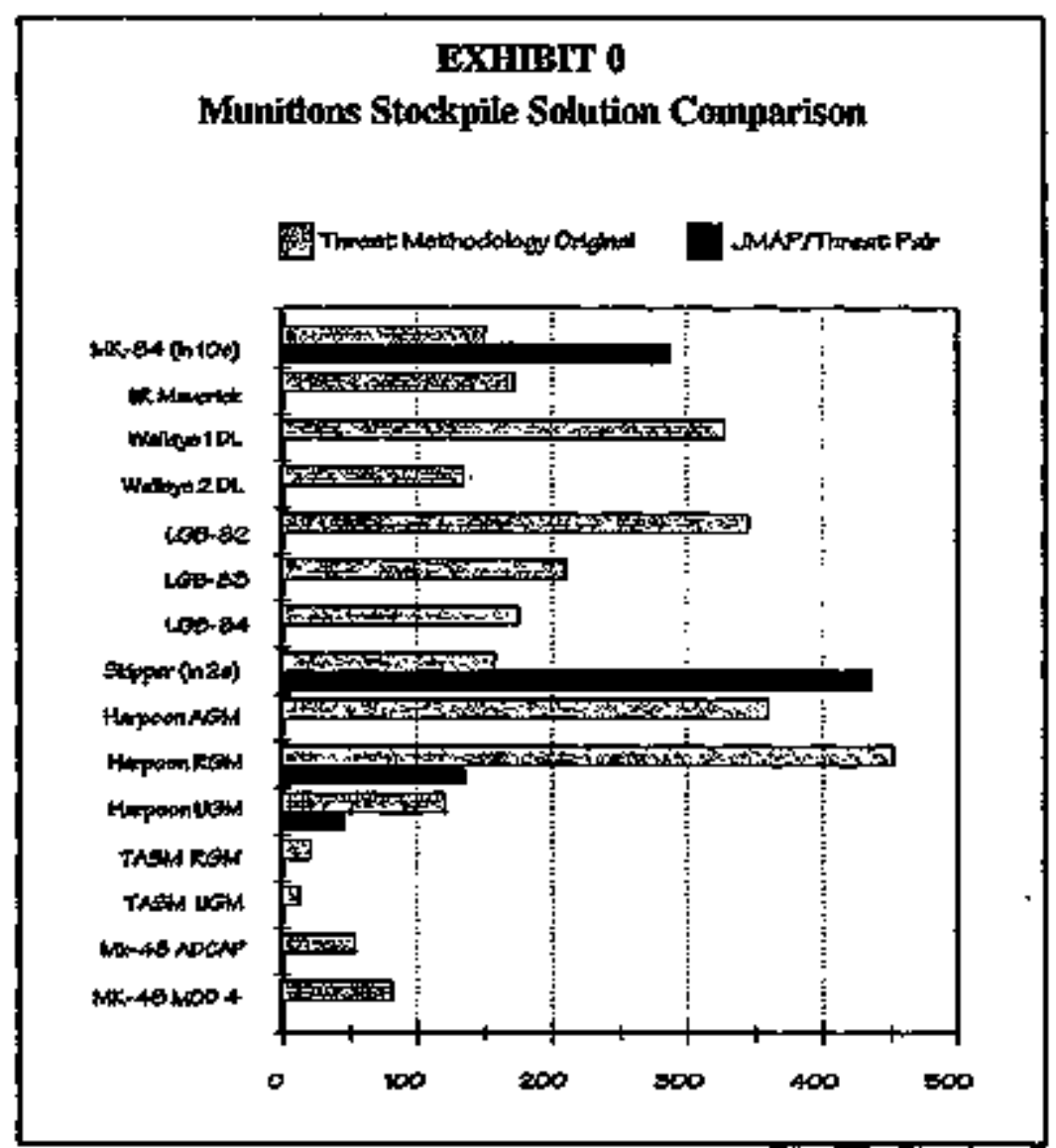


JMAP/Threat Pair coucentrates combat activity onto specific shooter/munition combinations.

You can see that submarines are forced to kill some minimum number of targets, which are then most efficiently taken with Harpoon and not with TASM or torpedoes. Sturface ships are also forced to kill some minimum number of targets, which are then most efficiently taken with Harpoon and not TASM. Airplanes handle the remaining targets, which are then most efficiently taken with Mik-84 (shown in units of 10) and, so it geems, Skipper (shown in units of 2). But the allocation to Skipper is by forcing 450 expenditures (as in reference [d]) which translates into Exhibit O's recommended stackpile of 871. The JMAP/Threat Pair also works fine when JMAP is constrained to make exactly the Threat Methodology's allocation of shooters to targets but with the choice of munition free.

However, when the Pair is partially consirained in this allocation, we have sometimes observed erratic convergence behavior. One particular erratic behavior pattern is the bi-stable solution; this is one which oscillatos alternatively from one type of allocation to another. We bave also observed multi-stable solutions and other erratic behavior, including non-convergence. We surmise that convergence to a single solution fails because: (1) the cost factor changes introduced into each JMAP iteration could be a likely sonrce of the observed multi-stabte solutions from alternative linear goal programming runs, and (2) the cumulative effect of numerical rounding on many thousands of iterative calculations carried out in both the Tbreat Model and in the $181 \times 330$ dimensional JMAP linear goal program could be the other likely source.

The operation of the JMAP/ThreatPair is not as clean and antomatic as we had hoped. Some modifications to our approach might solve thest difficultios but we were noable to conduct extensive tests at the present time. Nevertheless, we believe there is value to the Pair concept for it provides a better conventional munitions planning tool than either model separately. For example, the Pair could be used to optimize the incremental cost of adding munitions to existing stockpiles. It wonld do this by costing the munitions in existing stockpiles at zero (encouraging their use) and costing the additional munitions required in excess of current stockpiles at the projected bny price (which could be set to infinity for munitions which were out of production). The Pair could thus provide a coaventional munitions fiscal programming tool where neither of the original models could.

The remainder of this Memorandum comprises five parts. The first is a description of the structure and use of the OSD Threat Methodology. The second is a description of JMAP and its use. The third discusses the concept of the joint application of JMAP and the OSD Threat Methodology. The fouth displays sample output of the joint application. The fifth is a summary and epilogue. Finally, three appendices contain details of the formulation, data, and computer code.

\section{References}

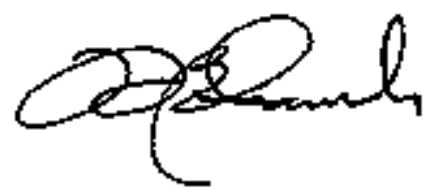

[a] "Fjal Roport for the Tark 1 implementntion of the OSD Threat Mathodolosy on the MRC. Wf est Scenterio", by J. J. Eolmerctib, Liods C. Thiet, and Etizabeth F. Amold, QUANTICS incorpontod (QM 54:93a), MEvterd PA 19355, 21 bly 1993 UNCLASSIFSED

[b] "Teehnical Documentation of the NATO Threat Mechodology", by 3. J. Bolmarcioh, M. A. Cerchidi, and G. B. OTr, QUANTICS incorporatod (QR 9:91), Malvern PA 19355, Dectuber 1990 UNCLASSIFIED

[eI Joint Munitions Assessnzent apd Planding Model (MMAP): A Medwodology Developed to Astess Convedtionsl Mustions Capabilities - Final Roport", Tho Los A Jamos National Labotatoty LA-UR-89-3896, 15 November 1989 UNCLASSIFIED (The Moble Hazd Prototype)

(d) "Deseriptian of the Maritime Modwle of the Joint Munitions Assessment and Planning Modei (MMAF)", by W.L.May, RL.Btitus, M.L.Stein, and R.C.Gerdon HI, LAUR-92-1868, Miliny Systems Andysis Group, Loo Alomos Nationel Labotatory, May 1992 UNCLASSIF[ED [The Maritime Prototype)

[c] "JMAP Vertion 1,0 User Guids", by Alanna Burke and Kym Kittel, Military System Analysiz \& Simulation Group, Los Alemes Natisned Labocatory, Oetohn 1993 UNCLASSIFIED \{Yersion 1.0 Production Modal\}

[f] "High Lovel Conventoonal Manitions Models: A Tochnical Evaluation", by Dauglas P. Anson, A-5:93-183, Military Systoms Anglysis \& Simulations, Los Alamos Nabonnd Laboralory, Sopember 1993 UNCEASSTFIED

[8] "Statisliond Analysis of QUANTICs" Threat Model: A Tochnioal Bvaluatton", by Patt Kvam and Bick Picand, TSA-1, Los Alomes Netional Lahoratory, May 1994 UNCLASSIFIED

[b] "High Level Muotitioos Models Evalnation: Utility and User Fritadipass", by Jay Mandelbaum, ODASD PR. November 1993 UNCLASSIPIED

[j] "Estimatiag Targot Overlap for Tnok Warfare Sustaitahility", by J. J. Boimarcich, O. B. Orr, and D. M. Pasceri, QUANTICS incorporated (QR 1:91), Malvett PA 19355, Jartary 1991 UNCLASSIFJED 


\section{The Structure and Use of the OSD Threat Methodology}

The purpose of this section is to discuss the structure and use of the OSD Threat Methodology. We briefly discuss the basic approach, how the approach is implemented, which softwase products are used, how the methodology is best used, and what information of potential importance to the Office of Munitions it can not provide att its own.

The pupose of the OSD Threat Methodology is to estimate how many munitions of various types cach of the Services need to win a fiture war. Because today's war-reserve munitions' stockpiles were primarily designed to fight a global war that has not come off, it is only prident now to redesign them so as to "right-size" munitions' stockpiles for more likely future wars. Once this is done, munitions inyentory analysts can create an explicit, feasible plan to manage the transition from the eurrent stockpiles to the new desired stockpiles.

The basic approach of the OSD Threat Methodology to the sizing of munitions' stockpiles is to achieve robustness through controlled overstocking: If you were fighting a war today, you might reasonably arrive at the stockpile you need tomorrow by simply replacing what you expended yesterday. But if you are not fighting today, then how do you proceed? The Threat Mefthodology proceeds by first assuming: (1) that you view your job as one of providing a robust stockpilo so future command can improvise in response to the unexpected, and (2) that you trust future wartime command decisions to take the stockpile you provide, set combat goals, resolve combat uncertainties as they arise, and win. The Methodology thus purposely avoids forecasts of unpredictable combat action details; it uses skeleton scenarios, general employment concepts, and simple models in order to get the munjtions stockpiles roughly right.

The major implementation assumptions and concepts are: (1) count up all the targets in the scenario, (2) assume shooters kill targets, on average, in proportion to shooters' TASCFORM'M figures of merit, and their longth of time in scenario, (3) angment average targets to be killed by munition type on the basis of past wars' kill variability - for robustness, (4) assume shooters select munitions which provide the quickest kill of each target type, and (5) compute the munitions required to kill $\mathrm{X} \%$ of tho angmented targets on average, or to kill at least $\mathrm{X} \%$ of the targets wilh Y\% assurance. For the prototype application discussed here, we select the former measure of offectiveness since it is simpler to implement.

In order to accomplish its job, the OSD Threat Methodology uses two kinds of software. First, R:BAsE is used: (1) to hold the OSD threat data base, (2) to allot targets to shooter types, (3) to select the quickest-kill munition type for a shooter type to use against a target type, (4) to allocate overlap and false targets to each monition type's average target allotment, and (5) to construct input files for the next piece of software - the OSD Tureat Model - one file for wach munition type of each Service. (QUANTICS has also constructed specialized wINDOWs-basel database editors which can build and maintain databases similar to that of the OSD threat database.)

The second piece of software is the OSD Threat Model itself. Its job is to estimate each munition type's expenditures neded to kill $\mathrm{X} \%$ of all assigned targets. It also estimates the munitions sthooters need "on-hoard" (up to maximuml Joads) in order to bavo munitions where they are necded when they are needed (it thus compensates for munitions' losses through attrition). It balances initial loads and combat reserves for repienishment so that $\mathrm{X} \%$ of targets can be killed on average based on past wars' analyses of the engagement variability from shooter to shooter. This leads to a specific war-reserve stockpile recommendation for each munition type by Service. The stockpile recommendation Iess the estimated number of rounds expended in killing targets represents the non-expenditures left over after the war which the Model says you need as safety stocks to assure that munitions are in the right place at the right time.

The OSD Threat Model is designed to provide a basic combat load to each shooter and then to plan to replenish the highest expenders who might exceed their basic load. The Model cannot recommend war reserve stockpiles greater than total expenditures plus doctrinal basic loads. The Model is best used when "loadouts + expenditures" are too expensive or where post-scenario residuals are not a concern (for example, you expect to rebuild stockpiles later on in peacebime). You can mimic this latter situration in a mone general context by packaging up enough scenarios to span one procurement cycle, say two years; the OSD Theat 
Model will produce sufficient munitions' residuals to bridge the gap between scentrios' expenditures and new buys. You might also package up sufficient war and training scenarios to span the lifecycle of a munition; the Model will then estimate the total number of munitions of the type needed until the IOC of its follow-on.

There are several important things that the OSD Threat Model is not designed to do. First, because it is "tims independent", it cannot assess whether or not its recommenided mimitions can be successfully delivered over time, noither the shooters ability to shoot it nor the logistics ability to transport it; it presumes the ability of your force struchure to kill the onemy given enough time. Second, it cannot assess the relative desirability of buying or selling mnnition " $A$ " versus munition " $B$ " when each has recommended stockpiles which differ from the currently projectod in-bin, neither for inventory management nor for inventory procurement strategy; the Model calculatos stockpile requirements without reference to existing inventories. Third, it cannot force the consumption of an in-bin munition nor assess any "second best" tradeoffs, neither for munitions on the samse shooter nor for different munitions on different shooters; however, after you review the Model's output, you are free to "factor" existing munitions against the Model's recommended stookpiles.

In summary, the OSD Threat Methodology exists to provide a forward-looking munitions' war reserves stockpile independent of existing inventory. R.BAse is used to invoke simple methods which embody aggregate time and space considerations and which producs a controlled overestimate of the number of targets each munition type should be prepared to kill. The Threat Model is designed to estimate both munitions' expenditures and nonexpended safety stocks to produce controlled overestimate of munitions needed during combat so that $\mathrm{X} \%$ of the targets are killed on average.

\section{JMAP}

The Joint Munitions Assessment Planning Model (JMAP) is a model designed by LANL to provide a methadology to enable the OSD Office of Munitions to do rapid turn-around, first order, munition trade-off ansalyses. It applies a linear goal programming technique to optimally allocate shooter effort and munitious to targets within the conflict daration. Mobile Hard Prototype of refer- ence [c] tsed two overall goal constraints: a cast goal and a target-kill goal. The cost goal is there to minimize total munition cost and tho kill goal to maximize the total number of targets killed.

The Mirritime Prototype of reference [d] added fractional kill goals for selected target types and in attrition goal in order to minimize the total attrition to shooters. JMAP Version 1.0 (the production version) of reference [e] maintains these goals. The Version 1.0 also maintains the chance constraints on the number of rounds to kill a target which the Maritime version introduced. The remainder of our description refers to JMAP Version 1.0.

IMAP Version 1.0 has three sets of goal constraints and five sets of physical constraints. The three goal constraints are a cost goal, a targetskilled goal, and a shooters-killed goal. The cost goal is there to minimize the cost of total munitions expenditures plus the cost of lost shooters plus the cost of mnitions lost on those lost shooters. For each target type in each time period there is a goal constraint on desired fraction of targets killed. For each shooter type, there is a goal constraint on the maximum fraction of shooter attrited.

MAP Version 1.0 has three sets of physical constraints on manitions. They are (1) upper bounds on muitions expenditures due to stockpile availability as incremented by the maximum amount of manitions which could be produced within the time interval, (2) npper boinds on mumitions expenditures limited by the operational rates of fire from shooters, and (3) lower bounds on munitions expenditures which must be fired due to doctrinal considerations in each time period, for example, artillery fired for suppressive effects. All these munitions constraints are "hard' physical constraints and must be met.

There are also two sets of physical constraints on targets. (1) upper bounds on the number of targets available to be killed, and (2) upper bonds on certain types of targets to be engaged by certain munition types due to limitations on operational availabilities in each time period; this can account for lost opportunities because of battlefield geometry and manteuver. All these target constraints are 'hard' physical constraints and must be met.

Under the restriction that 'hard' physical constraints must be satisfied, JMAP tries to select 
munitions for each stroster type in such a way that the total targets killed is as close to the high target goal as possible, the total shooter attrition is as close to the low attrition goal as possible, and the total cost is as close to the low cost goal as possible. In this sense, one may say that JMAP attains the maximum effectiveness in shooter/munition' target selections, and, hence, gives the best "bang for the buck".

JMAP Version 1,0 requires a number of imputs which can be categorized into the four sets found in Exbibit 1. Inputs representing goals are italicized. Not alt these inputs ane necessary for the joirt application of JMAP with the OSD Threat Methodology. The next sextion indicates how we chose to modify JMAP Version 1.0 so that it can best be used with the OSD Threat Methodology.

\section{Operating JMAP and the OSD Threat Methodology as an Integrated Pair}

MAP optimizes the allocation of munitions aud shooters to targets, trading-off some for others, while under constraints on munitions stocks, expenditures, target kills, shooter attrition, and costs. MAAP tells you how you should fun a war to consume the fewest dollars you have invested in munitons and shooters. The OSD Threat Methodology tells you the munitions stockpilos (expenditures * safety stocks) yon need to run a war flexibly given the various ways you might end up operating your warfighting capabilities. Our idea for a working JMAP/Tireat Integrated Pair combines these two different points of view in the following way:

MAP dons nat trade-off munitions stockniles; rather it trades-off munitions expendittress. JMAP could tradeoff stockpiles if the Threat Model would assess the safety stocks corresponding to JMAP's expenditures, Munitions expenditures from JMAP's goal optimization tum ont identical to those of the Threat Model when the Threat Model operates with the same allocation of shooters/mimitions to targets as does JMAP, and when JMAP dispenses with its chance-constrained rounds-to-kill. The allocation of shooters/mumitions to targets that. the Threat Model ordinarily gets from the Threat Split Model can be substituted for by JMAP's optimization instead. So, the Threat Model could 'tax' JMAP's expenditures for the cost of safety stocks and JMAP could be run with 'inflated' munitions' costs when generating its allocations.

\section{EXHIBIT 1 \\ JMAP Input Summary}

Stocks:

(1) the number of shooters of each type available sal the destred finction of each you will tolarate being attrited,

(2) the ulumber muaitions of each type ayalable to be expended;

(3) the nomber of targets of each type available to bo killed and the destred fruction of each you wish to kils;

Allocations/Asolignments:

(4) for exul paining of one shooter type with one target type, the number of munitions for tach type employable by the skooker per engagetnent, the mumber of engagements needed to kill a target, and shooter attrition per engagemeat,

(5) the maximum fraction of each larget type availabte to be killed by each munition type;

Costa:

(7) the cost of one mumition of each type;

(8) line cost of one shooter,

Thmes:

(9) the length of each time period,

(10) maximimn (operationa) rates of fire by each shooter of each monition type,

(11) the minimum doctrinal rate of corsumption of each mumition type.

To make this idea work, we streamline JMAP so that it does what it does best, namely, provide an optimal allocation. Oar first action is to disponse with the chance-constrained rounds-to-kill. Next, we remave the time-based constraints so as to make IMAP as threat-oriented as possible and thus have it more closely match the ethos of the OSD Threat Methodology. JMAP Version 1.0 has already disposed of multiple time periods and, since JMAP treats time as a period aggregate (not as a daily curb), any daily rates within JMAP now serve to impose expenditures limits during the overall conflitet period. As a result, the time factors (9), (10), and (11) in Exhibit 1 disappear after we multiply the operational rates in (10) and the doctrinal rates in (11) by the total conflict time. This has the net effect of translating those timebased factors directly into expenditure constraints. 
Furthermore, asing IMAP with the Threat Model, whose job it is to estimate the right size of stockpiles, means that as a first cut even stockpile constraints should be lifted from JMAP. This would provide a baseline for the 'optimal' stockpiles. As a second cut, for example for out-of-production munitions such as Watleye, the current stock levels conld be fed to JMAP as a stockpile constraint so that JMAP can reallocate effort if the baseline caso required more than is available. Similarly, minimum exponditures of a munition, for example for doctrinal purposes or for to using up older munitions, can be introduced into JMAP as an expenditure constraint if the baseline case required fewer than we wish to consume.

In addition, to operate the JMAP/Threat Pair, we modify IMAP's cost goal. Ever since the Maritime Prototype JMAP has included in its cost goal the cost of lost shooters and the cost of munitions lost on those shooters. These formulations of JMAP mimic the Services mutitions selection models which optimize "bang for the beck" using these cost faxtors as well as others. The idea is that when a shooter incurs different risks in delivering different munitions then the cost of delivery is somehow germane to the mumition selection. But the Service models are not linear goal programs with attrition goal constraints while JMAP is; MMP has a separate attrition goal to alter its shooter fmuntion to target allocation. So why double count the impact of attrition. For our prototyp TMAP/Threat Pair, we drop the explieit costing of shooter losses within the cost goal. We maintain the shooter attrition goal to represent attrition's operational reality.

Similarly, we drop the explicit costing of mumtions lost on attrited shooters. The reason is that the Threat Model accounts for the safety stocks needed to suppont combat, which includes mumitions which might be lost due to attrition. Since JMAP, working in the JMAP/Threat Pair, already includes the cost of the safety stocks through a 'safety-stock tax' resulting in an inflated cost-perexpenditure, it would be double coenting to include the cost of these losses again.

The JMAP/Threat Pair operates through the cyclic application of MMAP and the OSD Threat Modal until a stable solution emerges. The procedure is: (1) the OSD Threat Split Model initially allocates shooted/manition combinations to targets as a baseline feed to the Threat Model; (2) tho Threat Model generates a set of munitions stock- piles comprising expenditares plas safety stocks this is the "TM-initialization'; (3) JMAP applies goal constrainis after JMAP's munition costs are modified to include the cost of the safety stocks this is accomplished by feeding JMAP the Threat Model's stockpile-to-expenditures ratios (the OSD Threat Methodology's quickest-kill mnnition selection is suspended so that it can initialize this ratio for each munition type); (4) MMAP's new allocation is fed back to the Threat Model which recalculates the stockpile-to-expenditures ratios; and (5) we reptat steps (3) and (4) until the iteration results stabilize. We end up with munitions requirements which are cptimal in the JMAP sense and which are war reserve stockpile recommendations in the Threat Methodology sense.

Finally, to make the JMAP/Threat Pair work in a truly integrated fashion, we choose to place allocation constraints on JMAP - because JMAP yearns to allocate all targets to the single most efficient shooter-typefmumition-type combination available. In order to use the operational capability of all the shooters put into the scenario, we include the influence of the baseline sllocation of shooters to targets provided by the OSD Threat Methodology. This Methodology allocates shooters to targets in proportion to each shooter's TASCFORMTA figure of merit multiplied by each shooter's length of time in scenzrio. This estimate of the amount of combat action each type of shooter in the scenario will likely see assumes shooters will be employed in rough proportion to their capability, not cost.

The OSD Threat Methodology already has within it a method of augmenting the number of targets which it will allocate to cach shooter/mumition type on the basis of past wars' kill variability (see reference [a]). It does this by estimating a standard deviation o in target kills, based on past warfare experience, and adding some number of $\sigma$ s to the baseline allocation. The idea is that in a real twar any particular combination of shooter-type/ manition-type may end up killing more targets than originally expected and the Methodology is designed to estimate stockpiles so that no shooter ruos out with high confidence. For our prototype integration, we apply various multipliers of the stendard deviation to create sets of both upper and lower bounds on the number of targets of each type which could be allocated to each shooter type by JMAP. JMAP remains free to select the 'optimal' munition type. Each set of kill-bounds corresponds to some confidence level that shooters will kill numbers of 
targets between these bounds - assuming the OSD Threat Methodology baseline allocation was a correct estimate of the results of the 'average' war.

The larger the confidence level associated with a set of bounds, the larger the resulting spread in kill-bounds, and the larger the spread in targets JMAP can allocate to any shooter. (Consult reference [i] for details.) For example, we take the $100 \%$ confidence set of kill-bounds to corresponds to a lower bound $3.3 \mathrm{o}$ below the bastline (bottomad by zero targets) and an upper bound 3.30 above the baseline (capped by the maximum number of targets). Similarly, the $85 \%$ confidence set of killbounds corresponds to a lower bound $1.04 \mathrm{a}$ below the baseline (bottomed by zero targets) and an upper bound 1.040 above the baseline (capped by maximum targets). As a numerical example, when the baseline allocates 100 targets of a total of 400 to a shooter type with 10 shooters, then 0 is about 30 targots and an $85 \%$ confidence set would allow an upper bound of about 130 targets and a lower bound of about 70 . (The ' $50 \%$ confidence' set adds and subtract 0.00 to the baseline allocation; this makes both the upper and lower bounds equal to the baseline and JMAP must allocate shooters to targets as specified by the Threat Methodology.)

A detailed formulation of the IMAP/Threat Pair is given in Appendix A. Exhibit A-l defines the terms used. Exhibit A-2 shows the inputs and outputs of a Threat Model run for a given munition type. Exhibit A-3 provides the JMAP formulation in detail. Bxhibit A-4 describes the precise iterative procedure of the JMAP/Threat Pair. Exhibit A.S compares the varions previous formolations of MAP from references [c], [d], and [e] with the Pair formulation here.

Our prototype applioation draws input data from the Maritime Prototype report of reforence [d] - as far as it goes. We retain the four target types (small major combatants, minor combatants, landing craft, and false targets), the 12 shooter (platform) types, the 17 munifion types, the forced expenditure of 450 Skipper, and the stockpile constraints of which only that on Submarinelaunched Happon (UGM) had any effect. Wo supplement some of reference [d]'s exchange ratios with the attrition data from the LANL MRC-West database. For the shooter and target figures-ofmerit, we utilize the relative platform weights and relative target weights from JMAP Version 1.0.
The initial allowance, refill size, and reorder point for each munition type on each shooter type is taken from the LANL MRC-West database. The thaximum rate of fire by each shooter of each munition type is based on the corresponding initial allowance. Appendix B coutains our sample data with a sample input file given in Exhibit B-1. We emphasize our 'scenario' could in no way be interpreted as a MRC-West scenario. In particular, the counts of enemy targets and US shooters were unlike those in the MRC-West scemario. In addition, the beseline allocation of shooter/munition combinations to targets (see Exhibit B-2) was obtained from the US Navy Threat Split Model rather than on the existing allocation from the application of the OSD Threat Methodology on the MRC-West scenario reported in reference [a].

\section{Results From the JMAP/Threat Pair}

The purpose of this section is to report on the some of the JMAB/Threat Pair sample rums which were made to prove the prototype concept. This section is divided into two parts. The first presents some general observations conceming our sample mins. The second examines the results of some specific sample runs for the purpose of illustrating the observed convergence and non-convergence behaviors of the JMAP/Threat Pair.

\subsection{General Observations}

For each of our sample nins, we needed to choose the nelative priority of JMAP's three goals - the kill goal, the attrition goal, and the munitions cost goal. We chose the target kill goal to be of the highest priority, that is, JMAP was asked to make sure that a minimum fraction of targets of each type were killed before any other tradeoff's were permitted. We chose the shooter attrition goal as the second priority, that is, JMAP was asked to kill a minimum fraction of targets of each type and, in the procoss, to also keep the attrition to shopters down to the maximum levels desired, yet consistent with killing the desired minimum fraction of targets. Thus, if attrition to shooters was sufficieutly high across the board for each engagement, the attrition goal would, of necessity, be violated, but to the minimum extent possible, while the target goal was being satisfied. The total murition cost was the third prionity goal. That is, within the bounds for the killing of minimum fractions of targets of each type and withim the bounds for maximum tolerable attrition, munitions were selected to reduce total munitions costs. 
We also needed to select the stopping rule for pair-iterations. We chose to stop at one of two criteria: either (1) the difference of Threat Model average expenditures in two consecutive pairiterations was less than $1 \%$ - which is a tighter criterion than the settling down of the JMAP allocation of munition to target, or (2) the number of pair-iterations bad reached 16 - which indicates that the process would not likely converge to a single solntion. We found that the number of pair-iterations were mostly more than 16 when applying kill-bounds associated with $77 \%$ through $99.5 \%$ confidence levels. Other cases normally converged in just a few iterations.

The stockpile solution for the most constrained ("50\% confidence") case had total munition costs of $\$ 0.968 \mathrm{~B}$ compared to $\$ 0.271 \mathrm{~B}$ for the least constrained ( $\mathbf{1 0 0 \%}$ confidence) case. Intermediate munitions costs corresponded to intermediate confidence levels - as the confidence levels increased, the cost solutons decreasedi monotonically. This was becanse JMAP had no freedom to allocate targets to shooters in the '50\% confidence' case while it had much greater freedom to allocate shooters to targets at the $100 \%$ confidence case where it then made the more efficient sclection of munition against targets.

\subsection{Some Specific Run Results}

Let us first consider the Pair's least constrained case of $100 \%$ confidence in kill-bounds. Exhibit 2, repeating Exhibit 0, shows the original Threat Methodology solution (the 'TM-initialization') and the final (the third) of the JMAP/Threat Pair iterative solations. The imposed expenditure of 450 Skipper appears in all iteration after the 'TM-initialization'. Exhibit 2 includes safety stocks of 421 from the final iteration (Skipper's total stockpile of $871=450+421$ is shown in twos). On the first pair-iteration (not shown) JMAP selects some LGB-82 in addition to the Mk-84 and Harpoon showa in Exhibit 2. On the second pair-iteration, JMAP drops LGB-82 in favor of more Mk-84. This allocation is retained in the third pair-iteration and each muxition's expenditures stabilized. (A forced fourth iteration tarued oxt identical to the third.)
EXHIBIT 2

Least Kill-Bound Constraint Solution Comparison
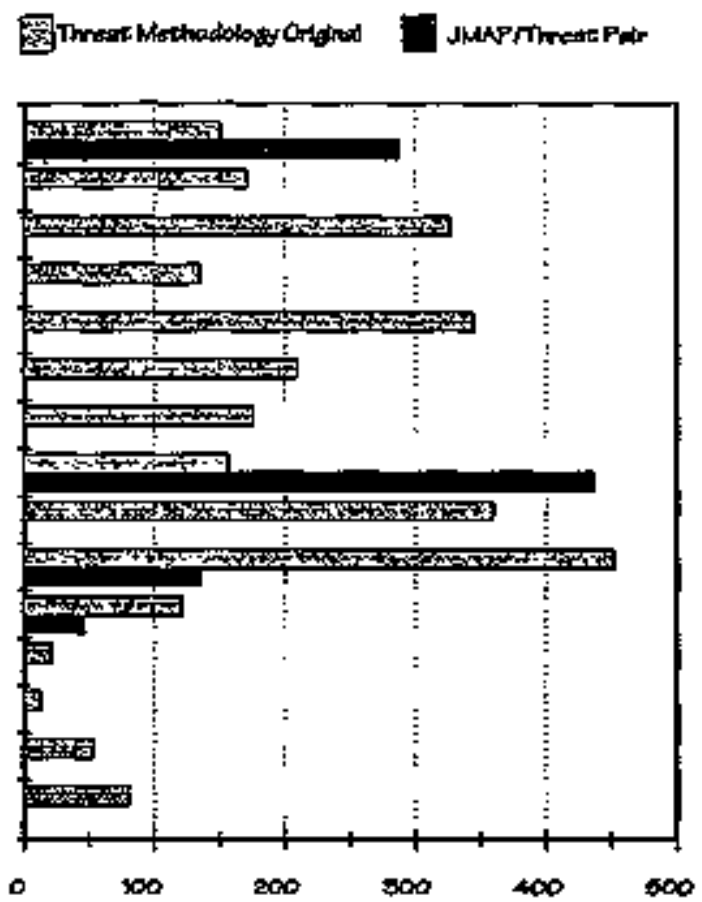

At the $100 \%$ confidence kill-brounds, it turns out that JMAP is constrained to allocate some minimal number of targets to surface ships and to submarines. AEGIS CGs and DDGs end op with the minimal namber of minor combatants and other DDGs and SSNs end up with minimal numbers of landing craft. JMAP ends up choosing Harpoon as the most efficient munition in each case. Without those constraiats JMAP would allocate all targets to Mk-84 after using up the forced 450 Skipper expenditures, which, as it turms ont, are most efficiently applied against minor combatants.

The Mk-84 turns out to come from all the attack and fighter aircraft types (A-6 SWTP, F/A18, F-14A/B, F-14D) each used most efficiently up to its attrition goal limits. Tho F/A-18 is used 'last' and takes up the slack just short of jts attrition goal. Unfortunately, all false targets end up allocated to Mk-84, defeating the stockpile purpose of the false targets which is to allow each selected munition type a few extra expenditures to compensate for mis-targeting. False targets might be better handled by the JMAP/Threat Pair by allowing the Threat Model to pass them on to JMAP by 
expanding the safety-stock tax idea into a combined a false-target/safety. stocks tax on expenditures. The JMAP/Tkreat Pair formulation here, however, retains the JMAP Maritime Prototype approach.

Next, let us consider the other extreme case, that is, kill-bounds at the ' $50 \%$ confidence' level. Here JMAP has no freedom to allocate targets to shooters but must duplicate the Threat Methodology's shooter/target allocation - the most constrained case although JMAP does get to select the munition the shooter uses. The JMAP/ Throat Pair stabilizes in three iterations. In addition to the 450 forced Skipper expenditures, JMAP selects Mk-84, Harpoon AGM, Harpoon RGM, Harpoon UGM, TASM RGM, and the Mk-48 MOD4. Exhibit 3 compares this most constraized case with the least constrained case of Exhibit 2. Several things need explanation.

First, in the most constraimed case, certain amounts of targets are allocated to each type of stooter. Compared to the Ieast constrained case, this shifts the target allocation towards surface ships and submarines and breaks the aireraft monopoly on targets; this then lowers the Mk-84 usage. Second, Skipper requirements are different because the 450 expenditure in the most constrained case are more concentrated on the F/A18 and the net safety stacks produced by the Threat Model fall from 421 to 352; this means the recommended stockpile falls from 871 to 802 .

Third, in the most constrained case the patrol and ASW aircraft must kill their baseline allocated targets using Harpoon AGM since their lower kili bound is no longer 0 targets as it was in the least constrained case. Fourth, in the most constrained case all surface ships must kill their baseline allocated targets using much more Harpoon RGM. Also the non-AEGIS DDGs are forced well over their attrition goal in order to kill their alloc日ted targets, so much so that thoy end up using some expensive TASM RGM in an attempt to balance munitions cost with attrition. Fifth, in the most constrained case both submarine classes must kil] their allocated targets; the most efficient munition
EXHIBIT 3

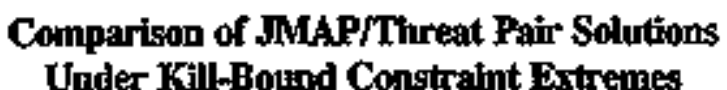
Under Kill-Boind Constraint Extremes

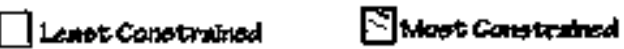

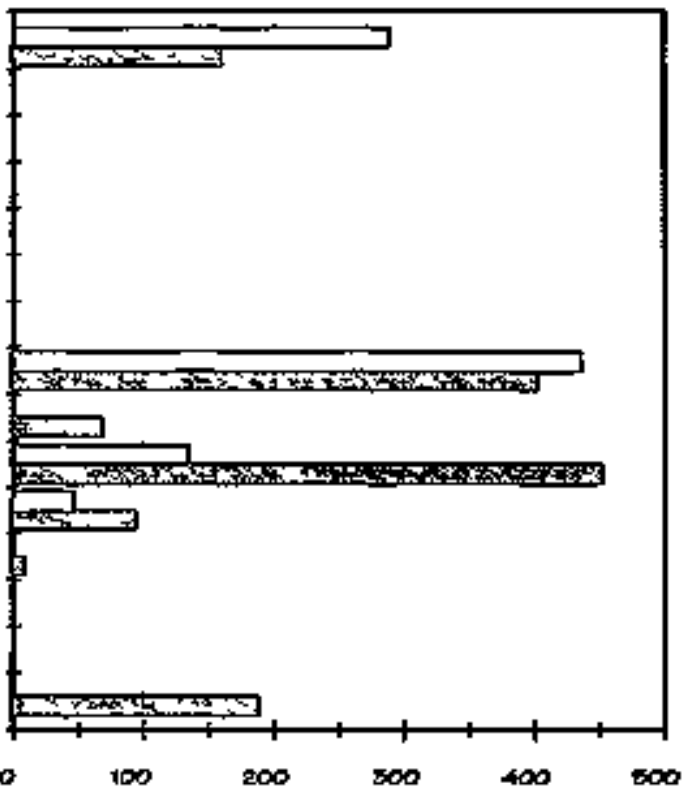

is Hapoon UGM but it bumps into its stockpile constraint and Mk-48 MOD4 is used to complete the kills.

For the $80 \%$ confidence level on kill-bounds, the iterative application of the JMAP/Threat Pair fails to converge to a single solution after 16 pairiterations. However, it exhibits a bi-stable behavior in that the JMAP/Threat Pair solutions for the 4-th, 6-th, 8-th, 10-th, 12-th, 14-th, and 16-th pairiterations (the even ones) strongly resemble one another while the solutions for the 5-th, 7-th, 9-th, 11-th, 13-th, and 15-th pair-iterations (the odd ones) also strongly resemble one another but are different from the even ones. Compared to the even ones, the odd one show a lot more Mk-84s, no LGB-82s, and a litfle less Mk-48 MOD4s. Compar. ing the pair-iterations 15 and 16 , the 15-th has a higher total munition cost (\$0.914B vs \$0.861B) but a lower total shooter attrition cost $(\$ 0.394 \mathrm{~B}$ v\$ \$0.653B). In gross dollars for just these two cost items you might prefer iteration 15 , but what about the other costs incident to the selection, such as storage, maintenance, etc. Exhibit 4 provides a graphical description of four consecutive pair-iteracions: the 8-th, 9-th, 10-th, and 11-th. 
Looking behind the pair-iterations displayed in Exhibit 4, you find that the same number of Minor Combatants (347) and FALSE targets (40) are killed in both the odd ones and the even ones. These numbers represent about the 0.8 goal of the total targets of each type available to be killed. The pair-iteratons displayed some jitter on the kills of the 3 Smatl Major Combatants - 2.40 odd vs. 2.44 even - but the major distinction is in the kills of the 82 LCPAs - 81.56 odd vs. 66.68 even. LGB-82s are used by $\mathrm{F}-14 \mathrm{~A} / \mathrm{B}$ to kill Minor Combatanis in the odd ones, while LGB-82 is not used at all in the even ones. On the other hand, more Mk-84s are used by A-6 SWLP, F/A-18, and F-14A/B to kilt Minor Combatants in the oven ones and that is why the even ones sustain a higher attrition. Basically, all the additional 14.88 LCPAs kitled in the odd ones are killed by SSN 688 using Mik-48 MOD4s.

This bi-stable pattern seems to be an artifact of the changes in stockpile-toexpenditure ratio from one ruis to another. But in addition, there is jitter in the Mk-48 MOD4/Harpoon UGM struggle for targets in both the odd cases taken among themselves and in the even cases taken among themselves. Such an effect within the same families would seem to point to the impact of numerical rounding from one rum to another.

Let us now consider the case of $90 \%$ confidence kill-boumds. The JMAP/ Threat Pair process again goes on for 16 iterations with the process flip-flopping for pair-iterations 5 through 12, similar to that in the $80 \%$ conffdence case. Exhibit 5 provides a graphical description of the Threat Model stockpites for four consecutive Pair-iterations, the 8-th, 9-th, 10-th, and 11-th. More Mik-84s and loss LGB-82s are expended in the even ones than in the odd ones. However, unlike in the $80 \%$ confidence case, the flip-flop behavior does not persist. From the 13-th pair-iteration to the 14th, the Mk-84 requirements only increase slightly while the LGB-82 requirements

\section{EXHFBYT 4}

Four MMAP/Threat Pair-Iterations Under Kinl-Bournd Constraints for the $80 \%$ Confidence Level
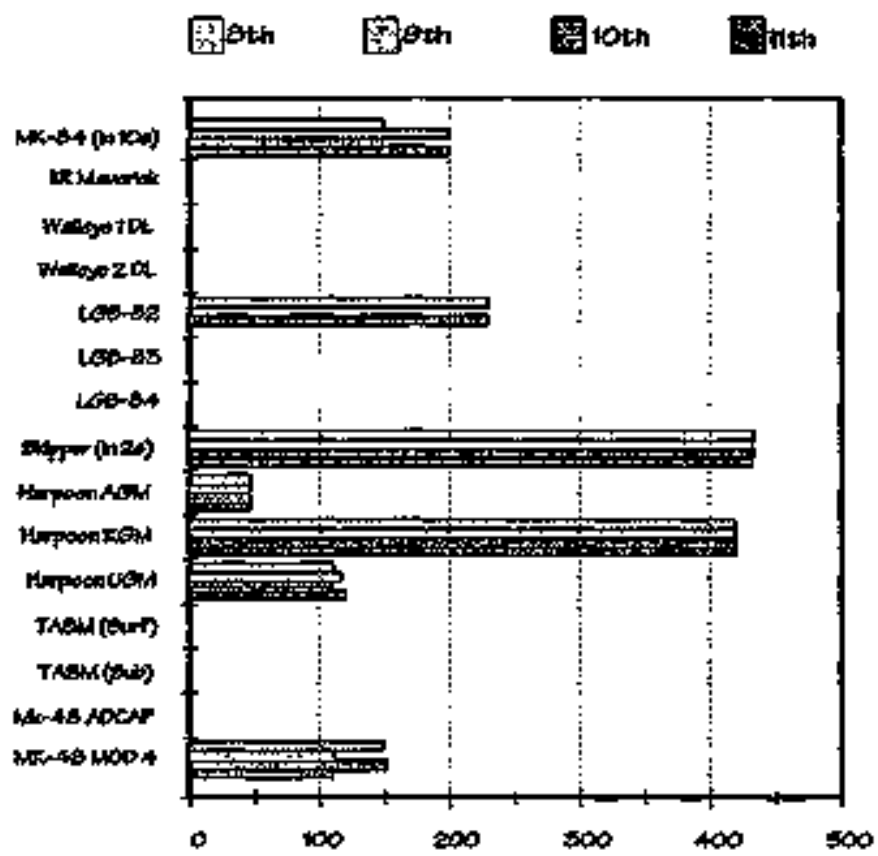

\section{EXHIBIT 5}

Four JMAP/Threat Pair-Iterations Under Kill-Biound Constraints for the $90 \%$ Confidence Lered
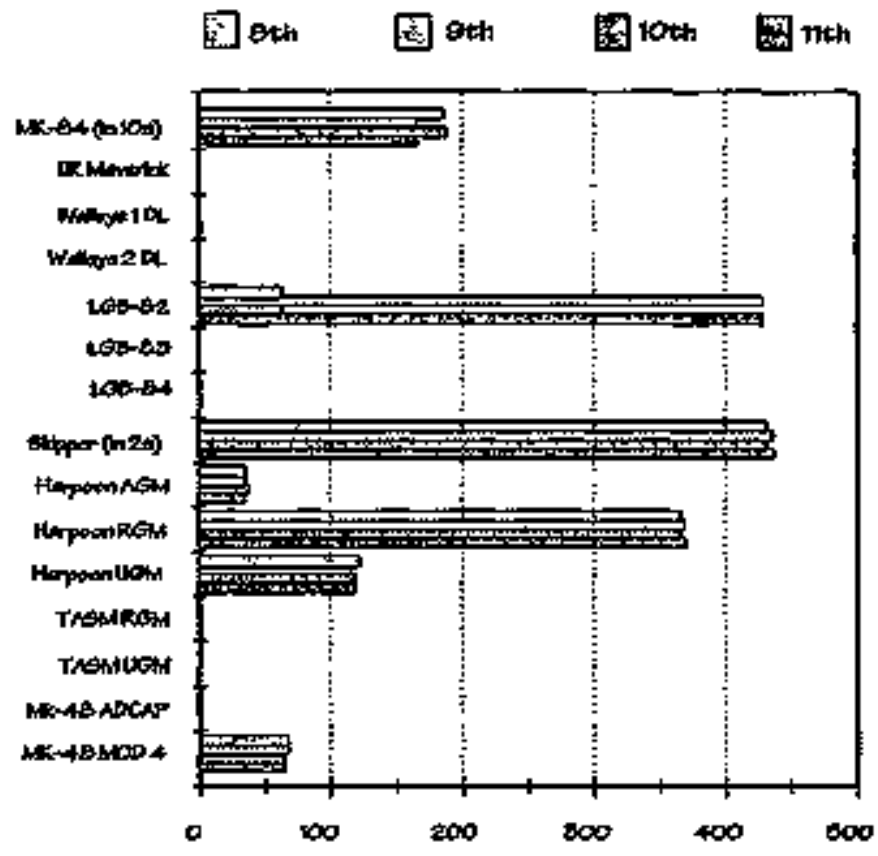
increase instead of decresse. On the 15-th iteration, the Mk-84 requirements increase to about that of the previous even ones while LGB-82s are dropped completely. This stabilizes on the 16-th iteration in that the difference in Threat. Model's expenditures with that of the next iteration would have been less than $1 \%$ for every munition type if the process had continued. Exhibit 6 illustrates the tail-end behavior for $90 \%$ confidence - showing the Threat Model stockpiles for pair-iterations 12 through 16.

Results for the $95 \%$ confidence killbounds (not shown) oxbibit no sign of bi-stable convergence. Consecutive iterations appear to look fairly close to one anather but fail to met our convergence criteria of $I \%$ differences in consecutive iterations' expenditures per munition.

\section{Summary and Epîlogue}

The joint application of MMAP and the OSD Threat Methodology discussed in this memorandum was conceived to produce a tool both to analyze and to optimize mumitions stodkpiles. From JMAP's point of view, the Threat Methodology helped it do its job by letting it work more realistically with stockpiles because in warfare not all of a stockpile can be expended at the enemy and the optimal shooter/ munition combination may not acquire each target. From the Threat Methodology point of view JMAP gave it a way to trade-off one munition for another given various constraints.

The concept of joint application relied on the cyclic use of JMAp and the Threat Methodology hoping a stable solution would emerge. The procedure was: (1) allow the OSD Threat Methodology to initially allocate shooter/munition combinations to targets, then to generate a set of munitions expenditures, and then to calculate the necessary safety stocks needed to support those expenditures; (2) invoke JMAP to apply constraints after factoring JMAP's munition costs to include the cost of the safety stocks - IMAP then produces a more cost-efficient allocation; (3) feed this ntew allocation back to the Threat Model and let it recalculate the corresponding safety stocks, and (4) repeat steps (2) and (3) nintil a stable solution obtains.

\section{EXHUBIT 6}

Five Final JMAP/Threat Pair-Iterations Under Kill-Bound Constraints for the 90\% Confidence Level
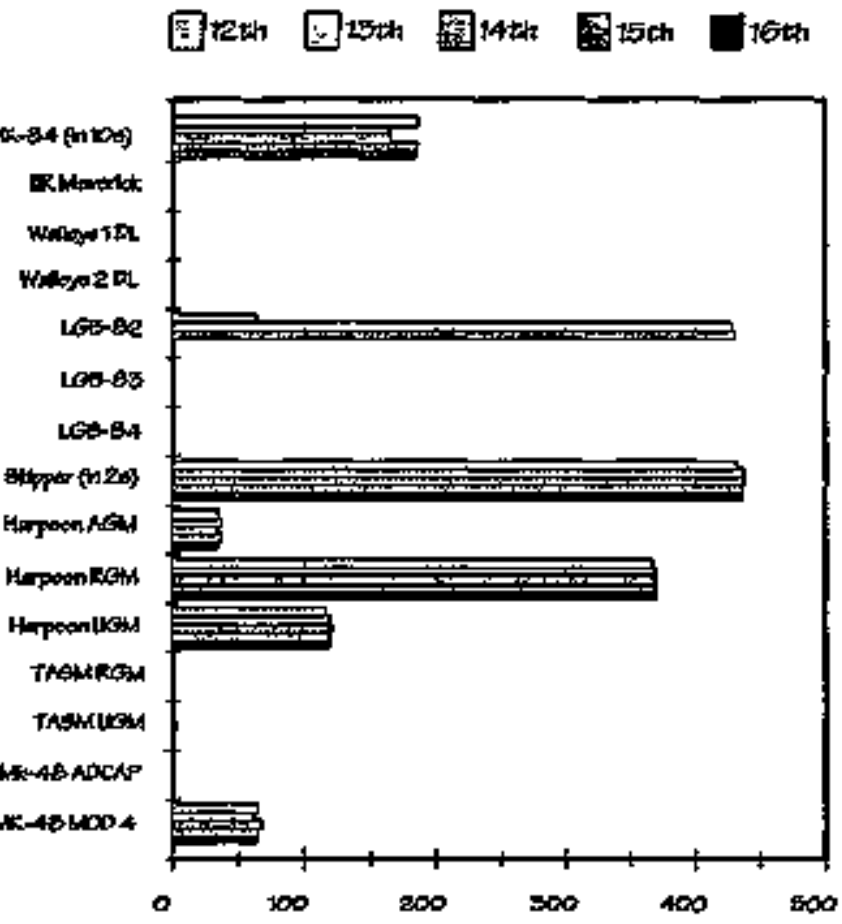

The results of our sample rins showed that the JMAP/Threat Pair iteration process 'converges' rapidly when JMAP either has a relatively small amount of freedom or virtually complete fredom to allocate shooters over targets, corresponding to the target overlap confidence level from $50 \%$ to $76 \%$ and also from $99.6 \%$ to $100 \%$. For most of the confidence levels in between, Pair iterations did not often converge to less than $1 \%$ differences between successive iterations. Some oscillated between two states but eventally converged, some exhibited bistable behavior without convergence, and some (such as the case of $93 \%$ confidence) oscillated among many states without convergence. increasing the convergence criterion to $2 \%$ differences turned out not to capture many more solutions.

At this time, we do not have a complete explan. ation for the erratic behavior exhibited by our sample runs. But it appears that JMAP's sensitivity to small changes, the Threat Model's itorative cost factor recomputations, and the cumalative effect of numerical rounding of the thousands upon thousands of calculations in both models sometimes combine to have a destabilizing effect on the solutions from the JMAP/Threat Model Pair. 
APPENDIX A

JMAP/Threat Pair

Fornulation 


\section{EXIFIBIT A-1}

Glossaky of Terms Used in the JMAP/Threat Pair

User Parameters :

$\mathrm{t} \quad \mathrm{KC} \mathrm{C}_{\mathrm{w}}^{0}$

FTBK $_{t}$

FATTR,

Cost_Goal

$\mathbf{P}_{\mathrm{e}}$

$\mathbf{P}_{k}$

P.

T_O_Confidence

Tolerance initial kill criterion for type $m$ munition (average fraction of targets to be killed by type in munition - input to Threat Model) minimum fraction of type $t$ targets to be killed (kill goal) maximum fraction of type $p$ platforms allowed to be attrited (attrition goal) overall cost goal priority level for overall cost goal priority level for kill goals priority level for attrition goals

confidence level for target overlap stopping tolerance

\section{Scenario Parameters :}

$\mathrm{CP}_{\mathrm{p}}$

cost of one type p platform

$\mathrm{CM}_{\mathrm{m}}$

cost of one round of type m munition

$\mathfrak{t}$

$\mathrm{PQ}_{\mathrm{p}}$

number of type p platforms

$\mathrm{MQ}_{\mathrm{m}}$

number of type min muritions

t

TQ

number of type $t$ targets

$\mathrm{T}_{\mathrm{pm}}^{\mathrm{o}}$

number of type $t$ targets to be killed by type $p$ platforms using type m munition (initial target split - input to Threat Model)

number of type $t$ targets to be killed by type $p$ platforms

$\mathrm{T}_{\mathrm{mt}}^{\mathrm{0}}=\Sigma_{\mathrm{m}} \mathrm{T}_{\mathrm{pm}}^{\mathrm{o}}$

$\mathbf{T Q}_{\mathrm{q}}=\sum_{\mathrm{p}} \mathbf{T}_{\mathrm{pl}}^{0}=\sum_{\mathrm{pm}} \mathrm{T}_{\mathrm{pax}}^{0}$

$\mathrm{RPE}_{\mathrm{pmt}}$

rounds-per-engagement of type m munitions, fired by type $p$ platforms, against type $t$ targets (i.e., salvo size)

j $\quad$ STK $_{\text {pat }}$

average number of salvos of type $m$ munitions needed to kill a type $t$ target, fired by a type $p$ platform

RTK $_{\text {pat }}$

average number of rounds of type $m$ munitions needed to kill a type t target, fired by a type p platform $\mathrm{RTK}_{\mathrm{pat}}=\mathrm{RPE}_{\mathrm{put}} * \mathrm{STK}_{\mathrm{pmt}}$

fraction of a type p platform attrited per engagmeat while attacking type $t$ targets using type $m$ munitions 
$\mathrm{DOCT}_{\mathrm{m}}$ - doctrinal minimum expenditares of type $m$ munitions per day

j $\quad$ ROF $_{\text {pas }}$

maximum rate-of-fire of type $m$ munitions fired by a type $p$ platform eacin day

TIME

number of days in the scenario

FOM_P

figure-of-merit (relative value) for type p platforms

FOM_T

figure-of-merit (relative value) for type $t$ targets

$\mathrm{IA}_{\mathrm{pw}}$

initial allowance of type $m$ munitions on a type $p$ plationm

t

$\mathbf{R S}_{\mathrm{pm}}$

Refill Size of type in munitions on a type p platform

t

$\mathbf{R P}_{\mathrm{pm}}$

Reorder Point of type m muritions on type p platforms

\section{Variables :}

t

$\mathbf{t}$

$\mathbf{t}$

j $\quad \mathbf{R}_{-} \mathbf{E}_{\mathbf{m}}$

$\mathbf{j} \quad \mathrm{T}_{\mathrm{pat}}$

j

j

j

j
$\mathbf{R}_{\text {m }}$

$\mathrm{E}_{\mathrm{pwx}}$

$\mathrm{E}_{\mathrm{m}}$

$\delta_{\mathrm{pt}}$

$\mathrm{X}_{\mathrm{pm} \mathrm{m}}$

$\mathrm{CG}^{-}, \mathrm{CG}^{+}$

$\mathbf{K G}_{\mathbf{i}}^{-}, \mathbf{K G}_{\mathbf{i}}^{+}$

$A G_{p}^{-}, A G_{p}^{+}$ requirements for type $\mathrm{m}$ munitions (Threat Model output)

average expenditures of type $m$ mtnitions by type p platforms against type $t$ targets

$\mathrm{E}_{\text {pat }}=\mathrm{KC}_{\mathrm{\alpha}}^{\text {a }} * \mathrm{RPE}_{\mathrm{prax}} * \mathrm{STK}_{\text {pux }} * \mathrm{~T}_{\text {pat }}$

average expenditures of type $m$ munitions

$\mathrm{E}_{\mathrm{m}}=\Sigma_{\mathrm{pt}} \mathrm{E}_{\mathrm{pml}} * \mathrm{KC}_{\mathrm{m}}^{0} *\left[\Sigma_{\mathrm{pk}}\left(\mathrm{RPE}_{\mathrm{prt}} * \mathrm{STK}_{\mathrm{pmt}} * \mathrm{~T}_{\mathrm{pmt}}\right)\right]$

requirements-to-expenditures ratio for type $m$ munitions

$R_{-} E_{m}=R_{m} / E_{m}$

number of type $t$ targets killed by type $p$ platforms using type $m$ munitions (IMAP outputs)

maximum allowable type $t$ target overlap for type $p$ platform

average number of type $m$ munitions, fired by type $p$ platforms, against type $t$ targets

$\mathrm{X}_{\mathrm{pax}}=\mathrm{RTK}_{\mathrm{pmx}} * \mathrm{~T}_{\mathrm{pat}}=\mathrm{RPE}_{\mathrm{pat}} * \mathrm{STK}_{\mathrm{pmlt}} * \mathrm{~T}_{\mathrm{pat}}$

deviation variabies from the cost goal

deviation variables from the kill goal for type $t$ targets

deviation variables from the attrition goal for type p platforms

Note: A ' $t$ ' in the left most column indicates the term is used in the Threat Methodology and a ' $j$ ' indicates the term is used in JMAP. 


\section{EXHIBIT A-2}

Inputs and Outputs of the Threat Madel

For given munition type $\mathrm{m}$ :

Input :

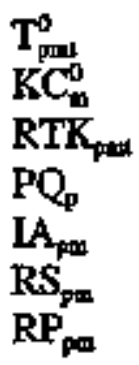

Output :

$\mathbf{R}_{\mathbf{a}}$ 
EXAIBIT A-3

JMAP Formulation

Inputs :

\begin{tabular}{|c|}
\hline $\begin{array}{l}\text { FTBK }_{\mathrm{t}} \\
\text { FATTR }_{\mathrm{p}} \\
\text { Cost_Goal }\end{array}$ \\
\hline R_E \\
\hline
\end{tabular}

RPE

DOCT,

STK $_{\text {por }} \quad$ ROF $_{\text {to }}$

ATTRTr $_{\text {pnt }} \quad$ COMP $_{\mathrm{q}}$

FOM_P $P_{p}$

FOM_T

AVAII $_{-\mathrm{ps}}$

TIME

Ontputs : $\quad \mathrm{T}_{\mathrm{pmt}}, \mathrm{CG}^{-}, \mathrm{CG}^{+}, \mathrm{KG}_{\xi}^{-}, \mathrm{KG}_{\mathrm{i}}^{+}, \mathrm{AG}_{\mathrm{p}}^{-}, \mathrm{AG}_{\mathrm{p}}^{+}$

Ohjective :

Minimize $\quad Z=P_{c}\left[\mathrm{CG}^{+}\right]+\mathrm{P}_{\mathrm{k}}\left[\Sigma_{\mathrm{t}} \mathrm{FOM}_{-} \Upsilon_{\mathrm{t}} \mathrm{KG}_{\mathrm{i}}\right]+\mathrm{P}_{\mathrm{a}}\left[\Sigma_{\mathrm{p}} \mathrm{FOM}_{-} \mathrm{P}_{\mathrm{p}}^{*} \mathrm{AG} \mathrm{G}_{\mathrm{p}}^{+}\right]$

\section{Goal Coostraints :}

- Overall Cost Goal :

$$
\Sigma_{\mathrm{m}}\left[\mathrm{CM}_{\mathrm{m}} * \mathrm{R}_{-} \mathrm{E}_{\mathrm{m}} * \Sigma_{\mathrm{pl}}\left(\mathrm{RPE}_{\mathrm{pmk}} * \mathrm{STK}_{\mathrm{pmt}} * \mathrm{~T}_{\mathrm{pmt}}\right]+\mathrm{CG}^{-}-\mathrm{CG}^{+}=\right.\text {Cost_Goal }
$$

- Kill Goal per Target Type :

$$
\Sigma_{\mathrm{pm}} \mathrm{T}_{\mathrm{pat}}+\mathrm{KG}_{\mathrm{t}}^{-}-\mathrm{KG}_{\mathrm{t}}^{\dagger} * \mathrm{FTBK}_{\mathrm{t}} * \mathrm{TQ}_{\mathrm{t}}, \quad \forall \mathrm{t}
$$

- Attrition Goal per Platform Type :

$$
\Sigma_{\mathrm{m}}\left(\mathrm{ATT}_{\mathrm{pwt}} * \mathrm{STK}_{\mathrm{pm}} * \mathrm{~T}_{\mathrm{part}}\right)+\mathrm{AG}_{\mathrm{p}}^{-}-\mathrm{AG}_{\mathrm{p}}^{+}=\mathrm{FATTR}_{\mathrm{p}} * \mathrm{PQ}_{\mathrm{p}}, \quad \forall \mathrm{p}
$$

Physical Constraints :

- Upper Bounds of Targets Killed by Platform Type :

$$
\sum_{\text {at }} T_{p a t} \leq T_{p t}^{a}+\delta_{p t}
$$

- Lower Bounds of Targets Killed by Platform Type :

$$
\sum_{\mathrm{a}} \mathrm{T}_{\mathrm{put}} \geq \mathrm{T}_{\mathrm{pt}}^{\mathrm{a}}-\delta_{\mathrm{pt}} \text {, }
$$

- Target Count per Target Type :

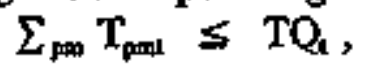

- Platform Attritions per Platform Type :

$$
\Sigma_{\mathrm{mx}}\left(\mathrm{ATT}_{\mathrm{pax}} * \mathrm{STK}_{\mathrm{pmi}} * \mathrm{~T}_{\mathrm{pmel}}\right) \leq \mathrm{PQ}_{\mathrm{p}} \text {, }
$$

- Munitions Available per Munition Type :

$$
\Sigma_{\mathrm{pt}}\left(\mathbf{R}_{-} \mathbf{E}_{\mathbf{\mathrm { a }}} * \mathrm{RPE}_{\mathrm{pat}} * \mathrm{STK}_{\text {pat }} * \mathrm{~T}_{\mathrm{pun}}\right) \leq \mathrm{MQ} \text { * } \quad \forall \mathrm{m}
$$

- Doctrinal Expenditures per Munition Type:

$$
\Sigma_{\mathrm{pt}}\left(\mathrm{RPE}_{\mathrm{pmt}} * \operatorname{STK}_{\mathrm{pat}} * \mathrm{~T}_{\mathrm{pm}}\right) \geq \operatorname{DOCT}_{\mathrm{m}} * \operatorname{TTME}_{1} \quad \forall \text { m }
$$

- Maximum Rate-of-Fire of Type of Munitions by Platform Type :

$$
\sum_{1}\left(\mathrm{RPE}_{\mathrm{pmx}} * \mathrm{STK}_{\mathrm{pmx}} * \mathrm{~T}_{\mathrm{pax}}\right) \leq \mathrm{PQ}_{\mathrm{p}} * \mathrm{ROF}_{\mathrm{pm}} * \mathrm{TMME} \text {, }
$$


set $\quad\left(P_{01} P_{5}, P_{2}\right)$

$\mathrm{T}_{\mathrm{pat}}^{0}, \quad \forall \mathbf{p}, \mathrm{m}, \mathbf{t}$

Tolerance e.g. $(3,1,2)$

e.g. output from the Threat Split.Program

e.g. 0.01

\section{[ Computed Inpurt ]}

[ Output ]

$\mathbf{T}_{\mathrm{pax}}^{*} \leftarrow \mathbf{T}_{\mathrm{pax}}^{0}, \quad \forall \mathrm{p}, \mathrm{m}, \mathrm{t}$

calculate average expenditures for the upcoming Threat Model nun

do

$E_{\alpha}^{*}<E_{m}, \quad \forall m$

run Threat Model :

$\left[\mathrm{T}_{\mathrm{pmx}}^{*}\right]$

$\left[\mathbb{R}_{\mathbf{n}}\right]$

calculate new requirement/expenditure ratios for the next JMAP run

run JMAP :

[R_E

[ $\left.\mathbf{T}_{\mathrm{pmal}}\right]$

calculate new target splits for the next Threat Model run

calculate average expenditures for the upcoming Threat Model run

while $\left(\left|1-E_{m} / E_{w}^{*}\right|>\right.$ Tolerance, for any $\left.m\right)$

Calculate average expenditures for the upcoming Threat Model zvm :

$$
\mathrm{E}_{\mathrm{p}}=\mathrm{KC}_{\mathrm{ma}}^{0} *\left[\Sigma_{\mathrm{px}}\left(\mathrm{RPE}_{\mathrm{pax}} * S T \mathrm{~K}_{\mathrm{pat}} * \mathrm{~T}_{\mathrm{pax}}^{*}\right)\right], \quad \forall \mathrm{m}
$$

Calculate new requirement/expenditure ratios :

$$
\mathbf{R}_{-} \mathbf{E}_{\mathbf{m}}=\mathbb{R}_{\mathbf{m}} / \mathbf{E}_{\mathbf{a}},
$$

$\forall \mathbf{m}$

Calculate new target splits :

$$
T_{\text {patt }}^{*}=T_{Q} * \mathbb{T}_{\mathrm{pmx}} /\left(\Sigma_{\mathrm{pm}} \mathrm{T}_{\mathrm{pmo}}\right),
$$

$\forall p, m, t$ 


\section{Comparison of Different Versions of JMAPs}

Nor_89 May_92 Oct 93 Jan 94

(Mobil Hard) (Marhime) (Ver. 1.0) (Paired)

\section{Constraints :}

Overall platform attrition $\left(\boldsymbol{L}_{\mathrm{p}} \mathrm{PQ}_{\mathrm{p}}\right.$

Overall east (munitions expended)

- - (munitions expended + munitions lest + platforms lost)

Overall targets killed $\left(\Sigma_{1}\right.$ TQ)

Fraction of targets killed by target type and interval (FTBK,

". " " for high priority margets (FTBK)

Fraction of platform attrition by plafform type (RA,

$\begin{array}{llll}\bar{\sigma} & \mathbf{G} & - & \bar{\sigma} \\ \overline{\mathbf{G}} & \bar{G} & \overline{\mathbf{G}} & - \\ \overline{\mathrm{pb}} & \mathbf{G} & \bar{G} & \bar{G}\end{array}$

Platform atistion by platform type $\left(\mathrm{FA}_{\mathrm{p}}\right)$

Munition - availability by munition type (STOCKMQ.)

- minimum production by munition type (PRODMN (R) $_{m}$

- rate-of-fire $\left(\operatorname{ROF}_{\mathrm{min}}\right)$

- doctrinal (DOCT)

Target $\sim$ connt by target type (TQ)

- availability by platform (AVAR,

- upper bounds of targets killed by platform type $\left(T_{p}^{0}+\delta_{r}\right)$

- lower bounds of cargets killed by platiorm type $\left(\boldsymbol{T}_{\pi}^{5}-\delta_{\mathfrak{a}}\right)$

\begin{tabular}{|c|c|c|}
\hline - & ph & $\mathbf{G}$ \\
\hline- & - & - \\
\hline $\mathrm{pb}$ & ph & pb \\
\hline ph & - & - \\
\hline ph & $\mathrm{ph}^{\mathrm{L}}$ & $\mathbf{p b}$ \\
\hline ph & $\mathrm{ph}^{\mathrm{k}}$ & pb \\
\hline ph & $\mathrm{ph}$ & $\mathbf{p b}$ \\
\hline $\mathrm{ph}$ & - & $\mathrm{ph}$ \\
\hline & - & - \\
\hline & - & - \\
\hline
\end{tabular}

Now : $G$ indicates goal constraint, pb indicales phystcal constraint, and superseript $L$ indicates time-poriod dependeacy.

RTK - random variable (Cbance Constrined LGP/LP)

Compound targets

Figure of merit (relative value) for platforms and targets

Number of intervals (L)

Number of days per interval

Number of platform types

Nomber of munition types

Number of target types

Gogls:

Priority Lovel :

Attrition

$\cos t$

Kill

Priority Weight :

Actrition

Cast

Kill

$\begin{array}{llll}- & x & x & - \\ - & - & x & - \\ - & - & x & x\end{array}$

$\begin{array}{lccc}1 & 3 & 1 & 1\end{array}$

$3 \quad 15,15,15 \quad 120 \quad 45$

$\begin{array}{cccc}10 & 12 & 81 & 12 \\ 9 & 17 & 97 & 17 \\ 10 & 4 & 124 & 4\end{array}$

\begin{tabular}{|c|c|c|c|}
\hline - & 2 & 1 & 2 \\
\hline 1 & 3 & 1 & 3 \\
\hline 1 & 1 & 1 & 1 \\
\hline - & I & 40 & 1 \\
\hline 1 & 1 & 400 & 1 \\
\hline 1 & 1 & 1 & 1 \\
\hline$\underset{\text { Aniederitus }}{\text { LGP }}$ & $\begin{array}{c}\text { LGP } \\
\text { stroieded ans }\end{array}$ & $\underset{\text { Linto }}{\text { LP }}$ & $\begin{array}{c}\text { LGP } \\
\text { Scheriedefinos }\end{array}$ \\
\hline
\end{tabular}


APPENDIX $\mathbf{9}$

JuAp/Threat pair

Input File : tile.in 


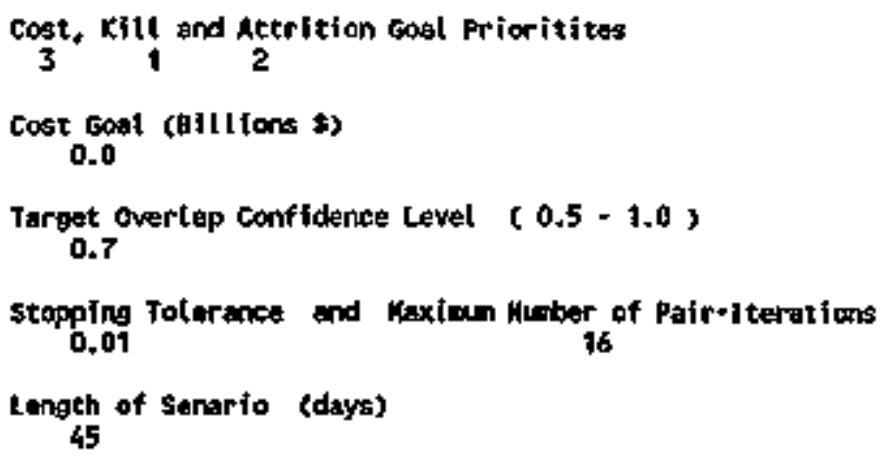

\begin{tabular}{|c|c|c|c|c|c|}
\hline $\begin{array}{l}\text { (p) } \\
1 \\
2 \\
3 \\
4 \\
5 \\
6 \\
7 \\
8 \\
9 \\
10 \\
11 \\
12\end{array}$ & 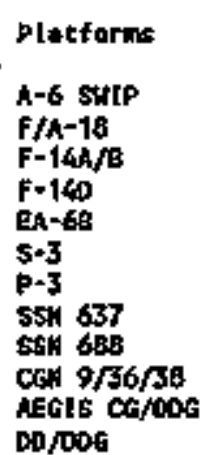 & $\begin{array}{c}\text { Cost(kitlions) } \\
+(0 P) \\
34.0 \\
41.0 \\
37.0 \\
37.0 \\
80.0 \\
25.0 \\
20.0 \\
186.0 \\
800.0 \\
122.0 \\
886.0 \\
512.0\end{array}$ & $\begin{array}{c}\text { owantity } \\
\text { (pa) } \\
84 \\
109 \\
45 \\
46 \\
75 \\
30 \\
16 \\
1 \\
15 \\
3 \\
16 \\
9\end{array}$ & $\begin{array}{l}\text { Kerit } \\
\text { tfow.P3 } \\
22.9 \\
19.8 \\
36.5 \\
36.5 \\
50.0 \\
8.7 \\
13.3 \\
130.0 \\
229.0 \\
116.6 \\
394.6 \\
175.9\end{array}$ & $\begin{array}{c}\text { of Attrition } \\
\text { (FArTk) } \\
0.05 \\
0.05 \\
0.05 \\
0.05 \\
0.05 \\
0.05 \\
0.05 \\
0.01 \\
0.01 \\
0.01 \\
0.01 \\
0.01\end{array}$ \\
\hline
\end{tabular}

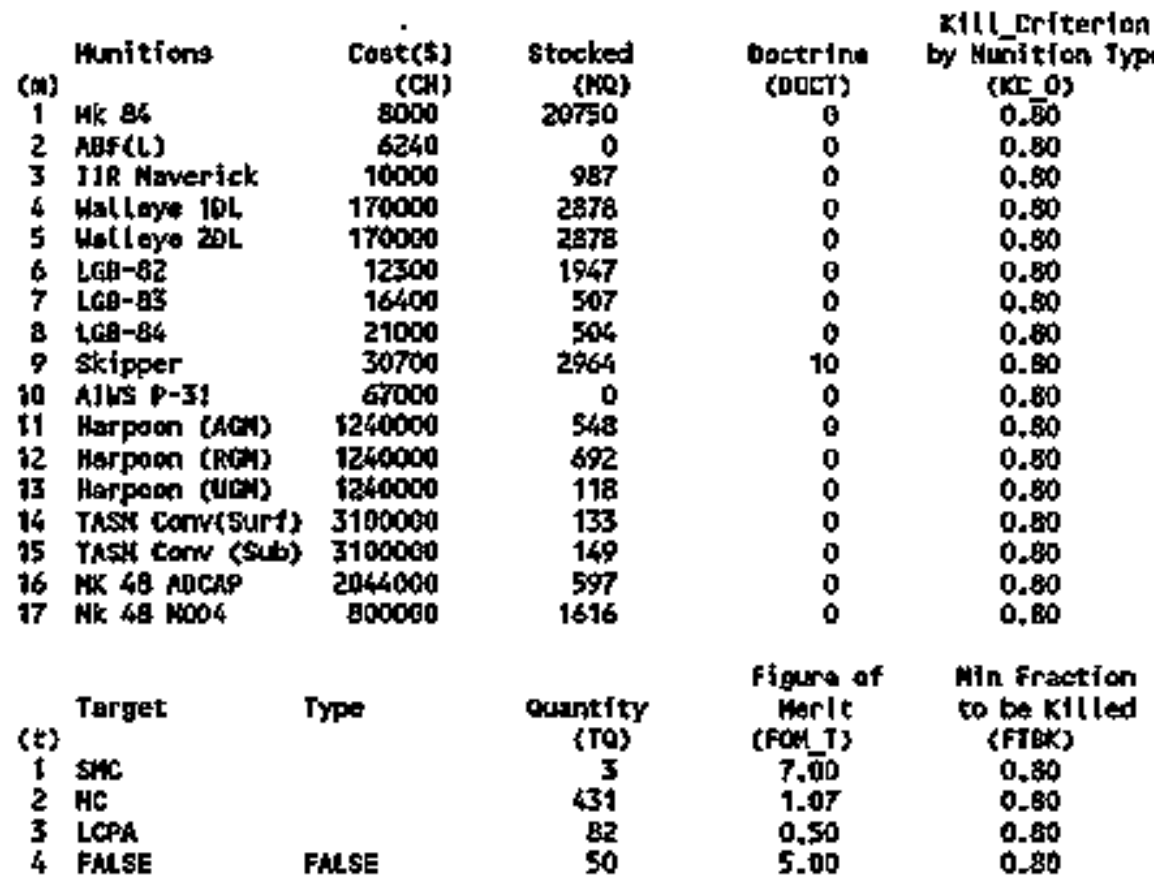




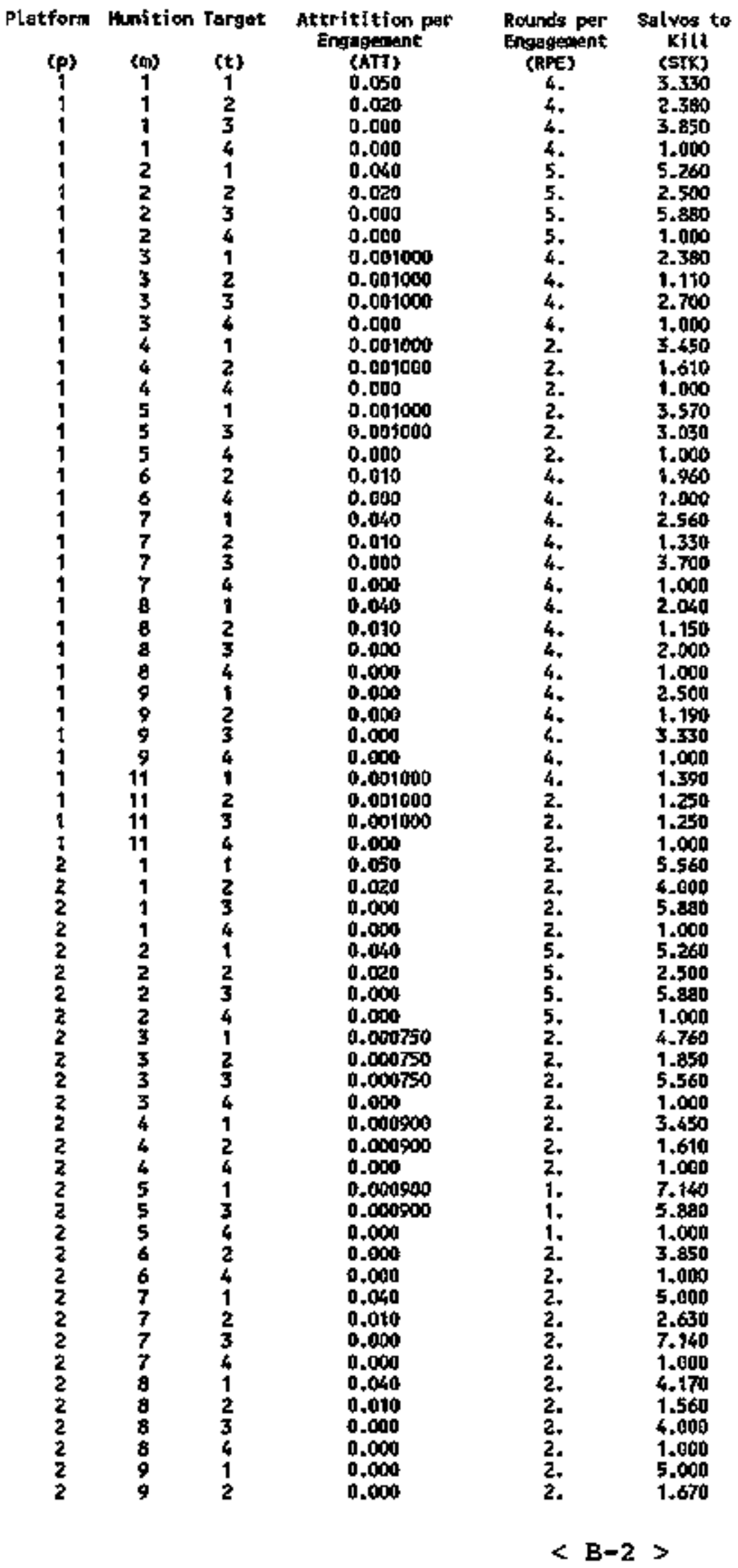




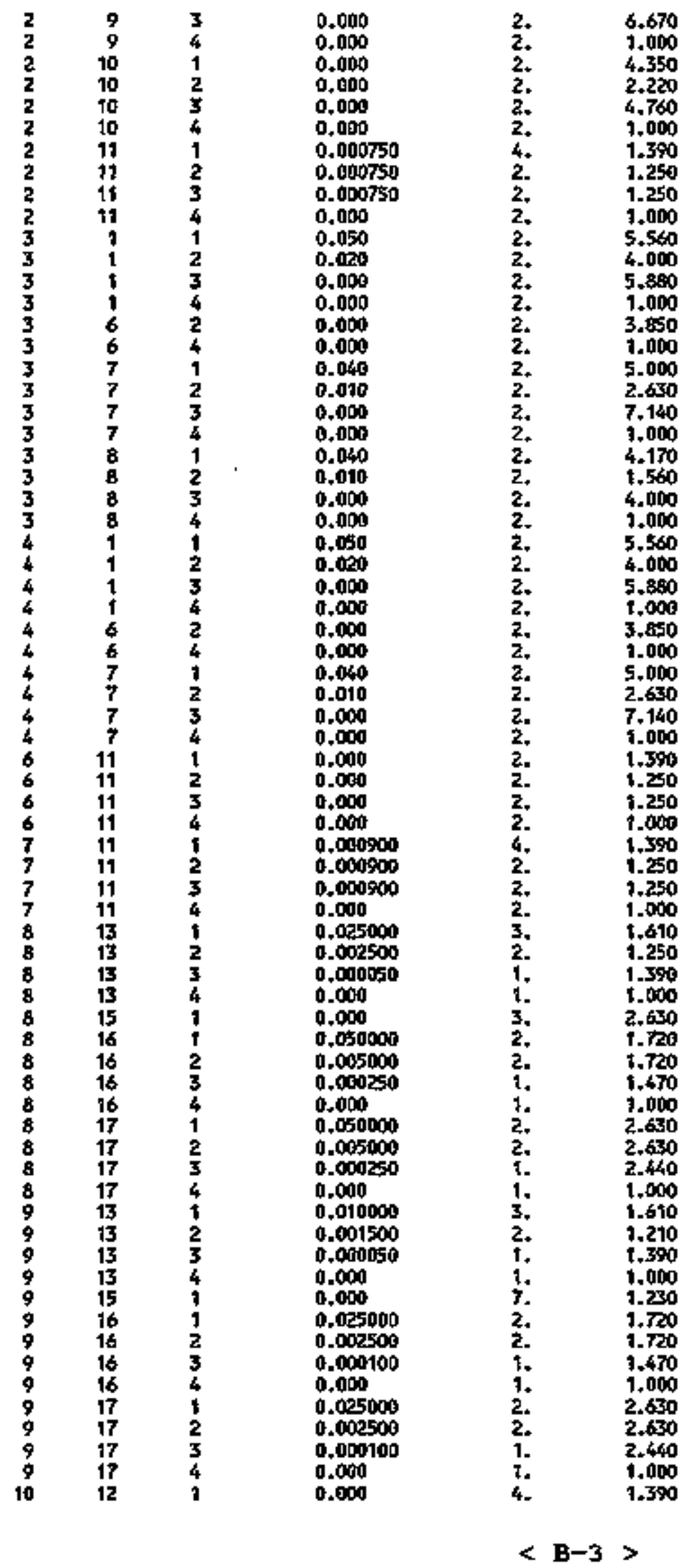




\begin{tabular}{|c|c|c|c|c|c|c|}
\hline $\begin{array}{l}10 \\
10 \\
10 \\
10 \\
11 \\
11 \\
11 \\
11 \\
11 \\
12 \\
12 \\
12 \\
12 \\
12 \\
0\end{array}$ & $\begin{array}{l}12 \\
12 \\
12 \\
14 \\
12 \\
12 \\
12 \\
12 \\
14 \\
12 \\
12 \\
12 \\
12 \\
14 \\
0\end{array}$ & $\begin{array}{l}0.000 \\
0.000 \\
0.000 \\
0.000 \\
0.000 \\
0.000 \\
0.000 \\
0.000 \\
0.000 \\
0.012500 \\
0.007500 \\
0.007500 \\
0.000 \\
0.000500 \\
0.000\end{array}$ & $\begin{array}{l}2 . \\
1 . \\
1 . \\
6 . \\
4 . \\
2 . \\
1 . \\
1 . \\
7 . \\
4 . \\
2 . \\
1 . \\
1 . \\
6 . \\
0 .\end{array}$ & & $\begin{array}{l}250 \\
390 \\
000 \\
330 \\
390 \\
250 \\
390 \\
000 \\
230 \\
390 \\
250 \\
390 \\
000 \\
330 \\
000\end{array}$ & \\
\hline $\begin{array}{c}\text { Platform } \\
\text { (p) } \\
1 \\
1 \\
1 \\
1 \\
1 \\
1 \\
1 \\
1 \\
1 \\
2 \\
2 \\
2 \\
2 \\
2 \\
2 \\
2 \\
2 \\
2 \\
2 \\
2 \\
3 \\
3 \\
3 \\
3 \\
3 \\
4 \\
4 \\
4 \\
4 \\
6 \\
6 \\
6 \\
7 \\
8 \\
8 \\
8 \\
8 \\
9 \\
9 \\
9 \\
9 \\
10 \\
10 \\
11 \\
11 \\
12 \\
12 \\
0\end{array}$ & $\begin{array}{c}\text { Hunltion } \\
\text { (m) } \\
1 \\
2 \\
3 \\
4 \\
5 \\
6 \\
7 \\
8 \\
9 \\
11 \\
1 \\
2 \\
3 \\
4 \\
5 \\
6 \\
7 \\
8 \\
4 \\
10 \\
11 \\
1 \\
6 \\
7 \\
8 \\
9 \\
1 \\
6 \\
7 \\
9 \\
2 \\
6 \\
11 \\
11 \\
13 \\
15 \\
16 \\
17 \\
13 \\
15 \\
16 \\
17 \\
12 \\
14 \\
12 \\
14 \\
12 \\
14 \\
0\end{array}$ & $\begin{array}{c}\text { Rate-of-Fitefory } \\
\text { (ROF) } \\
8 \\
16 \\
4 \\
4 \\
4 \\
8 \\
8 \\
4 \\
8 \\
8 \\
\text { E } \\
16 \\
4 \\
4 \\
4 \\
8 \\
8 \\
4 \\
8 \\
6 \\
8 \\
8 \\
8 \\
8 \\
4 \\
8 \\
B \\
8 \\
8 \\
8 \\
8 \\
8 \\
8 \\
8 \\
8 \\
8 \\
20 \\
30 \\
16 \\
8 \\
40 \\
60 \\
16 \\
16 \\
16 \\
16 \\
16 \\
122 \\
0\end{array}$ & $\begin{array}{c}\text { Initial } \\
\text { Allowance } \\
\text { (1) } \\
4 \\
8 \\
2 \\
2 \\
2 \\
4 \\
6 \\
2 \\
4 \\
4 \\
4 \\
8 \\
2 \\
2 \\
2 \\
4 \\
4 \\
2 \\
4 \\
3 \\
4 \\
4 \\
4 \\
4 \\
2 \\
4 \\
4 \\
4 \\
4 \\
4 \\
4 \\
4 \\
4 \\
4 \\
4 \\
4 \\
10 \\
15 \\
8 \\
4 \\
20 \\
30 \\
8 \\
8 \\
8 \\
8 \\
8 \\
61 \\
0\end{array}$ & 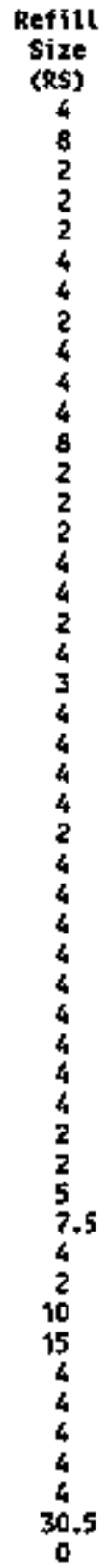 & 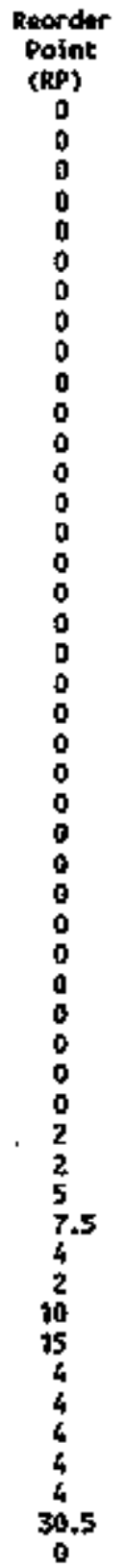 & $\begin{array}{l}\text { Hot used } \\
\text { Mot used } \\
\text { Hot used } \\
\text { Hot used } \\
15<-14 \\
16 \leqslant 15\end{array}$ \\
\hline
\end{tabular}


JMAP/Threat Pair

Input File: t_splits.in 
initisl Targats Splits by Platfom and Hntion

A-6 SW F/A-18 F-14h/ F-140 EA-6B S-3 P-3 SSN 63 SSH 68 CEN $9 /$ AEgIS $00 / 0 D$ Total

Hk 84

$\begin{array}{lrrrrrrrrrrrrr}\text { SWC } & .20 & .25 & .11 & .11 & .00 & .00 & .00 & .00 & .00 & .00 & .00 & .06 & .00 \\ \text { HC } & 35.76 & 46.40 & 19.16 & 19.58 & .00 & .00 & .00 & .00 & .00 & .00 & .00 & .00 & 120.90 \\ \text { LCPA } & 2.27 & 2.05 & 1.22 & 1.24 & .00 & .00 & .00 & .00 & .00 & .00 & .00 & .00 & 7.00 \\ \text { EALSE } & 4.59 & 5.95 & 2.46 & 2.51 & .00 & .00 & .00 & .00 & .00 & .00 & .00 & .06 & 15.51\end{array}$

ABF(L)

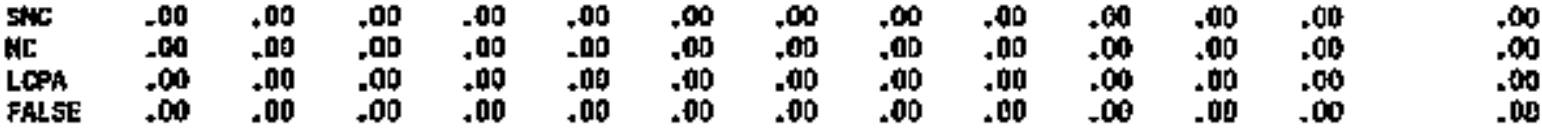

I1R Naverick

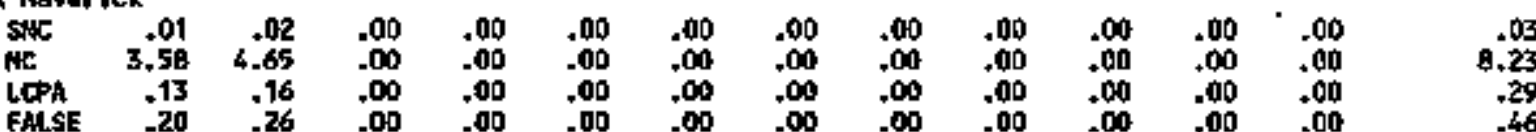

Wal leye 1BL.

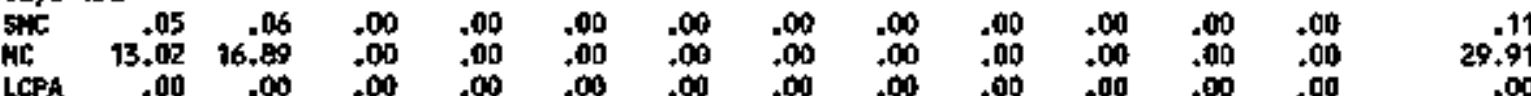

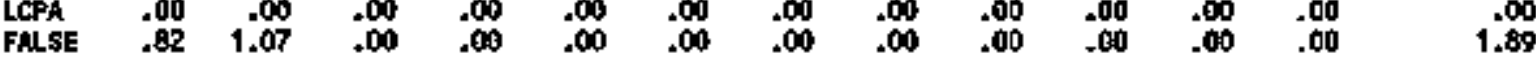

Ual leye 20L

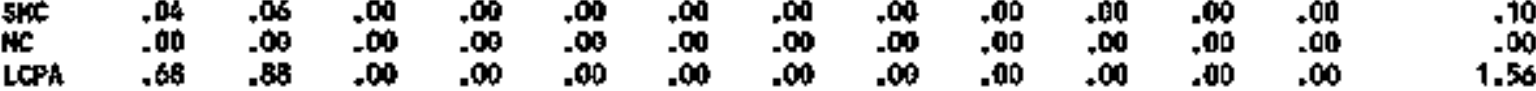

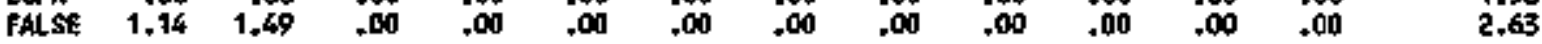

$10 B+82$

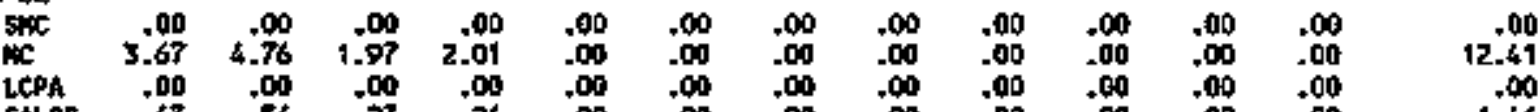

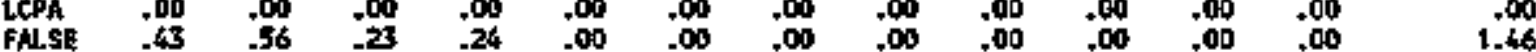

Lef?

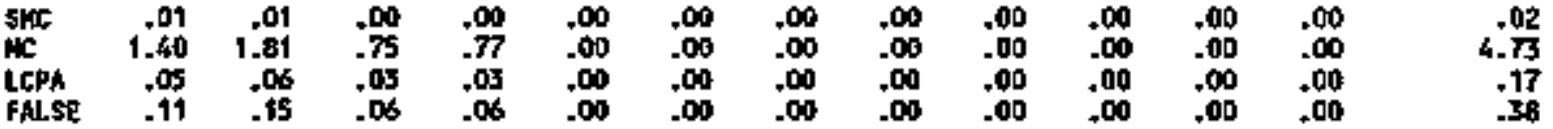

LGB+B4

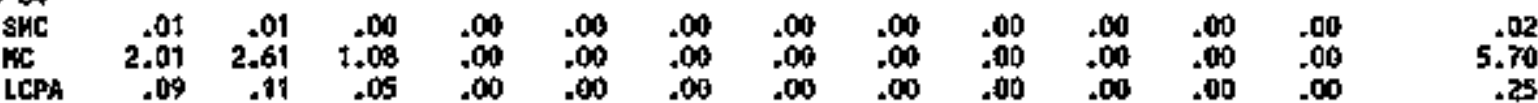

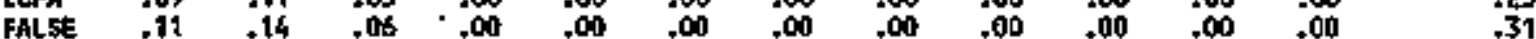

skippor

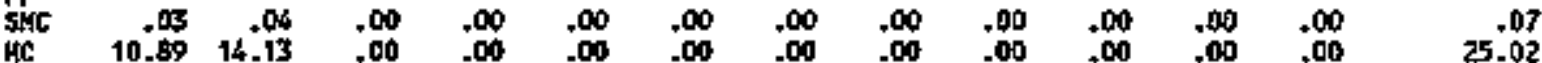

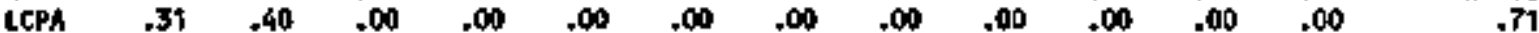

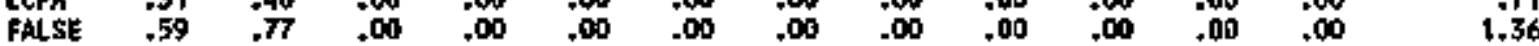

A[4: P-3I

$\begin{array}{llllllllllllll}\text { FHC } & .09 & .00 & .00 & .00 & .00 & .00 & .00 & .00 & .00 & .00 & .00 & .00 & \\ \text { WE } & .00 & .00 & .00 & .00 & .00 & .00 & .00 & .00 & .00 & .00 & .00 & .00 & .00 \\ \text { ICPA } & .00 & .00 & .00 & .00 & .00 & .00 & .00 & .00 & .00 & .00 & .00 & .00 & .00 \\ \text { FALSE } & .00 & .00 & .00 & .00 & .00 & .00 & .00 & .00 & .00 & .00 & .00 & .00 & .00\end{array}$ 


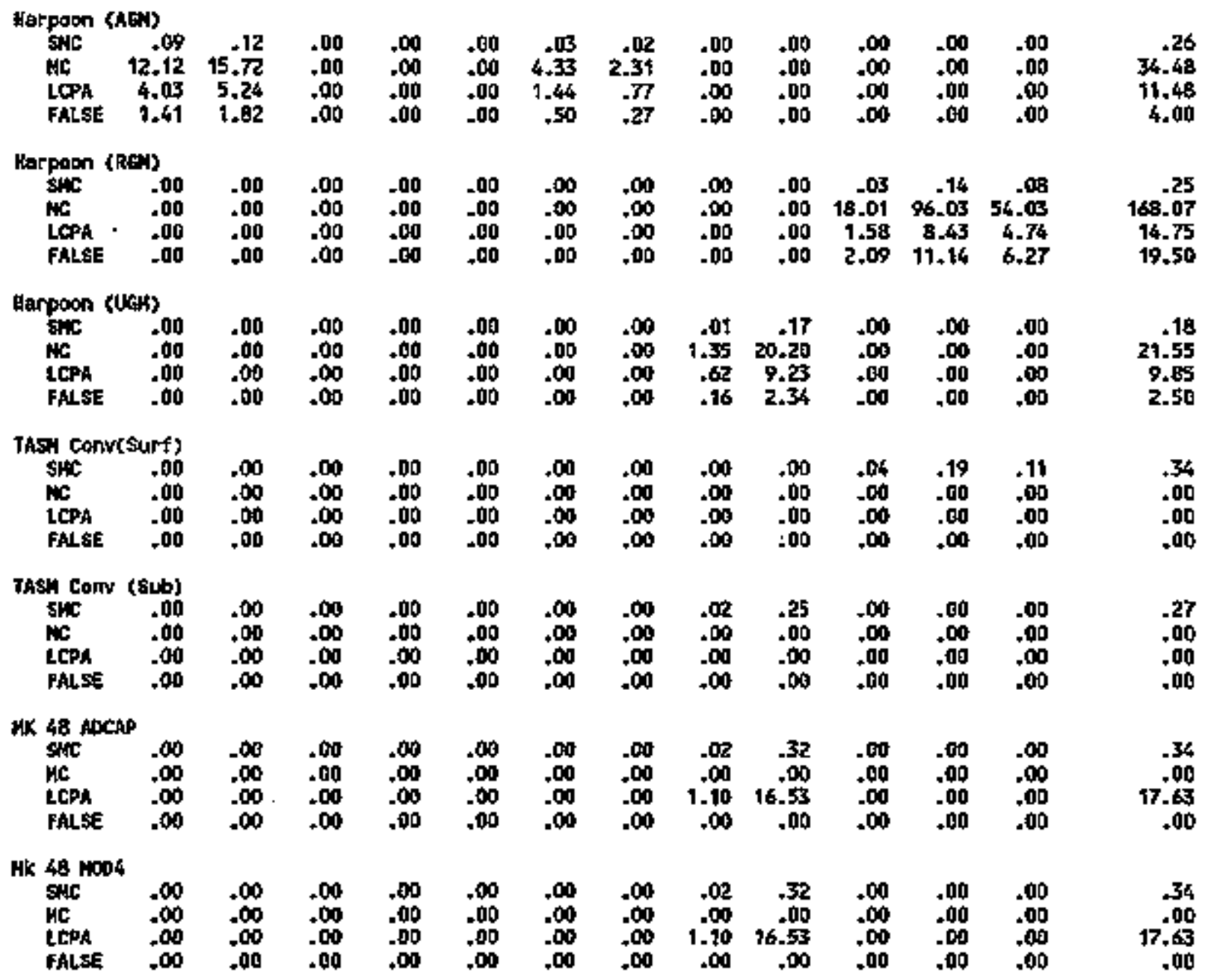

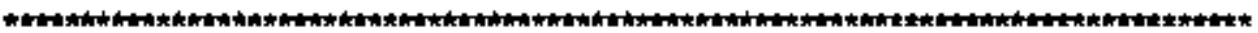
* The following are obtalned by suring the above over munition typas.

They are not read in as inputs. They are for inforantion purpose only.

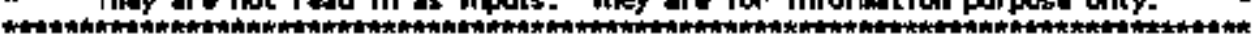

Inltiol Targats splits by Platform

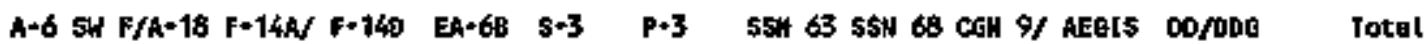

$\begin{array}{lrrrrrrrrrrrrr}\text { SHC } & . .44 & .57 & .11 & .15 & .00 & .03 & .02 & .07 & 1.06 & .07 & .33 & .19 & 3.00 \\ \text { KC } & 82.45 & 108.97 & 22.96 & 22.36 & .00 & 4.33 & 2.31 & 1.35 & 20.20 & 18.01 & 96.03 & 54.03 & 431.00 \\ \text { LCPA } & 7.56 & 9.80 & 1.30 & 1.27 & .09 & 1.44 & .77 & 2.82 & 42.79 & 1.58 & 8.43 & 4.74 & 82.06 \\ \text { FALSE } & 9.40 & 12.21 & 2.81 & 2.84 & .00 & .50 & .27 & .16 & 2.34 & 2.09 & 14.14 & 6.27 & 50.00\end{array}$


APPENDIX c

Jinp/Threat Pair

code File: pair.for 


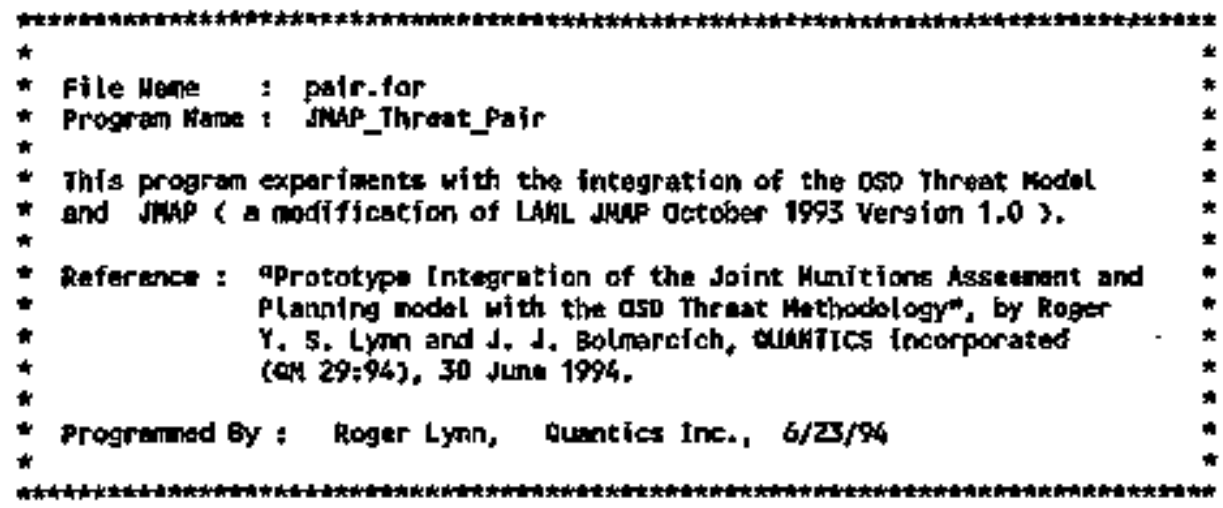

FORTRAL Source files :

PAIR - top levels pair.for

JMAP - This portian of the source code ts a modificoting of the EAHL, JHAS (Hay 19g2 Maritim Module) which utilizes the jinap. for schn[eqdarjens Linear coal Programing solver.

Threat Nethoditony * o50 Threet notiel

tin injut. for

tan mante. for

ta_ Inter, for

tin_rand. for

Incelude files

pair_t.ine

pair_z. Ine

FORTRAM EXecutable file poir texe

Impout fltes :

file.in

t_splits.in

inputs to JHAf Threet_pafr reth

initial target splits (fron Targat split Progran)

output files : overlap.tend

tm t in. F

thecho.\#

tin req.

j_t_out.\#

fint;

Pair_ann.

overvien

t_lge-in

icen

iobj

couft

ishs

J_lop.out

upper and loter bounds of target splits

Threat Model targat splits incut for pafiriteration \#

Threat Model input expo for poir-iteration *

Threat Model overoge requirements output for pajr+iteration \#

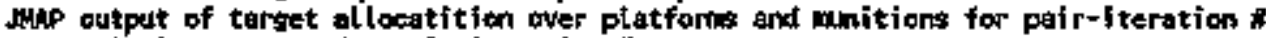

JHAP solution sumery for paf $r$-iteration

high Lwel sumary of Threat Nodel and Nus outputs for pair-iteration *

wis cost solusiun and fractions of targets kitted tor ALL pair-iterations

input for 1.6P solver

constrialnt type

objective terms

coeffictents for the last pafr-itoration

right-hand-oldes

LGP report for the tast pair-iteration

$$
\langle c-1\rangle
$$


progran silap_The bat_Palr

* This progran experiments with the integration of the 050 Threat Modiet

* and JHAP ( o nodification of LAkid JHAP October $19 \% 3$ Verston 1.0).

"

fnelude 'pair_1. Inc'

Integar pass

real

pax_aberration

call initializetion

pass $=1$

max_abarration $=1.0$

do while ( (pase . (e. nax_pass) -and.

(nax_eberration .gt. stopping_tolerances))

call gtore_average_expendi tures

call threet nodel (pess)

coll cal_new_req_expenditure_retfosipass\}

eall fouppass)

call col_new_targat_splits

coll cel_me_exp_tor_coming_tm_run

call col_mex_aberration (pass, andaberration)

pess $=$ pass $\$ 1$

endos

c ind Map_Throat_pair $\quad$ \%)

$<\mathrm{c}-2>$ 
inlitelization read_inputs

read_Init_t_spl i ts_cal_bounds factor

reed_first_targat_spl its

set_percents_for_conf idence

Int tial 1ze_raqueserattos

cal_ave_exp_for_coming_to_run

do for ead pair-iteration

stort_sverage_etpend! tures

thre日t_andel

get_torget_splite

do for ou mintion type I

gat_inputs

eseign

tho_threst, modol_inputs

moin_up

mean

chk_acaling

itrventory

get_zter

inteialize

zero

monte

box

"ef_setup

refitio

rande(1)

andlyze

zerod

dist

colcterget

randm(2)

candury

orsitedist

cdf

getbd

the

colc_neon

frol

kfllperc

interpsetup

interp

chechrng

displey

errddo

call cal_tn_req_for_mnition_typeks?

cal_new_req_expendi ture_fetiog

Jn:ap

open_ffles

gping

geon overall cost

g_con_targets kslt

g_con_platfornettrition peir.for

pair-for

pair.tor

pair.for

paîr.tor

paitr.tor

paitr.for

peitr_for

palr.tor

palr-for

palir.for

ton_inpurt.for

to frout. for

ta_tinput.for

tin_irput . for

tn_monte.for

tinimonte. for

to monte.for

ti. -monte. for

tingente.for

trimontefor

ta mente. for

th_mente tor

tm_cand. for

tin_monte.for

thinente_for

tin rand. for

tm_ente-for

trifmente for

ton_minte_for

thinente-for

th_eonte_for

tinirand. for

tim conto for

tri_monte for

tm eontw.for

tin_monte,for

tom monten, for

tri_monte, for

trinonte.for

tn_monte. for

th_inter_for

trinter.for

to_inter for

thinput.for

$p$ a $r$. $f$ or

pair.for

Jnap, for

Jnep, for

Jnap, tor

jmap.for

jusp.for

jorap.for

$<c-3\rangle$ 
Ph_con_upper_bound_targets_k3ll

ph_con_lokn_bound_tergets_kJt I

Ph_con_target_counts

ph_con nax platform attrif tían

ph_con_minition_ovaītable

ph_con_doctrinat

lspoolve

ph_con max rate of_fire

start

simplx.

leprint

prtsotu xet

close_files

cal_net_target_splits

cal_my_exp_for_conting_tol_run

peir.for

en__nax_cberrotion

pair.for

t. endato

$\langle c-4\rangle$ 
subroutine intialtzation

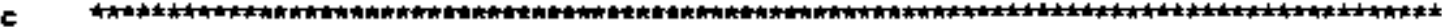

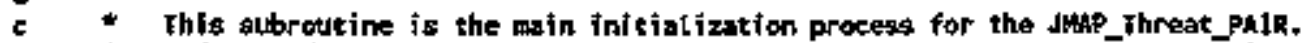

c * Referenced bys tialn program *

esll read_inputs

esll read init t splits cal boundis

call read_firse_tierget_eptifte

catl set.percents for_confidente

call initielize_req_exp_ratios

call cal_ave_exp_for_coüing_tu_rum

return

end

c

(* intrialization *3 
slbroutine road_inperts

JHCLUUE 'pair_z.inc'

DINENSEON STOK1JK(WWKL),STOEV]JKOMAKL)

REAL LANBDAIK(UAXL), LANBDA(HAXI, HAXK,WWL)

CHARACTER*132 GEADIFG,ALCT IMES

cheracter +14 file_in

print*.' Entar inous file nast

read $(5,1000)$ tite in

open(1, fileafi le.fin)

REHIKD 1

IF (PTEST .EA. O) TAEN

PTEST=1

EMD1F

TESTOO

HL LRE $=0$

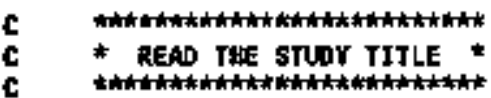

REAO (1, 1000) TITLE

1000 FORNAT (A)

HL LAEE-HL The +1 


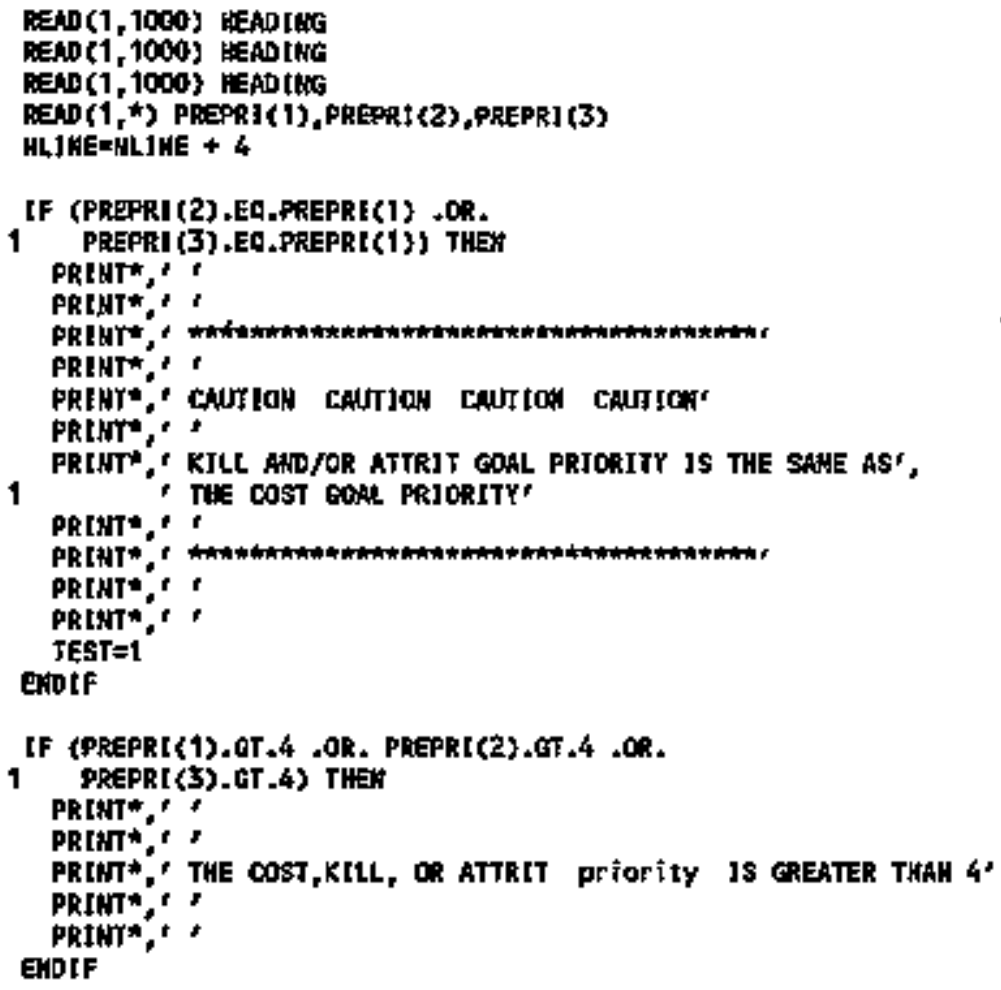

J Harthired

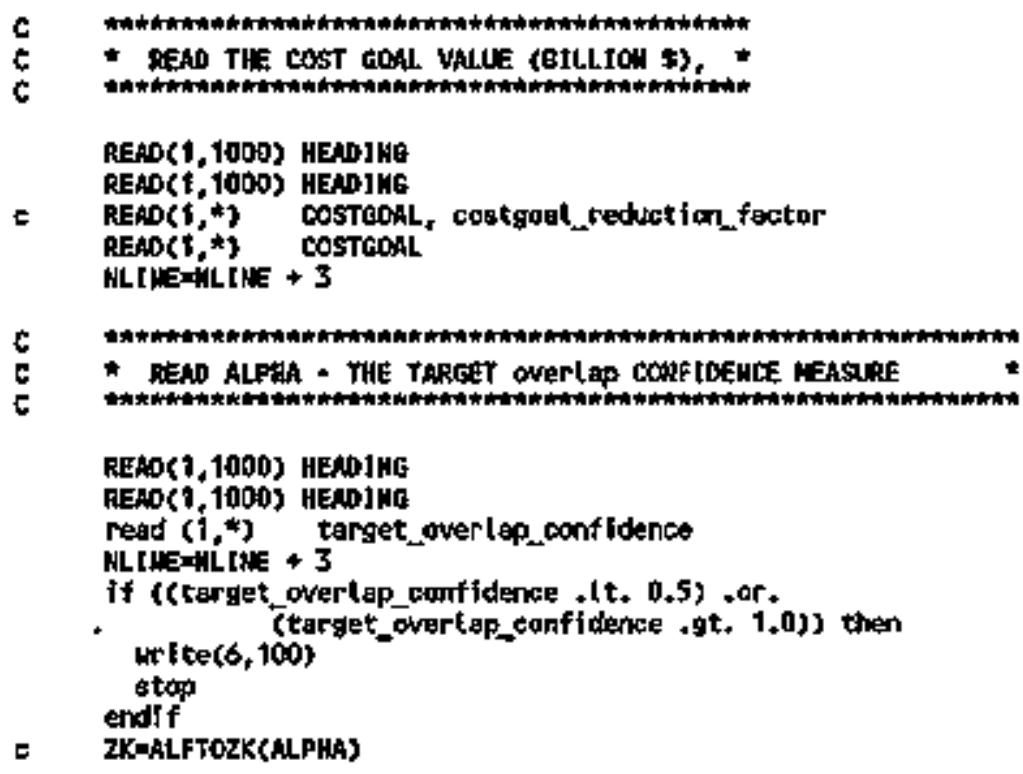

FEAO(1, 1000) HEADING

REAO (1,10OD) HEADING

read (1,*) stodpind_tolerance, max_pass

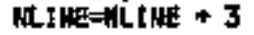

$$
\langle c-7\rangle
$$




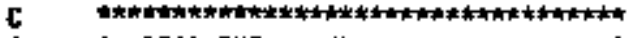

1. DEAO TEE MODEL TIRE JNTERYALS *

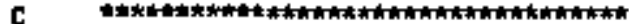

REAOC 1,1000$)$ HEADIIOG

REAB (1, 1000) HEADTHO

RESD(1.*) TJEE(t)

ILLINE=NLINE + 3

REHO $(1,1000)$ HEADTNS

READ $(1,1060)$ FEADING

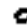

REFD $(1, *)$ HBT, HBd, NBK, MBL

READ $(1, \hbar)$ HEI, HBJ, NBK

HBL $=1$

II

HLINE=ULLIHE +3

IF tMBI_GT_NAXI ,OR. MBS.GT_MHXJ _OR. HBK.GT_MAXX

1 . OA. MBL, GT, NhXi t thell

PRJMT*:

PRJHT*"

PRIUT*" CHECK FILE 15

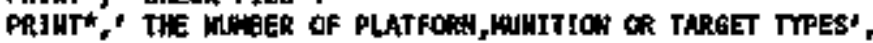

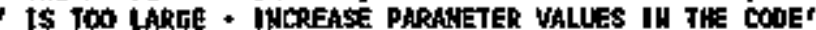

PRJUT".

PRIUT*:"

SToP

EublF

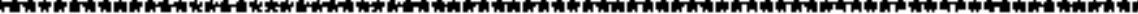

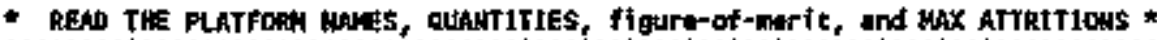

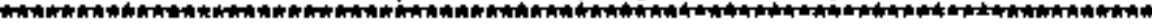

DEAD(1, 1000) HEADJHE

QEEAD(1,1000) HEADING

READ (1, 1000) HEADJHG

to $1 \mathrm{t}=1$,

c REAb(1, 1005) N,PLATCI),PLATCOST(I),PO(I),FATTR(I)

c1005 fobut $(13,2 X, A, F 9,0, F 12,0,4 F 15,0)$

REAB(1, 1005) H,PLAT(I),PLATCOST(1),PA\{I),FON_P(I), FATTR(1) I

1005 FOCAHATC $13,2 X, A, F 9,0, F 12,0,4 F 15,0)$

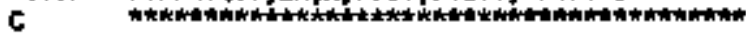

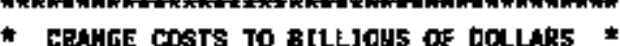

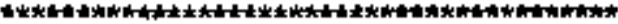

PLATCOST $($ I)=PLATCOST $\{I\} \div 1, E-3$

1 coost the

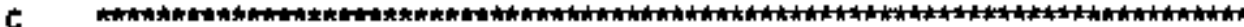

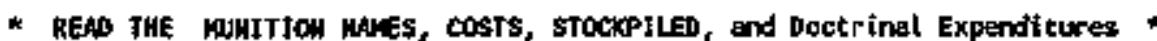

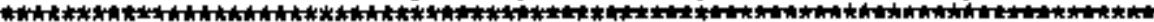

GEAD ? 1090) HEADJKC

QSEADS1, 1000) HEADJHG

TEAD (1, 1000) HEADJHE

READ $\{1,1000)$ HEADINB

STKCOSTE=

$002 \quad t=1,4 B$.

RERO(t,1005) W, WUH(J),CH( $(J), \operatorname{sTOCX}(J), 00 C T R I M(J), X C, D(J)$

C

thith DOCTRIU(J) ADOEJ ON 7 FEE ${ }^{2} 2$ :

$<\mathrm{C}-8>$ 
CI(J)FCH(J)*1 .E-9

a coHTJNUE

STKCOST=STKCOST + CM(J)*STOCK(J)

TOTARBS 0

READ(1, 1000) HEAOIKC

REATC 1, 1000' HEADING

RENT(1,1000) HEAOHNO

REAOC 1,1000 S HEADING

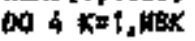

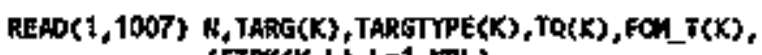

$1007^{\circ}$ FOnist $(13,2 x, 2 A, F 17,0,5(F 15,0)\}$

Do 3 2=1, $\mathrm{NBL}$

If (FTBK(K,L), GT. 1.0) TKEH

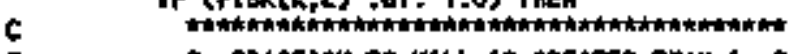

c - ERACF TOK-TO-KILL 15 GEEATER THAH 1 .

C

FRIUT*',

PRIHT+", CHEDX fJLE 1"

PRIUT+, SOWE FRACTJOWS-TO-KILL ARE GREATER THAW 1 "

PRIUT*",

TEST $=t^{\circ}$

Evif

3 CONTIKLE

TOTARCS=TOTARCS + TR(K)

\section{4 cont itus}

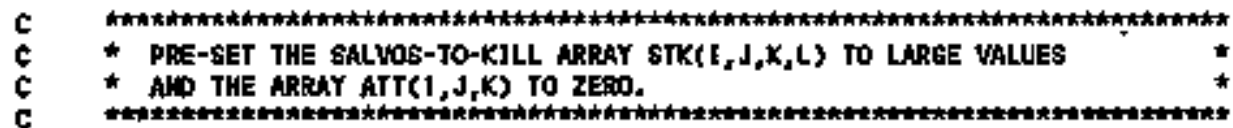

$0020 \mathrm{I}=1$, 㑑

DO 15 JFT, 胉

bo id $x=1$, IaK

$00 \quad 5 \mathrm{~L}=1, \mathrm{HOL}$

5

$$
\text { STK( } 1, \&, K, L)=1 . E 25
$$

$A T)(I, d, K)=0,0$

CONTIME

15 ContJmuE

20 CONTIMUE

It:

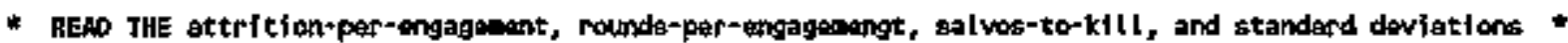

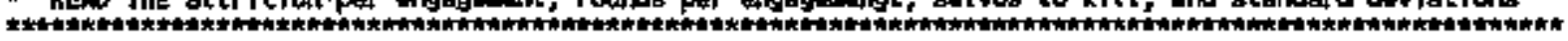

READ (1, 1000) HEADJHG

READ (1, 1000) HEADIHC

READ $(1,1000)$ HEADIFG

READ $(1,1000)$ HEAbIHo

HLIRE=HLINE + 4

HI $4=0$

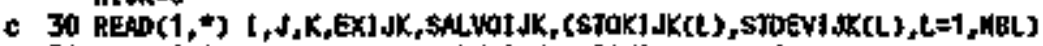

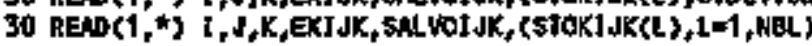

$<c-9>$ 


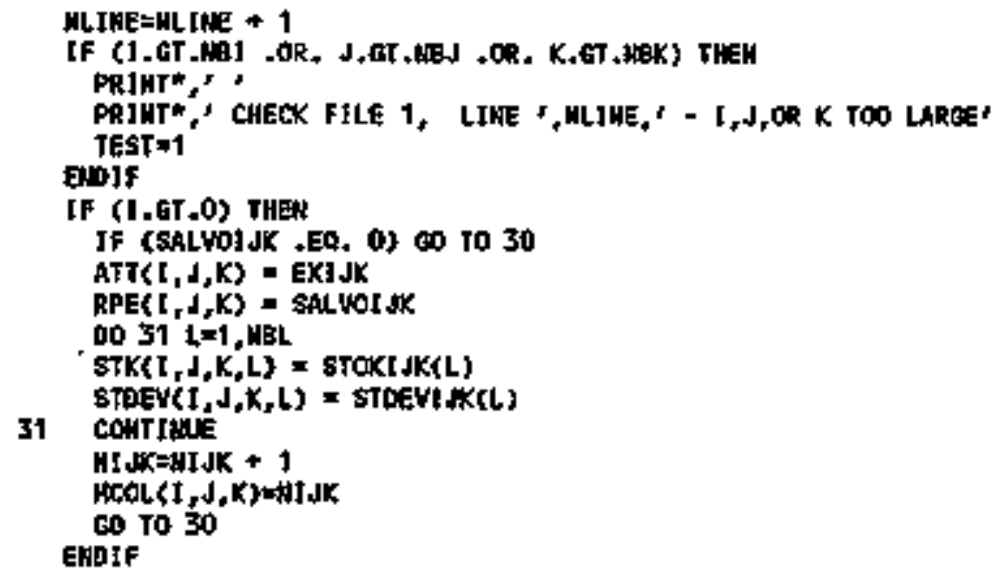

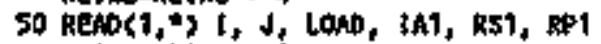

RLIDEALIHE + 1

JF (I.GT.HBI .OR, J.GT.MBJ) THEH PRINT*:

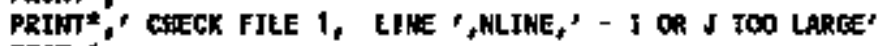
TEST=1

70 COHTIHUE

open(B, f31\%='overvitiw'?

mirlte( 8,200$)$ target_overtap_confiderce

mite(8,701) peepri(1)

wite(8,702) propri(2)

wite(8,704) pcepri(3), (targ(k), k=1,tak)

$$
\langle c-10\rangle
$$


return

100 format' Target overlap conflatince is NOT between 0.5 and 1,0 Is

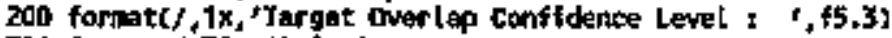

701 formetc $/, 38 x_{,}$,prisority".

- $\quad 1,1 x_{*}$ 'Overat Cost

702 format $12 x$, 'F rections of Targets Killedr, $13 x, 11)$

704 forat (9x, 'Fractions of Platfores Attritedr, 9x, i1,

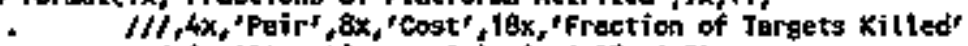

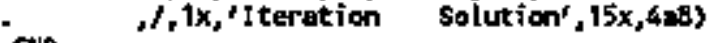

$\boldsymbol{c}$

t read_inputs

$\langle\mathrm{C}-11\rangle$ 
$T\left[K \_0\left\{t_{r} K\right)=T I K(t, K\}\right.$

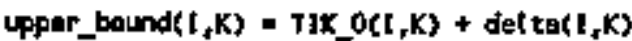

(diter_bound $(I, K)=\operatorname{cax} \overline{\bar{\chi}}(\mathrm{TIK}, 0(1, K)-\operatorname{dalta}(1, K)), 0.0)$

endida

endoto

c

--- Calculate initiat target aplits by mition type

do $y=1$,, $\mathrm{BB}$

tomini $=0.0$

do $J=1,16]$

do $k=1$, Hok

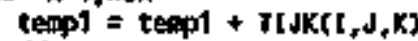

andido

enddo

Td $O(J)=$ templ

endido

fllaname = "averlap,bud"

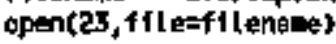

c - W. Urite Target Splits by Platforn

write\{23,B20) filename

writo 23,169$\rangle$

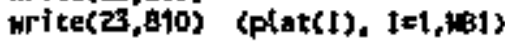

do $K=1, H B K$

write(Z3,803) targ(K), (IIK(I,K), [=1,Net), tot_target $6(K)$ enddo

c

-.- Write the overlap bounds for targats to be killed write( 23,815$)$ terget_overlap_confidence

witst(2),811)

do $K=1, H a K$

urita $(23,808) \operatorname{targ}(K),(d a l \operatorname{ta}(t, K), 1=1, H B I)$

endoto

c $\quad$ Write the loner bounds for tergets to be kitled write(23,812)

do $k=1$, kiteK

write(23,E0B) targ(K), (lower_bound $(1, K),[=1, k 81\}$ and

c.

-.- Write the uppor bounds for targets to be killed writs( 23,813$)$

do $K=1$, kiteK

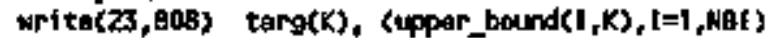
enddo

$\mathbf{c}$

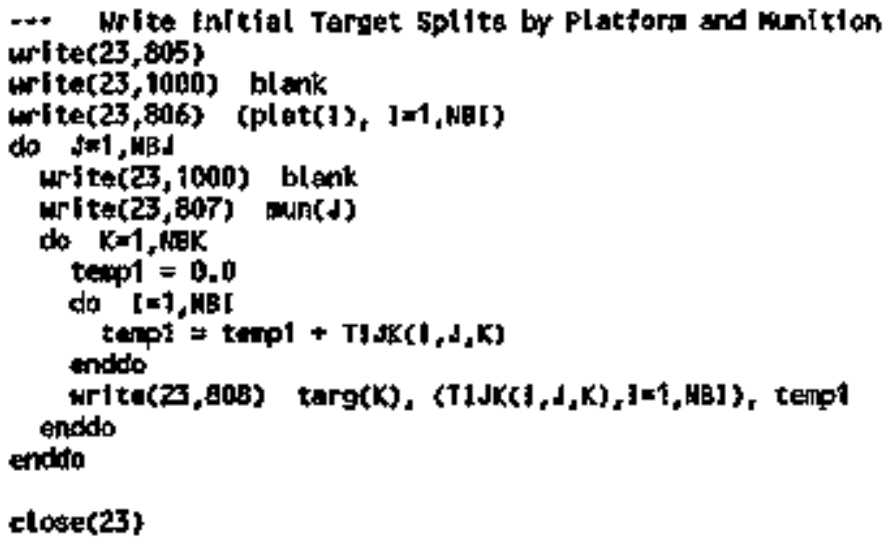

ctose(23) 
raturn

100 formet $(a 14)$

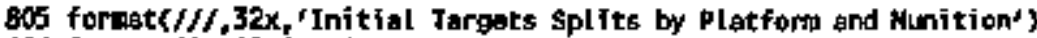

Bas format (10x, 12(1 $x, a b), 6 x_{x}$ 'Tatol')

807 forpat(a15)

808 forate $(3 x, a 5,12(1 x, f 6,2), 2 x, 2(5 x, f 6,2), 5 x, f 6,4)$

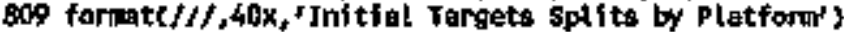

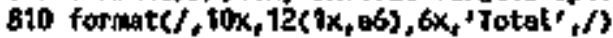

Bt5 foratat $(f / N, 1 x$, Target Ovartapoing Confidence $=t, t 5.3)$

sil format $(f, 30 x$, 'Owaclapping lounds for Targats to bo kitled')

812 forpat $(/ / /, 30 \times$, tower Bounds for Taraets to be ki1led's

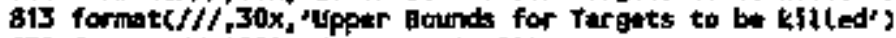

B20 focuat ( $/$, ifile Wame : , a14)

1000 foratc(a)

end

c (* read_init_t_splits_cas_bounds $\Rightarrow$

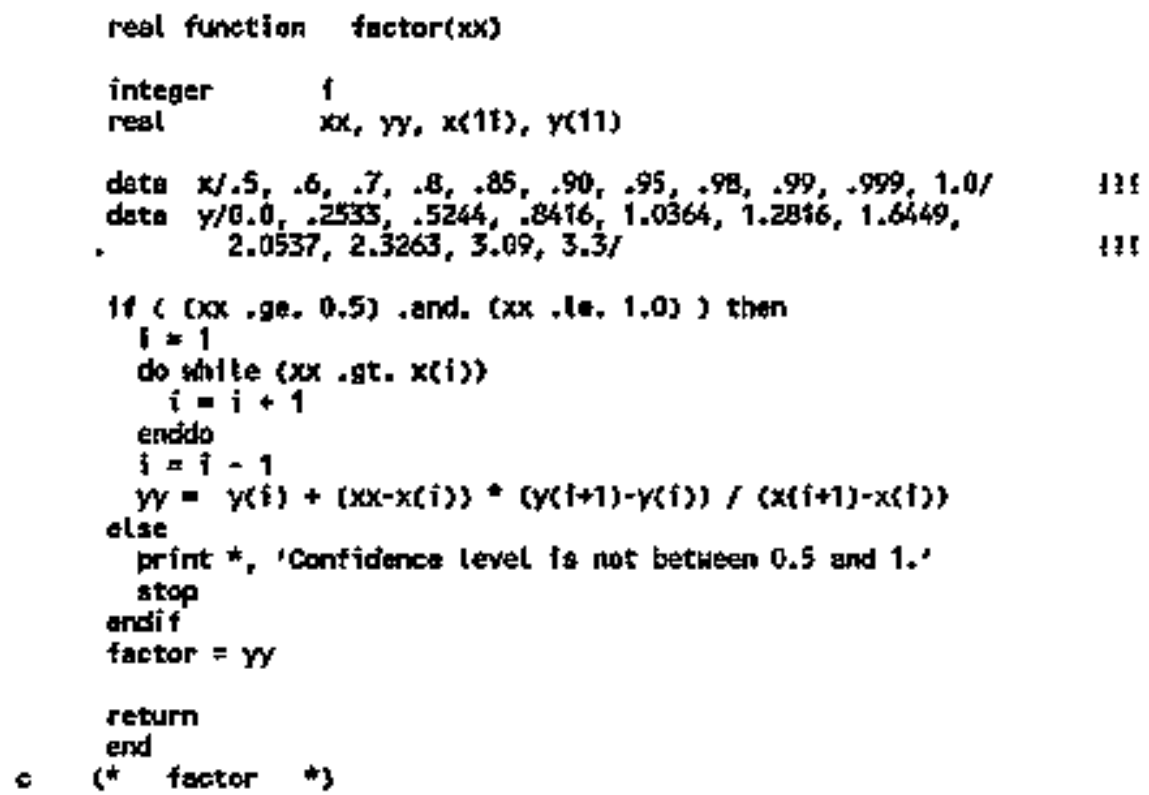


subrowt the read_first_target_splits

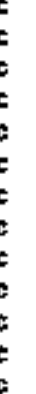

tonclude 'paì $r_{\leftarrow} 1 . i n c$ '

$\begin{array}{ll}\text { character"14 } & \text { filoname } \\ \text { charactar"15 } & \text { name } \\ \text { character"132 } & \text { hegding } \\ \text { integer } & \text { I, J, k }\end{array}$

c $\quad$-.. read Enftiol terget eplits

print* * Enter file nane for the first target splits' read $(5,100)$ flleneme open(51, fjlewfilenane)

read(51, 1000) heading read $(51,1000)$ heading read $(5 t, 1000)$ heading read(st, 1000) heading read (st, 1000) heading

do $J=1$, us

read(51, 1000) heading

read(51,807) nans

do $k=1$, Nak

read (S1, 80g) nape, (TIJK(I,J,K), $(=1, M B 1\rangle$ entida

endido

ctose 51$\}$

return

100 fortinat (a14)

gof fornat (a15)

ode forlat $(3 x, a 5,12(1 x, f 6.2), 2 x, 2(5 x, f 6.2\}, 5 x, f 6.4)$

1000 format(a)

and

4.

(* read_first_cargat_splits ${ }^{\circ}$ 
subroutine set_perconts_for_conf tance

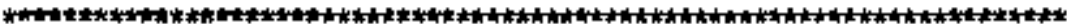

- Chobse confiderce level to.

- In evaluating the fraction of targets killed at different levels

- of contidence, perckill are the chosen conftdences cactugl ly in

t fractional form, not $x$ ).

- Referenced by:

instializet

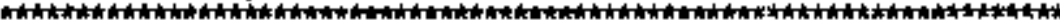

comor/percents/perck I l (\$) , nparc

intogar npers

real perckit

Inteser

1

ripert $=6$

!!! $\quad$ V

do je1, npetc

perckitt(i) $=0.75 *(i-1) * 0.05$

endidg

perckiti $(6)=0.99$

!!

return

end

$c^{\star}$ set_percents_for_contidence

$\rightarrow$

stbroutine intialize_req_exp_ratios

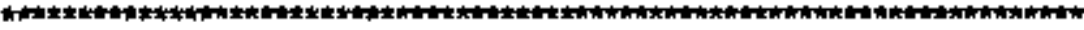

- This aubrout int Inftial fzes the requirant-ta-expendi ture ratios. *

- Referensed by

initialization

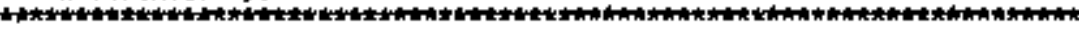

include 'psir_l. Inte'

do jej, $N B d$

$R \_(j)=1.0$

end $\bar{d}$

return

end

initiel jze_req_exp_rstjos †

$<\mathrm{C}-16>$ 
subroutine cal_owe_exp_for_coming_tn_ru

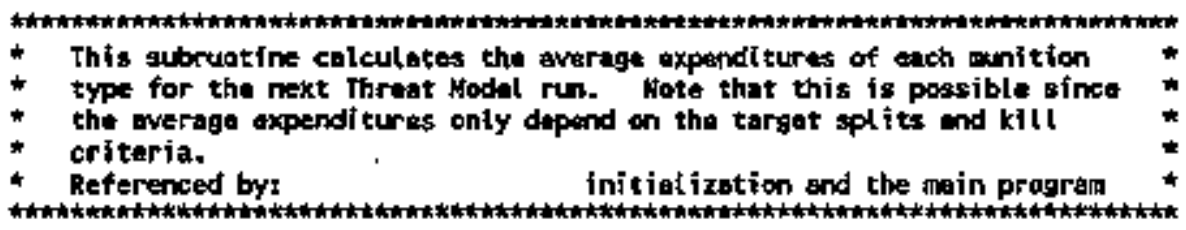

return

end

$i^{*}$ col_ave_exp_for_coming_tm_ru $\#$

subroutithe store_overaye_expendi tures

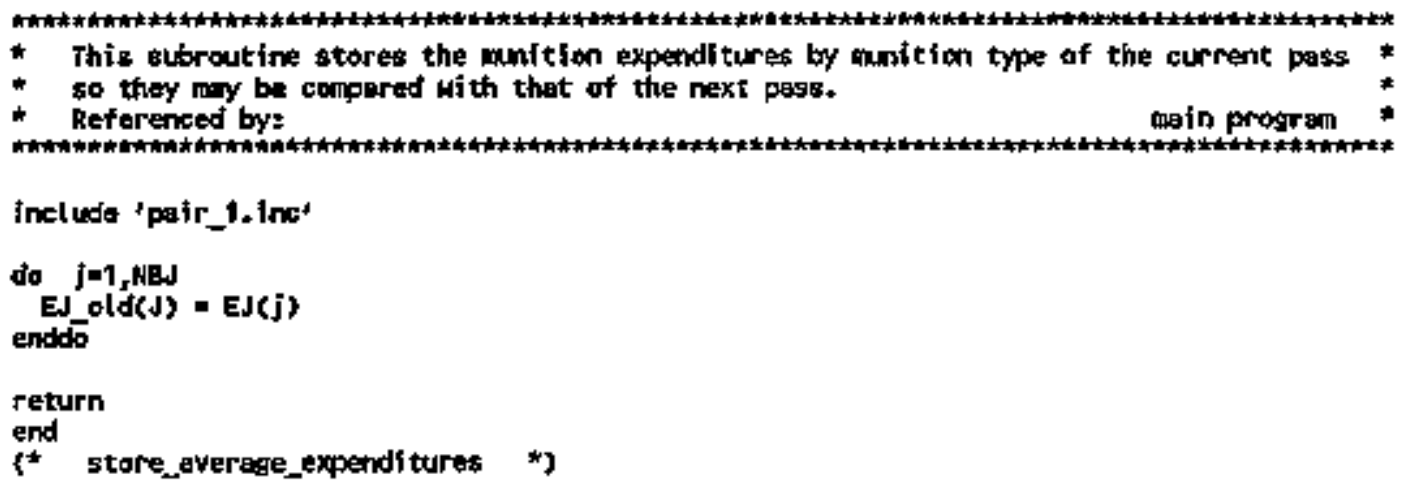


subroutine threst_model (pess)

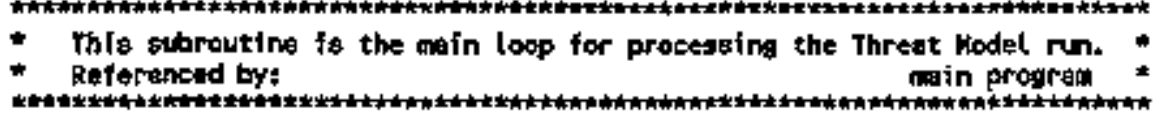




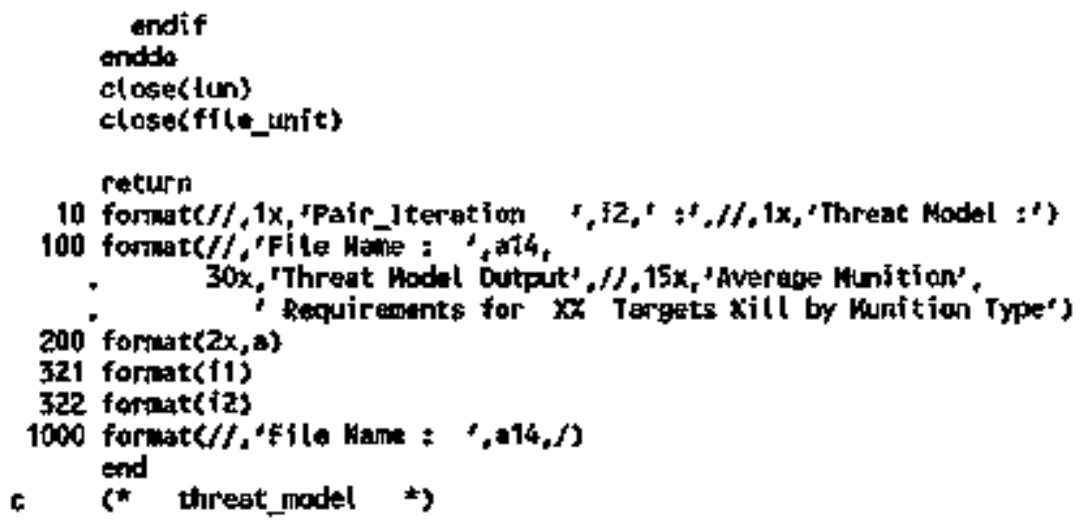


stbroutine get_targat_splits(pass)

Include 'pair_l. ince'

\begin{tabular}{|c|c|}
\hline $\begin{array}{l}\text { Integar } \\
\text { charecter*y } \\
\text { character*f } \\
\text { charecter*14 }\end{array}$ & $\begin{array}{l}\text { pass } \\
\text { ch_pess1 } \\
\text { oh_pass2 } \\
\text { fitensin }\end{array}$ \\
\hline $\begin{array}{l}\text { charecterit } \\
\text { integer } \\
\text { resil } \\
\text { real } \\
\text { real } \\
\text { dete }\end{array}$ & 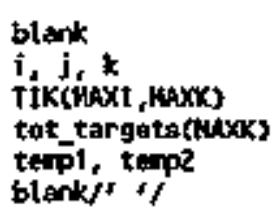 \\
\hline
\end{tabular}

If (poss .tt. 10) then

write(ch_pacst,321) pass

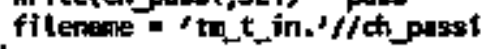

else

wr1to(ch_passz, 322) pass

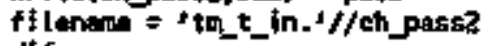

endi $f$

open(24, file=fit tenome)

c ... Culculate Target Splits by Platform

do $K=1, \mathrm{NHK}$

teip $1=0.0$

dis $[=1,48 \mathrm{C}$

$\tan 20=0.0$

do $J=1$, wh

temp2 $=$ tenpe $+1 \mathrm{TJ} K(I, J, K)$

endso

$\operatorname{TIK}(I, K)=$ temp 2

tenp1 $=$ teap1 + texp2

endido

tot_tergets(K) $=$ temp1

enddo

c $\quad \cdots$ urite Target sptits by Platforn

write 24,820$)$ filensine

wite( 24,809$)$

wrtte(24,810) (plat(1), [=1, HBI)

do $K=1, \mathrm{~N}$ BKK

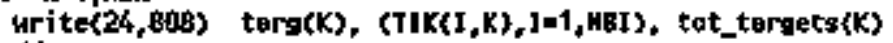
enddo

c ..- Hrite Threat Model Input = Target Sptits by Platform and Munition writ te(24,805)

write 24, 1000) blenk

Mrite(24, e06) (plat(1), I=1, MB1)

do Jel, Fing

write 24,1000$)$ blenk

urite(24,807) mant(J)

do $k=1, \mathrm{MBK}$

tenpi $=0,0$

do $t=1, n,[]$

$\operatorname{tanp} 1=\operatorname{tenp} 1+11,3 K(1, J, K)$

encilso 


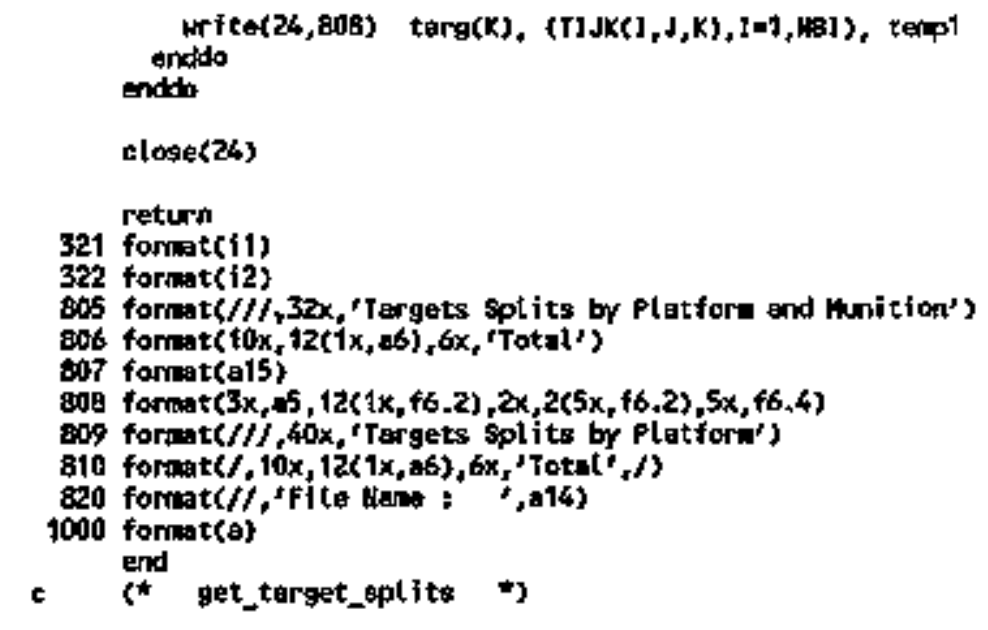

$\langle c-21\rangle$ 


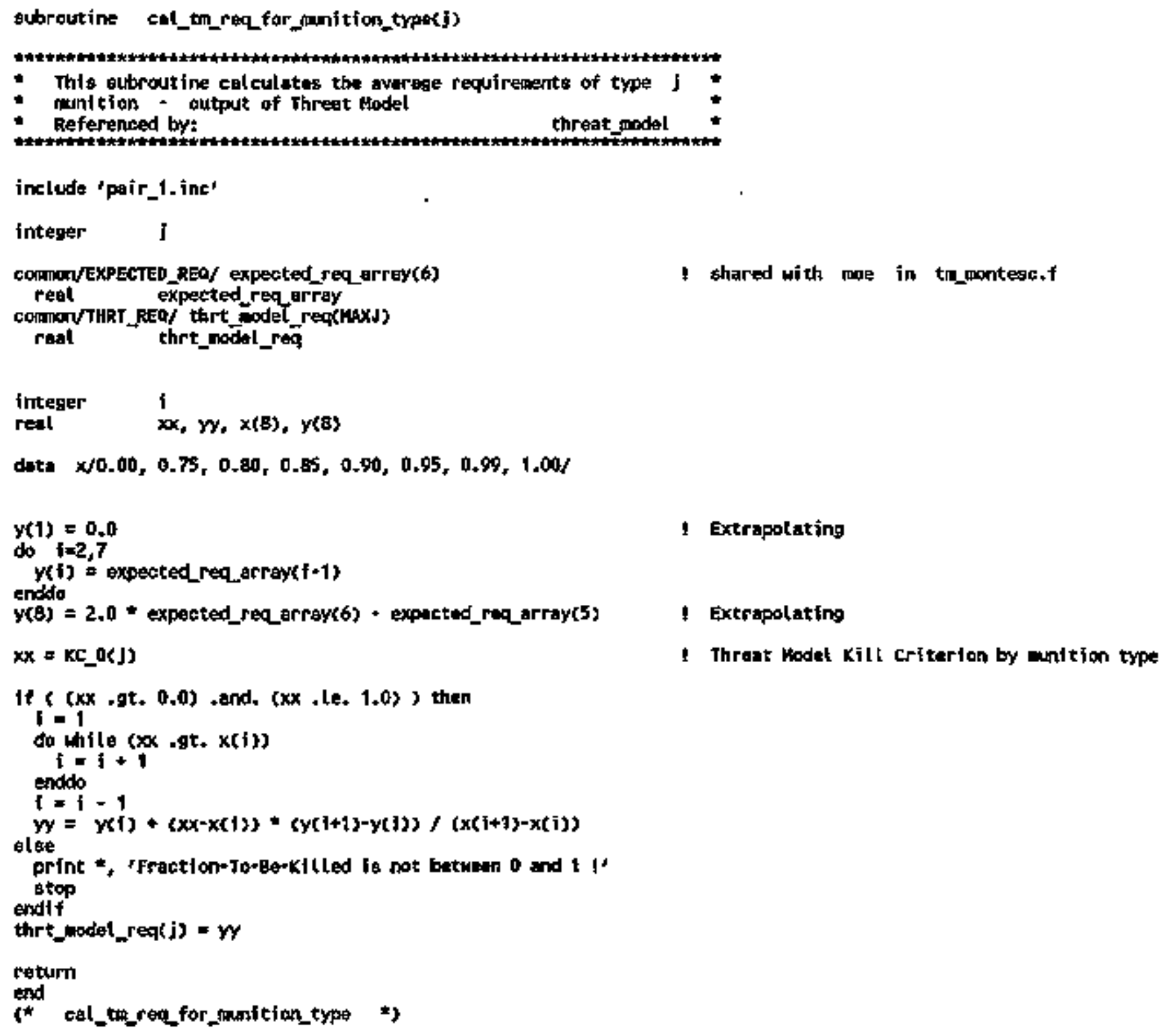

1 Extrapolationg

1 Extrapolating

1 Threat kodek Kill Criterion by anteion type 


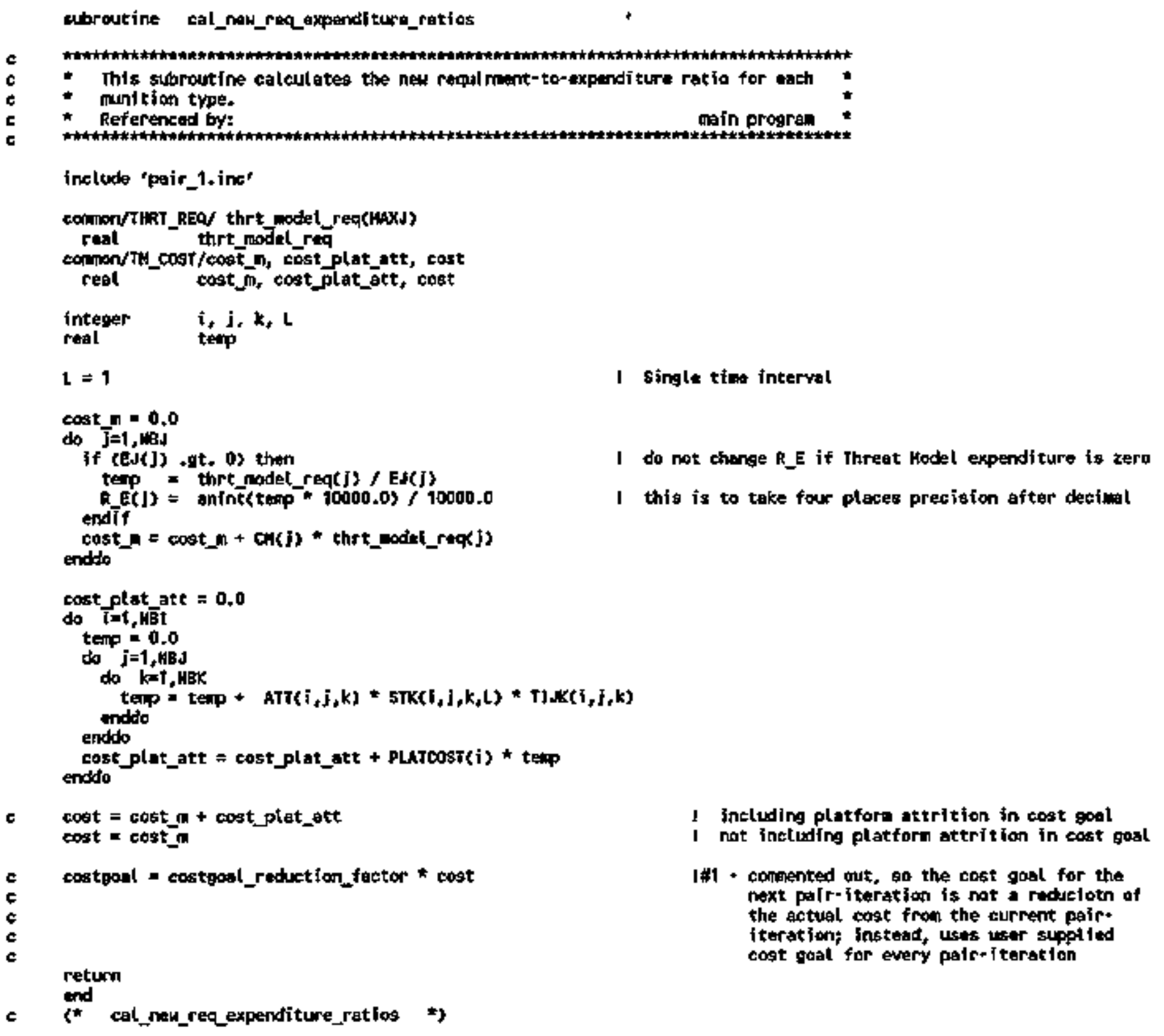




\section{subrout ine jap(pass)}

$c$
$c$
$c$

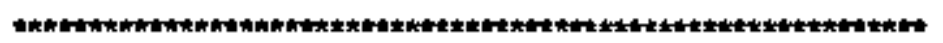

* This abcatine is the hain pracess far the Jiap rum. *

* Rofarenced by:

eatin progorat t

integer pass

call open_f1Les(pass)

call topinp

call (spsolvexpess)

coll close_files

\section{retum}

c
11 find it in jagp, $f$

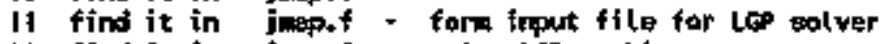

11 find it in jacop.f - solve LeP probletn

II find it in josp. $f$ 
Hubroutine cat_jax_aberration(pass, max_dberration)

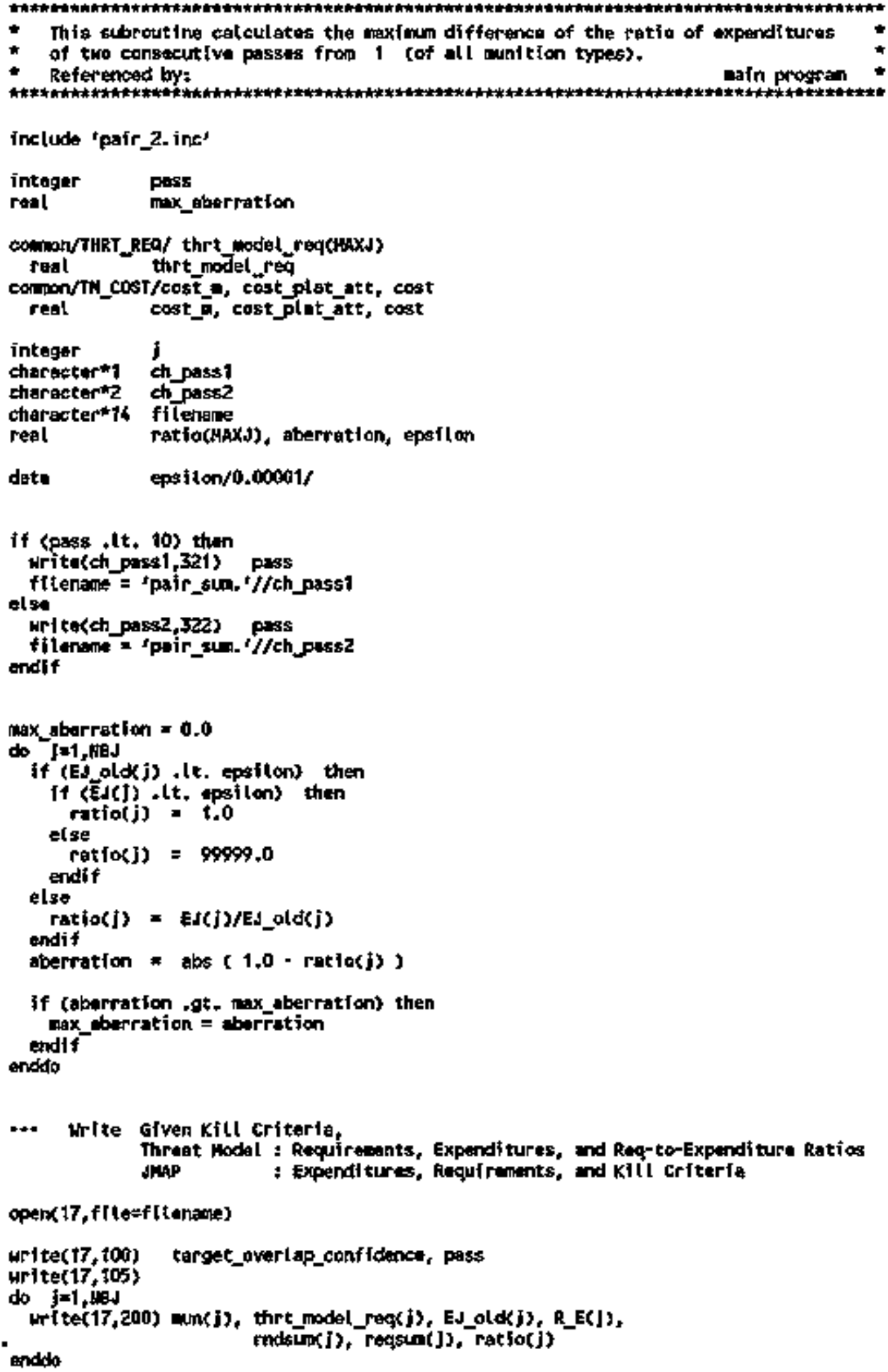




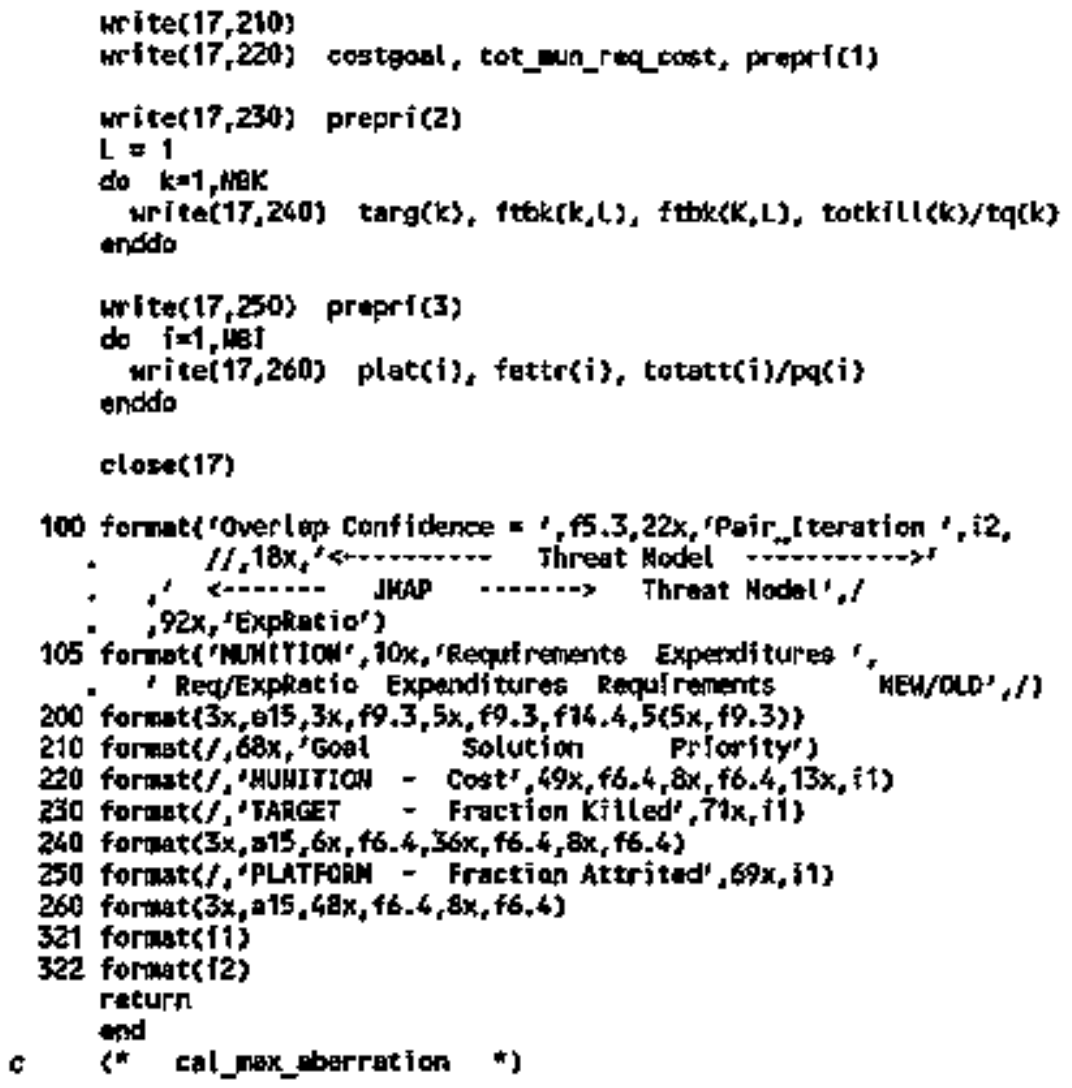




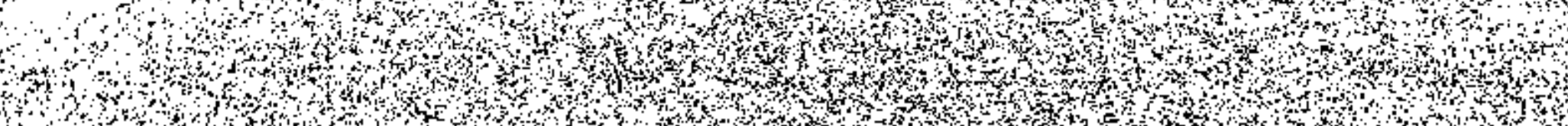
row

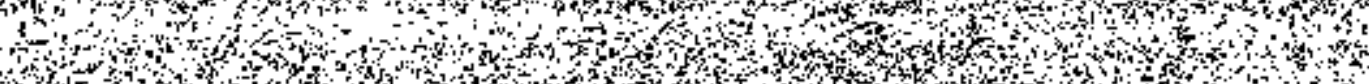

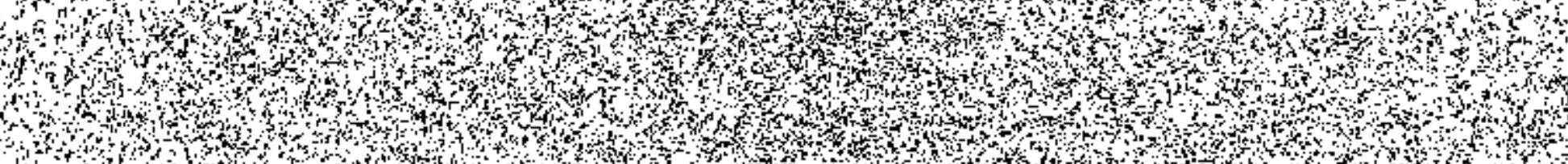
(n)

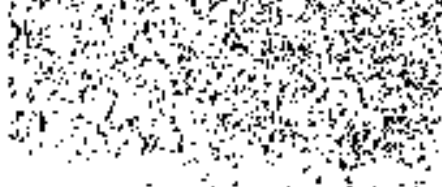

(1)

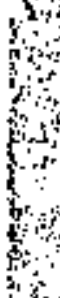

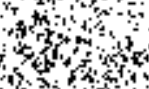

ons

How

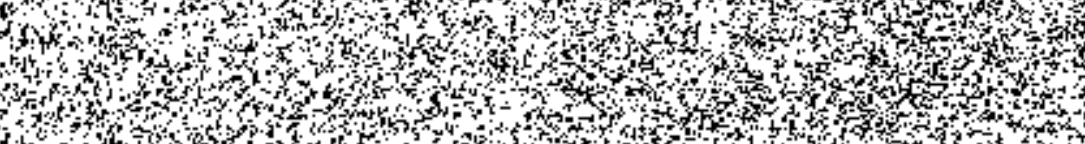

tist

Ans

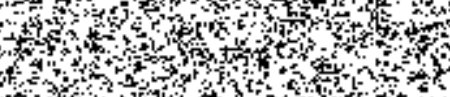

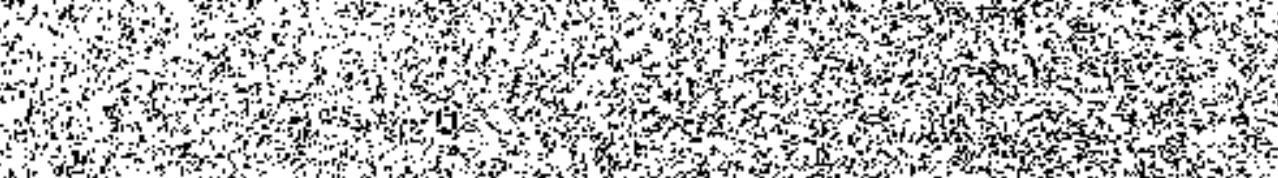

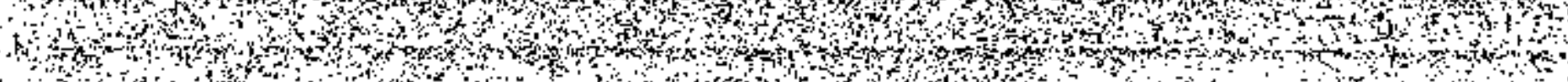

ind

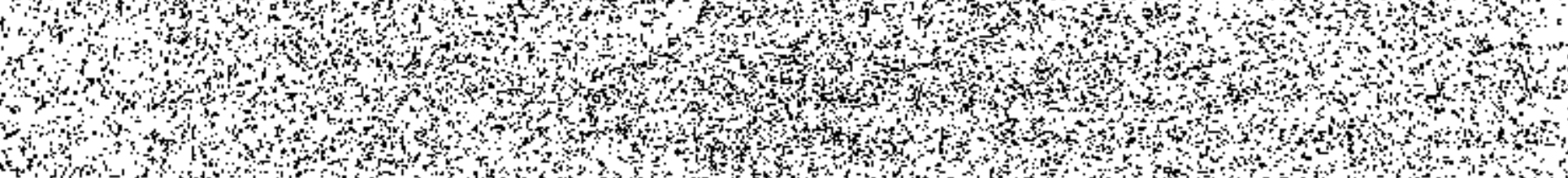

(2)

(n)

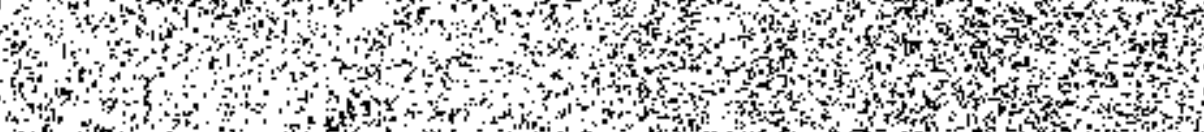

rito

o 3 ,

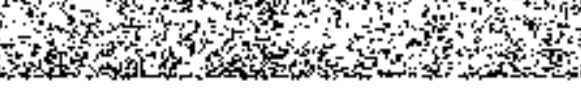


c Based on auf $5 / 92$ Mortim Module

c Nodifiad for addaption on HP-90000 MP-UX FORTRWA and HS Powerstation FORTRAK. 4/5/94 Roger Lym

Arrangenant of Progrea Untts :

$\mathbf{t}$

open_flles

\&

topinp

g_con_overal I_cost

g_con_targats_xil I

econ_plotforä_attrition

ph_con_ma olat form_ater f t is

Ph_con_minftion_ovat table

phecondoctrinal

ph_con_cax_rate_of_fir

ph con target counts

ph_can_upper_baund_targets_kill

ph_con_lower_bound_torgats_kill

LePSOLVE

START

SIFPLX

LGPR INT

PRTSOL

TEX

XET

alogefiles

$\ldots$ besed on ....

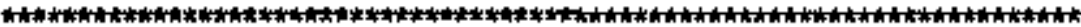
- INPUT FILES:

* 1 MUHITION MOJEL DESCRLPTORS - DETAJLE INFO

* cutput fjles:

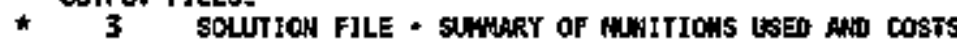

* 15 LGP REPORT FILE

C 9 input fite for LeP SOLVER

c 10 constraint type

c 20 objective toms

c 30 coefficients

c 40 Rtght-Hand sides

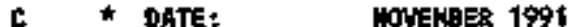

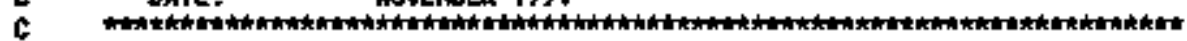

$\langle c-28\rangle$ 
subroutine open_files(pass)

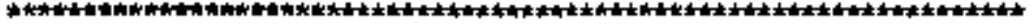

* This stbroutine opens all the flles used by the jrap nodule. *

* Refererked br:

Jाmp *

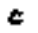

include 'poir_1.ine'

integer

cherectorky ch pass1

characterit2 ch pass?

cheracter*14 fitenteme

If (pass +1t. 10) then

write(th_pass 1, 321) pass

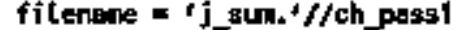

else

write(ch_pessz, 3z2) pass

filename = 'j_sun.'//ch_pass?

entif

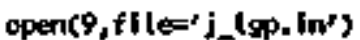

open(10, file $=r]$ con't)

open(20, file='jobjt)

open(31), fi(e-r) coeff")

apen(40, fiten' $\mathrm{f}$-rhs')

opent 15, filesf]_tgp,oute')

opent 3 , fil ent tiename)

write $(3,100)$ target_overlap_confidence, filenans

return

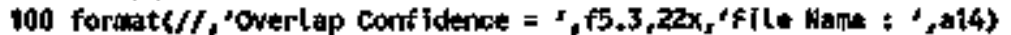

321 fornatitis

322 foriat (i2)

1000 fornatcas

end I open_files 


\section{SUAROUTIUE LEPIHP}

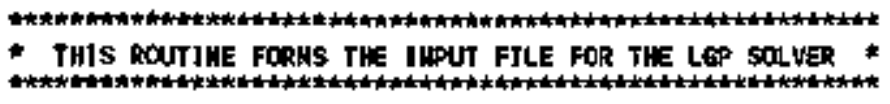

Henczono

Do $200[=1, \mathrm{HB}[$

DO $190 \mathrm{~J}=1, \mathrm{MBJ}$

Do $185 \mathrm{~K}=1, \mathrm{KBK}$

00 t80 LE1, MBL

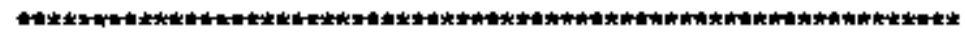

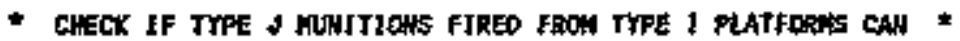
- HARH THFE K TARCETS

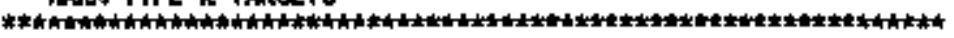

If (STK $([, J, K, L)$.EO. \$.EZS) GO TO 180

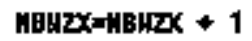

JF (NEMIX . BT. MAXX) THEN

PRIHT",

PR1HT*,

PRIHT*, THE HB OF NOW-ZERO $X^{2} B$ HAS EXCEEDED THE E[H]T',

1

PRINT*,

Maxx = J MaxX

PRINT*, JNCREASE THE VAUE OF TAE PARANETER MAXX IN HK COOE.'

PRINT*",

PRIKT:",

STOP

EHIF

TARECHK(KY-TARCCHK(K) + t

180 COMTIMUE

1 COS CONINLE

190 COATINUE

200 CONTJHUE

c

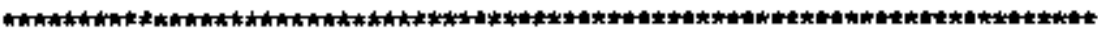

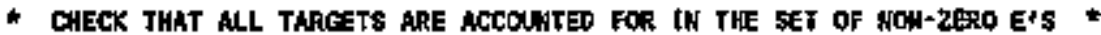

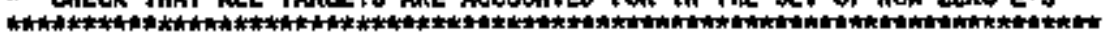

$\operatorname{cccc}$

ceces

$\operatorname{coctc}$

rect

PRINT*, $\div$

PRINT*; *

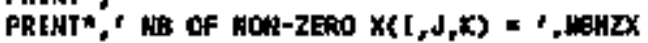

PRENT*. I

$<\mathrm{C}-30\rangle$ 


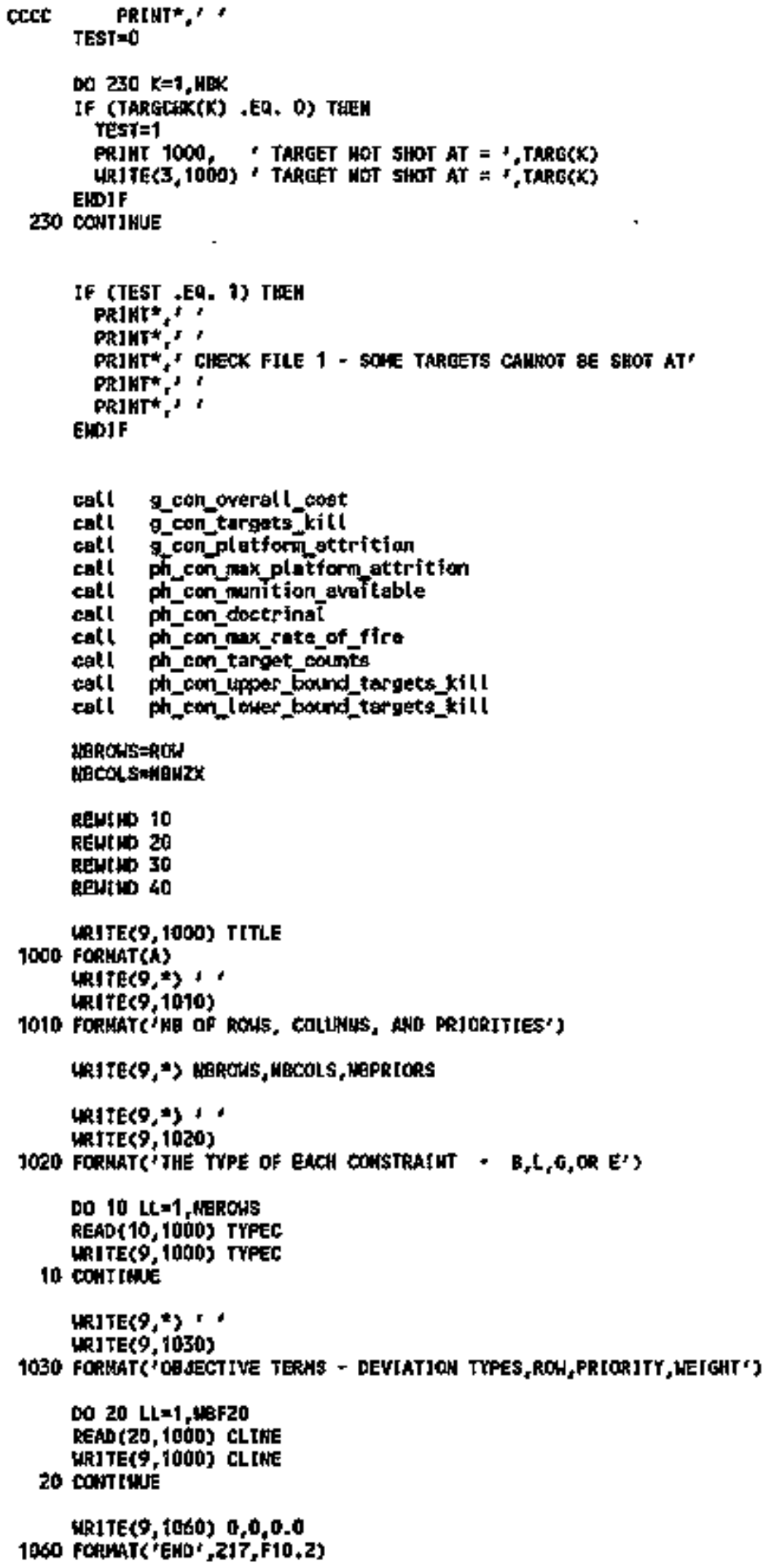

WR1TE( 9, to60) $0,0,0.0$

1960 FCAMAT('ENO', $217, \mathrm{~F} 10,2)$

$$
\langle c-31\rangle
$$


WRTTE $(9, *) ; *$

(RITE 9 , t070)

1070 FORKAT('COMSIRAIKI COEFFS. - ROW,COLWH, NALEE')

DO $30 \mathrm{~L}=1, \mathrm{HBF} 30$

READ (30, 1600) ClIME

WRTTE(9, 1000) CLINE

toed FORALT (217,E15.6)

30 contriak

WhITE(9, 1090) $0,0,0,0$

WRITE(9,*) I

URIYE(9, 1090)

9090 FORHATS'RIGH' GAND S10E WhLUES Of CONETRALXTS')

to $40 \mathrm{tR}=1$, MeROus

READ $(40$, t000) CLINE

HRITE $(9$, tDO0) CLIHE

40 cost thue

REWI 9

Retura

Elit

I LGPINP

$\langle c-32\rangle$ 


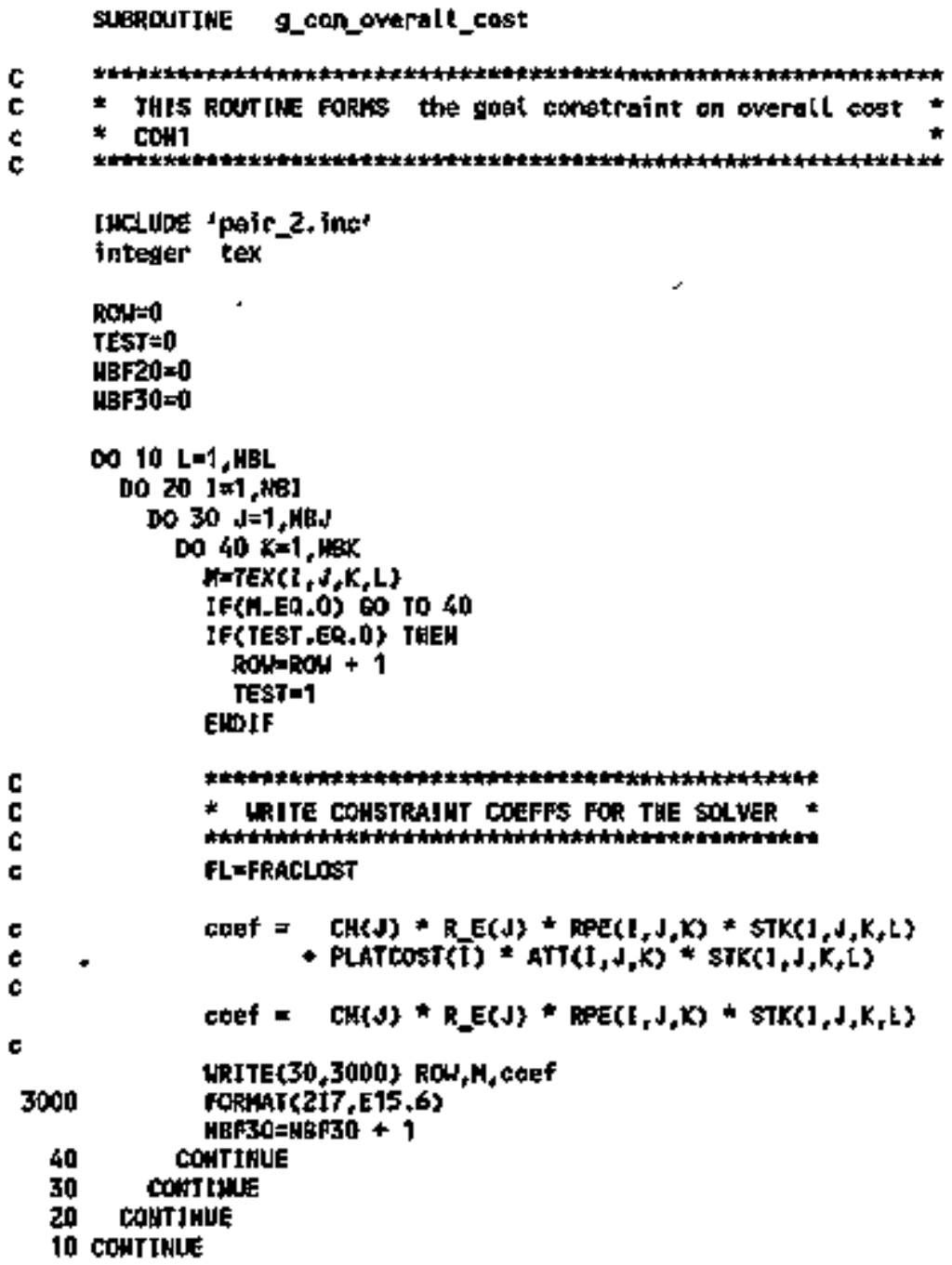

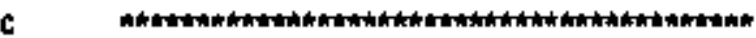

C * LR1TE DEJECTJVE TERHS FOR THE SOLVER *

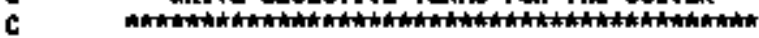

WRITE(20,2010) ROW, PREPR L (1),1.0

2010 FORNAT ('POS',2I7, F10.2) MBFZOMNAF2O +

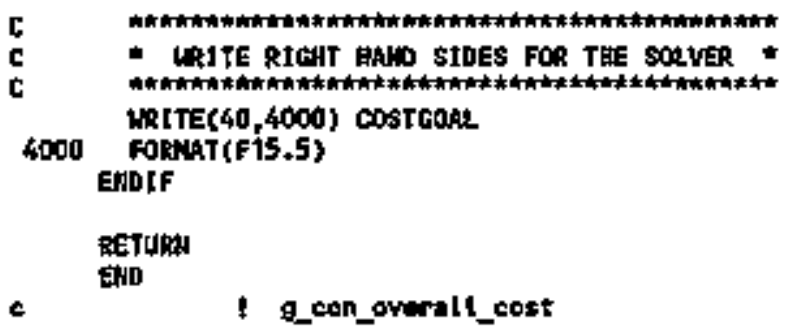

I

I if pletform atcrition tost is inctuded in overall cost

I platform attrition cost not included in oversll cost 


\section{SUBRDUT IRE g_con_targets_kill}

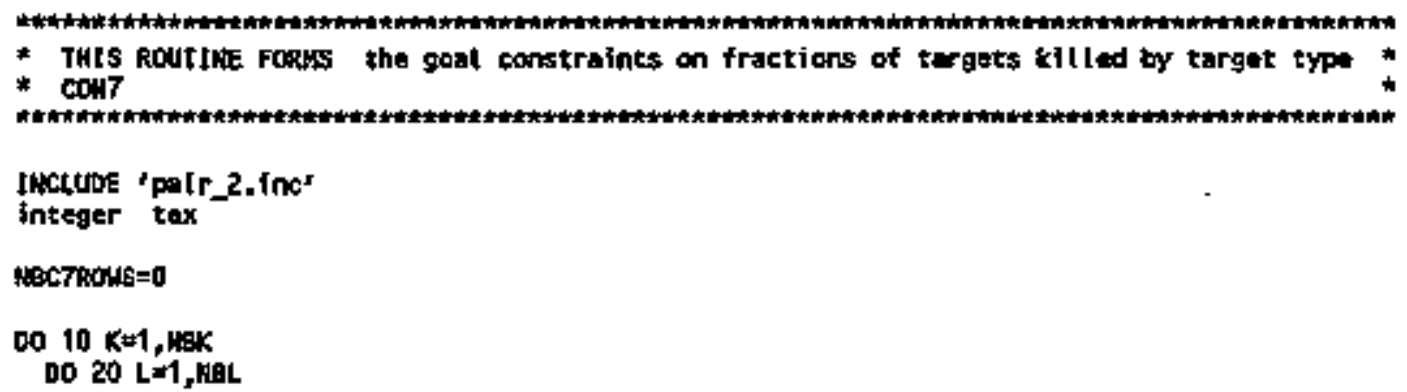

$1907 \mathrm{KOHS}=0$

$0010 \mathrm{k}=1, \mathrm{MEK}$

DO 20 L=1, HEL

TEST 0

D) 30 [ $=0$, , HBI

$0040 \mathrm{~J}=1$, Hed

N=Tex(t, $, k, l)$

IF(N_EA.0) 60 TO 47

IF\{TEST_EQ.0) THES

BOJ=ROW + 1

vactrousmochous + 1

TEST=1

ENDIF

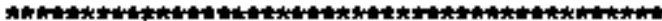

- irite constraint coeffs for The solver *

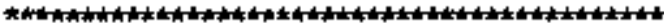

LRTTE(30,3000) ROW, W. 1.0

FORKAT (2I $7, E 15,6)$

NBF30 4 IEF 30 + 1

DO $45 \mathrm{LF}=1, \mathrm{t}=1$

$n=\operatorname{TEX}(1, J, K, L P)$

1F (N.EQ. O) GO TO 45

JF (TEST EA. O) TAEN

RONARON + 1

TEST=1

EMDIF

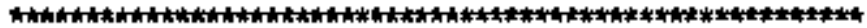

* MRJTE CONSTRALNT COEfFS FOR THE SOCVER

* Sfrom the surviving targets of the fight-hand-side)

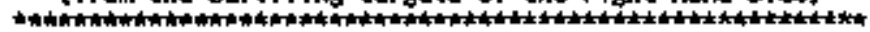

URITE(30,3000) ROW, N, FTEK(X,L)

NEFSOCHBF30 +1

CONTIIUE

40

30

COHTINUE

COHT LMUE

IF CTEST .HE. O) THEH

c

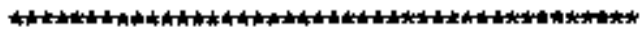
* WRITE COLSTRAJNT TYPE FOR THE SOLVER *

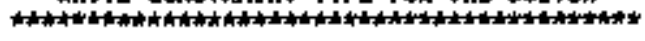
URITE(10, 1000) 'B'

1000 FOBANAT (A)

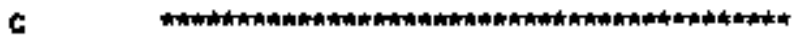

C $\quad$ WRITE OBJECTIVE TERS FOR THE SOLVER *

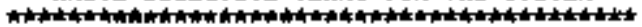
LRJTE(20,2000) ROU, PREPRI(2), FON_T(K)

2000 FOBHAT('HES',2[7, f10.23

NBF20 $=218 F 20+1$

$<c-34>$ 


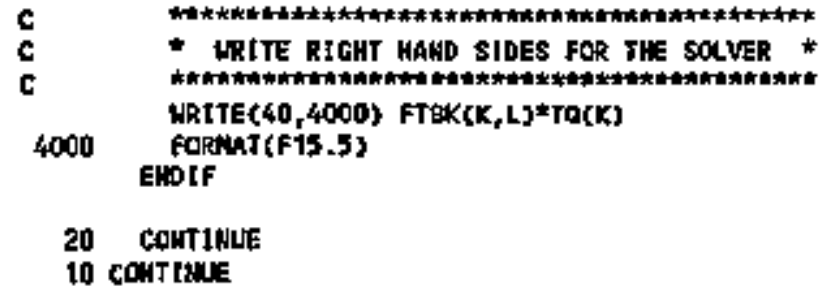

I g_con_targets_kill 


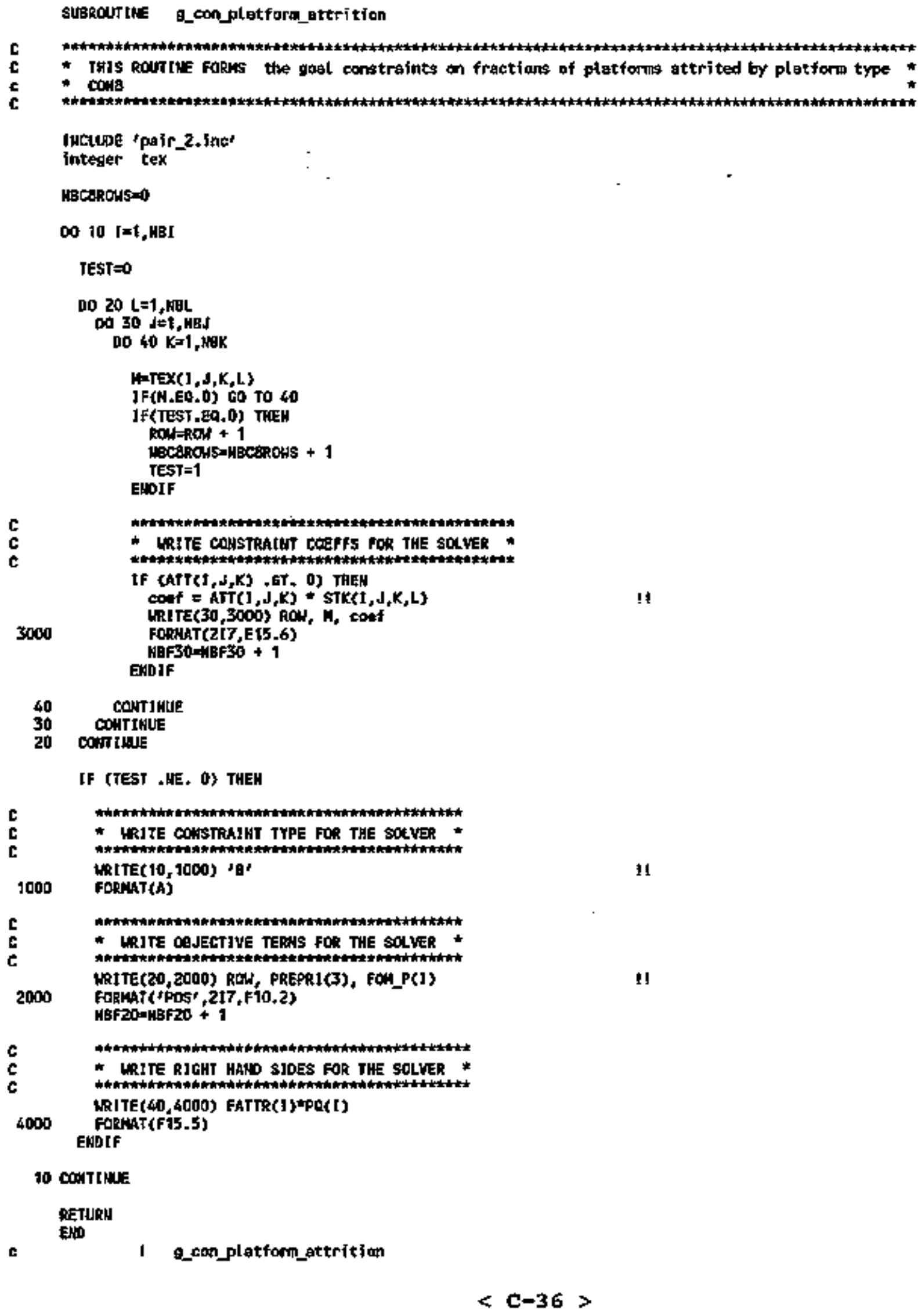

IF (TEST . HE, O) THEN

C C * HRJTE COHSTRAHT TYPE FOR THE SOEVER *

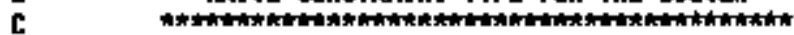
WRTTE $(10,1000)$ ' 19 ' 1000 FORNAT(A)

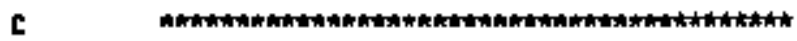
f * IRJTE OgJECTJWE TERAS FOR THE SOLVER *

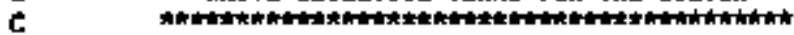
NRITE(20,2000) R(W, PREPR1(3), FOH P(1)

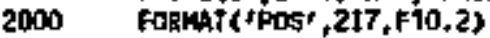
MBFZOMABF 20 +

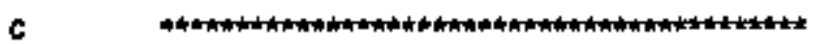

c * IRITE RJGHT HAND SJOES EOR THE SOLVER *

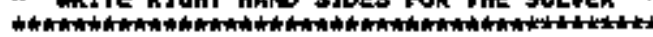

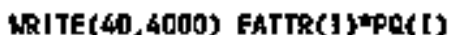
FORHAT(FT5.5)

10 controue

\section{PETURN}

END 


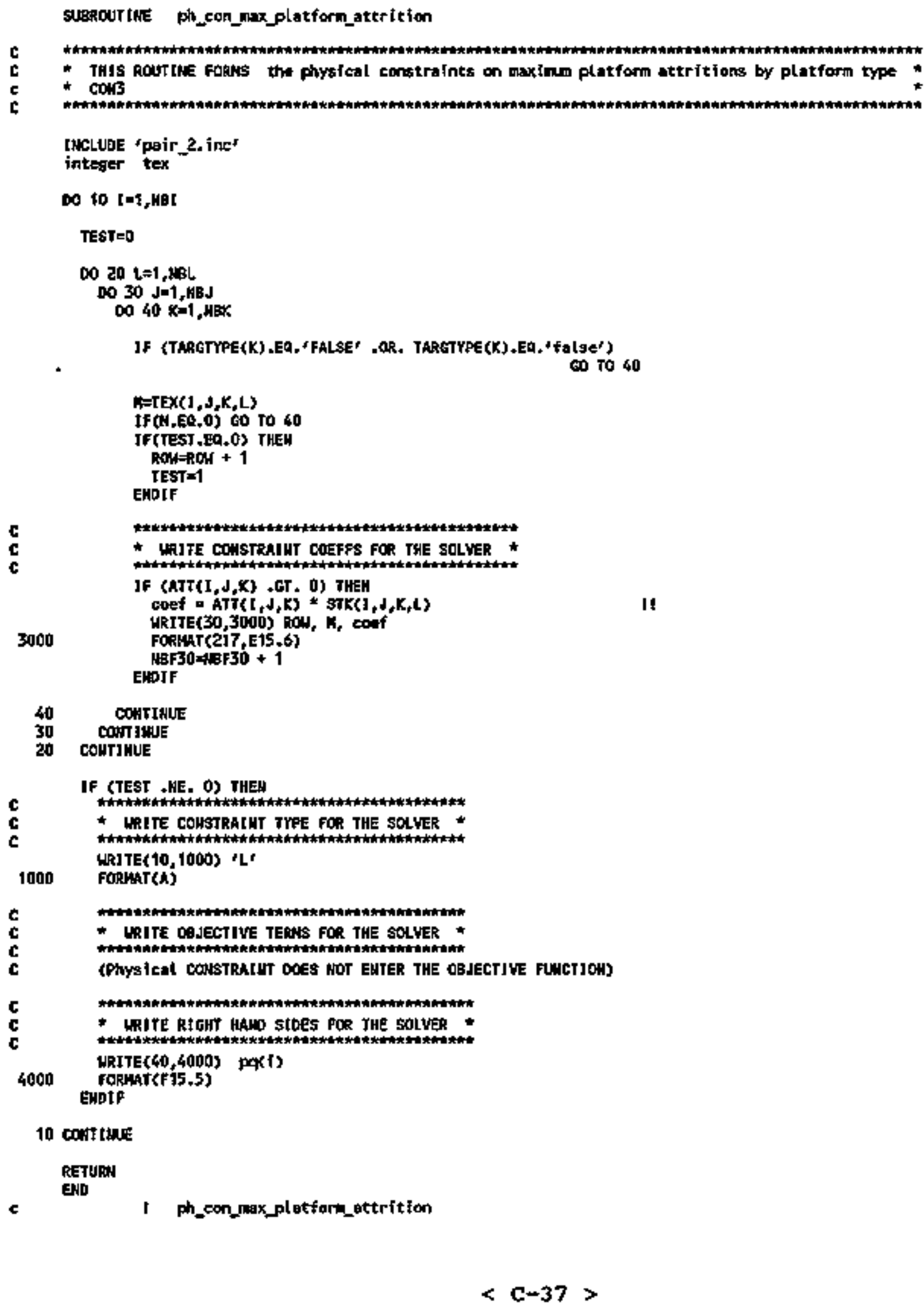

10 conit thes

RETUPW

END

$\boldsymbol{c}$

I Ph_con_max_plotfarin_ottrition

$<\mathrm{c}-37>$ 


\section{SUBRoUr [NE ph_con_mnition_available}

IMtLLLDE 'patr_z,InC'

intoger tex

HBCSROHS=0

or $10 \quad J=1,18 \mathrm{~B}$

TEST $=0$

DO $20 \mathrm{~L}=1$, $\mathrm{BBC}$

$0030 \mathrm{I}=1$, Fi:

Do $40 \mathrm{~K}=1, \mathrm{HBK}$

$\operatorname{MiTEX(1,J,K,L)}$

1F(H,EO,0) to to 40

JF(TEST.EO.O) THEH

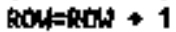

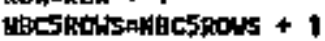

test:1

EnotF

c

c

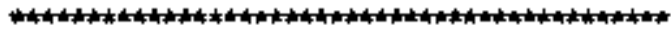

- IRITE COHSTRAIMT COEFFS FOR THE SOLVER *

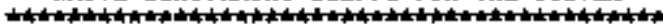

FL=FRACLOST

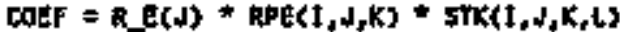

WRTTE(30,3000) ROW, H, DOEF

EaRMAL 217 , E15,6

$A B F 3 B=19 B 30+1$

$$
\begin{gathered}
\text { cont Jeire } \\
\text { continue } \\
\text { tontiale }
\end{gathered}
$$

IF (TEST ,HE, O) THEN

C

C $\quad$ औ TITE CONSTRAIHT TYFE FOR THE GOLVER *

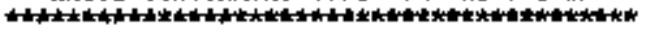

MRITE(10, 1000) 'L'

IOUD FORHAT(A)

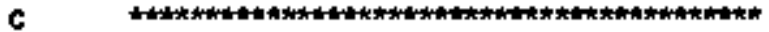

C औ MITE OASECT]VE TERMS FOR THE SOLVER *

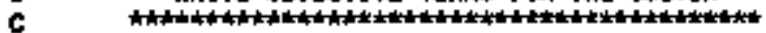

c (PhYsical COHSTRALNT DOES MOT EHTER THE OBNECTIVE FUHCTLOM

C

C * WRITE RIGHT HART SIDES FQR THE SOLVER *

C

URJTE 40,4000$)$ STOCK $(J)$

4000

FORMAT (F15.5)

EW1F

10 COHTJHJE

RETURI

E⿰冫欠

c

1 Dh_con_monition_evailable

$\langle\mathrm{c}-38\rangle$ 


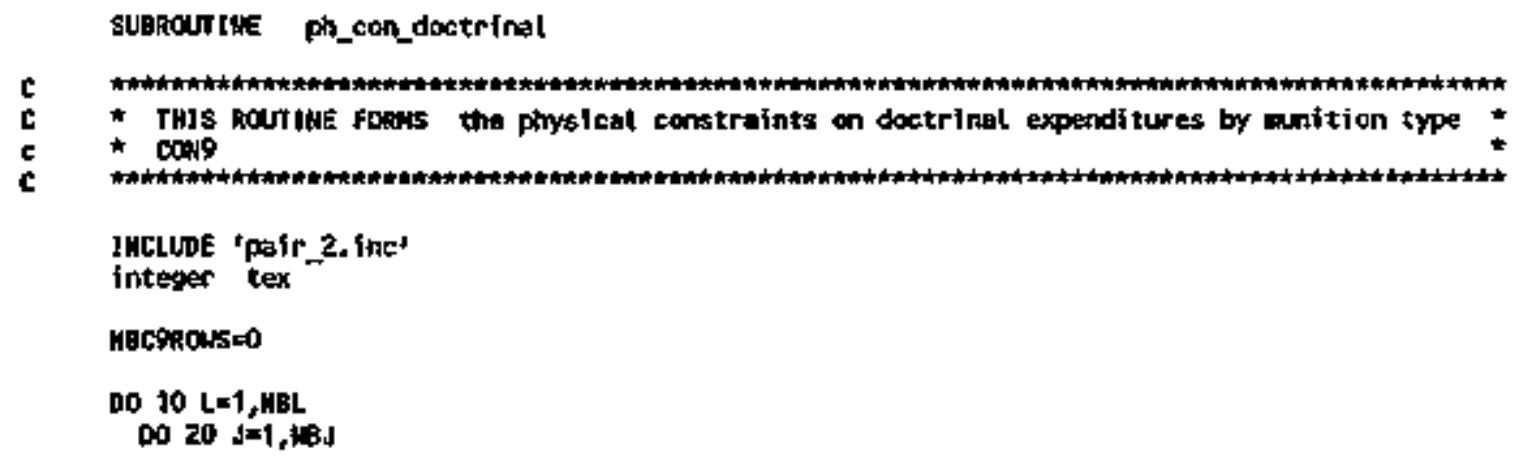

IF 〈OOCTRLK(J) ,EQ, 0) fO JO 20

TEST $=0$

BO $30 \mathrm{i}=1$, $\mathrm{kBg}$

Do $40 \mathrm{k}=1$, HBK

$N=T E X(1, d, X, L)$

IF(H.EQ.0) GO 7040

IF(TEST,EQ.0) THEH

ROtufRON + 1

HBCrROWS $=$ NBConows +1

TESTEY

Ente

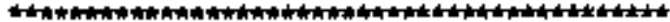

* nRtTe constratht coeffs for the sorver *

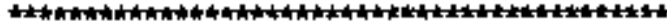

$\cos f=\operatorname{Rog}(i, j, k) \star \operatorname{sTk}(i, j, k, 1)$

URITE(30,3000) ROH, $K$, coof

$3000 \quad$ FODinJ $(217, E 15.6)$

NBF $30-\mathrm{HBF} 36+1$

40 CoNT IWUE

B CONTIHLIE

JF (TEST -HE. O) THEH

C

c * URITE CONSTRALNT TYFE FOR TEE 5OLVER *

C.

WRITE (10, 1000) ' $G$ '

1000 FORIAT(A)

c

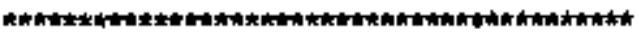

- IRtTe ogsective tepas for tKe solves *

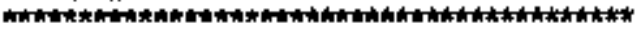

(Physicai COHSTRALNT DOES NOT ENTER THE OBJECTIVE FunCTION)

:

c

c

C

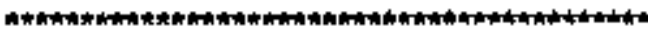

- URITE RITHT HALB SLDES FOR THE SOLVER *

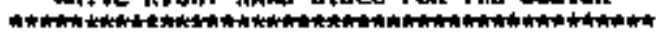

WRITE(40,*) DOCERIH(d) $* \operatorname{TTME}(L)$

4000

FORHAT (Fi5,5)

END IF

Cont I IX:

10 CONTIKive

RETURA

END

1 Ph_con_doctrinet 


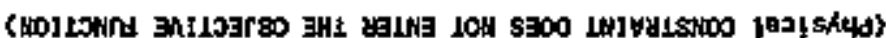

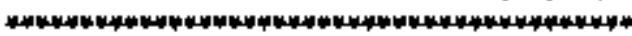

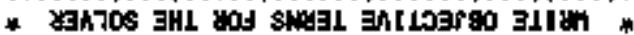

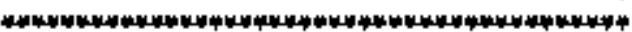

(Y)LWPod 17. (cood*ol)altat

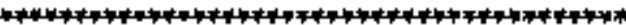

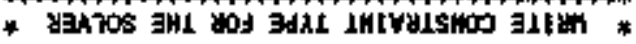

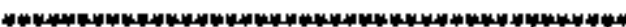
Ha日 60 " $3 N^{*}$ LSEL) AI

3001]1000

ot

II

$1+$ ossalposedan (9-519'212) Lindos

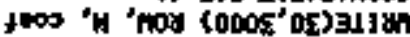
$\left(7^{*} x^{*}+1\right.$ t)

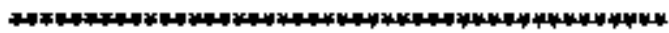

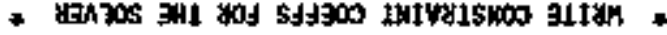

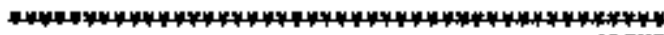
Juang $1=1591$

$1+$ snostoalt=snosypat $1+$ nOd $=40$ 어

NaH1 $\left(0^{\circ} 0^{*} 1591\right) \mathrm{d}$

ot of $00\left(0^{\circ} 0 \mathrm{~g}^{\circ} \mathrm{W}\right) \mathrm{d}$

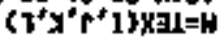

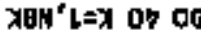
oesh1y $0=153 t$

Pan'l=r of at Igit' $\mid=1$ oट od 7 1日: $t=7$ of 00

orsyoupagh

Yas sebaju 

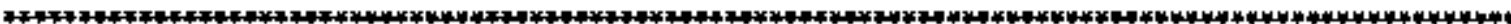




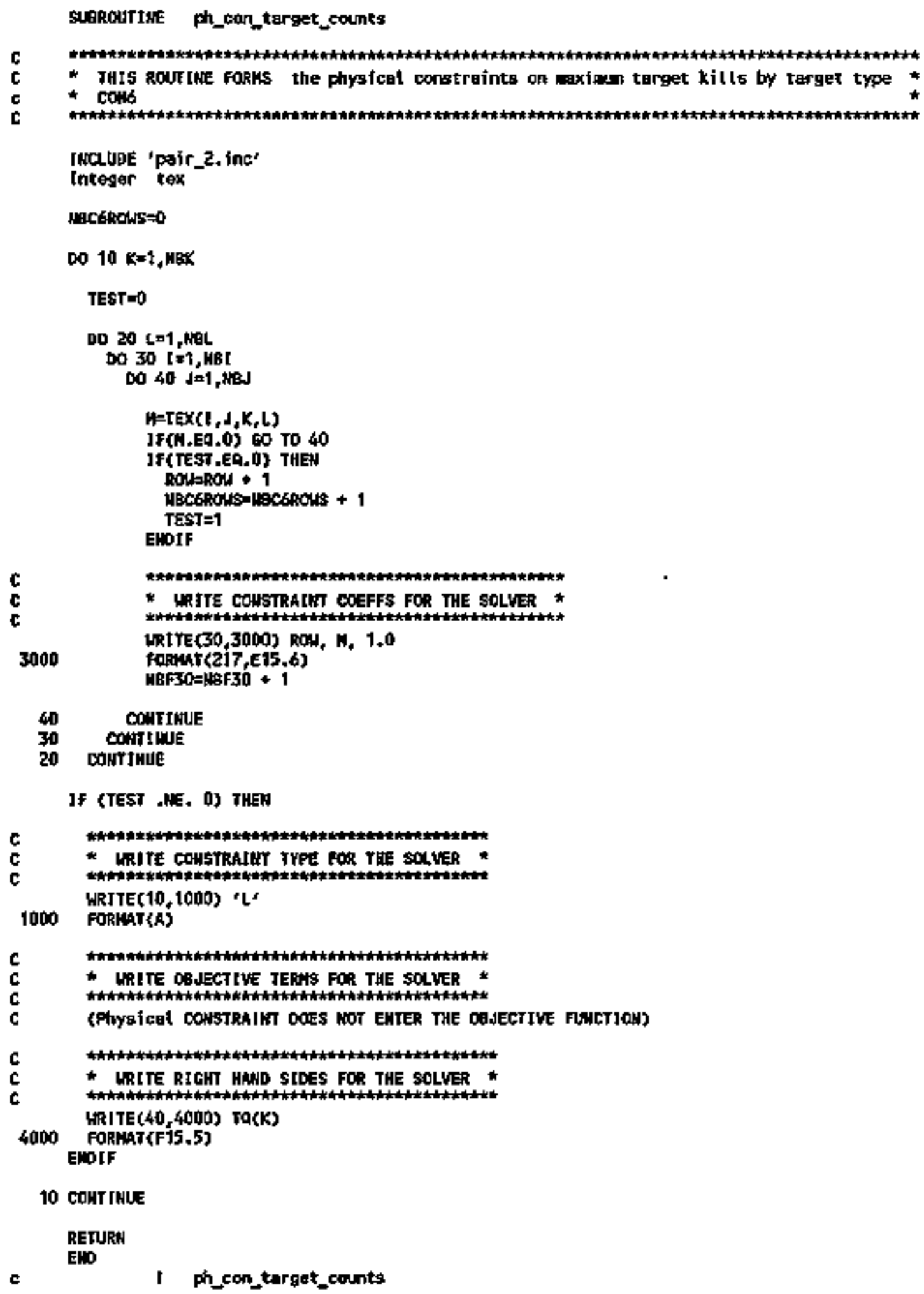

JF (TEST ANE, O) THEA

10 COHT INIE

RETURN

EWO

I Ph_con_target_counts. 


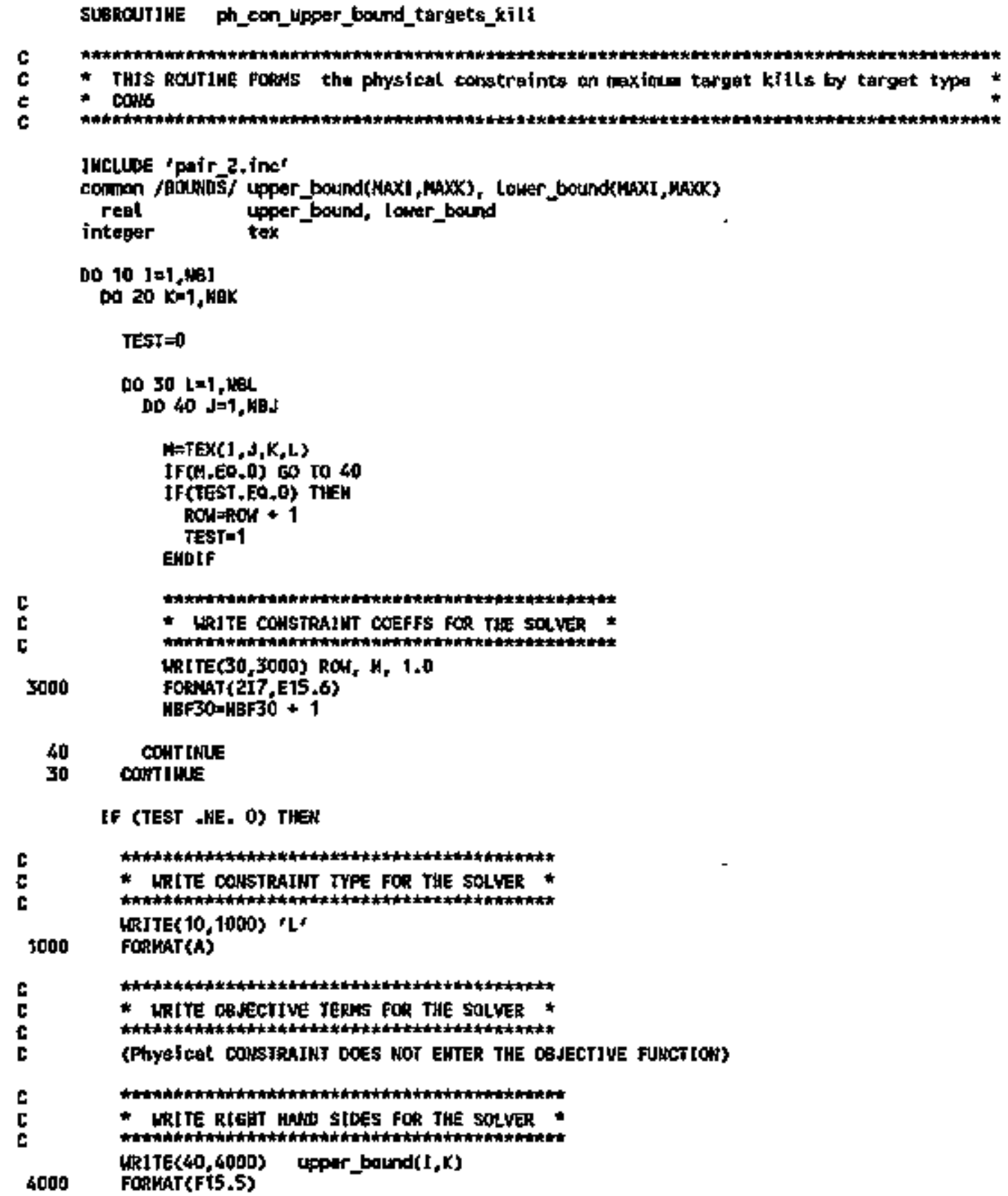

If (TEST .HE. O) THEN

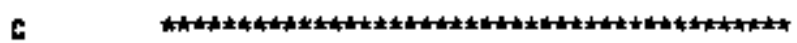

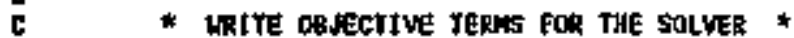

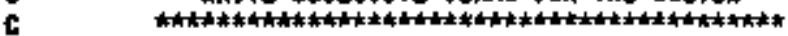

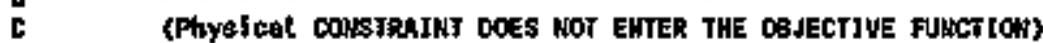

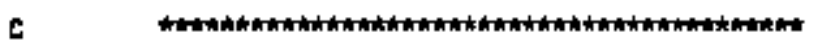

C * WRITE Rtgat Hatt stbes fok THE SOLVRR

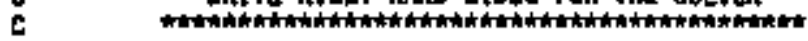

UR1TE(40,4000) upper_bolind(I,K)

4000 FORVAT(FT5.5)

ENDTF

29 COMTIRIS

10 CONT LAME

\section{RETURH}

EHD 


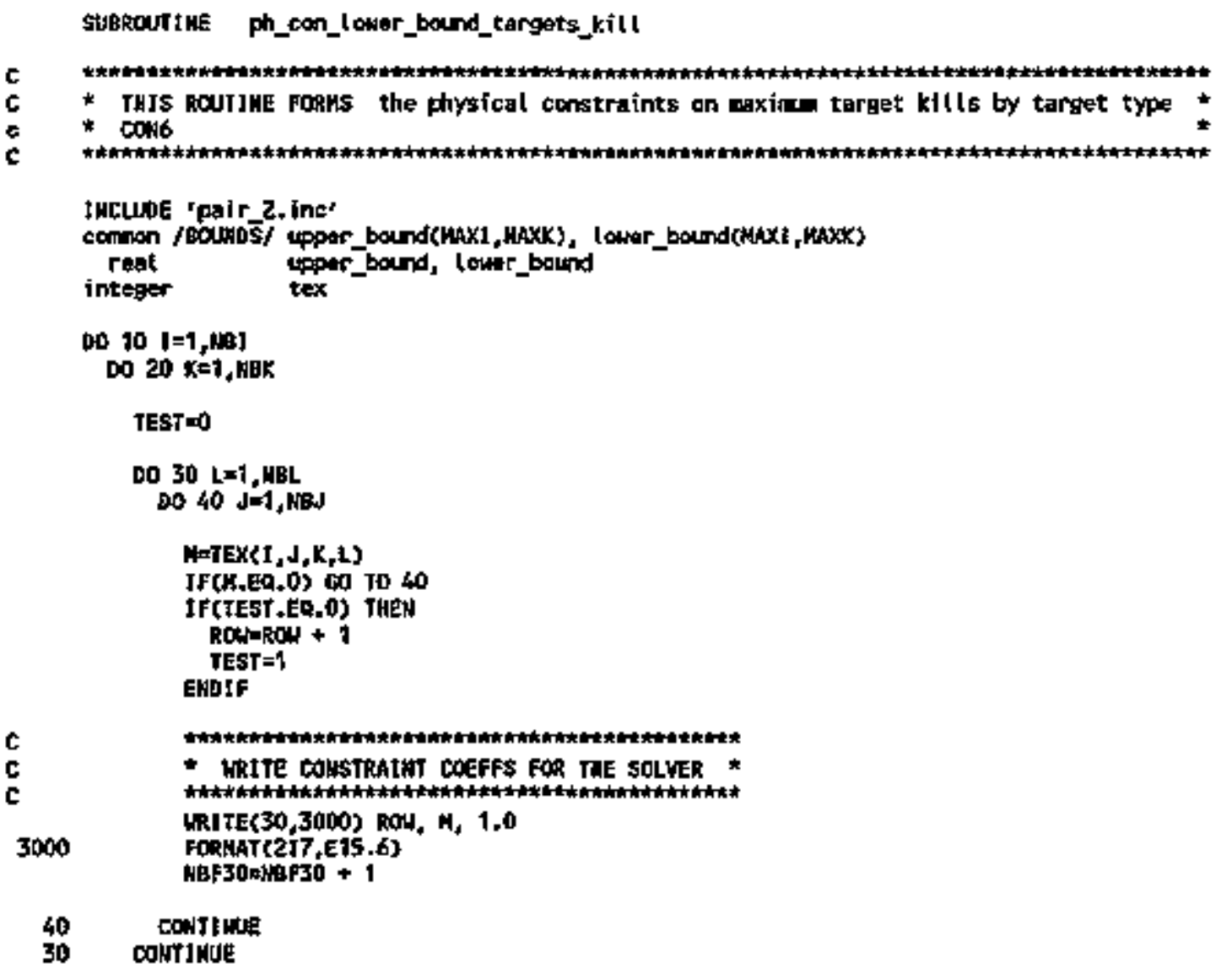

IF \{TEST .WE. O\} THEN

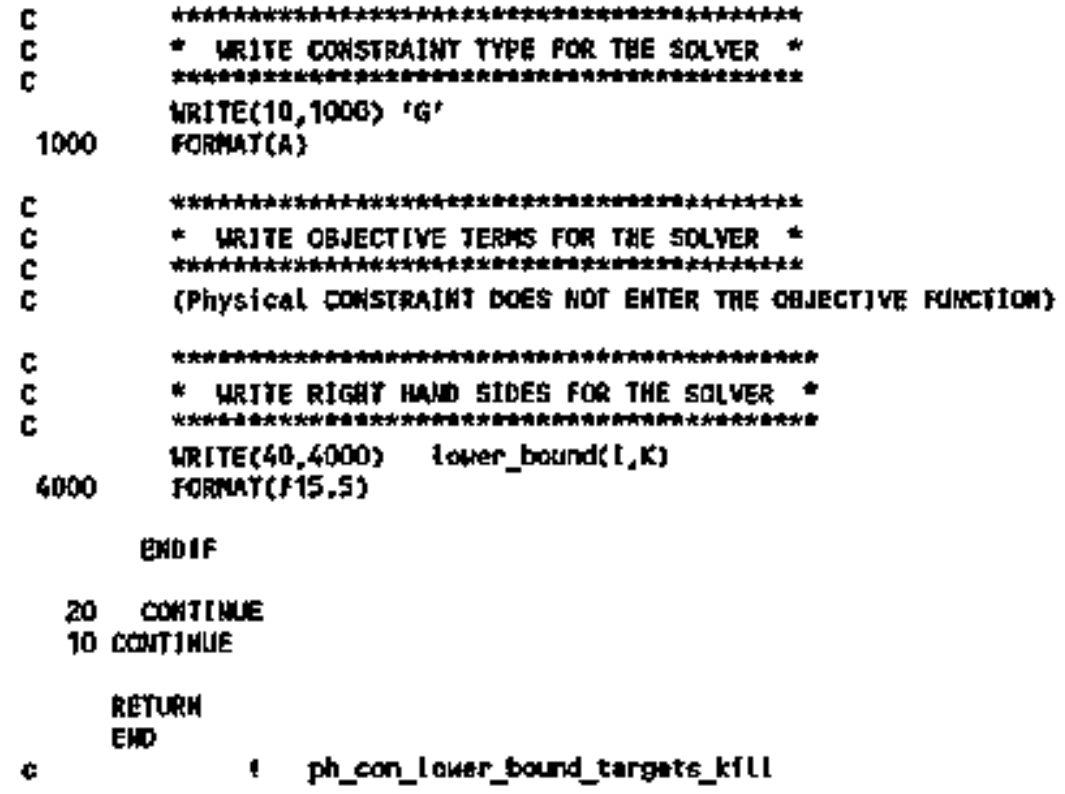

$$
\langle\mathrm{c}-43\rangle
$$




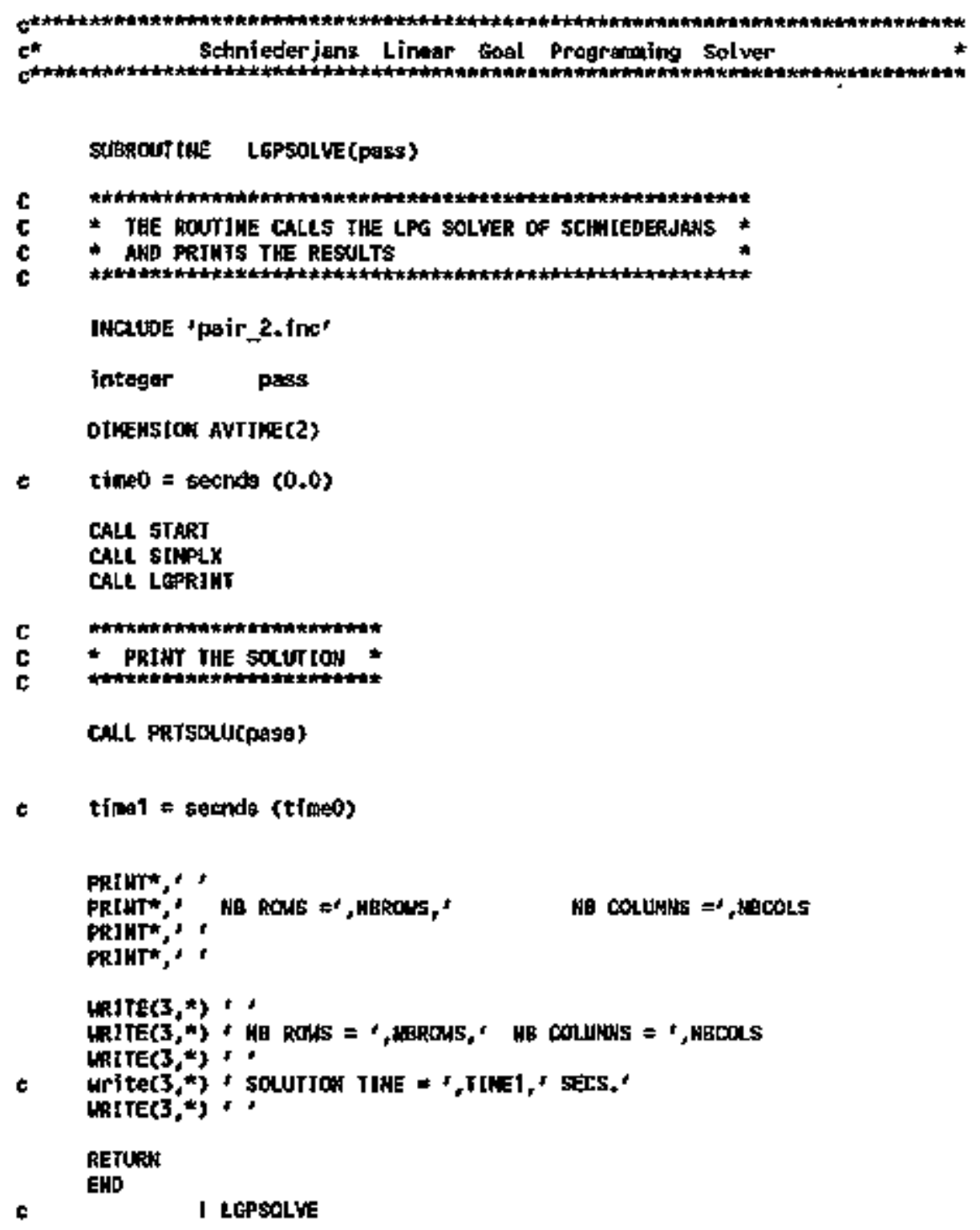

CAll PRTsuld(pase)

tíma1 = secunde $(\operatorname{time} \theta)$

PRT UTT*, *

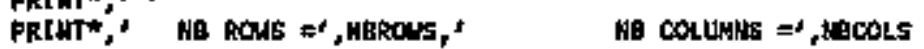

PRIHT*,'

PRJHTE, :

Hate(3,*) t

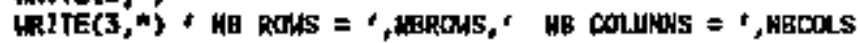

WITE $(3, *)$.

c

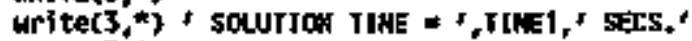

WRITE(3,*)*

RETUR木

EHD

I LGPSOLVE

$\langle c-44\rangle$ 

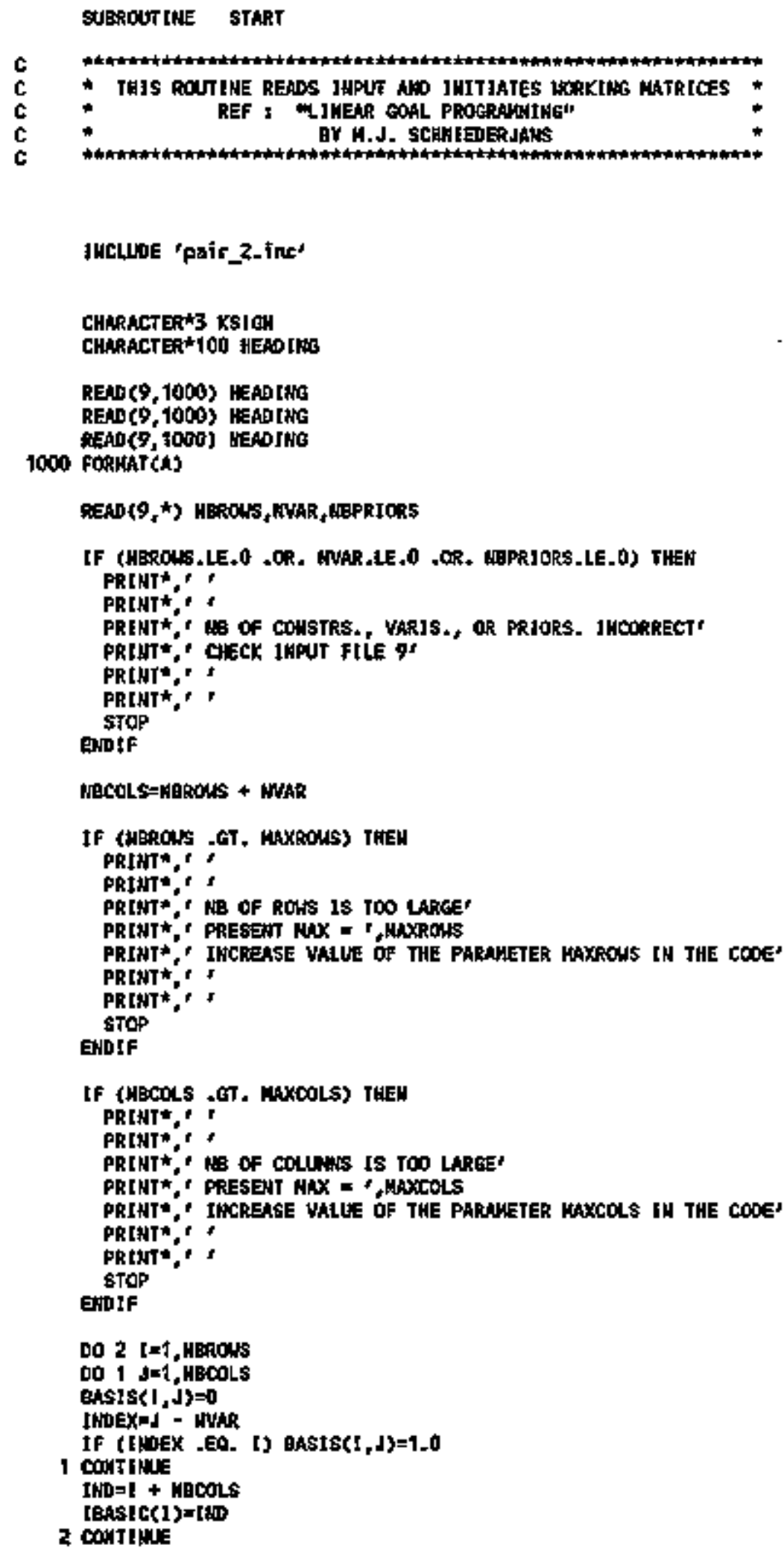

to 3 Jef, HBcols 


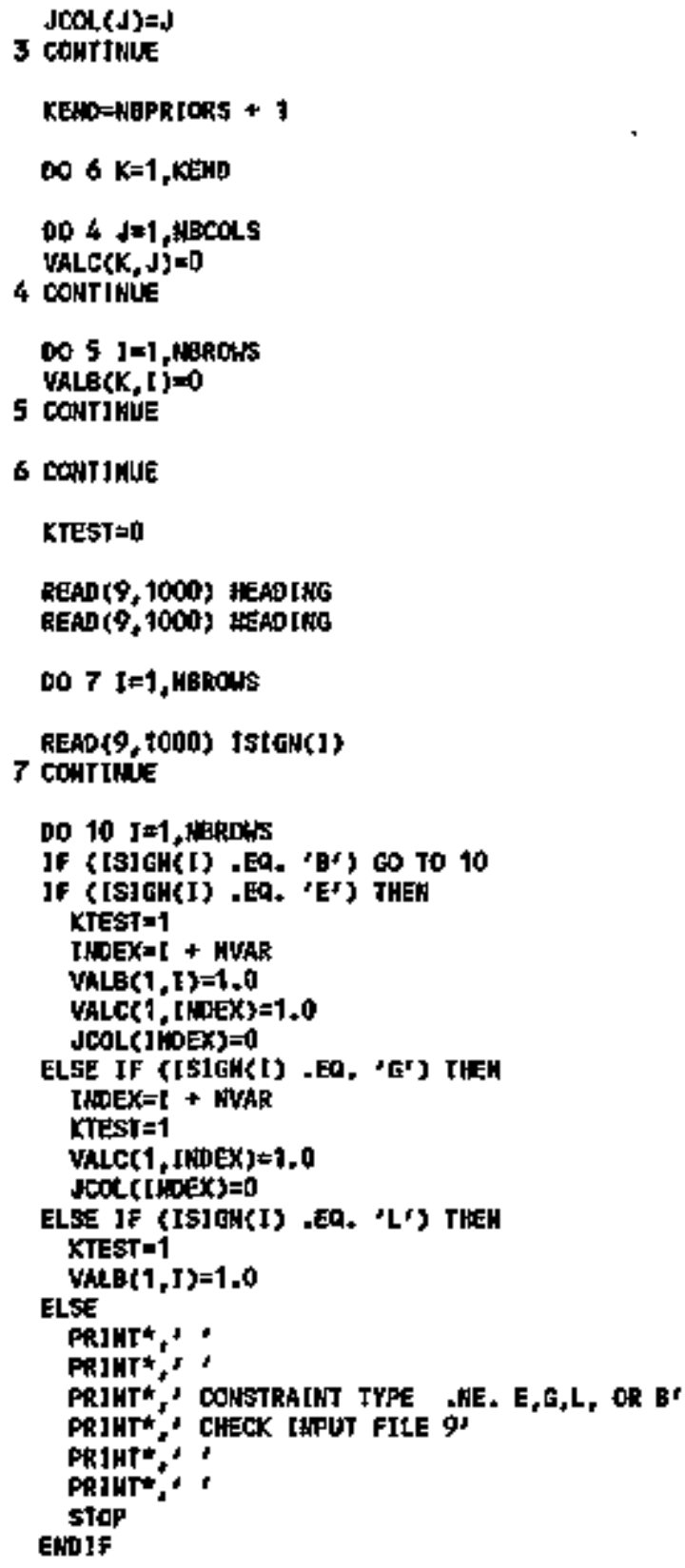

10 continue

IF (KTEST .EQ. 1) HBPRLORSAMPRIORS + I

READ(9, 1000) HEAOTKG

READ $(9,9000)$ HEADTHG

11 SEAD $(9,2000) \mathrm{KSIGH,I,K,HGT}$ 2000 FORWAT $\left(\mathrm{A}_{*} 2 \mathrm{Z} 7, \mathrm{~F}+0.2\right)$

IF (KSIEH , HE. 'ENOS) THEN

If (KTes; .EQ. 1) $K=K+1$

if (KSIEU . EO. 'oOS') THEN VALBCK, I) =ULT

ELSE IF (XSICH .EQ. 'NEG') THEM IIODEX $=1+$ WVAR 


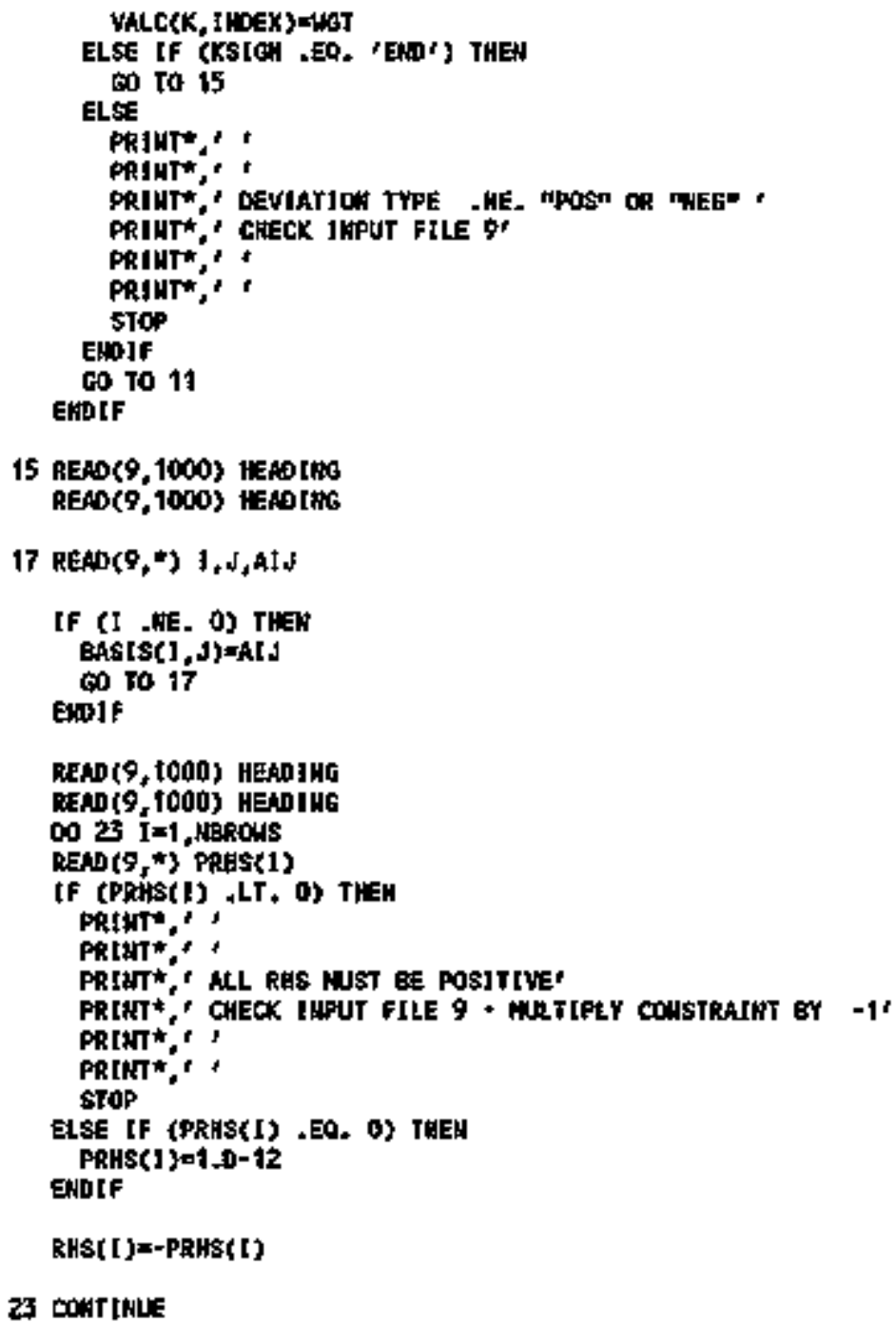

15 REAOC9,1000) HEAOLRO READ $(9,1000)$ HEAOING

17 READ(9,*) 1,5,AI

If (I .HE. O) THEH BAS[S(], J)=A[ 601717

DO $31 \mathrm{~J}=1$, sigcols

If (JoOd (J) ,EO. O) THEN DO 30 t=1, HBROLS GASIS $(t, d)=0,0$

30 CONTHUL entoif

31 contr tente

RETUbR

ENo

c

I START 
SUBROUTINE SIHPLX

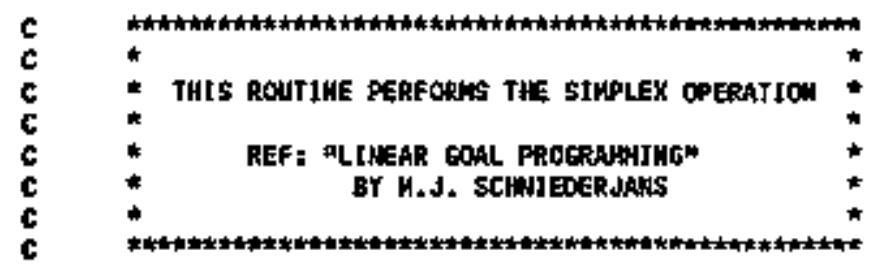

JHCLDE 'pair_z.inc'

DIHENSLON JFAIL (MNXROLS), APICK (MAXCOOL 5 )

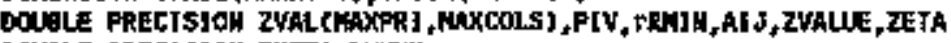

OOUELE PRECISIOH THETh, OLASY

tTeR500=0

KEFIDAMIBPR LORS + ]

$0016 \mathrm{~J}=1, \mathrm{NBCO} L$

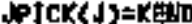

I6 COHT LWVE

to $18 \mathrm{~J}=1, \mathrm{macols}$

Do $17 k=1$, Mapricas

If (VALC(K,d) .GT. 1.0-10) THEN JPICK(J)-X

$$
\text { ENDIF }
$$

17 cowitture

t8 Contrine

ITER $=0$

1 KEYROH=O

KEYCOL=O

MWACH=0

Do 2 IFI, HBRONS

JFAJ.<I $)=1$

2 CONT'IUUE

c

IDENTIFY THE HIGIEST UNACHIEVED PRIORITY

DO $4 K=\}_{\text {, MBFRtaRS }}$

DO 3 I=5, HERONS

1F (VALB(X,1) , GT, 1,D-10) THER

KuAACH=K

so to 11

erbtf

3 contulne

4 contrine

C JDENTIFY THE WOST HEGATIVE RHS

11 reath $=+1,0-10$

Do 12 [ $=t$, MBROH

IF (RHS(E) . BT. rRath) to To 12

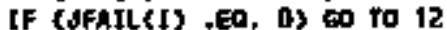

KEYROW=]

minilu=kthe 1 )

12 CONTINJE 
EWotF

15 (KLHACH, EQ, O) PRINT*, ;

PRIAT:" ALL COALS ACHIEVED'

PRIMT:, "

EHOJF

\section{KF [Noknuaca}

C THE ZJ AATR1X IS DEVELOPED

\section{KMKUNACH, HBPRTORS}

to 32 jef, Macols

ZWh $(K, J)=0.0$

If (JCOL(J), EQ. O) $\mathrm{EO}$ TO 32

IF (JPICK(J) -LT. KFIN) GO TO 32

Do 31 [ $\$$, HBRous

IF (VALB $(K,[)$, ,LE. 1.D-1D) GO TO 31

IF (DABS(BAS[S(1,J)) .LE. 1.0-10) 00 TO 31

CCCC IF (ABS(EASIS(I,J)\} -LE. 1.D-10) CO TO 31

zW/L $(K, J)=Z V A L(K, d)+$ VALG $(K, t) *$ gusts $(i, d)$

37 COST ITUE

$\operatorname{ZVA}(K, J)=Z \operatorname{VAL}(K, J)+\operatorname{VALC}(K, J)$

32 cont inde

33 Cont IHUE

\section{ZNALEF $=-9.0-8$}

a0 $36 \mathrm{~K}=\mathrm{KLHACH}$, FBPRIORS

bo $35 \mathrm{~J}=1$, HBpois

tF (JCOLL(J) EE, O) Go to 35

If (JP[CK(J) -LT. KfIN) GO TO 35

If (ZVAL(K, J) , CE, ZVALUE) GO TO 35

If (K .LE. KuHACH) 60 TO 39

Hex-1

$0036 \mathrm{~L}=1, \mathrm{M}$

If (2VAL $\langle L, J), \mathrm{Ce}, 1,0-8)$ 的 To 35

\section{4 conit towe}

39 ZVALUE $Z 2$ WAL $\langle K, d\rangle$

xeycol $=$ J

35 DOitime

tF (KEYCOC.G. B) 60 To 37

$K H J M=K F T H+1$

36 COAT LMUE

IF CKEYCOL Ea. O) 


\section{Do $3 B: t=1$, HaRG}

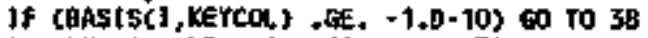

If (RHS(t) . LE. $-1,0-10)$ 60 T0 38

If (RHS(I), LE. 1.0 +10) RHS(I)=1.0-10

ZEIA-RHS(I)/BASIS( I, KETCOL)

IF (2ETA .CE. THETA) BO TO 38

THETh $=2 E$ IA

KEYROLII

39 contJhIE

Jf (KEYROW , Le. G)

goto 99911

44 PIVEAASISCKEYROW, KEYCOL)

DO 43 Int, nBinows

If (I .EQ. MEYROW GO TO 43

If (OABS(BASIS(I, KEYCOL)) .LE, 1.0-10) Go to 43

IF (OABS(RHS(KEYEOW) ) LE. 1.D-10) GO TO 41

cect tf (Aast(aASTS(1, KEYCOA, ) , tE, 1,D-10) Go To 43

CCCE If (ABS(RHS(KFYROU)) -LE. 1.D-10) to To 41

RHS(I)=RHS(I) - (RAS(KEYROW)/PIV) * BASIS(I,KEYCOL)

41 vo $42 \mathrm{~J}=1$, thecols

IF (S .EA. KeVtOOL) WO TO 42

IF (DABS(BASTS(KEVRON, d) ) .LE. 1.0-10) 60 TO 42

CCCC IF (ABS(BA515(KEYROH,d) .LE. 1.D-1(1) 60 To A2

BAS $[S(I, J)=B A S[S(I, d)$ - (BAS1S(I,KEYCOL)/PIY)*BASI $5(X E Y R O N, J)$

A2 CONTIRUE

BASTS(1, CEYCOL $)=\theta A 5 I S(1$, KEYCOL,$/ P I V$

43 contrmuE

IF (OABStRHS(KEYROH)) , G7. 1.D-10) THEN

CECC 1F (ABS(RHS(KEYROW) .6T. 1.0-10) THEN

RHS(KEYROW) $=-$ RHSS(WEYROW)/PJV

ERtif

44 bo $45 \mathrm{~J}=1$, HBCOLS

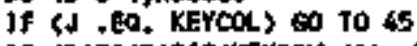

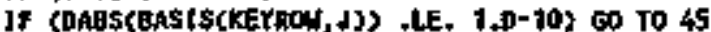

CCOC If (ABS (BASIS(KEYROW, J)) .LE. 1_0-10) to TO 45

BASIS(KEYROW, J)=-BhSIS (KE YROW, 4 )/PIV

45 CONTIHUE

AAS1 1 (KEYROW,KEYCOL $)=f . / P[\mathrm{~V}$

IUDEX-ACOL (KEYCOL)

JCOL(KEYCOL.)=18ASICCKEYROW)

IBASIC(KEVROW) $=I$ UDEX

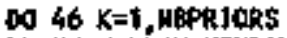

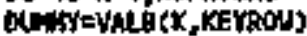

IF (0UNIY, ,CE. 1.0+8) JPICK(KEYCOL) $=K$

VALB(K,KEYROU) $=$ VALC $(K$, KEYCOL $)$

VALC(K, KEYCOL) $=0 \mathrm{Wary}$

46 DOHTINUE

tF (KTEST, ,NE. 1) to TO 51

IF (VALCC1,KEYCOL) .EA, 0.0) GO TO 51

JDOL (KEYCOL $)=0$

Do 50 [-1, ubsous

BASIS I KEYCOL) $=0.0$

50 CONT IMUE

51 ITER=ITER + I

PRIVTH. + 


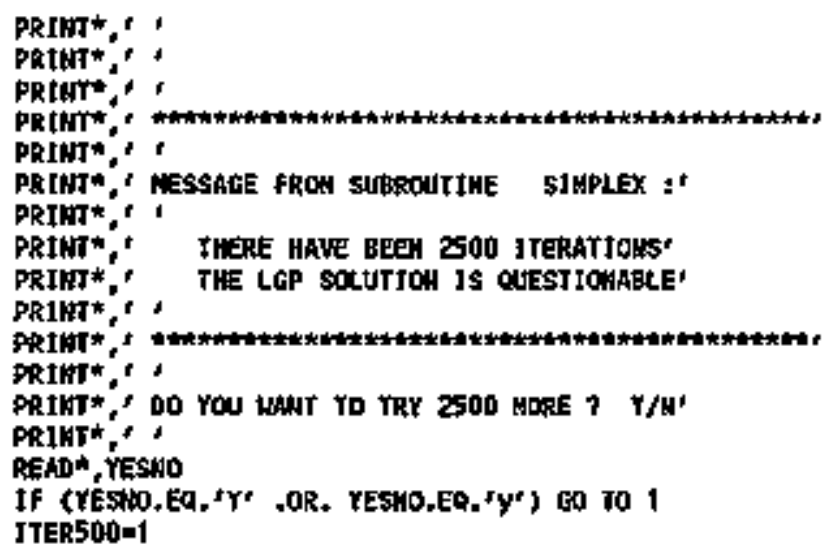

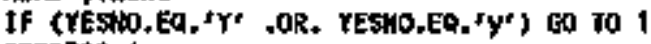
JTER500-1

endF

to To 1

999 print*. print:, rwuber of JMaP Iteretions $=r$, Iter return Eno

I SINPIX 


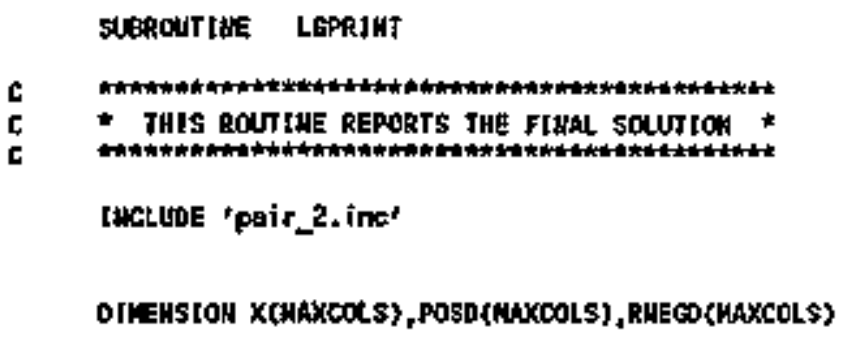

C. THIS SECTIOW REPORT\$ VALUES OF ALL HOOEL VARJABLES

REDIID 15

Do 1 Jut, GVAR

$x(J)=0.0$

1 conttale

Do 2 I=1, $\mathrm{ngkROHS}$

$P O S D(1)=0.0$

RHEED(I) $=0.9$

2 COHTINUE

DO 12 In1, MaRows

JWAKEIBASIE(I)

If (1WAR , GT. HBCOLS) THEH

IRE=IVAA - MBCOLS

POSD $(t)$ D $)=R H s(t)$

ELSE IF (INAR -GT. MUAR) THEH

TWDIVIAR - HWAR

RHESCD ( IAD) $=$ RHS $\{I)$

ELSE

X(IVAR) MRHS(1)

Elotf

12 contrillie

WRITE(15, 1000) ITER

C NRITE $(3,1000)$ ITER

1000 fQRAHTL[G.' [TERATIOHS'

WRITE (15, j001)

1001 FORHAT(' DECISIOH VAREAGUES')

HRITE 15,1002$)$

1002 FGRMAT ( $F$ "VARLABLE VAUE')

DO 15 I:1,HVAR

MRITE(15, 1003) $\downarrow, X(j)$

1003 PORMATC1X,15, 1PE 15.5 )

15 COATIMUE

WITE(15, 1004)

1004 FORMAT $/ / / f^{\prime}$ ANALYSIS OF DEVIATJONS FRON CORLS')

URJTE( 15, 1005)

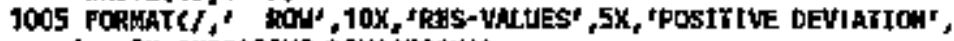

$12 x_{\text {, rWEGAT [Ve DEVtATION") }}$

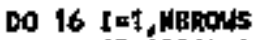

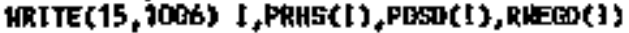

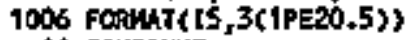

IO CONTJHUE

C THIS SECTION kedPORTS ON PRICRITY LEVELS

URITE(15, 1013)

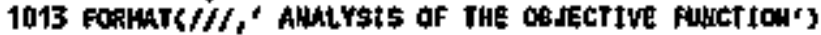

HRITE(15, 1014)

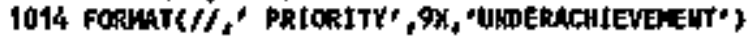

$<\mathrm{C}-52>$ 


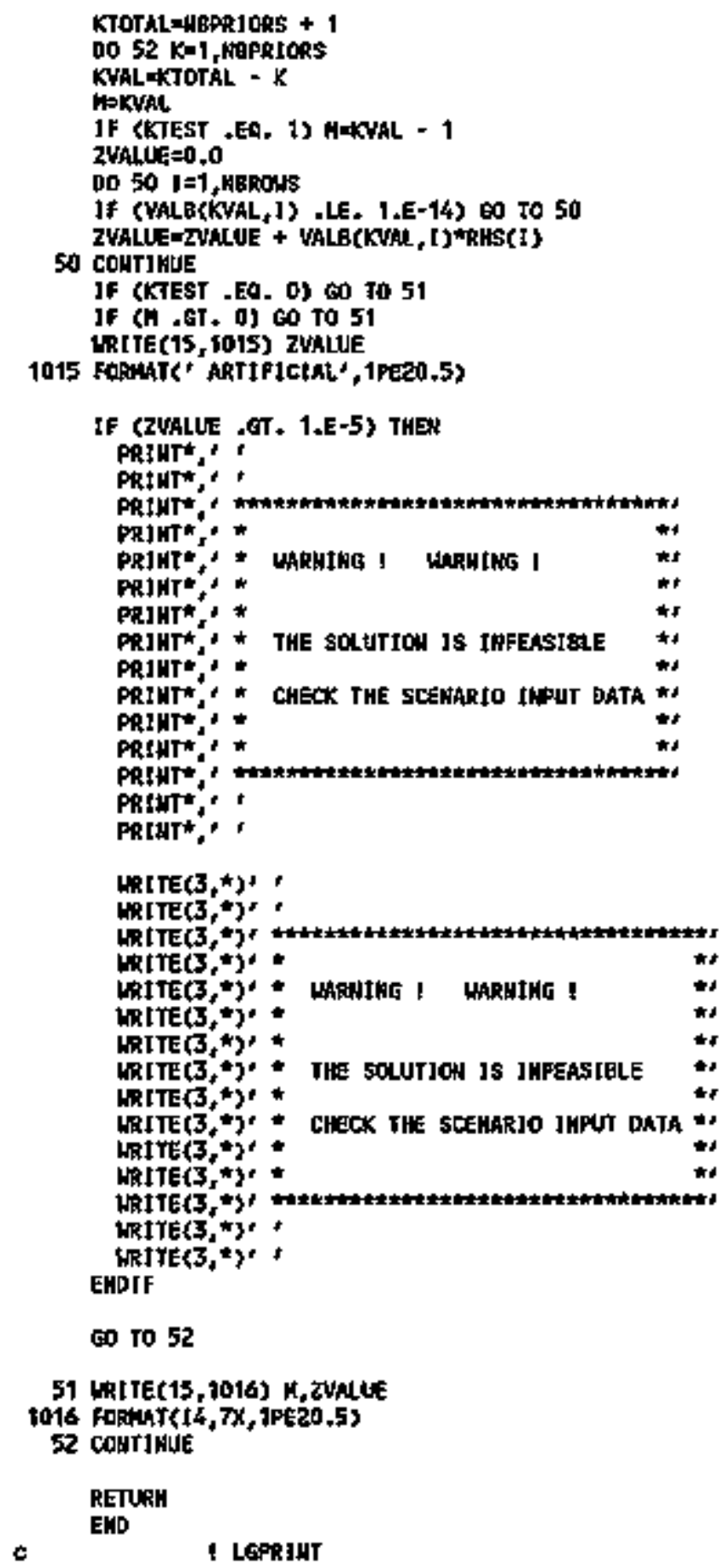

L LORIHT 
subroutulie PRTsoutu(pass)

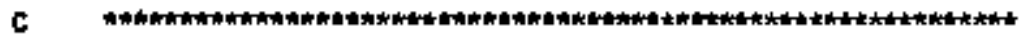

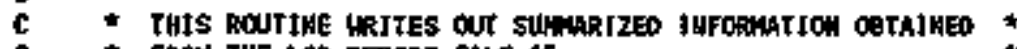

c FRCA THE teP REPQRT FILE 15

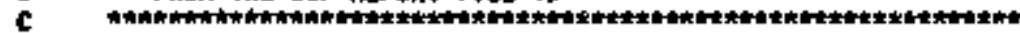

IHCUNE 'palr_z.ingt

integar puss

cheracter ${ }^{*} 1$ ch_poss1

charectork2 ch pases

character*14 fittrage

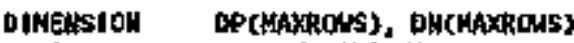

reel expend(HAXI, HAXJ)

real KG(HAXK), MG(NaX]), TIK(MaXX, MAXX)

real mnition_req_eost(HAXJ), platforp_att_cost(HAX])

reel tot plat_att_cost

real Menî́s

CHARACTER木17 SP17

CHARACTERA21 SP21

DATA SP17/"

DATA SPZ\%"

,

1

REMIRD 15

TTEST=0

$y=0$

C * initliat Ize THE MHITIOY SOH ARRAY *

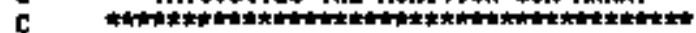

25 DO $27+491, \mathrm{HBd}$

RHDSU'AC $J\rangle=0.0$

recsuan(J) $=0$

Do 26 [-1, NB]

expend $([, d)=0$

26 continue

requit ret $\hbar, I>00$

27 LOHTJMUE

C t injtislize THE TARGET KLLL AND COST/KILL ARRAYS *

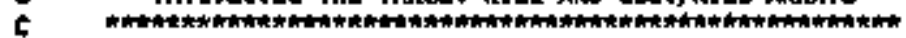

to $30 k=1$, Mex

TOTKLLL $(K)=0.0$

Jor $\cos T(K)=0.0$

do $I=1$, NBT

$T[K(], K)=0.0$

do $j=1,28 \mathrm{~J}$

$t[d K(t, d, k)=0.0$

enddo

ondto

DO $2 \mathrm{~dB}=1 \mathrm{maJ}$

SLtHKJEL $(J, K)=0.0$

28 Coftrinde

Do 29 int, MuxL

29 cosilute

TOTLXILL $(K, L)=0$

30 contintle

$$
<\mathrm{C}-54>
$$




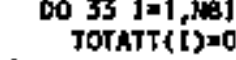

33 CONTINUE

READC 75, 1100) LINE

REAO<15,1100) LINE

READ(15,1100) LIHE

READ ( 15,1100$)$ LIKE

35 REAO (15, 1100) LIME

JF (LIME(1:10) .EO.

?

READCL[NE, 1900) HA, Xt

t900 Fonintit6,E15.5)

If (X1 .tT. 1,E-4) to To 35

catt. Xer (on, $t, d, x, b)$

xkitled $=x t$

Tluti, $i, j, k)=x i$ illed

$1)$ here, dacision variabies aro targets killed

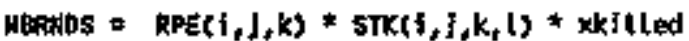

expend( $i, j)=$ expend $(i, j)+$ MBRkDS

requice( $(, J)=$ R_E(j) * expeno $(I, j)$

1f sum up expandl tures of mutitian $\checkmark$ by platform 1

1 sum up requirenents of munttion $J$ by platform d

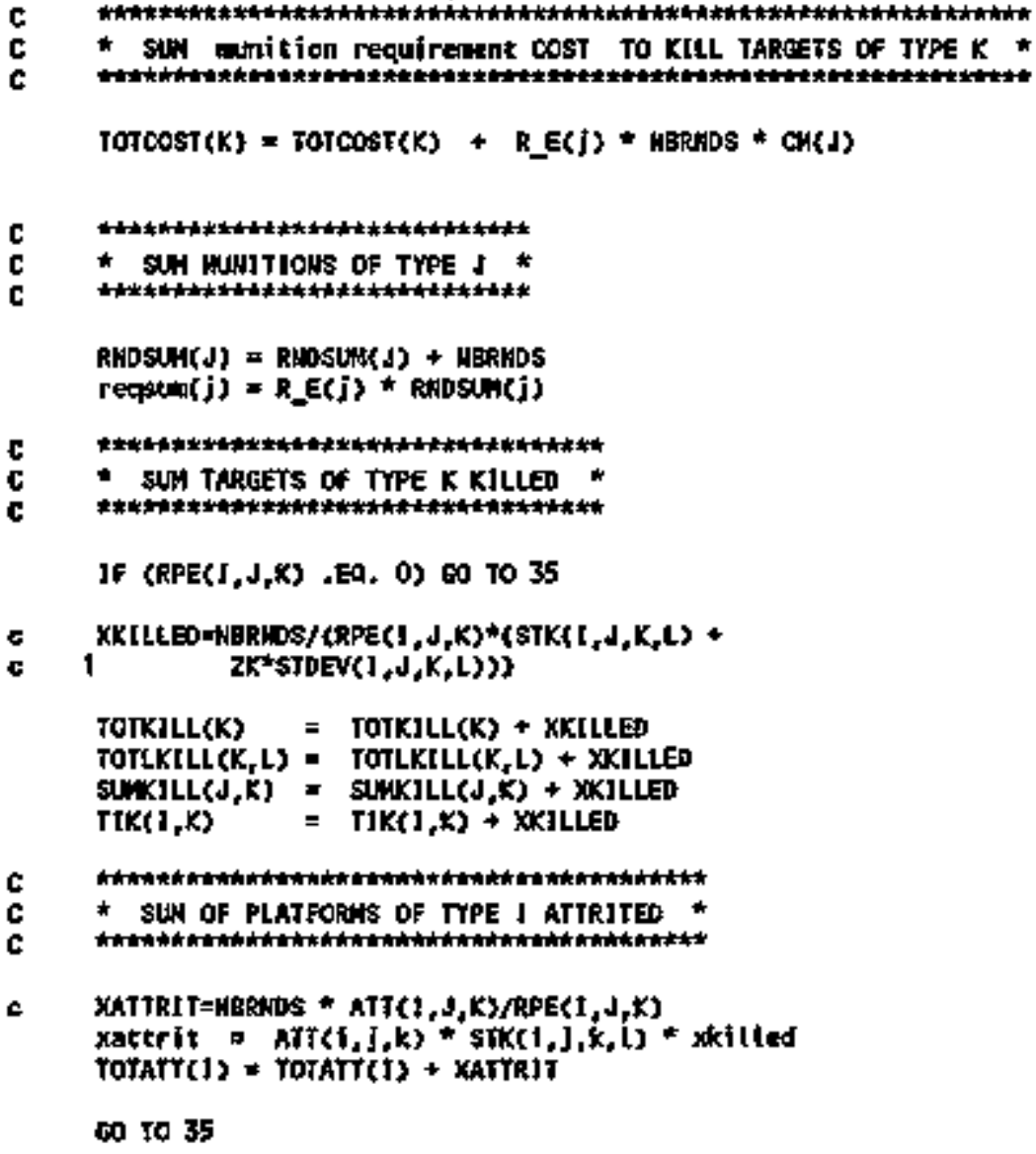

II here, xkitled $=x_{1}$, ene above

II sen up type K targats kitled by moition J I1

11

100 DEAD(15, 1100, EVO=1053 LIME

1100 FORHAT(A)

$<\mathrm{C}-5 \mathrm{~S}\rangle$ 
If (Llne(1:5) . WE. ' tow' GO TO 100

DO 103 ]:1,karons

$R E A D(15, \rightarrow 2, V / R, O P(1), D N(t)$

c. urite(3,*) R,VAL,OP(l), ONA(E)

103 cont 1 ulé

1! row, RHS, poos_tev, neg_der

195 contions

4

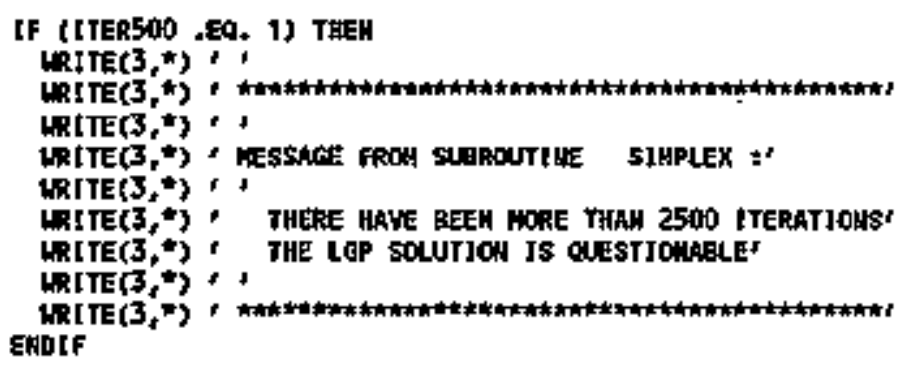

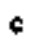

-- Urite wis output Suntary Information

writus 3,700$)$

c

irite(3,701)

mrite(8,730)

prepsi(1), costgosl, tot_mn_req_cost , tot_mn_req_cost+tot_plat_oztt_cost

I1 platform attrition cost not in cost-goel

11 srite cost solution for each pass
1! in allions

1) in biltions

$L=1$

do $K=1, N B K$

urite(3,703) targ(K), ftbk(K,L), totkill(K)/ta(K),

enddo

i. GG $^{*}$ totcost $(K) /$ totkihl(K) 


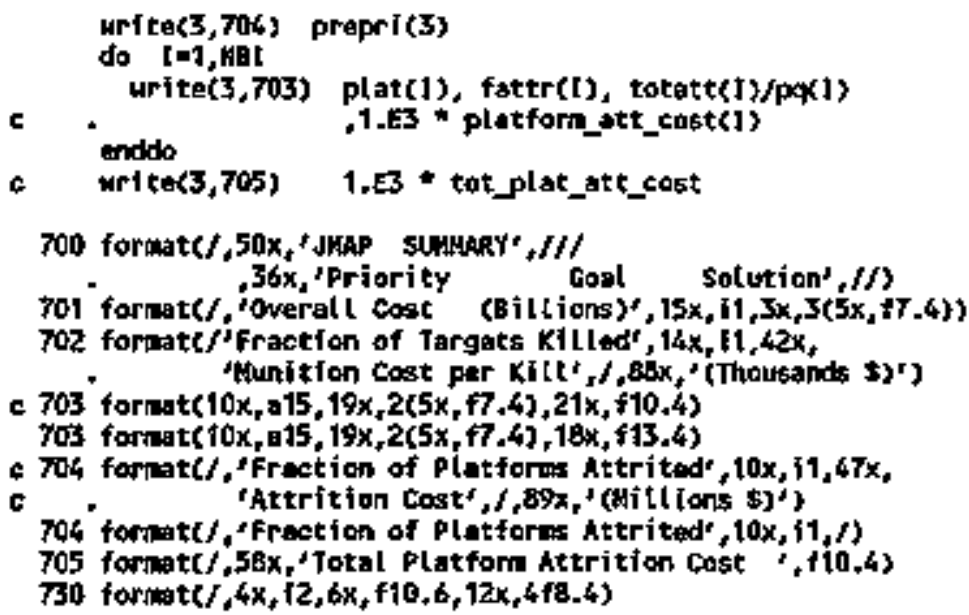

710 format $\left(/ / / /, 20 x_{4}\right.$ 'Hunition ExpendI tures, RequS rontants,"

+ Lett-în-Stock and Cost' ${ }^{+} / 1$.

- 40x, 'Exposnditures Requirenents Left-1n-stock' 11x, 'cost', - $89 x_{2}$ '<Bitlions 5$)^{\prime}$ )

711 formet< $15,20 x, 3(9 x, 77,1), 12 x, 77,4)$

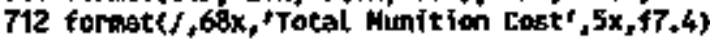

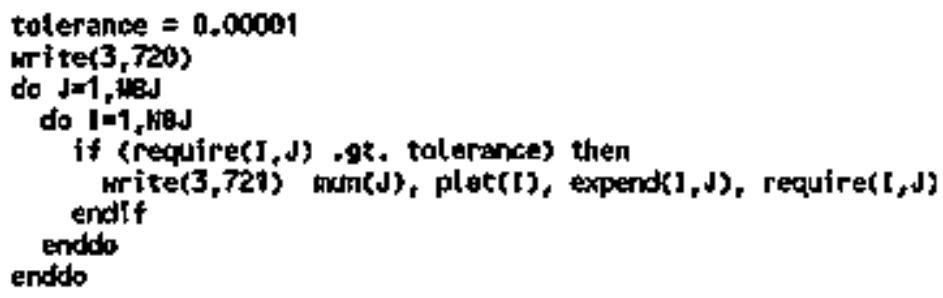

720 tormst $/ / /, 15 x$, Jumition Expenditures and Requi renents by' . 'Plotform',$/ /, 40 x_{\text {f }}$ Expendi tures Requirenents', $\left./\right)$ 721 formot $\left(a 15,5 x_{,}, 15,2(8 x, f 7,1)\right\rangle$

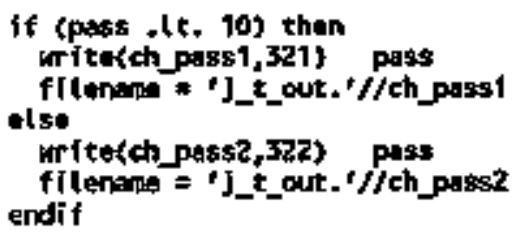


open(4, fitefit lenane)

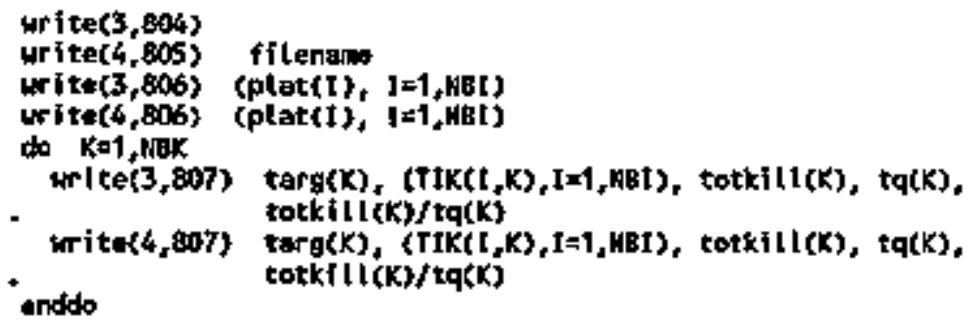

WRITE $(3,10003$ ITER

TOOO FOBANT(//,16,' [TERAT JON5')

c -.- Write JuAP+ Targat kitls by PAatform and unition

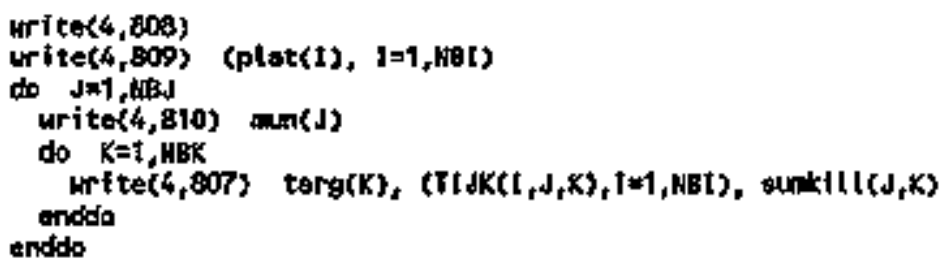

I PRTSOLU

INTEGER FUMCTJOW TEX(L, J,K,L)

LNCLLOE 'PAir_z. Ints'

IF (eCLOE $\left(I, d^{\prime} K\right), E O$, D) THEF TEX $=0$

ELSE

$T E X=\langle L-1\rangle * a t J K+M \infty O L(1, d, K)$

$$
\text { Eardf }
$$

DETURA

END 


\section{SLBROUT I ME XET $(n, L, J, K, L)$}

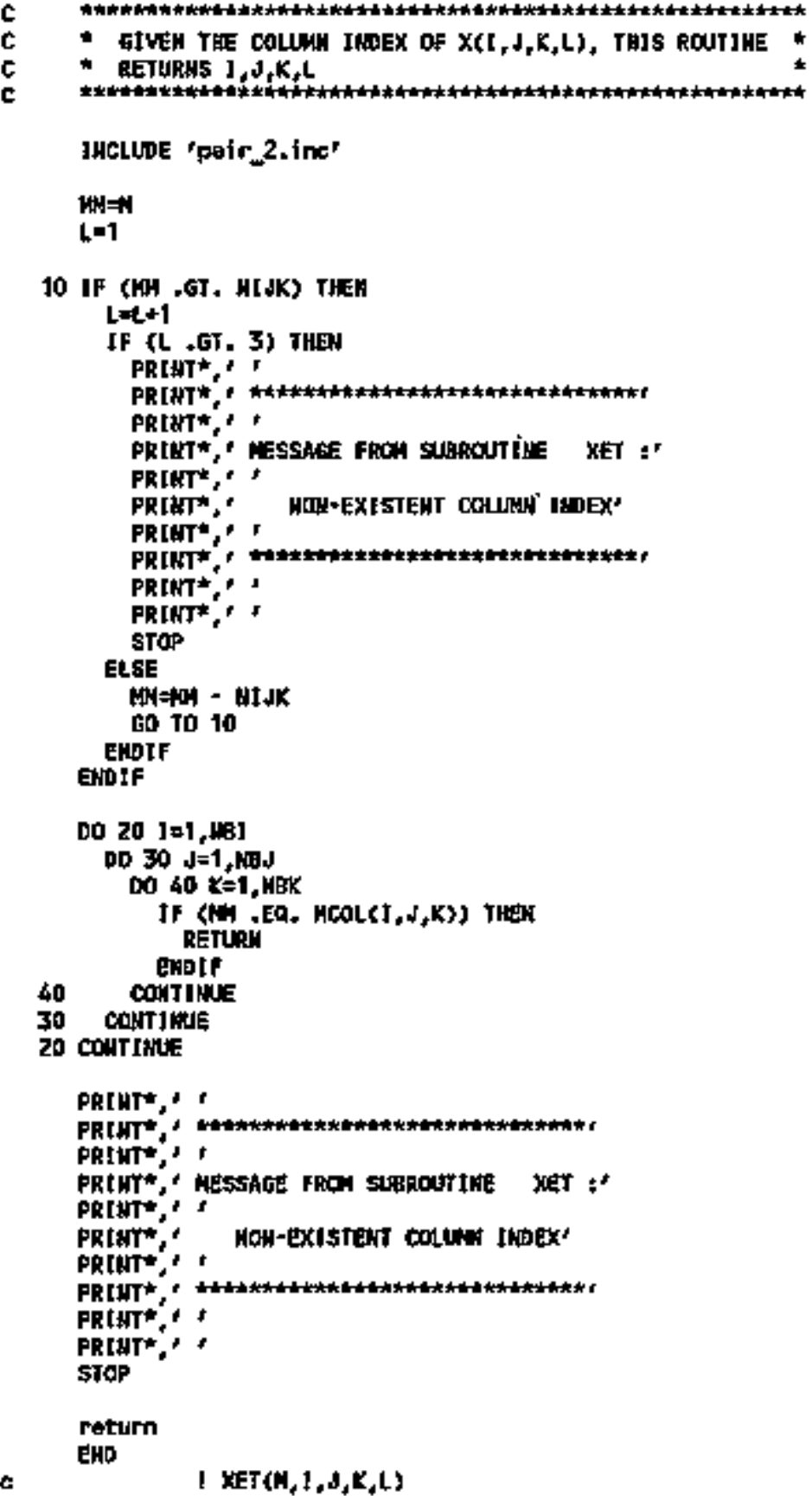


abroutine close_fites

close(g)

close (10)

close(20)

close(30)

etoses 40)

close(15)

close(3)

return

end I ctosa_flles

$\langle c-60\rangle$ 

roel parckill

parekill in evalusting the frection of targets kitled at different lovels of confidence, perikill are * the chosen confidences (actualiy in tractiond form, not $z$ )

I The numer of confidences chosen

noere

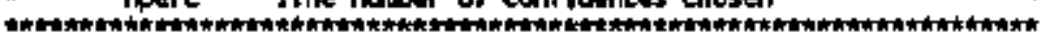

$\langle c-62\rangle$ 


\section{Gubroutine get_inputs(iflag,ffite_unit,}

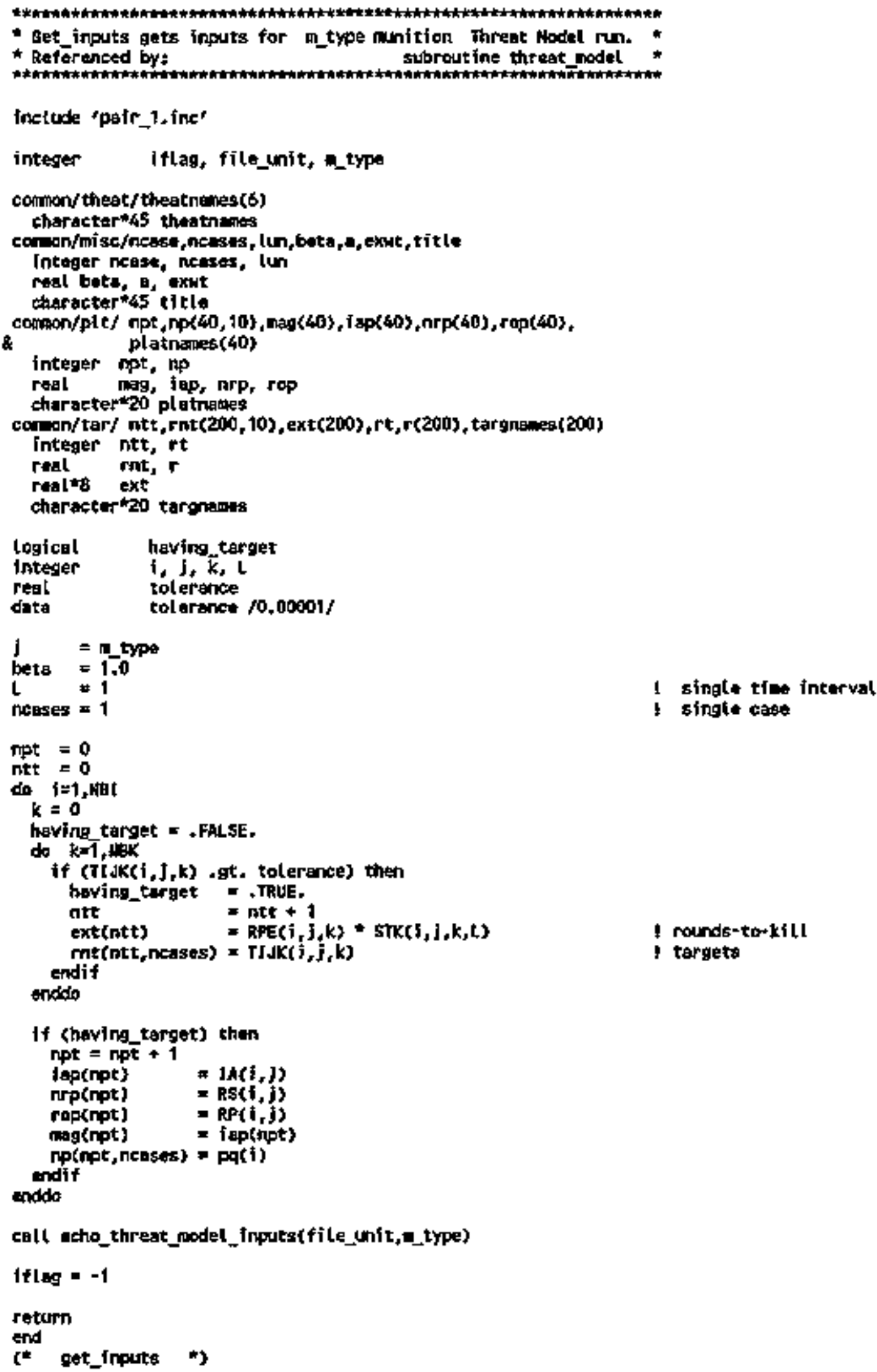

1 singt time interval

s singte case 


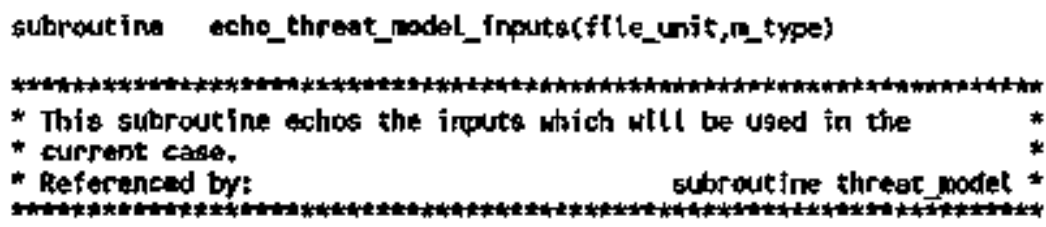

inctude 'pair_1.ine'

tinteger fite_untt, n_type

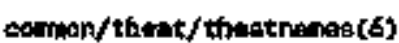

character*45 theatnades

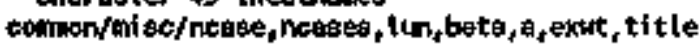

integar ncase, ncases, inn

roal bets, a, exit

characterk4s title

common/pt $5 / \mathrm{npt}, \mathrm{np}(40,10), \mathrm{neg}(40), \mathrm{i} 4 \mathrm{p}(40), \mathrm{nrp}(40), \mathrm{rop}(40)$,

.

integer npt, np

real mag, iap, nrp, rap

character 20 platnemes

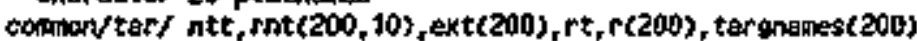

Integer ntt, rt

real rnt, r

realts ext

oherecter*20 targhanes

intager $\quad n$

nceses $=1$

Writectile_tnit, 100)

witedfile unit, 10t)

uritte(til._unit, 102)

mun(m_typu)

npt

uritedtile_unit, 193)

do $n=1, n t \vec{t}$

write(ffle_unt, to43 n, ext(n), rat(n,ncases)

encido

uritettile_unit, 105)

do $n=1, n p t$

writexfile_unft, 106) $n_{1}$ np(n,ncases)

endida

uritecifle_unit, 107)

do $n=1, n p \bar{t}$

uriteffite_unft, 104) $n$, Jeq(n), arp(n), $\operatorname{rap}(n)$

entido

return

100 formite $(, a)$

101 formate $3 x_{*}$, Munber of pletfora types $\left.{ }^{*}, 12\right)$

102 format $3 x$, Munber of platform/target type coninatlons :, 12 ,

103 format $\left(3 x_{4}\right.$ 'Rounds-to-X[1l and nubte of targats it'?

104 formet $(5 x,\{2,3 x, 3(3 x, 47,3)\}$

105 format $3 x$, shinger of platforis : 7

106 formot $\{5 x, 12,16 x, 17)$

107 format $\left\langle 3 x_{,} \cdot\right.$ inftial-loadout, cafill-\$Irt, and roordor-point :') end

(* eche_threat_wodel_zaputs $\Rightarrow$ 


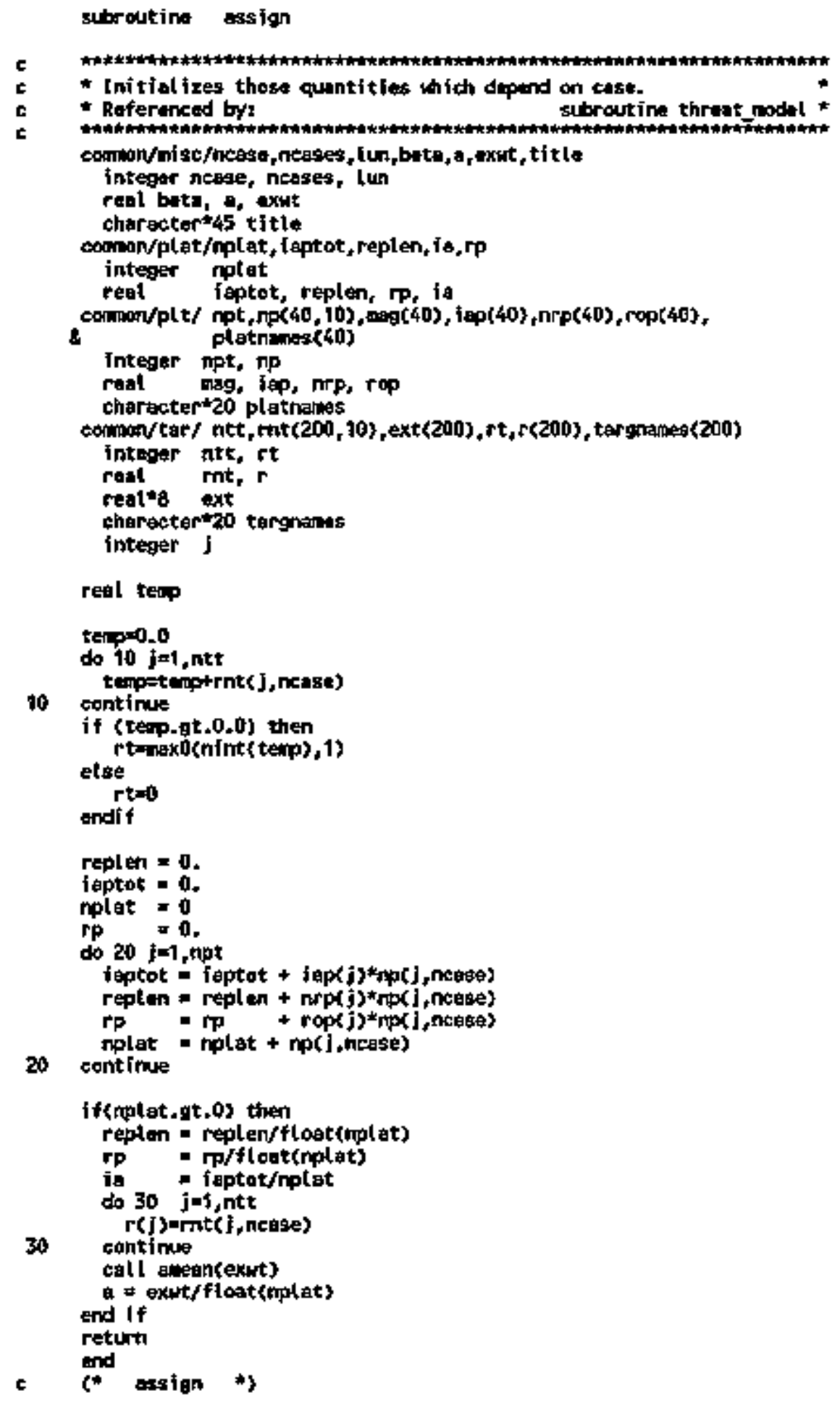


$<99-0\rangle$

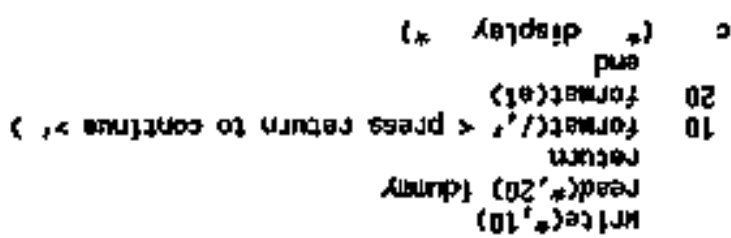

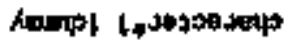

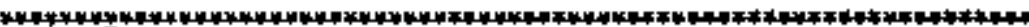

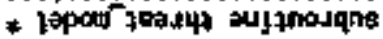
skq perraseley

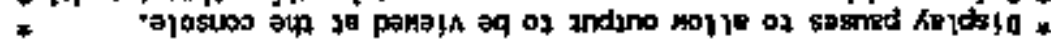

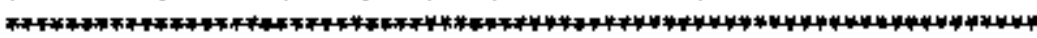

*4*⿻三丨 * Usisse autjouqhe If porususpay *

* *62aloba

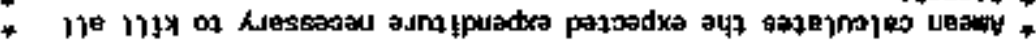

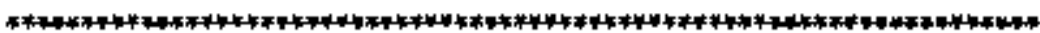


subrowtine extho

* This subroutine ecthog the inputs which will be used in the

- eurrent case.

- Raferenced ty

subroutine threat mol *

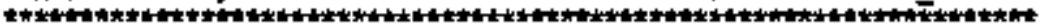

compon/theat/thentnanes(6)

chorecterk45 thesthancs.

confon/nisc/ncose, nteses, lun, beto, e, exut, title

integor ncase, ncastes, lun

real buta, $a$, exwt

cheracter*45 title

comon/plat/nplst, ieptot, repian, 1 a, rp

integir nplat

reat faptot, replon, rp, Ia

connon/plt/ npt, $n p(40,10), \operatorname{mag}(40), \operatorname{lap}(40), \pi n p(40), \operatorname{rop}(40)$,

8

integer npt, np

real mag, iap, nrp, rap

character 20 ol athanes

comon/tar/ ntt, ent(200,10\},ext(200),rt, r(200), targnames(200)

integer int, $t \mathrm{t}$

real cat,

rant*g oxt

charactarnzo tacganses

reat

ex

integer $j$

wr $\{\operatorname{tac}(4 \mathrm{Ln}, 5\}$

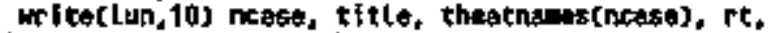

8 nplat, bets

if (nol at .00 .1 ) then

urite(tur,20\}

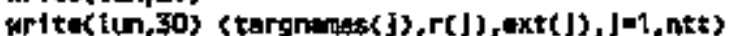

if (rt.go.1) then

ax a exwt/rt

write(lun, 40, ex, exht

writes $\left(u m_{x} 50\right)$

8

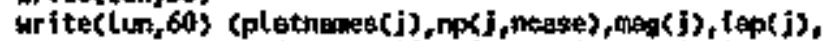

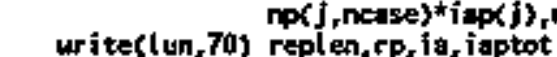

end if

and if

raturn

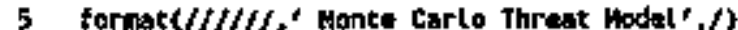

10 format' Case Humber' ', $12, / /$.

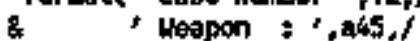

2 Theater: ',ats, $/ 1$

2 Number of Targets

$=r$, 14,1

2 Polya Pareneter = $\quad\{, 16,2\}$

20 format $/ / /^{t}$ target botes' $/$

2 ' Nano Nuber Expendlture/kild')

30 format $(1 x, a 20$, f9, $2,+13.3)$

40 formatc/" average Expenditure per $k 1 l l=*,+60_{2}, I$

8 $\quad$ Avarage Total Expanditures $=t, f B .2$ )

50 forthat $/ / f_{x}$ stooter Dete:

8* Initial initial'.d.

\&. Name Hunber o.

2. Magsz Laadout Jotlaed Refíz Rordpt's

60 format $(1 x, 020,17, f 11.2,+10,2,379,2)$

70 formet $(1+$ Avarege shootor Replanishanent size $=1, f 10.3,1$,

8 . Average shooter Reorder Polnt $=910.3 . \%$.

1 Averoge shooter inftial loadsut $\neq 1, f 10.3$, s

8 Total Shooter Initial Loodouts $=*+10.3\}$

end

c

echo t) 
losicat Function ons_yes(i)

Integer 1

characterit answer

ants yes = , true.

if (f.eq. 1) then

write $\left(*_{2}\right.$ 10\}

read(*,20) answar

if (answer.eq.' $H^{\prime}$.or. answar.eq.' $n^{\prime}$ ) ans_yes = .falte.

ets:

uritas*,30)

read $(*, 20)$ answer

If (answer ne.' $\gamma f^{\prime}$, and, answar, ne.' $y^{\prime}$ ) ans_yes = ,false. endlt

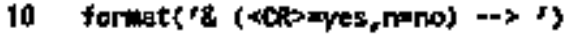

20 forant(ai)

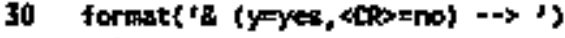
retern

$c$

erd

(* ons_yes *) 



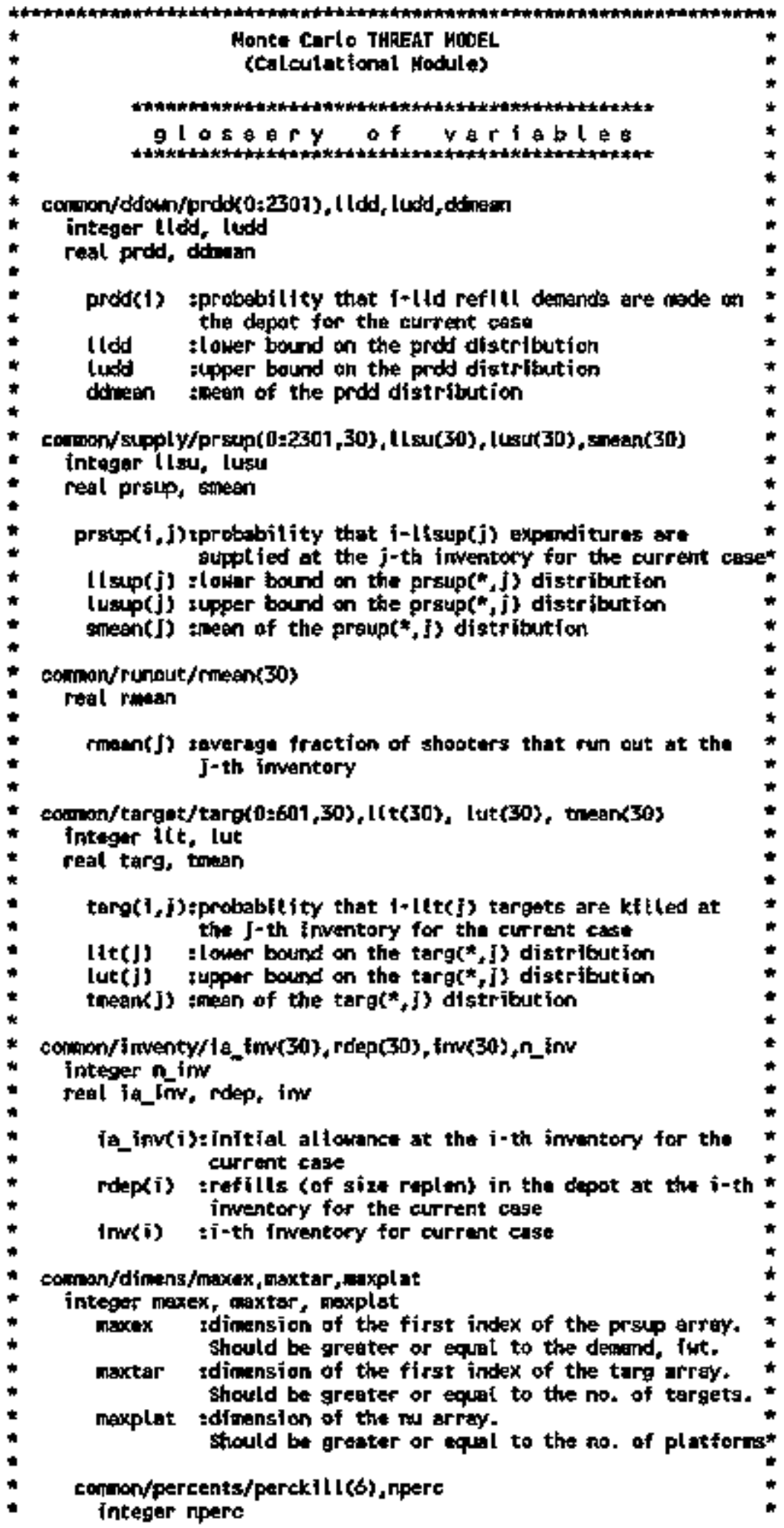




\section{raal parckill}

parckill In araluating the fractlon of targets killed at different levels of confidence, perckill are * the chogen coufidorites (ectully is frectional form, not $x$ )

nperc :The nuber of canfidences chosen

*

BLOCK OATA Initfal

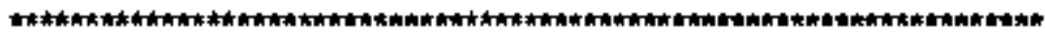

- store difanstions of arrays for expondituras, tergots, end

- platforis.

- The folcuing acroys must have dismoinston maxex as shown

- cominurapply I prasup(0amexex,30)

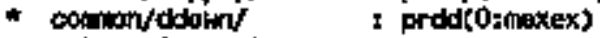

- subrout ine calcmen * X(0amaxex)

* subroutine cdf : prt0rmaxex)

* aubroutint cursin : a(0)mexex). b(0thaxax)

- subroutina dist = a(0Imexex)

* subrouting setba $\quad$ a $\theta(0$ maxex)

* subroutine print dist: a(0)maxex)

- subroutine zero I prtosmbxex)

- subrout íme zarod $\quad$ dpr(0zatexex)

- The following arrayz nust have dismension naxtar as shown:

* comon/target/ * targ(Otmaxtar,30)

- furction fral i t(omaxtar)

- auproutine monte i tarteap2(0amaxcar), sartempl (0sanaxear)

* n_dd(maxex)

- Gubroutine targBo : targ(Omaxtar)

- aubroutine target = pr(0:axter)

- The following arrays must have dismengion maxplat as shoint

- bubroutine enalyze 2 nu(noxplat), nz(2 maxplat)

* subrout Ine box I nu(matalbt)

- subroutine monte ; nutmaxplst), nz(2,maxplat)

- subroutine refitls : nu(makplet), nz(2,mexplat),n_dd(anxex)

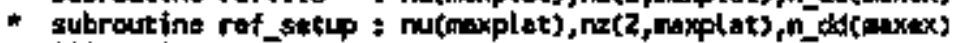

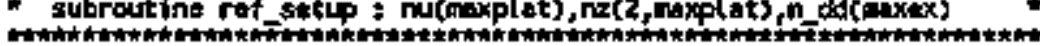

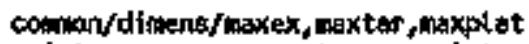

integer maxex, maxtar, maxplat

date $\Rightarrow x+e x / 2301 /$

idate suxtar/601/

date andelat/200t/

end

$\downarrow$

(* block data initial

•) 
SUBRour tWe main_up(ntar, itla)

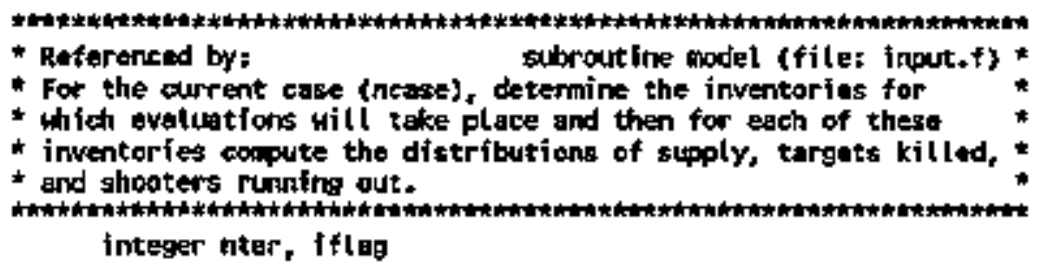

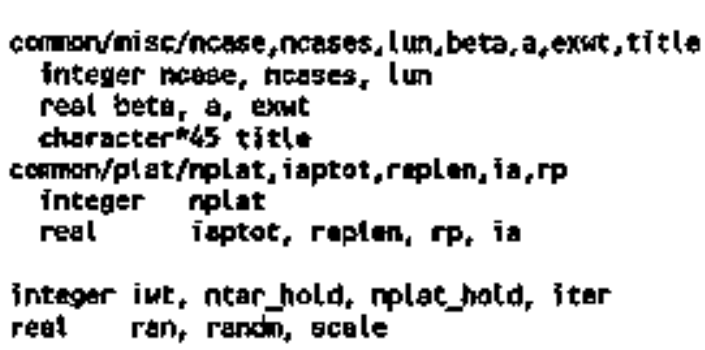

c wite(**) 'Working on cose "ncase ren * rendho(O) ntar_hold a ntar

I inttialize randan niaber generator nplet hold a nplat

colt chk_scal fing(exut, ntar, nplat, lun,nease, scato)

int $=$ intefoutt+0.5)

call inventory(iut)

call gat jter(jter, int, Iflag)

if (itar.gt.o) then call inftiolize(iwt, ntar, nplat, replen\}) call monte(1wt, ntar, iter) ren a randa(2)

call sumbry'title, np(at hold, ntar hold, lun, iter, nease) Iprint distributions call wolnplat, ntar, iun, scale,tittêt) endif return end

Iround axpenditures to integer idatermine imventories get nomer if iterations

I finitial ize arrays

I perforn monte carlo analysis

\section{levaluate recuireants for} I different NoEs.

* (* Gubroutine main_up *y 


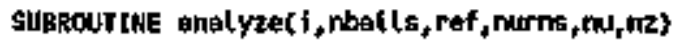

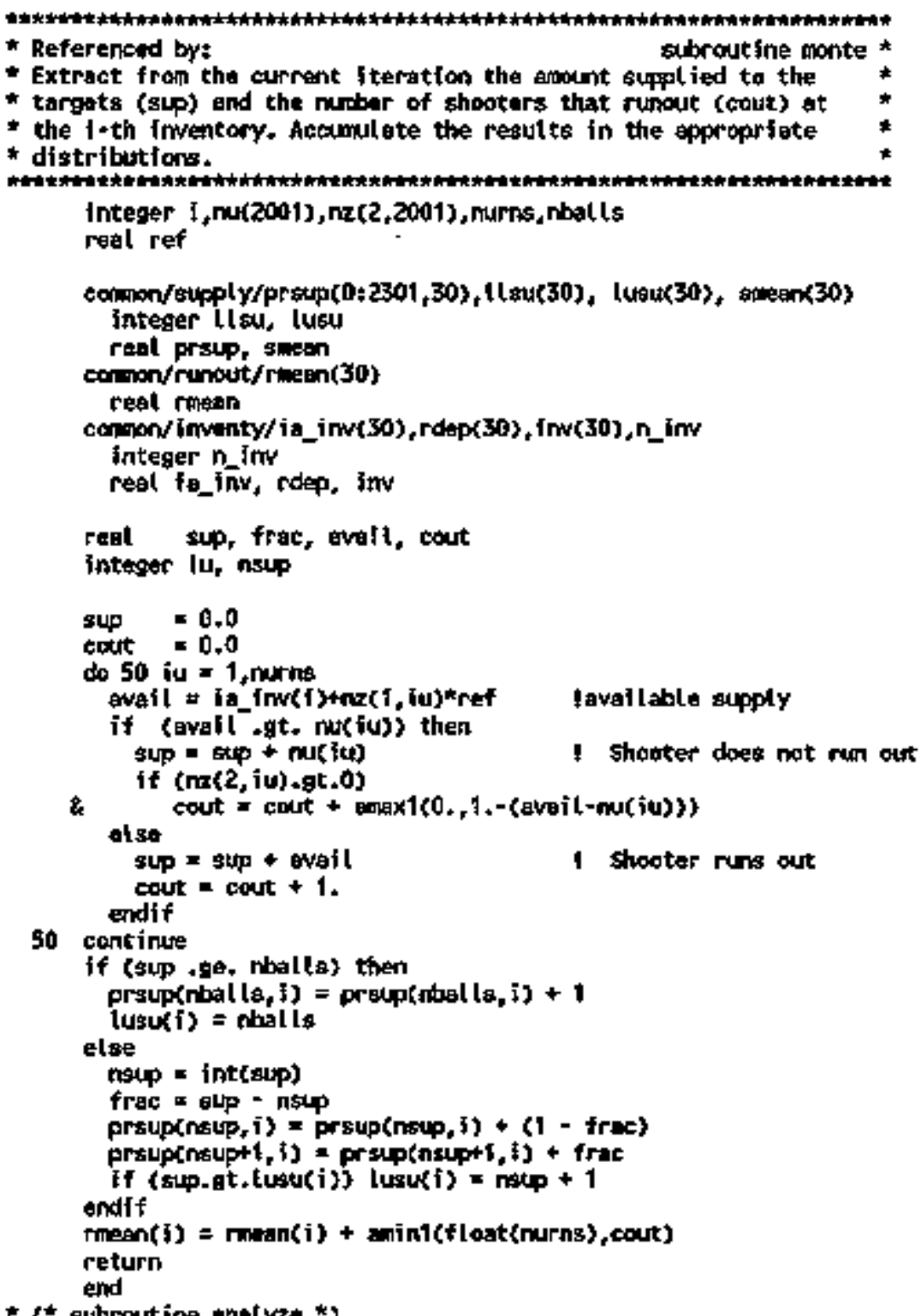

* $f^{*}$ oubrout ine matra* *z 
Susqout INE box(nhalls, wurns, rut)

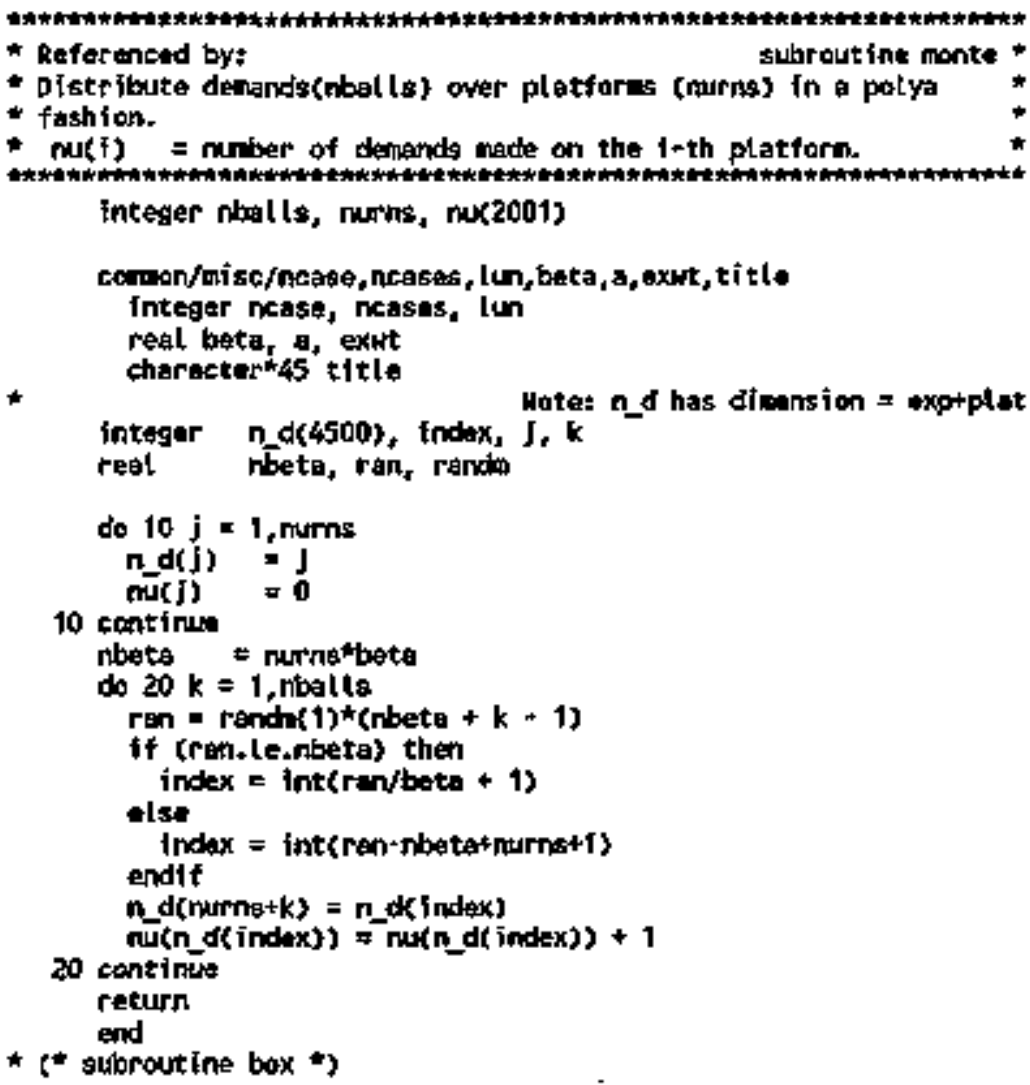

* 6 sthroutine box *) 


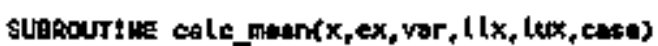

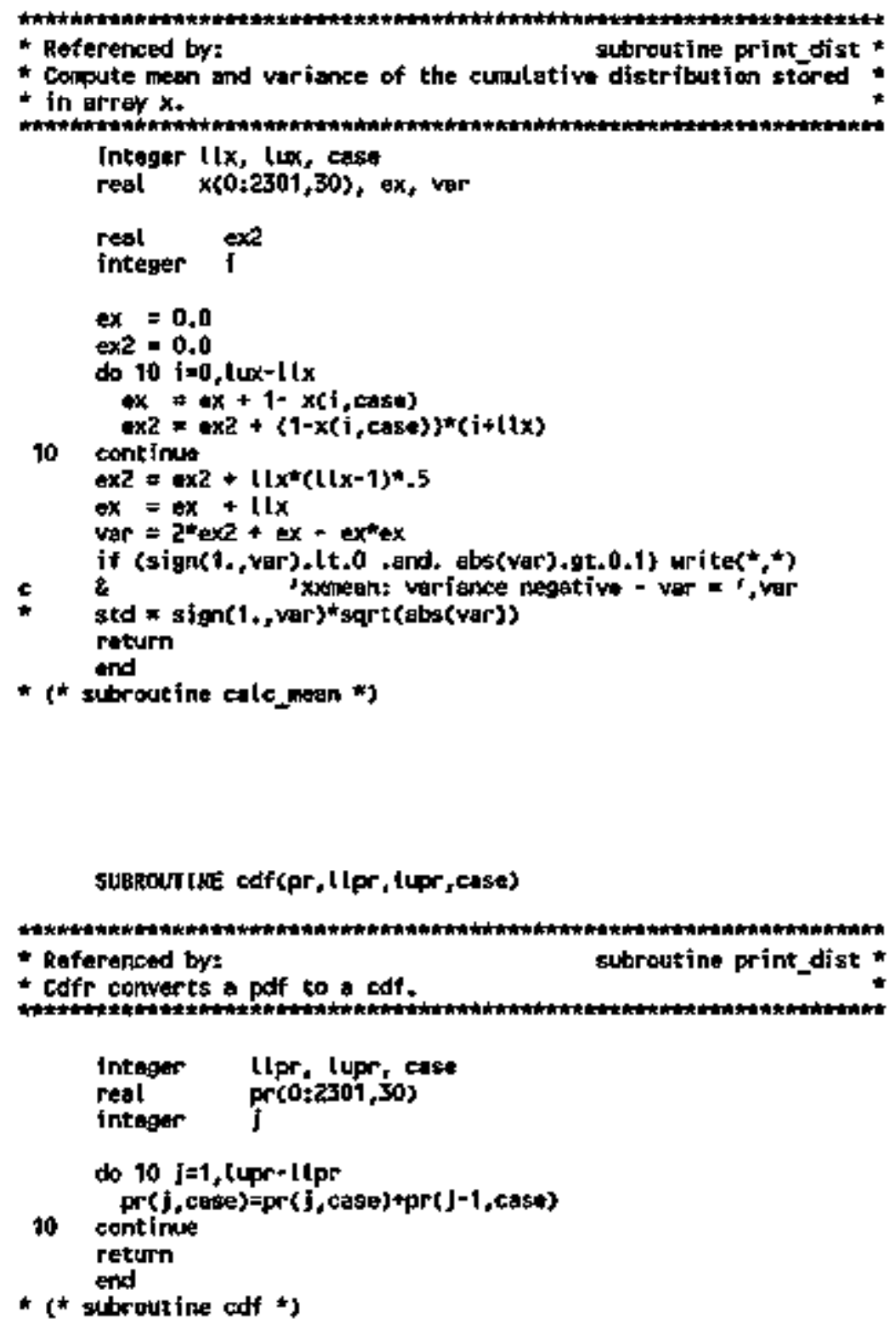


SUBRour IWE curstm(b, t tb, lub, a, t la, tta,prob, case)

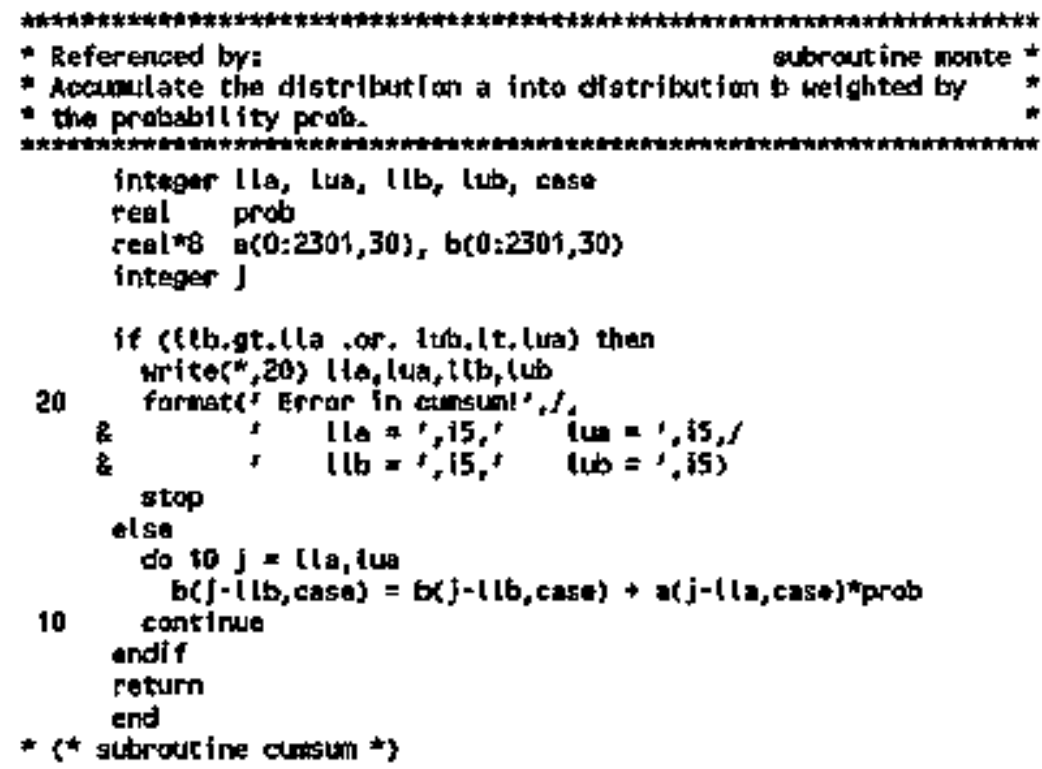




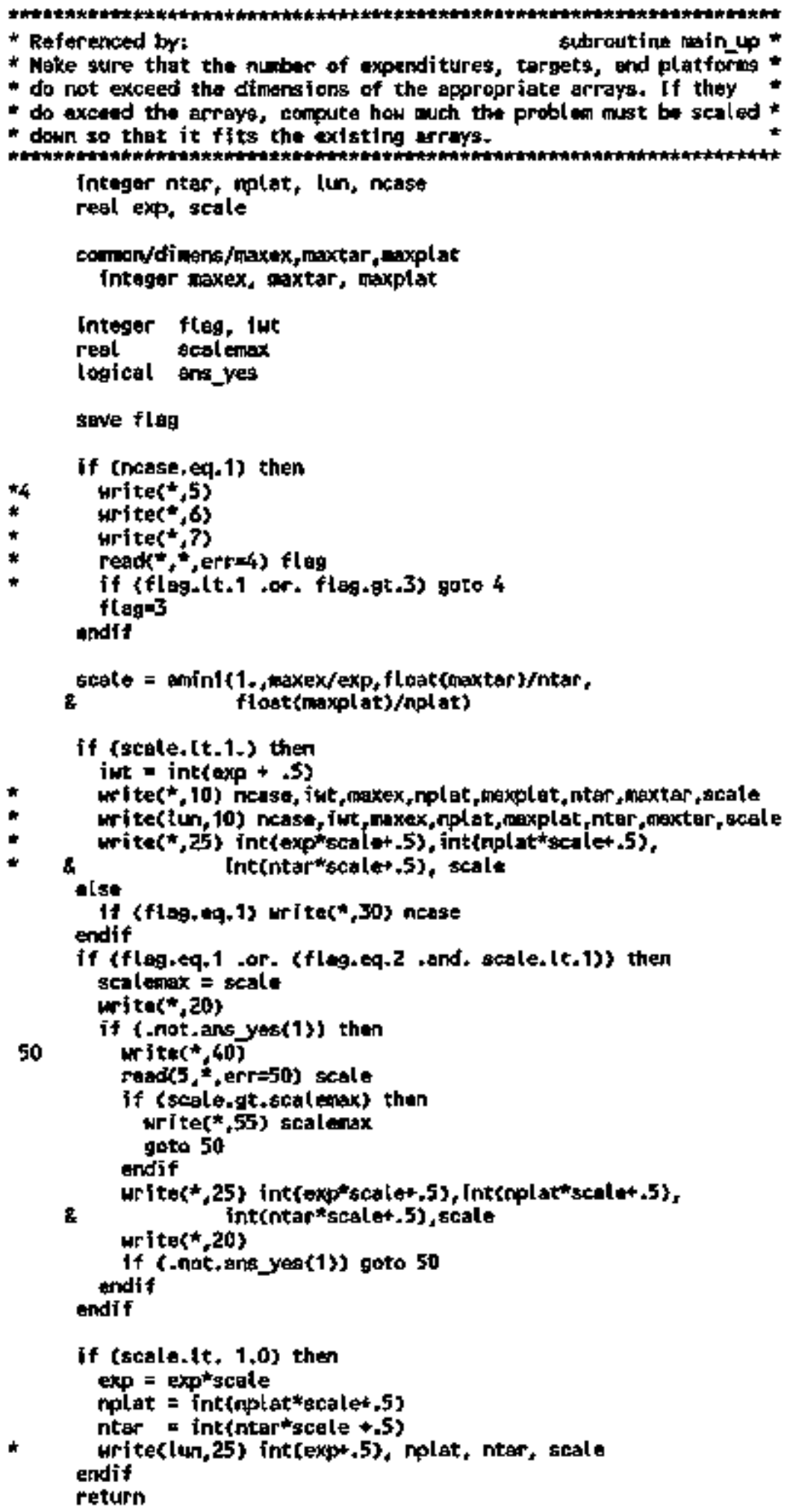

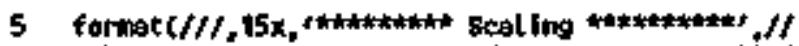

t. $5 x$, 'Array sizes In the code may be too small for the given *, 
5x, Inpurs, 11 this is the case, the model will gcale down',

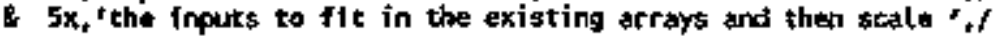

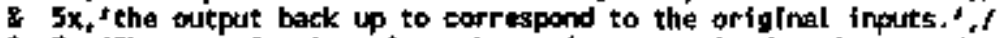

5x, 'The usor is also given the option to scale dom inputs', $f$

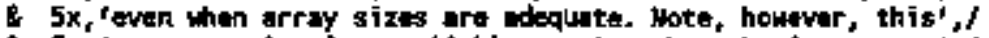

\& $5 x_{\text {r }}$ 'process ontr gives reliable results when the inputs gre',

\& 5x, "elarge". $" / h$

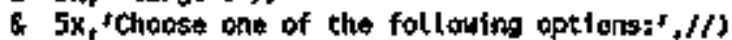

6 foringte

\& $5 x_{r}+1$. Prompt user for a tcaling factor at the beginning of ' $f$

$25 x_{r}+$ evary case.'.

$85 x_{f}+2$. Prompt user for a scaling factor at the beginning of', $f$

5 5x, only thoso cases for with the array sizes ore not' $f$

it $5 x,+$ adequate.',

$25 x+3$, Let the madal autonatically dacifo whether scalingt,

\& 5x, It needed.')

7 formate/ Enter cholce. (1, 2, or 3) $\Rightarrow$ ')

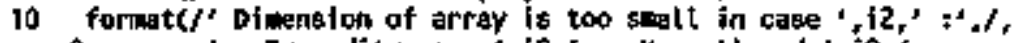

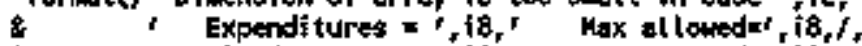

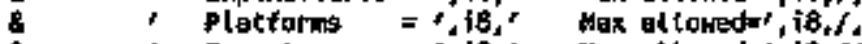

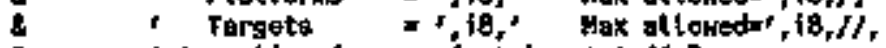

8 'A scoling fantor af at loast',f6.3,

8 'is required to run the case. ' $/ 2$

$z$ formakt " The Modsl will be run with the following inputs: ${ }^{\prime} /$,

8 Experaditures $=1,18, f$

8 Ptatforns = 18.1

. Tarots $=* 18,1$

a formate' Is this ok ? 's

30 formatc/ Array ofizes in case ' 13.

d I are adequste, scaling vili not be done. ')

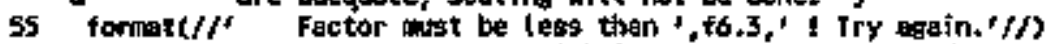

40 formst(' Entor the anount by wich inputs will be seeled down. ') and

* (*) antsoling *) 
SUbrout INE dist(a, Ita, Itua, nqoint, cose)

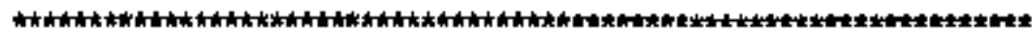

* Referenced by:

Gibroutine monte *

- Comport from nunber of evants to distribution of arents, that

* 1s, divids all points in array fron a(0) to aclua-(La) by npoint."

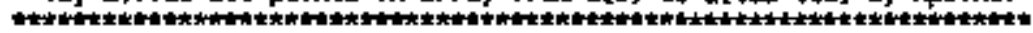

Integer Lla, lua, npoint, case

reat a(0;2301, 30$)$

Integer I

do 10 je1ts, tus

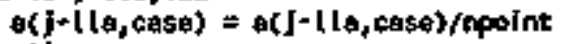

10 contimis

return

end

* (* subrout ine diot *)

reat function fral(t, llt, lut, $k$, tese $)$

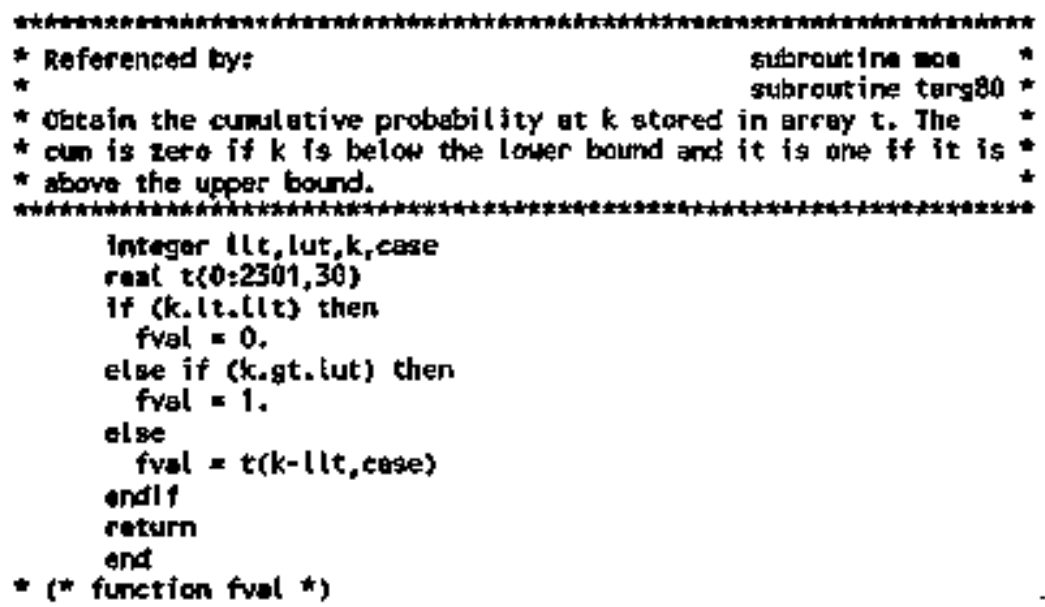


SUEROUT JHE getboka, I la , lua, case)

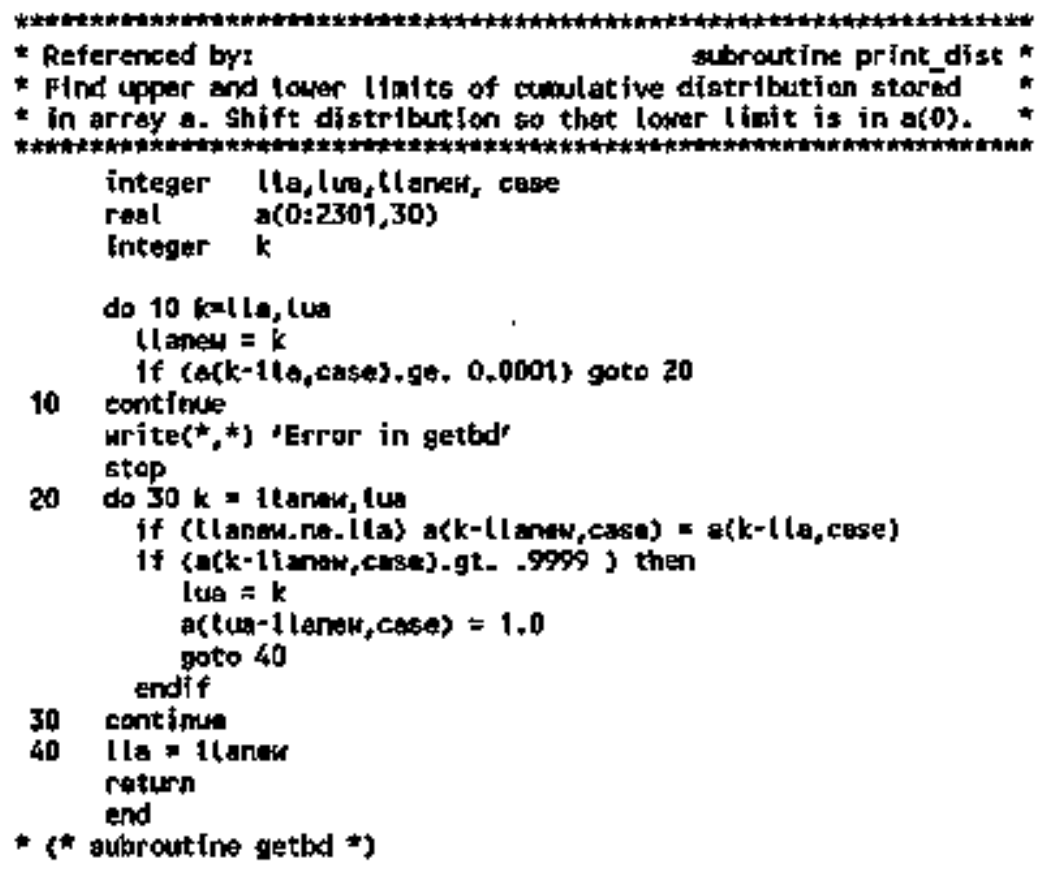


suarout Lne get_iter(iter, int, 1 flag)

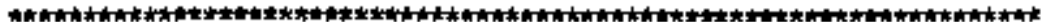

* tefarenced br:

sthroutine main up

* Deternine tha numer of itecations to perfotm. Currently, this *

- stbroutine calculates the numbar of Itaratians neodied to nake

- epproximately 400,000 randon draus. The reconomaded numbr of

- Itorations 18 then taken to be the ninimen of 100 and this

- nalculated nuber.

lict integar iter, iut, iflag

conmen/imventy/ia_inv(30), rdept(30), inv(30), n_inw

integer n_lny

rẹt iatim, rdep, Inv

real maref

logical ans_yes

It (itlag.gd.0) then

Iter = ifleg

- lst

makref $=\operatorname{rdep}\left(n \_f m-1\right)$

Imaximun $*$ of refills

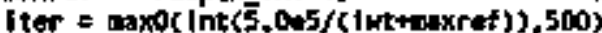

crite(*,10) iter

If (iflag.eq,-2) then

uritet $(15)$

if (. not ,ens yos(13) than

writer.,30)

read(**) itar

endif 1

andif

entil 1

return

10 formats The dafaute mubur of iterations is $x, 110$ )

15 formate is this okfr)

30 formate

s I Enter the nuber of iterations for this case. *t *)

and

" (" subroutine get_fter *)

$<\mathrm{C}-\mathrm{BO}>$ 
StlBoun LWE initinl ize( iwt, ntar, nplst, replen)

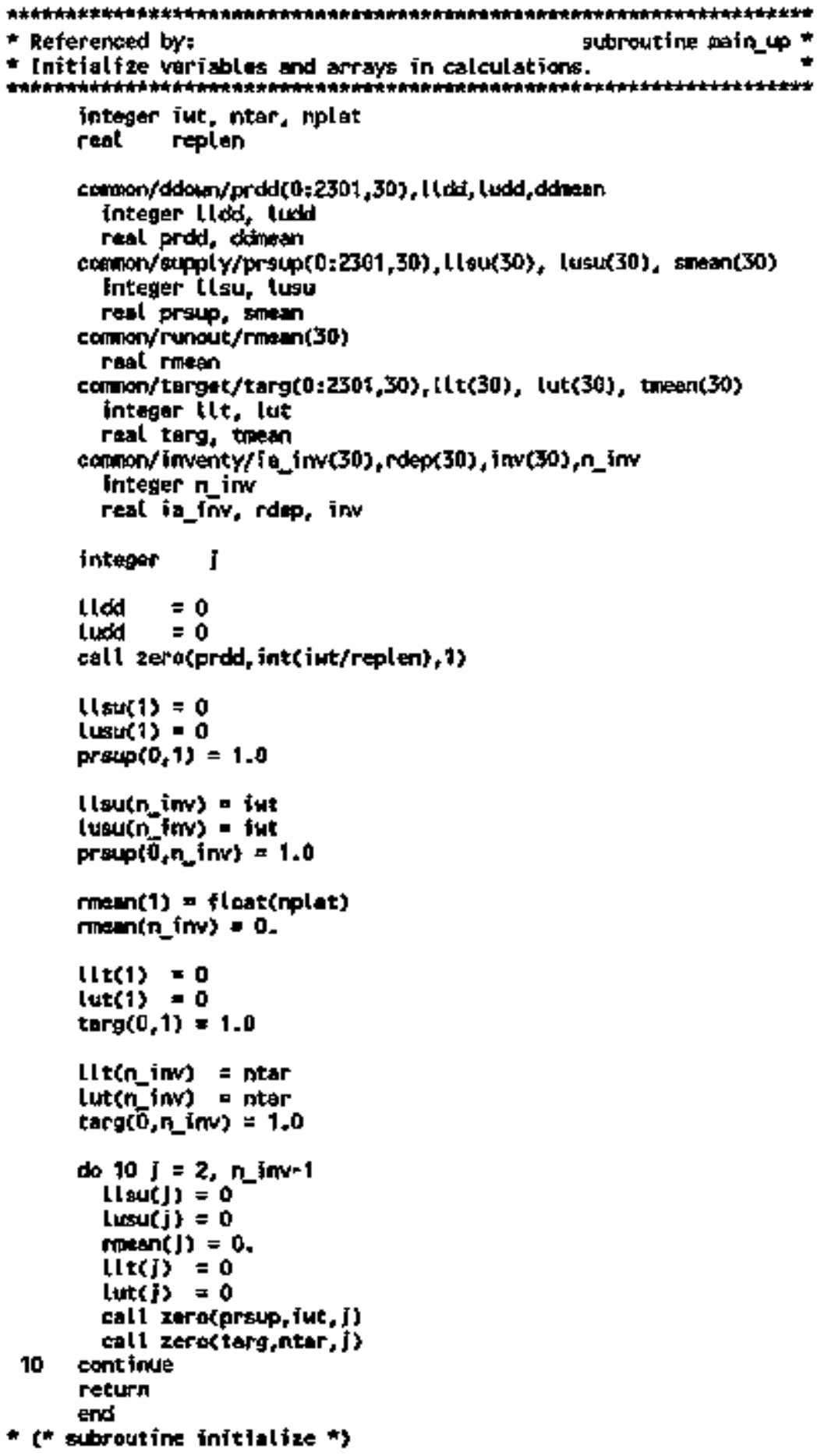


suagut1we Imventory(exp total)

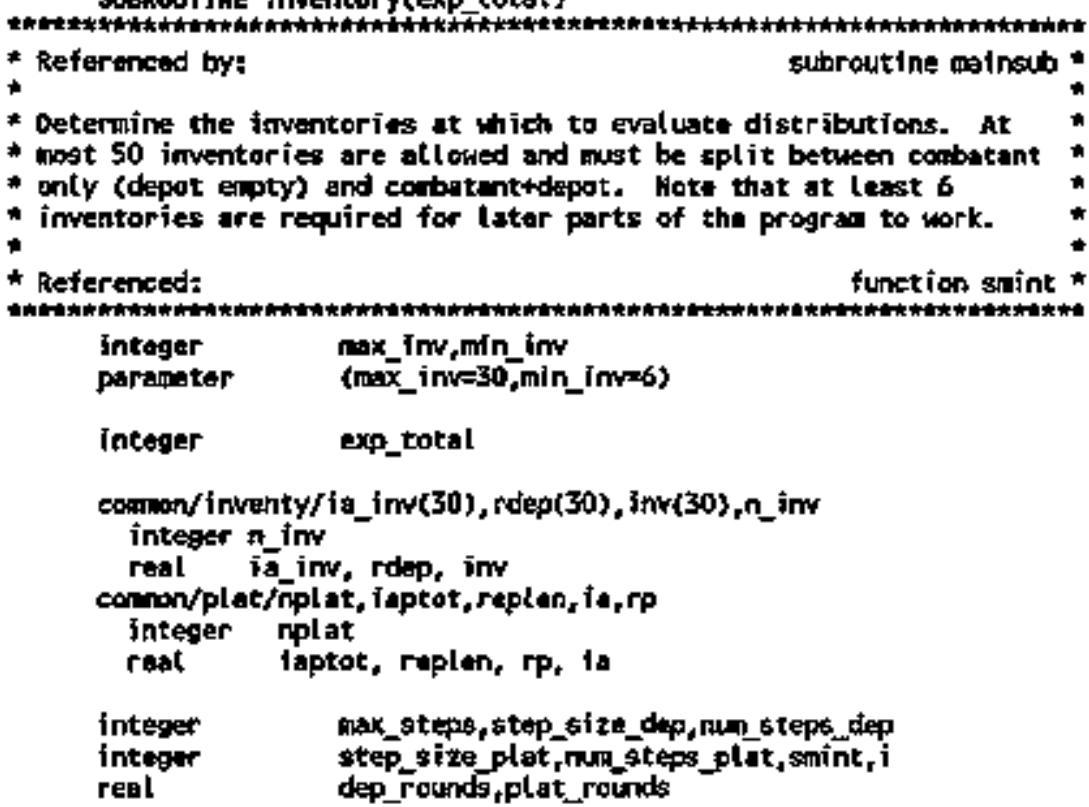

* (* subroutine inventary *) 
Subroun INE maq(nplat, ntar, lur, scole, titlę)

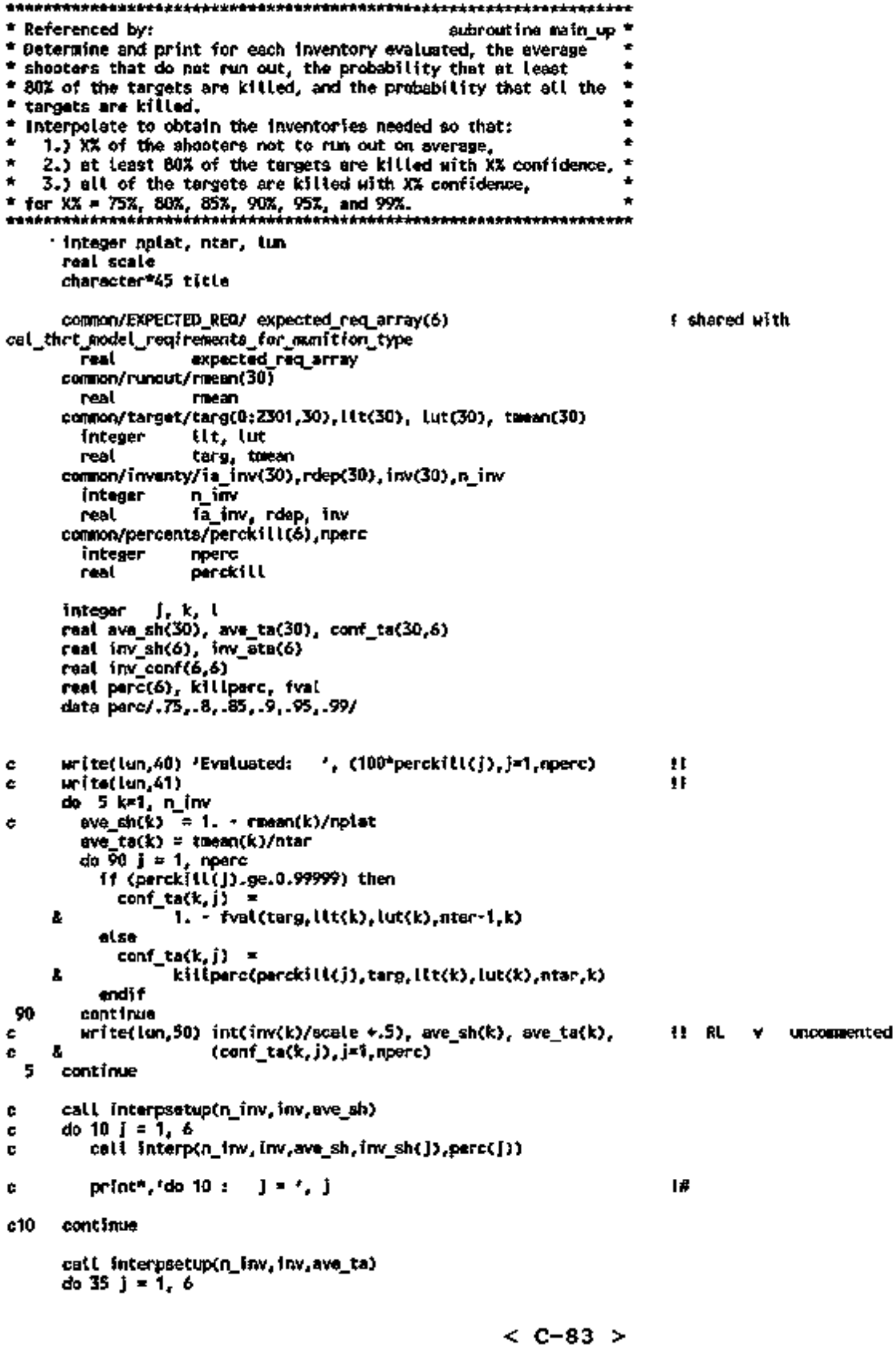

f shared with

I! RL $\checkmark$ uncomented 
call [nterpon_inv, im,ove_te, im_ata(J), perce(j)

continum

do $301=1$, nperc

call interpsetup(n_inv, im, conf_ta $(1,1)$

do $20 \mathrm{j}=1,6$

cald interptn_im, im, conf_ta $(1,1), i_{-}$conf $\left.(J, t), p e r c(j)\right)$

contînus

c30 continute

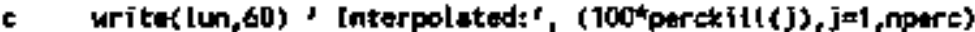

hritex $(u n, 61)$

do $80 k=1,6$

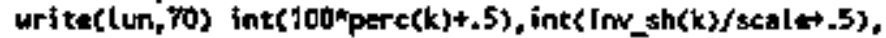

8 intinv ata(k)/scale+.5).

8 [Inte $\left(i \bar{w}_{2} \operatorname{con} f(k, 1) /\right.$ scal $(*+, 5), j=1$, nperc $\}$

expected_req_array $(k)=i n y_{\text {_ato }}(k) /$ scale

Bo continus

write(tun, 75)

write(lun,76) (expected_req_erray(k), k=1,6)

11 RL $6<2$

1) RL V uncombented

1I Average requi rements neaded for

Il $k$ fractions of the tergets killed

I! Average requirenents neaded for

ti $k$ fractions of the targets killed

II RL ヘ

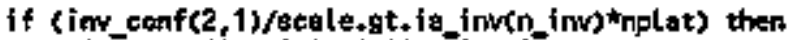

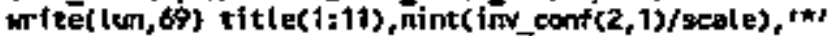

else

writeflun, 69) title( $1: 11), \operatorname{mint}\left(i t v_{2} \operatorname{conf}(2,1) / \operatorname{scal}(e)\right.$, endif

\section{return}

69 forrat $(a 11,17,3 x, 81)$

40 format $/$, a13, $/ /$,

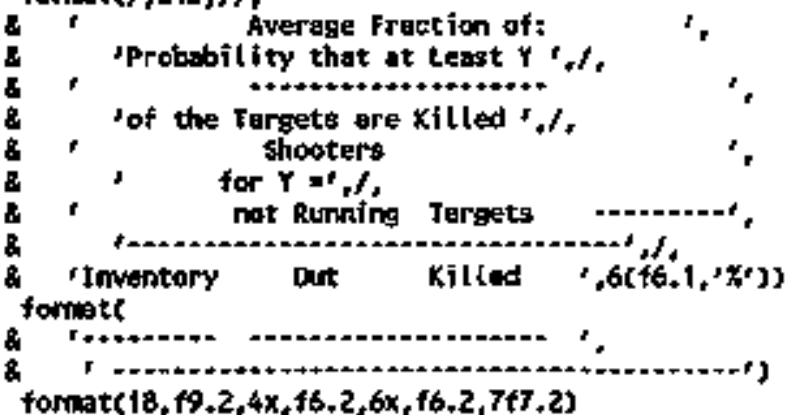

50 format $18, f 9.2,4 x, f 6.2,6 x, f 6,2,767,2)$

60 formet $/, 13, / /$,

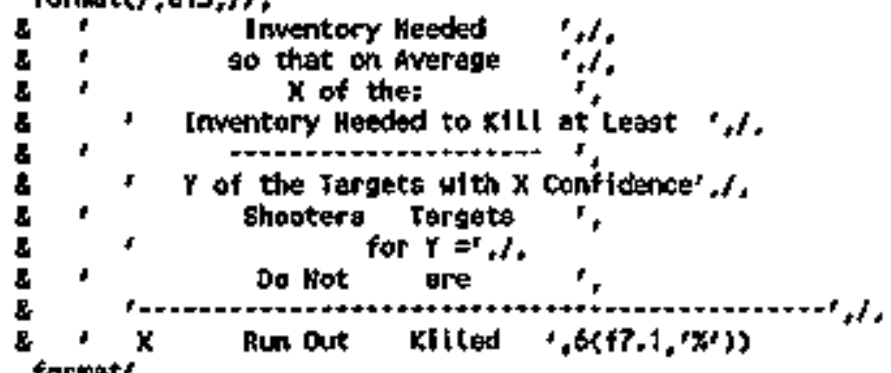

76 formot $\{10 x, 6 f 10.3\}$

end

* (" subroutine noe t) 


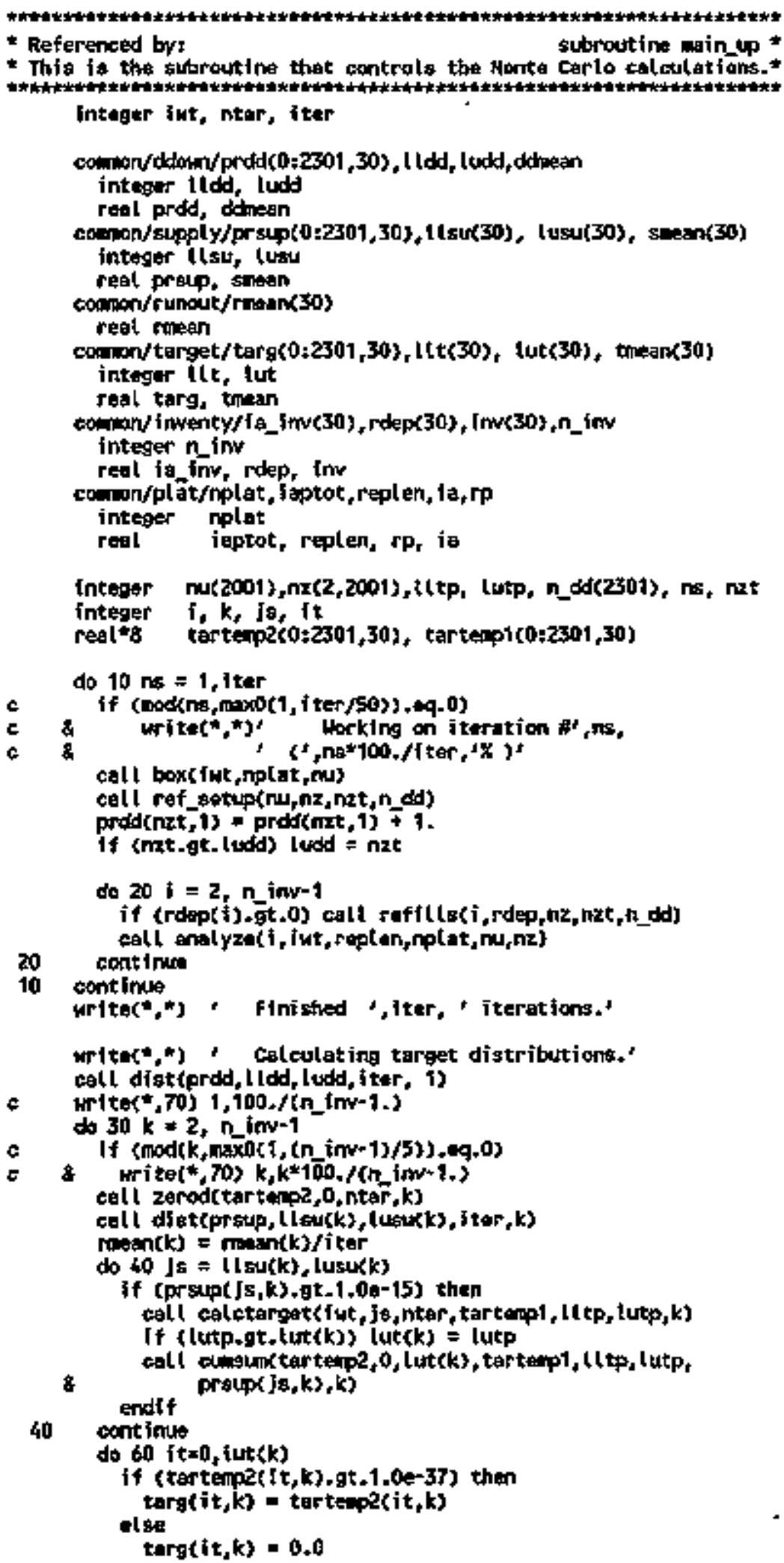

write(**) ' calculating target distribution*** 


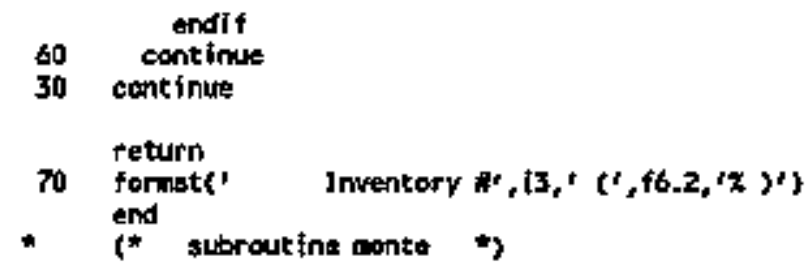

Feal fuktion killperceperc,tars, llt, lut, ntar, tease)

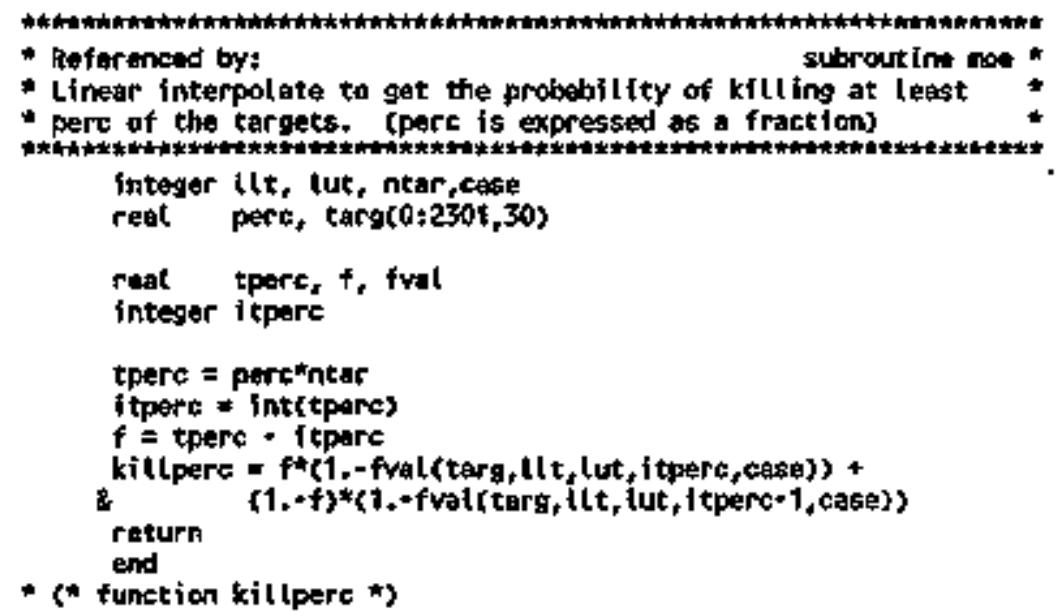

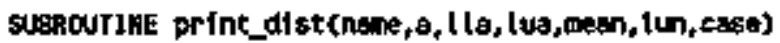

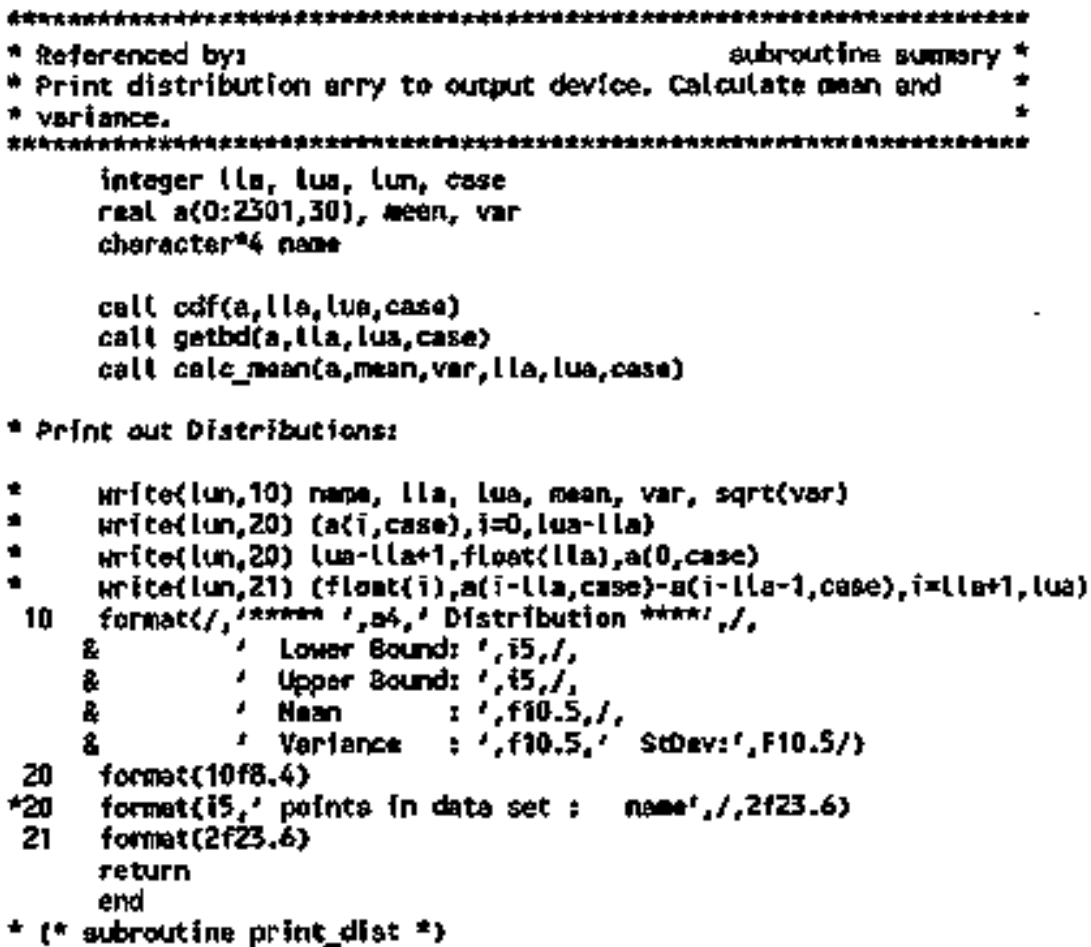




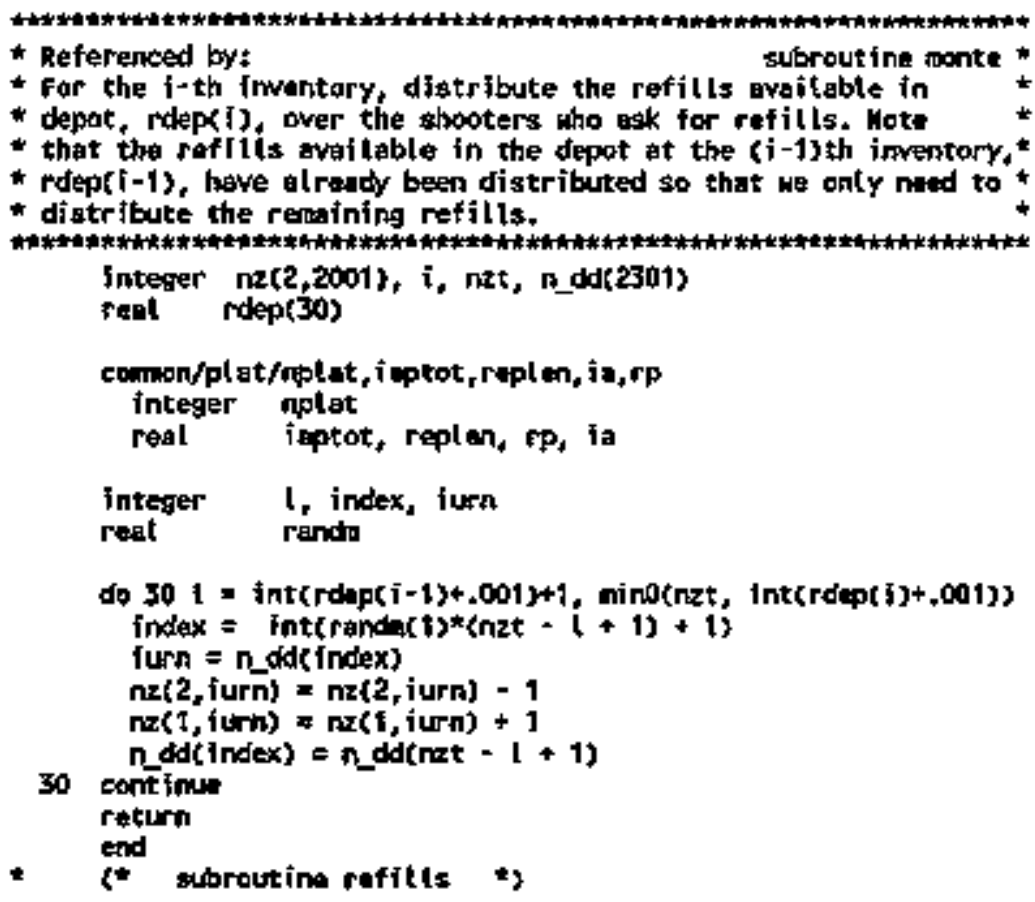

SUGkOUT JHE ref_satup(nu,nz,nzt,n_dd)

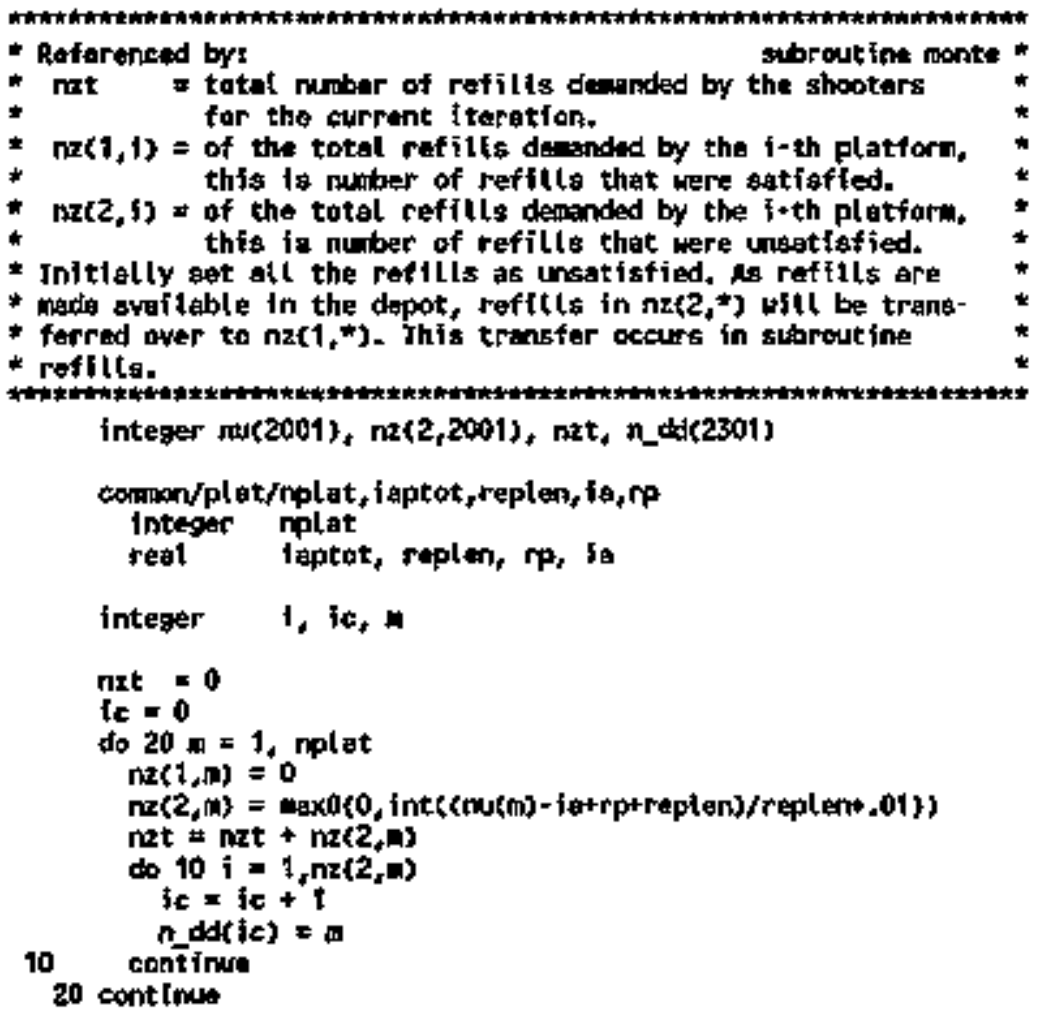


end

* t" subroutine ret_satup *y

integer flakCT JON smint $\{x\}$

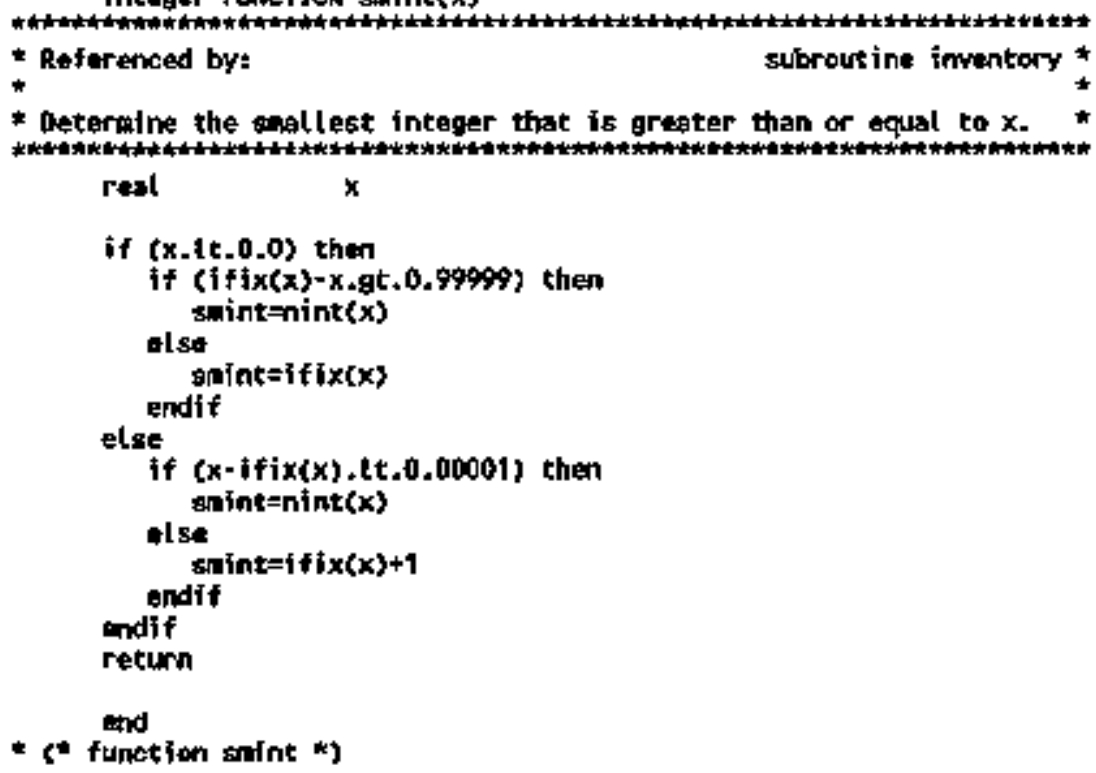

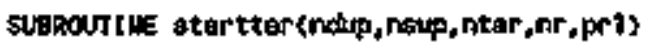

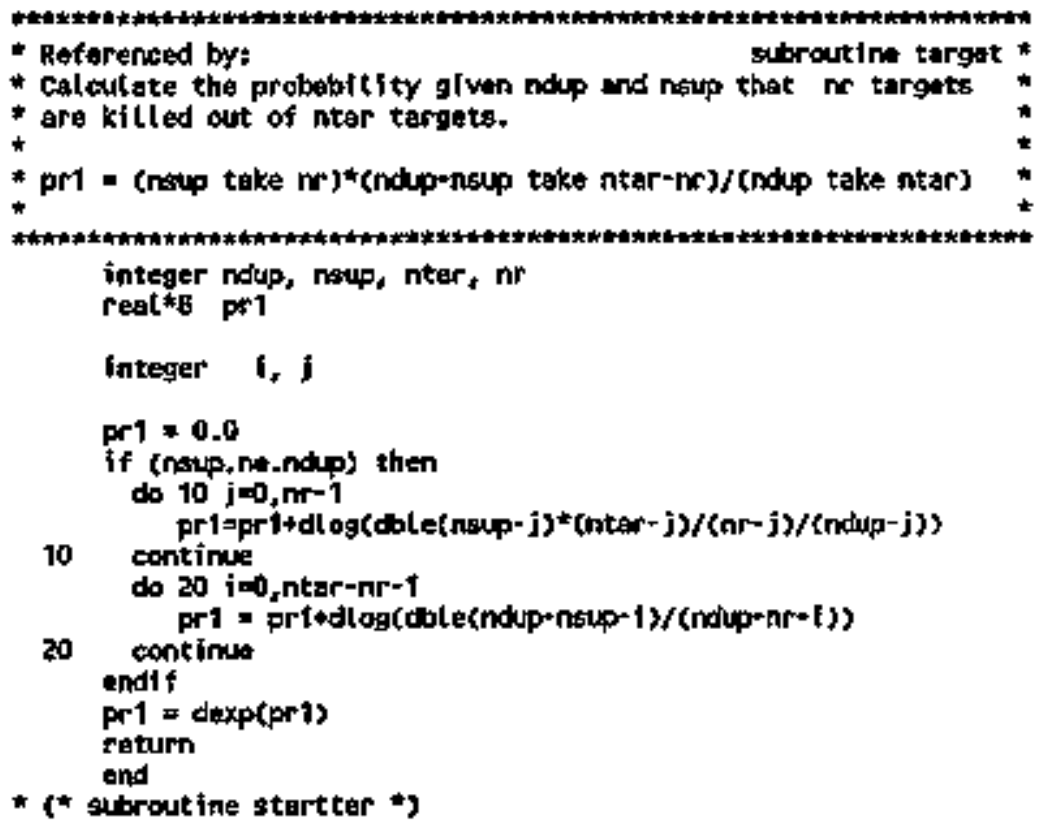




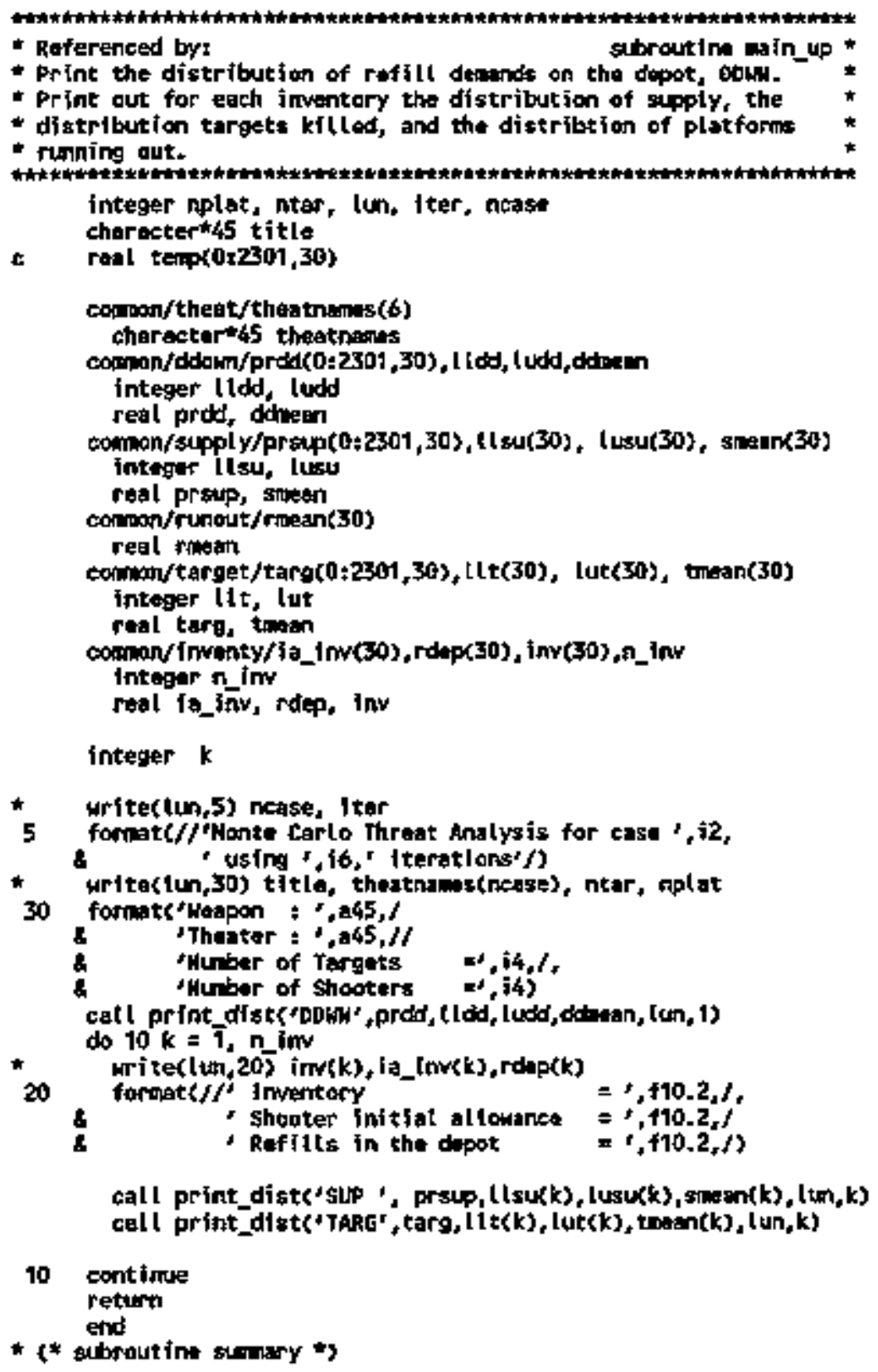




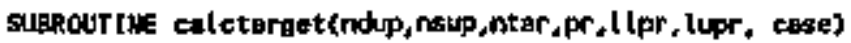

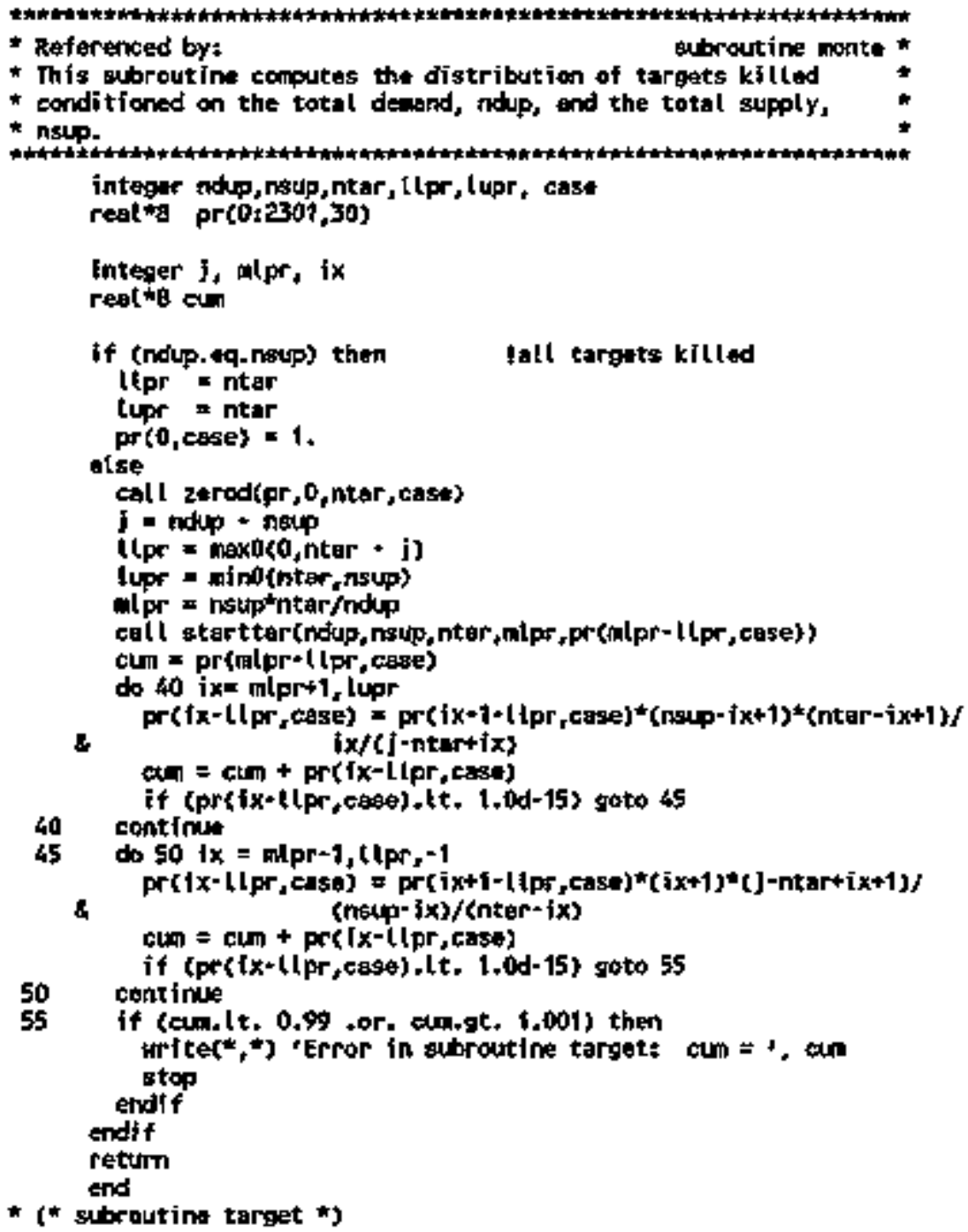

SUBROUTIME zero(pr,mox, case)

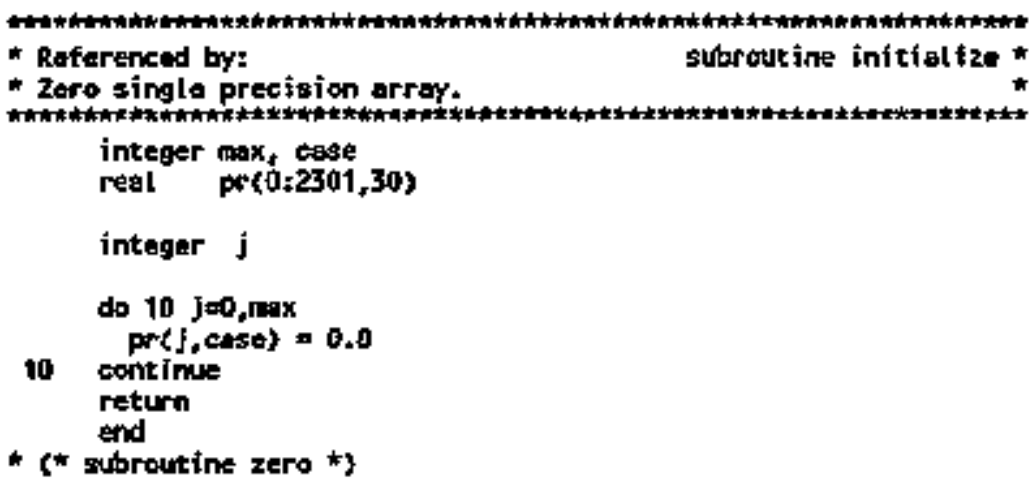


SUBROUT INE 2errod(dpr, LI, (u,cese)

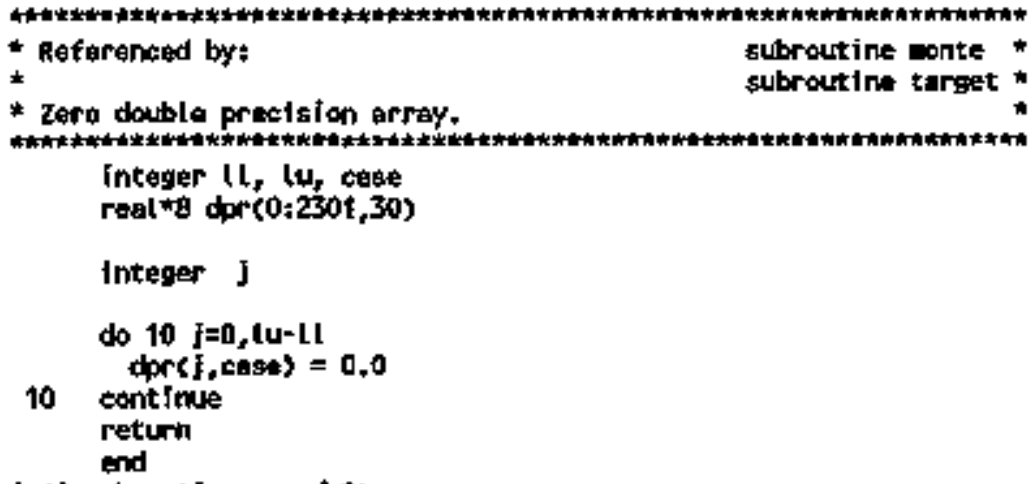

(" Ethroutine zerod *) 


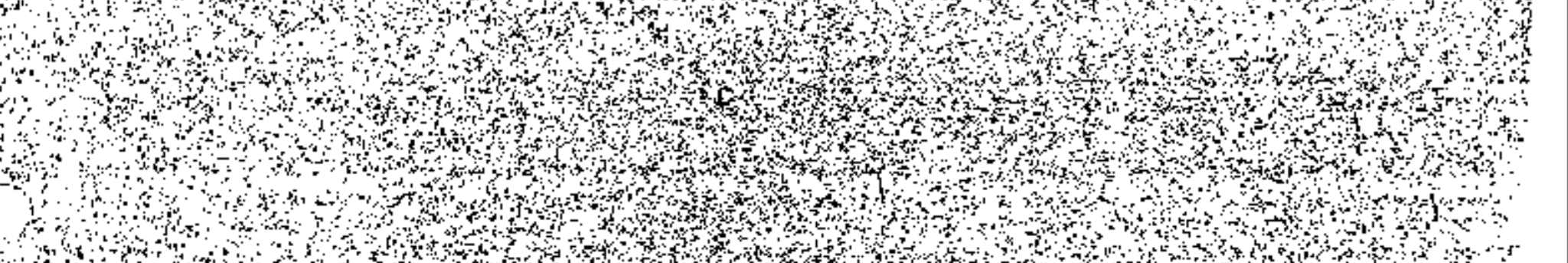

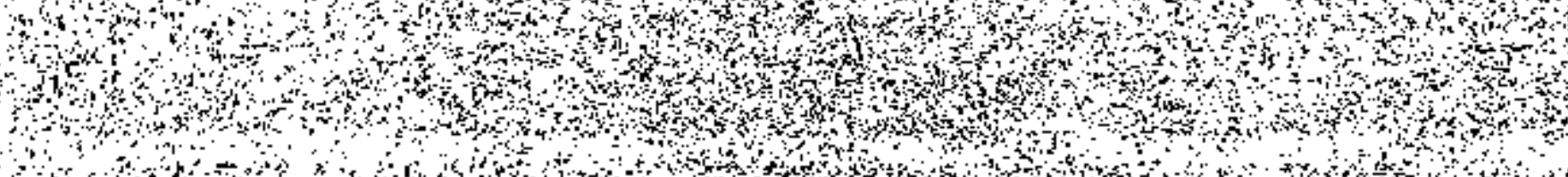

H. 1.7. (2) W. H.1.7. 3.

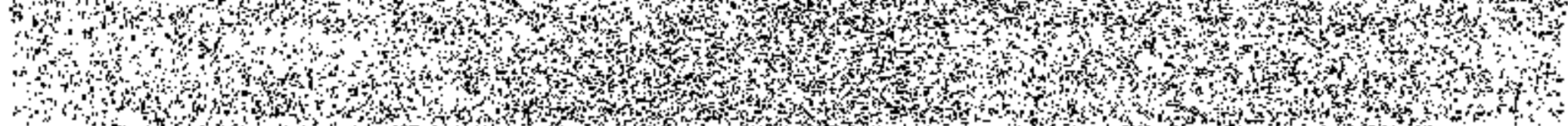
3.t. W

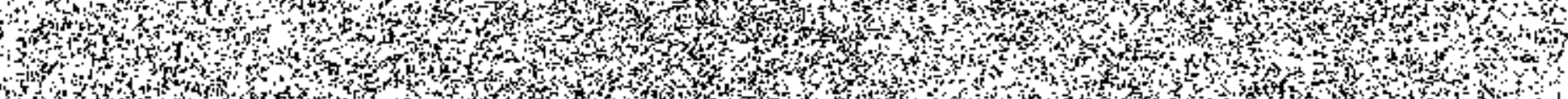
Now (n)

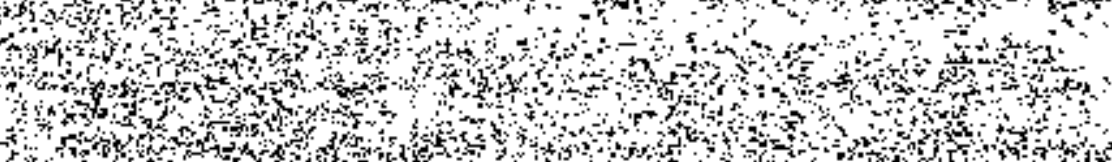

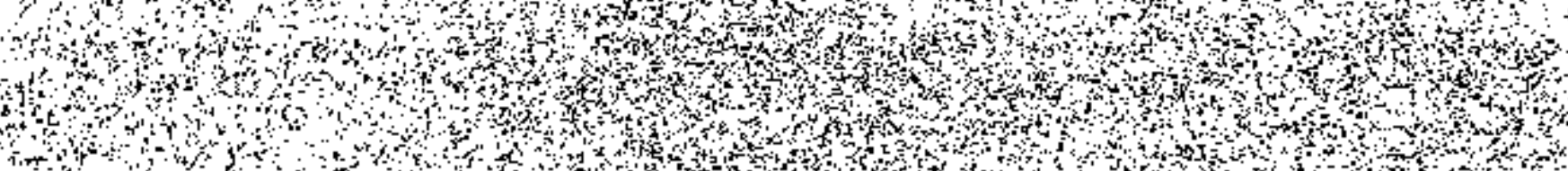
(n) (n)

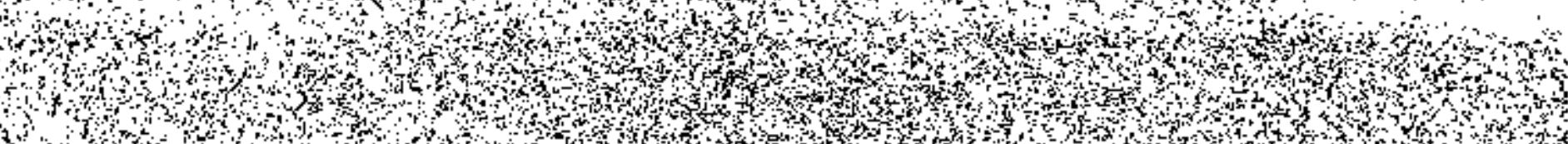

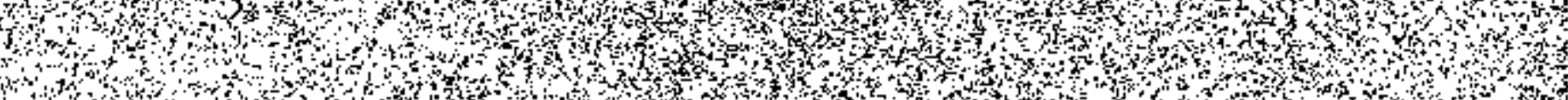
(1) 


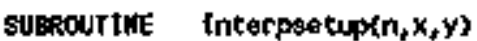

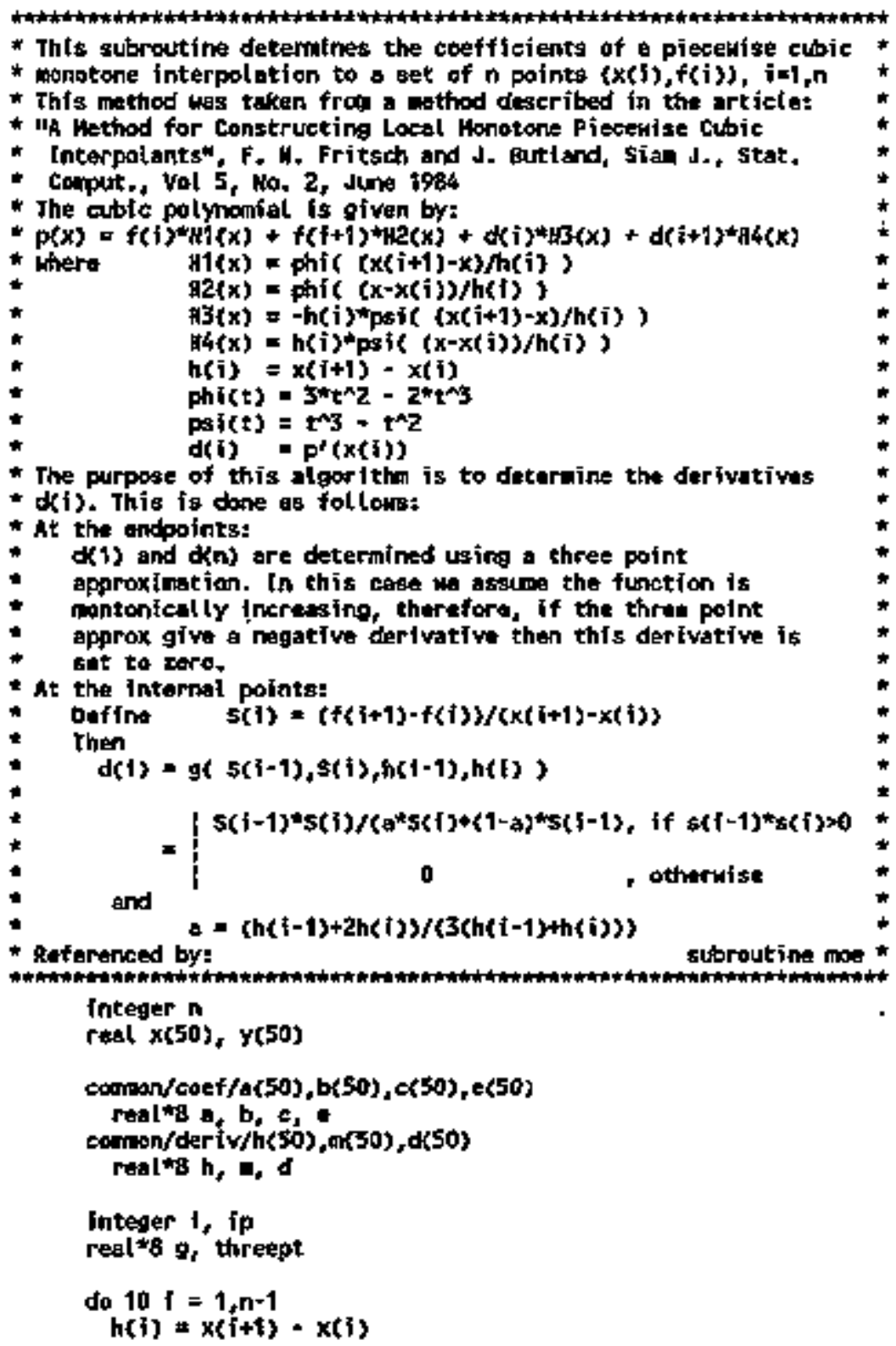


$m(i)=(y(i+1)-y(i)) / h(i)$

continus

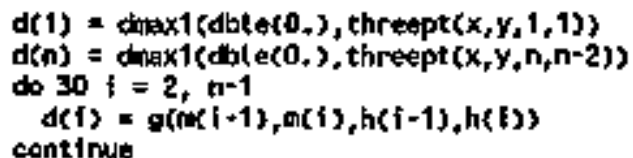
continulit

30

- Io solve for a gliven $p(x)$ we must rehrite

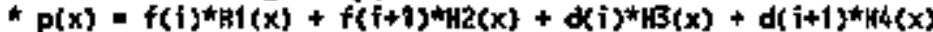

* as $p(x)=a(i)+b(i)^{\star}(x-x(i))+c(i)^{\star}(x-x(j))^{\wedge} z+a(i)^{\star}(x-x(I))^{\wedge} 3$

do 50 Ip $=1, n=1$

$4(1 p)=\left(2^{*}(y(j p)-y(j p+1\})+h(5 p)^{*}\{d(j p)+d(i p+1))\right) / h(i p)^{* * 3}$ (ip) $=$

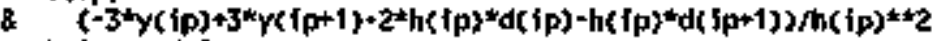
he(p) $=\alpha(p)$

50 continue $\theta(i p)=\gamma(p)$

return

end

- (* interpsetup *)

reat*g fuwction threept $(x, y, i, j)$

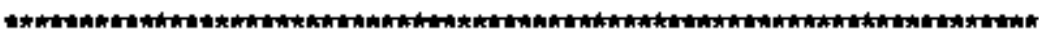

- Use thres point foenuls to estinete derivative at point $x(i)$ *

- toing the three points $x(j), x(j+1)$, and $x(j+2)$

- Referanced by:

abrout in interpsetion

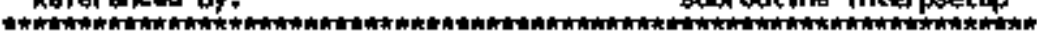

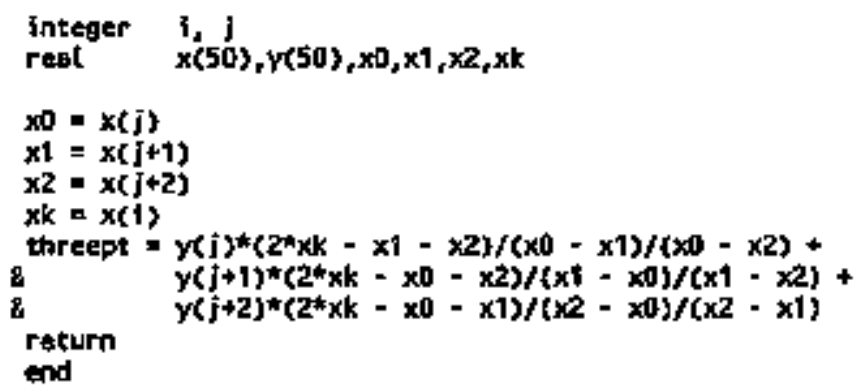

* $c^{\star}$ threept $)$

resl*B FUHCTIOM $0(\$ 1,82, h 1, h 2)$

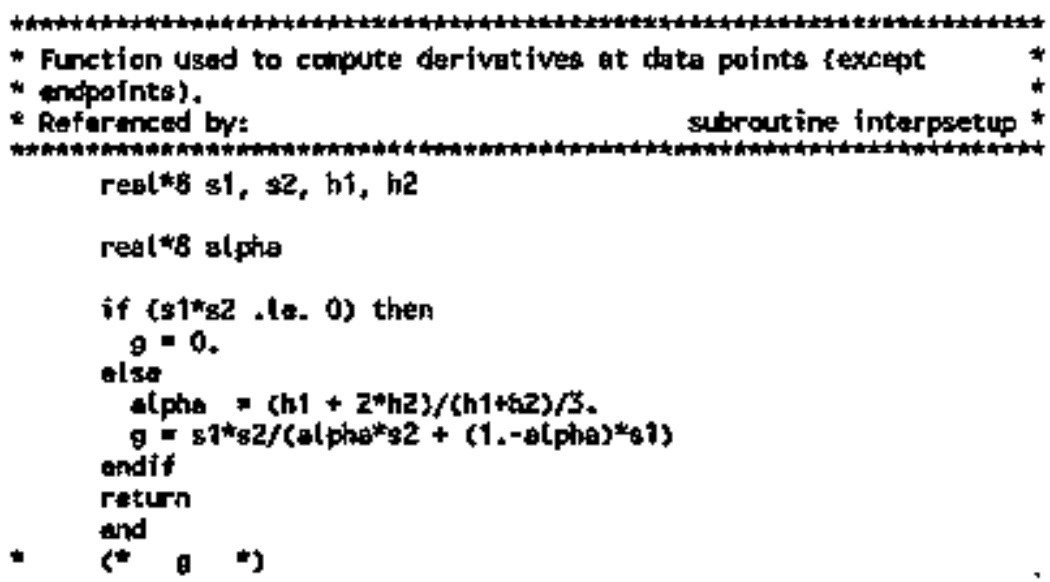


SUEROUT IHE interp $\left(n 1, x, f_{,} \times\right.$Yal, fral $)$

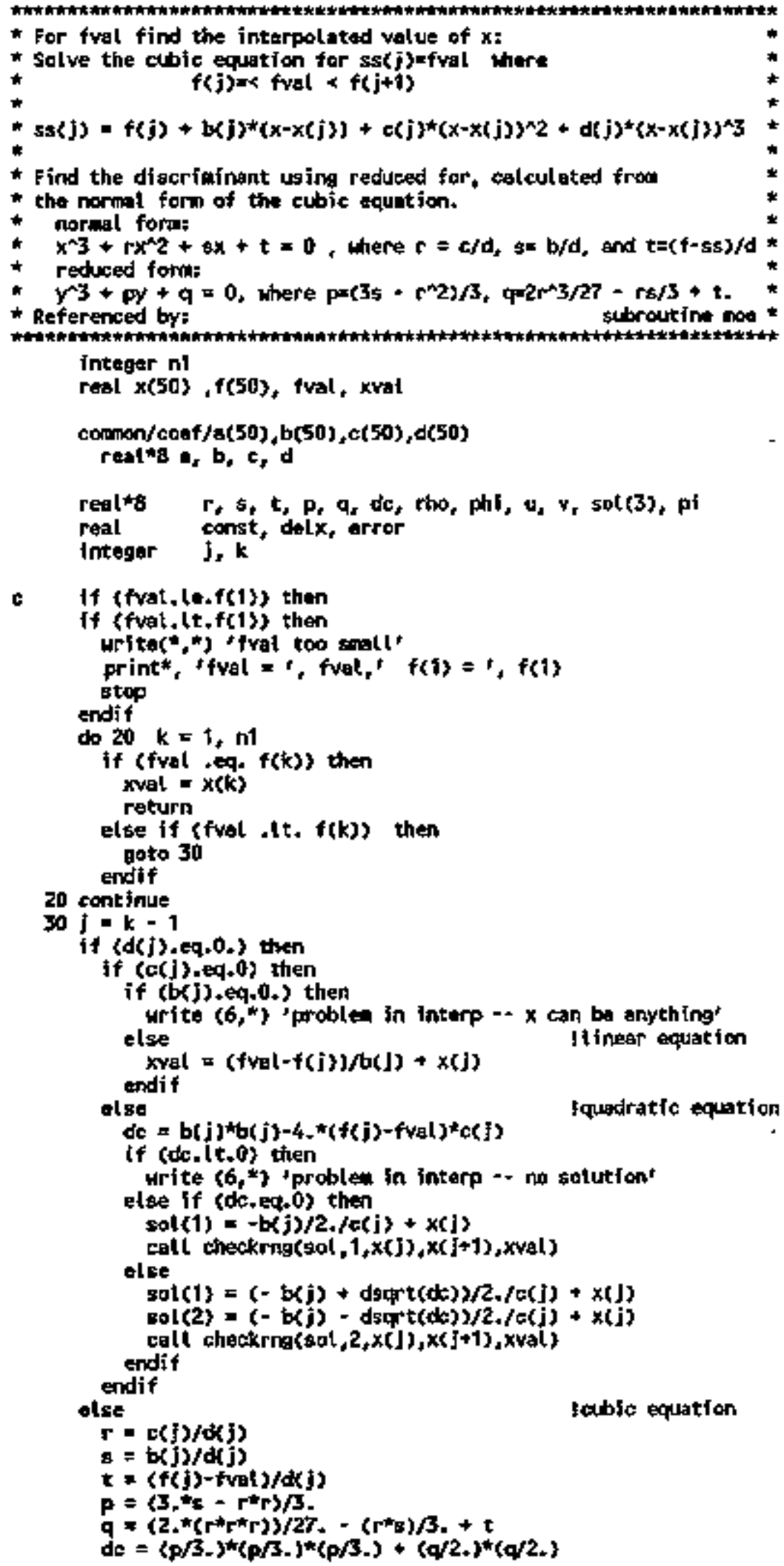




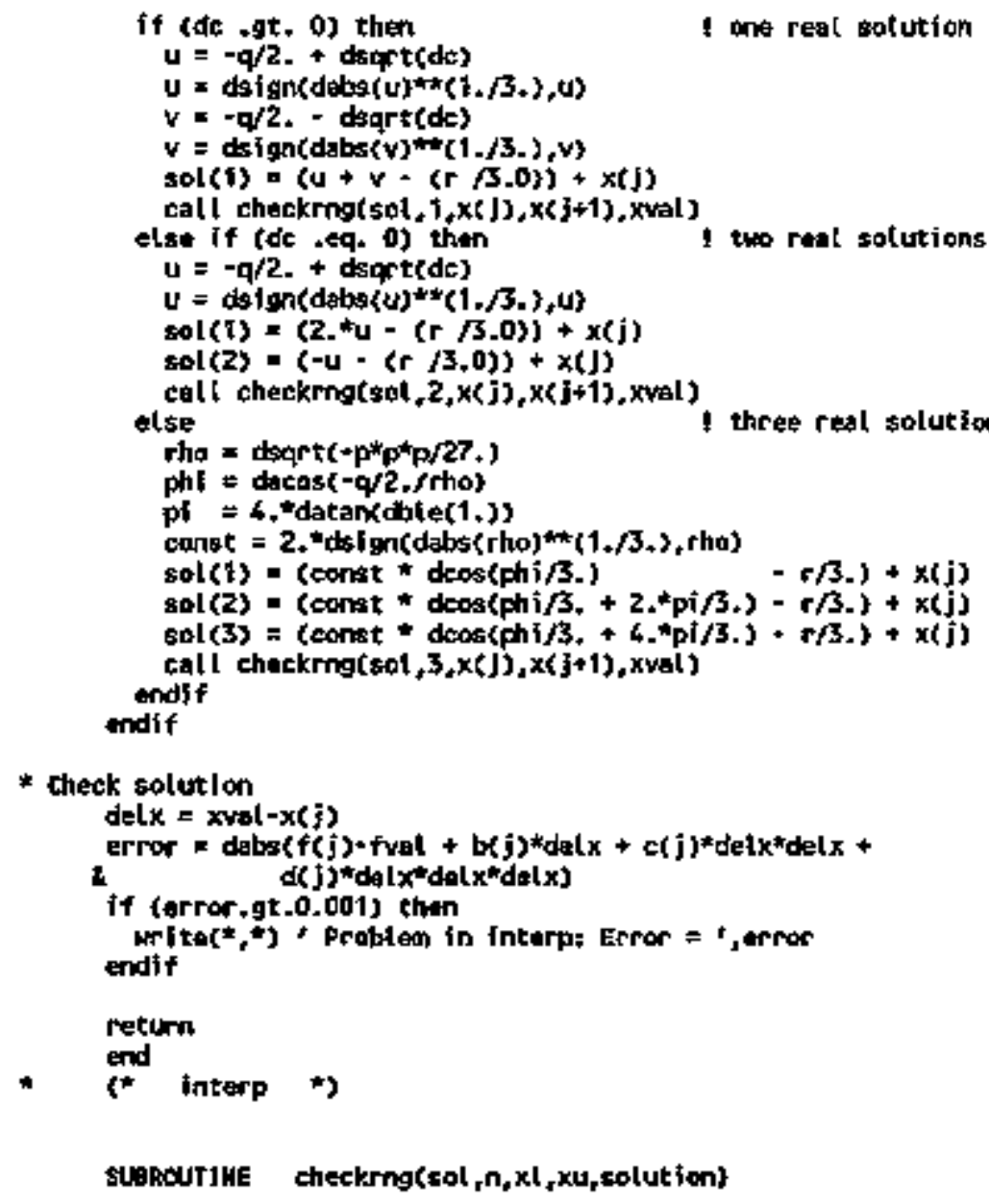


SUBROUT INE pol $Y\left(n, x_{t} y, x d, y d\right)$

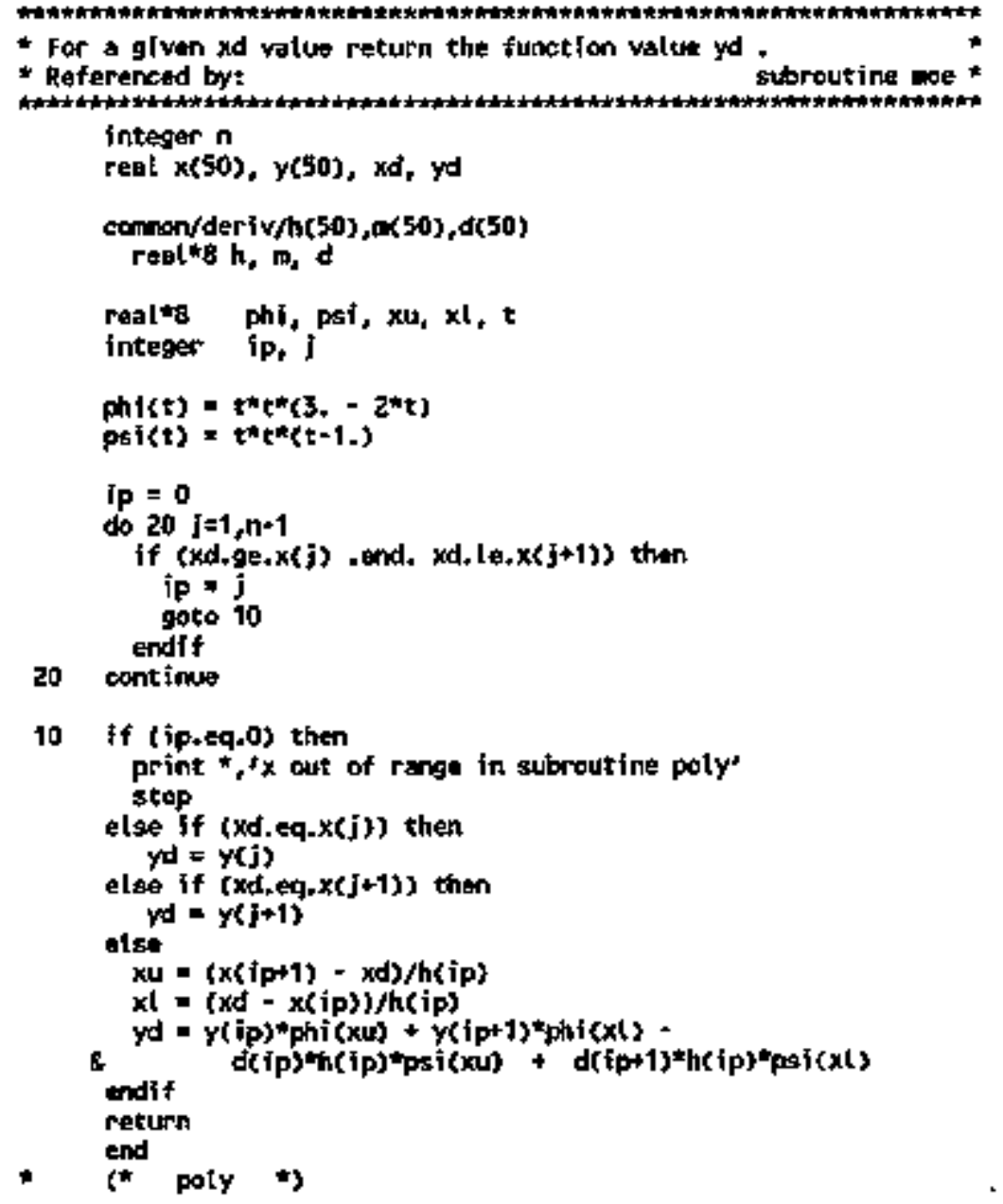



c

Fito wew : th_rard.for

real FuHCTION rendm( icheck)

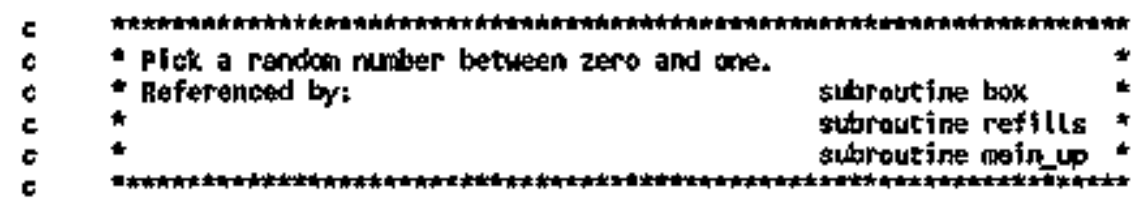

integer icheck

colmpon/mi sef ncase, ncases, lun, beta, a, exut, t itle

intoger nease, meases, Itn

real bets, a, exut

character*45 titlis

real minem

integer $y_{*}$ notr

oave $y_{r}$ ndr, treaen

if (ficheck.eq. 0) then

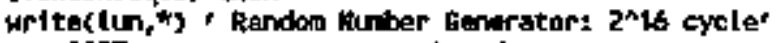

$y=1103$

Isend

indr a 0 rentin $=0$.

alse if (icheok.eq.z) then

write(tun,")'tl of randon draws = ',ndr,' wean = ', rmoan/ndr

olse

indr $=n d r+1$

$y=725173+13849$

$y=\bmod (y, 65536)$

randin $=f \operatorname{logt}(y) / 65535$

ratan = coneen + rancin

endif

return

end condh ty

I

$<c-97>$

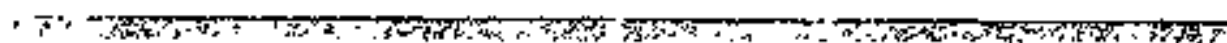


Integer maxi, maxj, maxk, maxl, maxrows

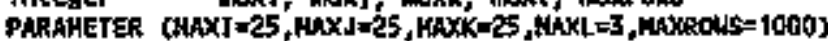

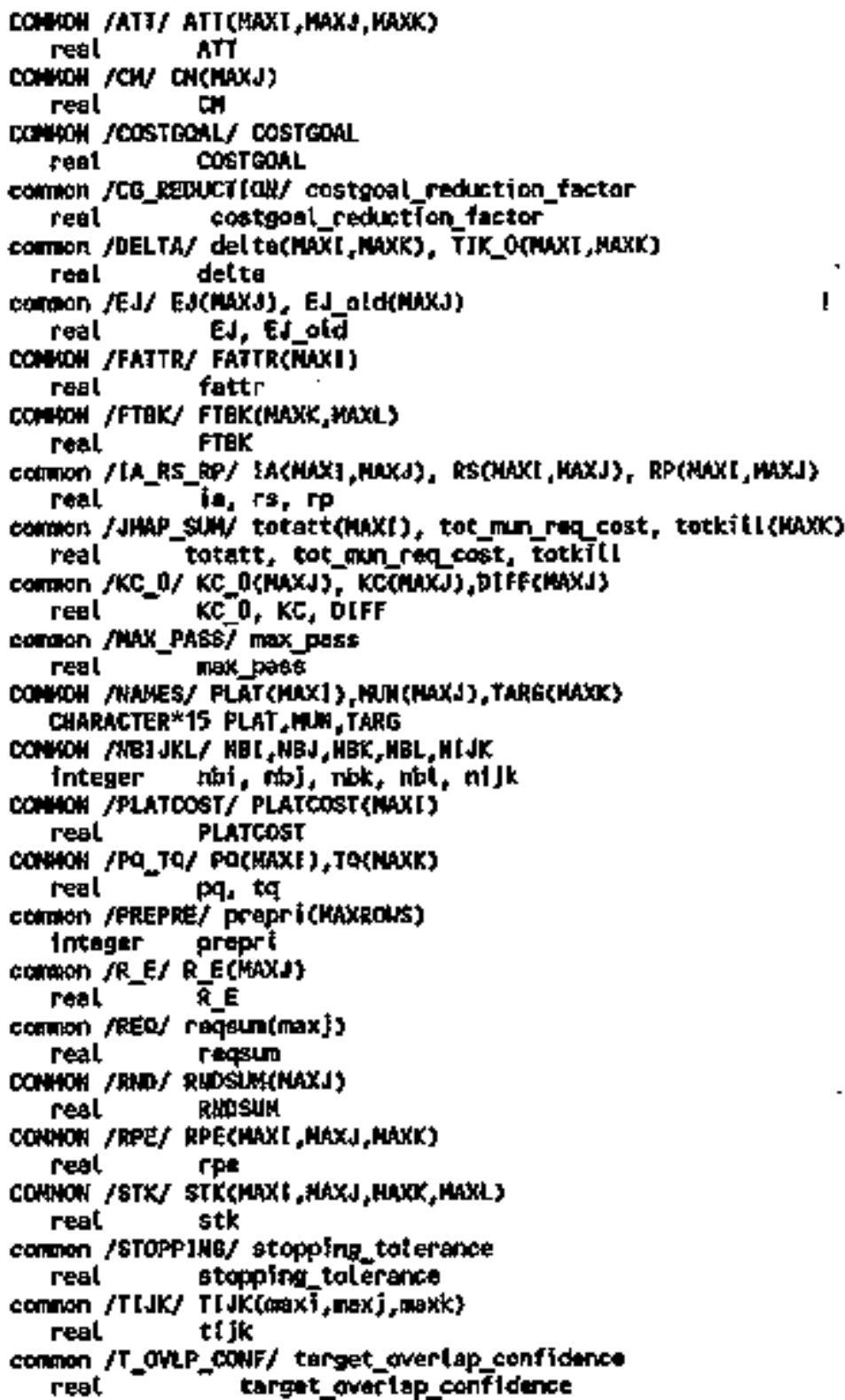

1 ATT \&- EXCHAMKE

I Munition cost

I Cost soal conputed by the Threat kodel

I Cost gool reduction factor

Dverlapping bounds for targets to be kitled and initiot target splits by pletfom

I Threat Hodel expenditures of two consecutive passes

i Platfors attrition fractions

1 Mintan fractians of targets to be killed

1 Initiol Allownce, Rofill-size, Regrdepr-Point

1 JNAP output - platform attrition, munition cost 1 targets killed

1 Kill Criterion by Munition Typ

1 Haxtenn minher af palir-iterations

1 Hams of platform, mution, and target types

I of types of platfom, mitition, and target

1 Platfora cost

I * of platform and targets of uach typo

1 priority lewel of cost goal, kitl gogls. and attrition gosls

I Regul rement-to-Expendi ture rat lo

I JWAP+ requjrenents by munition type

I JMAPt expenditures by matition type

I Rounds-per-Engagenent, RPE <- SALvo

I Salvo-to-kill, STK \&- ShLvoTox

1 Stopping tol erence

I Targets killed

1 Target overlap confidence 
Hat

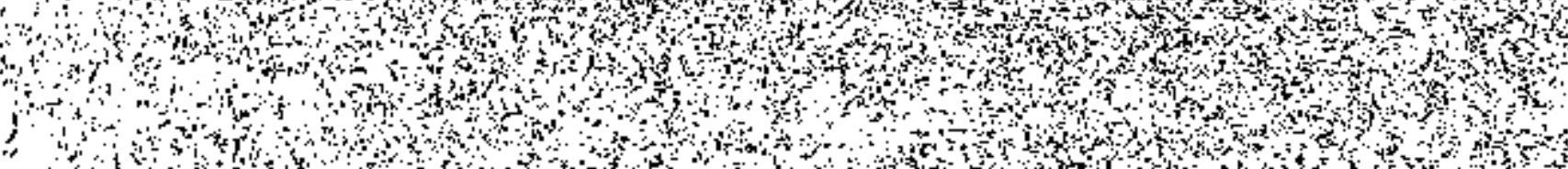

rit.

W. Prt t

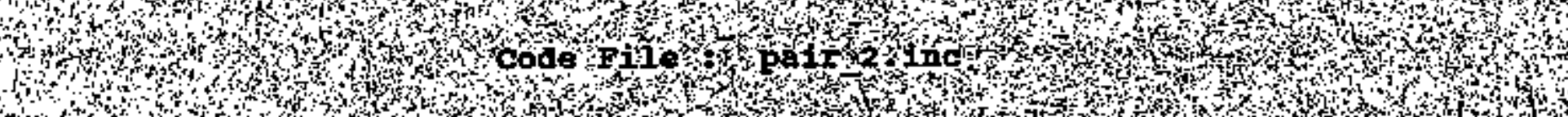

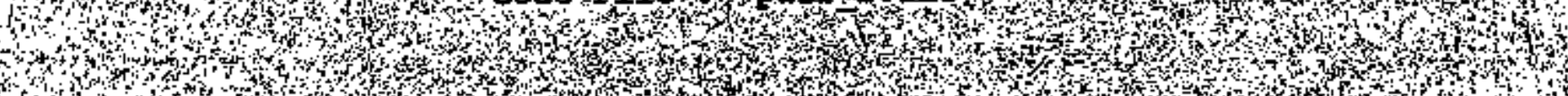
1.

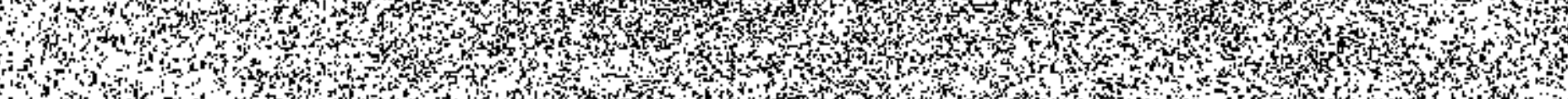

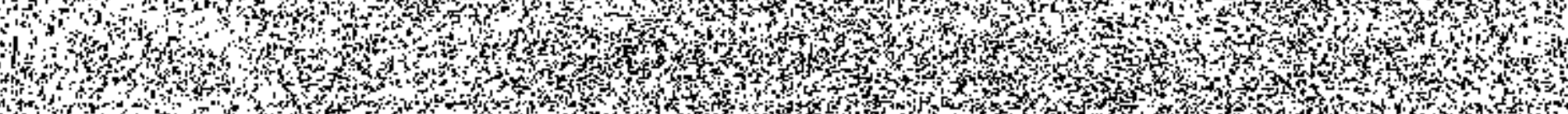

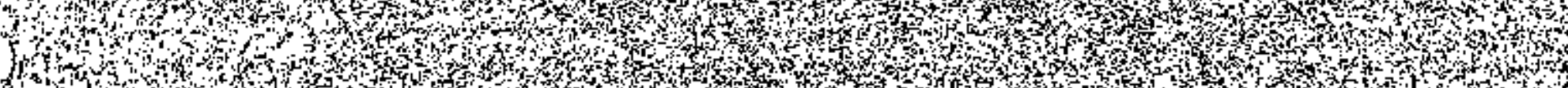
W

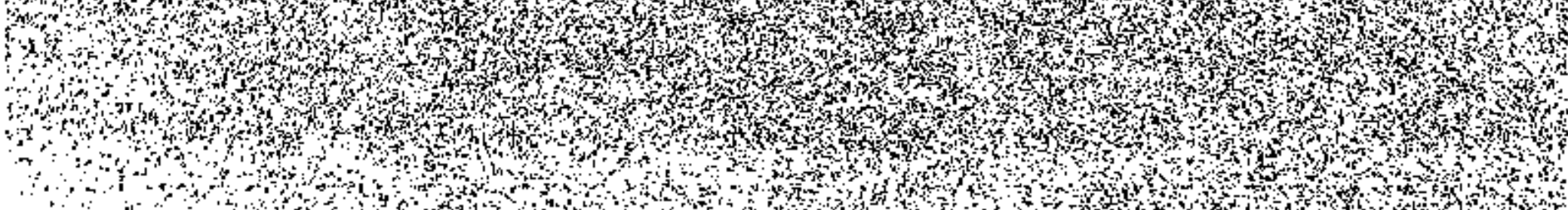

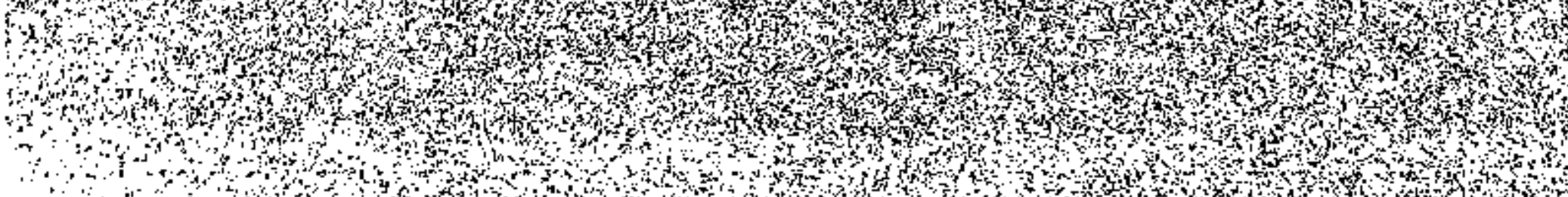

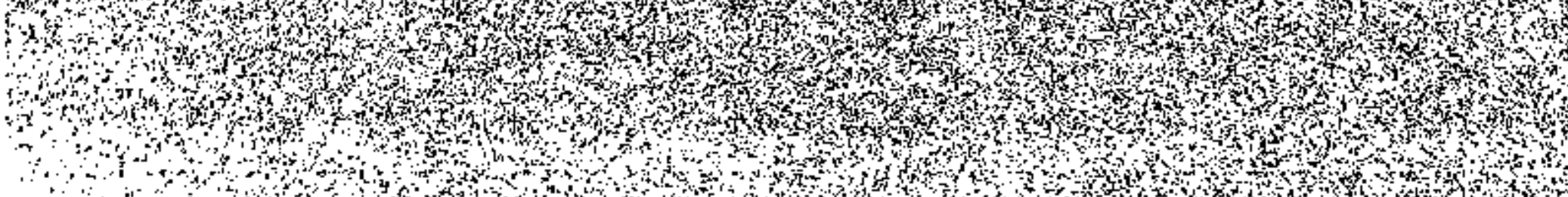

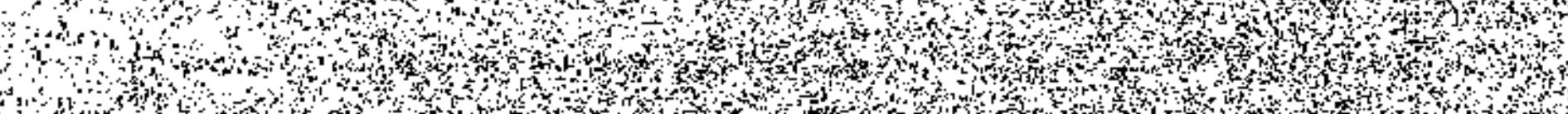
H.m.

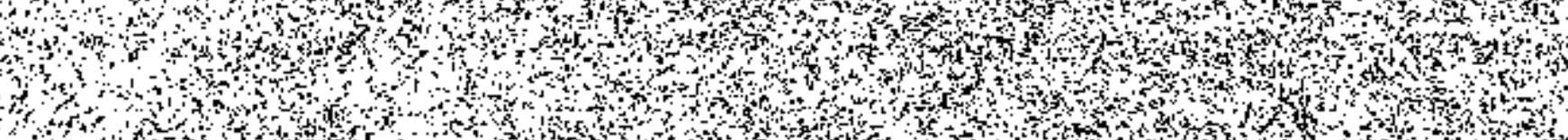
m.

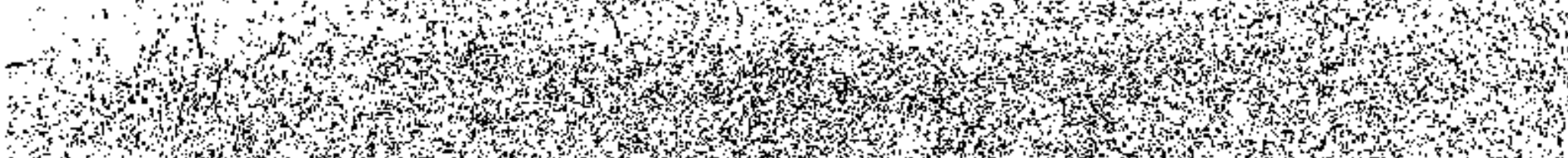

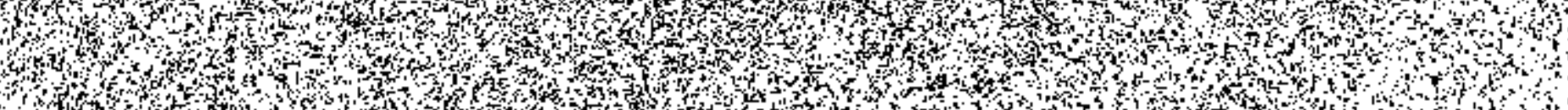

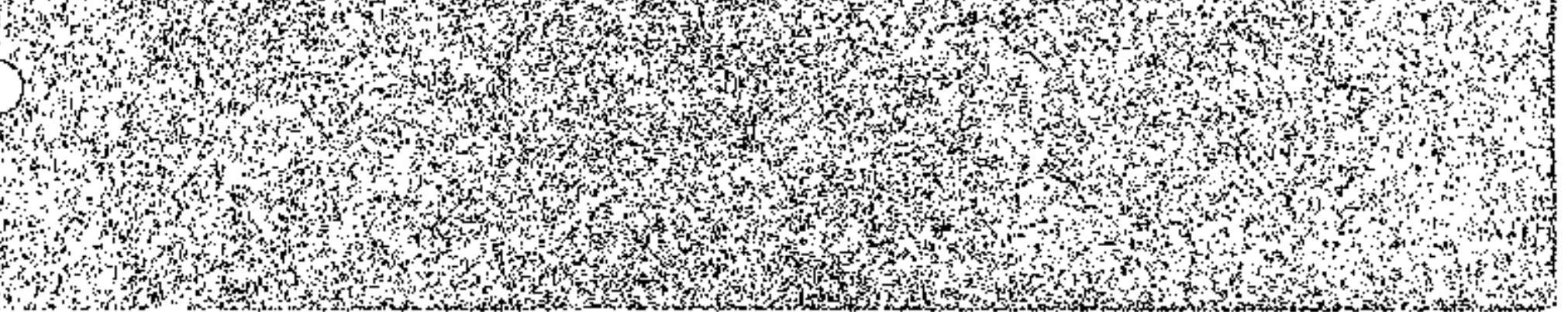



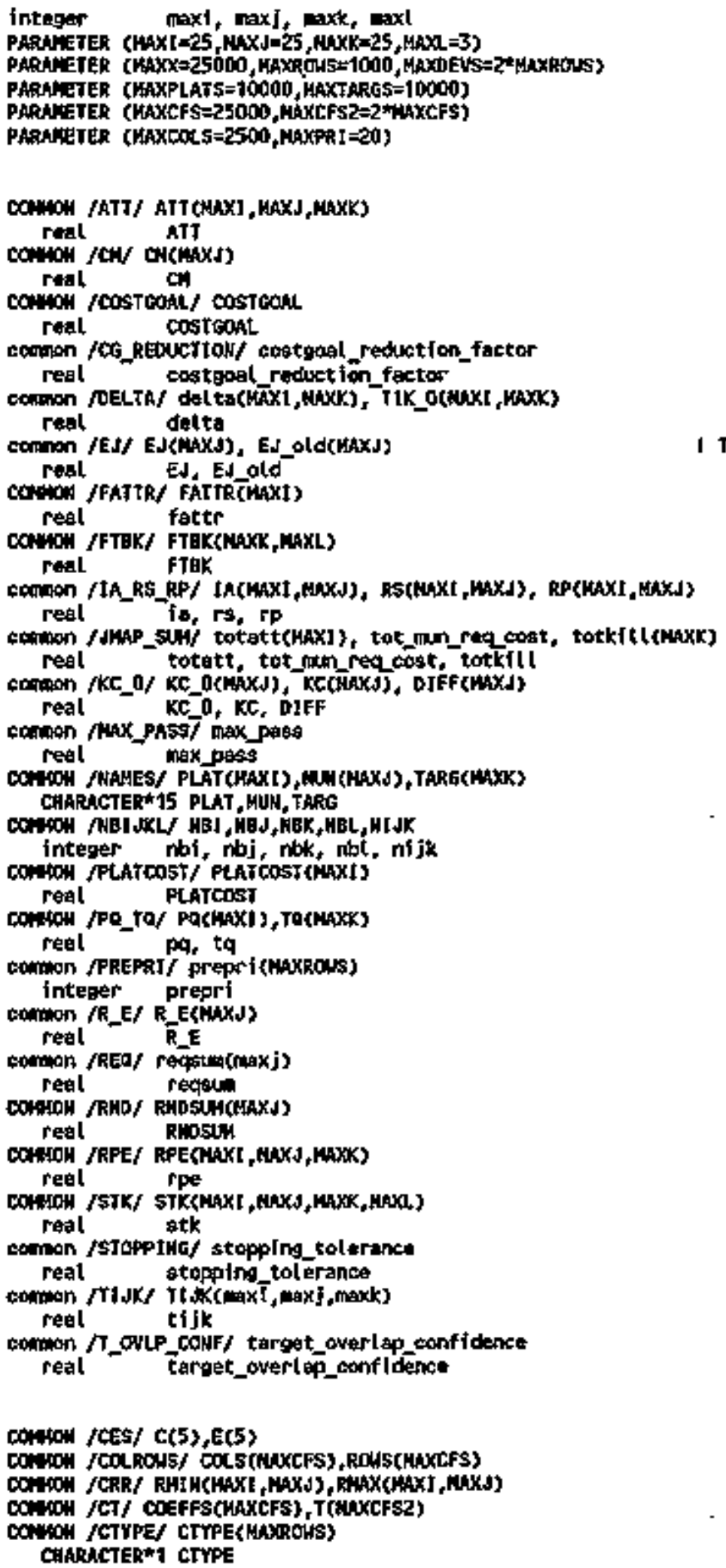

I HTT <- EXCHANES

I Hnition cost

1 Cost goal conputed by the Threst Hodel

1 Cost goal rediction fattor

1 Overlepping bounds for tergets to be killed 1 and initial targat sptits by platform

I Threas Hodel expenditures of two consecutive paseses

I Plstform attrition fractions

! Hinitian freations of targets to be kilted

I Initial Allowanck, Rafill-size, Roarder-point

| JMAP dutptut - platforw attritian, matition cost ! targets $k ! l$ ted

! KIIL Eriterion ty Alunition Type

I Naximun number of paim I terations

I Hamos of platform, anition, and target types

I of typor of platfarm, thenition, and terget

I Pletfore cost

I I of platfores and target of pach type

! priority lavel of wast gool, kith sools,

1 and attrition gasls

I Roguírent-tó-Expendi ture ratio

1 Jupt regul renonts by fandition type

I JuAp+ expenditures by tantition type

1 Rounds-par-Engagorment, RPE ২- SALVD

1 Salvo-to-kill, STX \& SALvOTOK

1 Stopping tolerance

1 Torgets kilted

1 Target overlap confidance 
COABow HOOCTRINE/ DOCTRIN(whoxds)

conmion /FCN/ FON_P(HAXI), FOH_T(MAXK)

COHAOH /FRACLOST $\overline{7}$ FRACLOST

COHUON /I1/ 18ASIC(WAXROUS), JCOL (NHXCOLS)

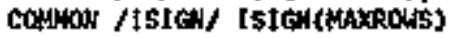

CHABACTER*1 1SIGH

COAHON /ITERSOO/ ITER500

CONAON /OADOUT/ LOADOUT(MAXI,HAX(S)

CONWON MCOL/ NCOL (MAXI,NAXJ, HAXK)

COAHON AHPSS/ HPSCOLS, NPSRHS, HPSTOT

Coronon /NB2030/ NBF20, NBF30

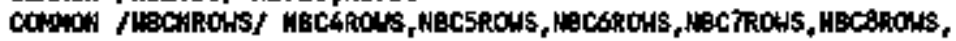

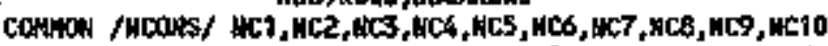

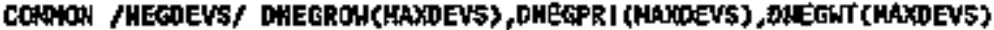

COHWON /HECPEVSO/ DHECROWO(NAVDEVS), ONEGPRLO(NANGEVS),

1 DNEETTOSHXOEVS)

CONWOW /HRC/ HBROUS, HBCOLS, AWAR, HBPR[ORS, KTEST, J TER

COWNON /POSOEVS/ DPOSROW(WADEVS), DPOSPRI (NWXOEVS), DPOSWT (HAXDENS)

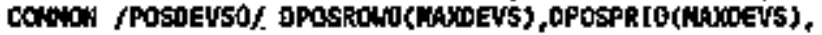

1 DPOSWTOCHAOEEYS)

COOWON TTARCCHK/ TARGCHK(MAXTARES)

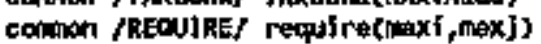

CONHW $/ S / 5$

INTECER 3

COHNON /STDEV/ STOEV(MAXI, MAXJ,MAX, HWXL)

COWHON /STOCW STOCK(HAXJ)

COWHON $R 1 /$ BASIS(MAXRGUS, NAXCOLS)

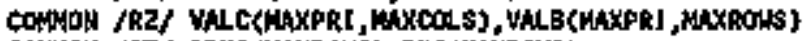

CONWON /R3/ PRHS(NAXROL'S), RHS(HAXROWS)

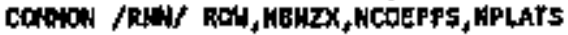

THTEGER ROW

CONONON /R5TEP/ RANCHIU, RAGMLX, STEP

CONOWOH /hOF/ ROF (MAXt, NUXJ)

CoNwow /STKCOST/ SHKCOST

CONWOA /TARGTYPE) TARETTPE(MAXK)

CARARACTER *S TARGTYPE

CONHON /TOTJME/ TOT INE

CONWOW /TITLE/ TITLE

COHWOH /TOTARGS/ TOTARES

coNHow /2K/ 2K

COHON /ALPHA/ MLPHA

COAHON /TIME/ TtME(HAXL)

DDTBLLE PRECISION GASIS, VALC, VALB, PRHS, RHS

DIMEASION TOTCOST CMAXK)

DIHENST IOW TOTLKILLCAAXK, NAXL), TOTLK(HLXL)

DINENSION BCRKDS(HAXJ),ECFK(HAXK), ECCPK(HAXK)

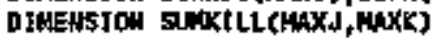

CHARACTER YESTO

CHARACTER-80 TITLE

CHARACTER*132 LINE, CLINE

$$
\langle c-100\rangle
$$

